\title{
Textile dyeing with a flavonoid dye: \\ photo-stability and analytical chemistry methods
}

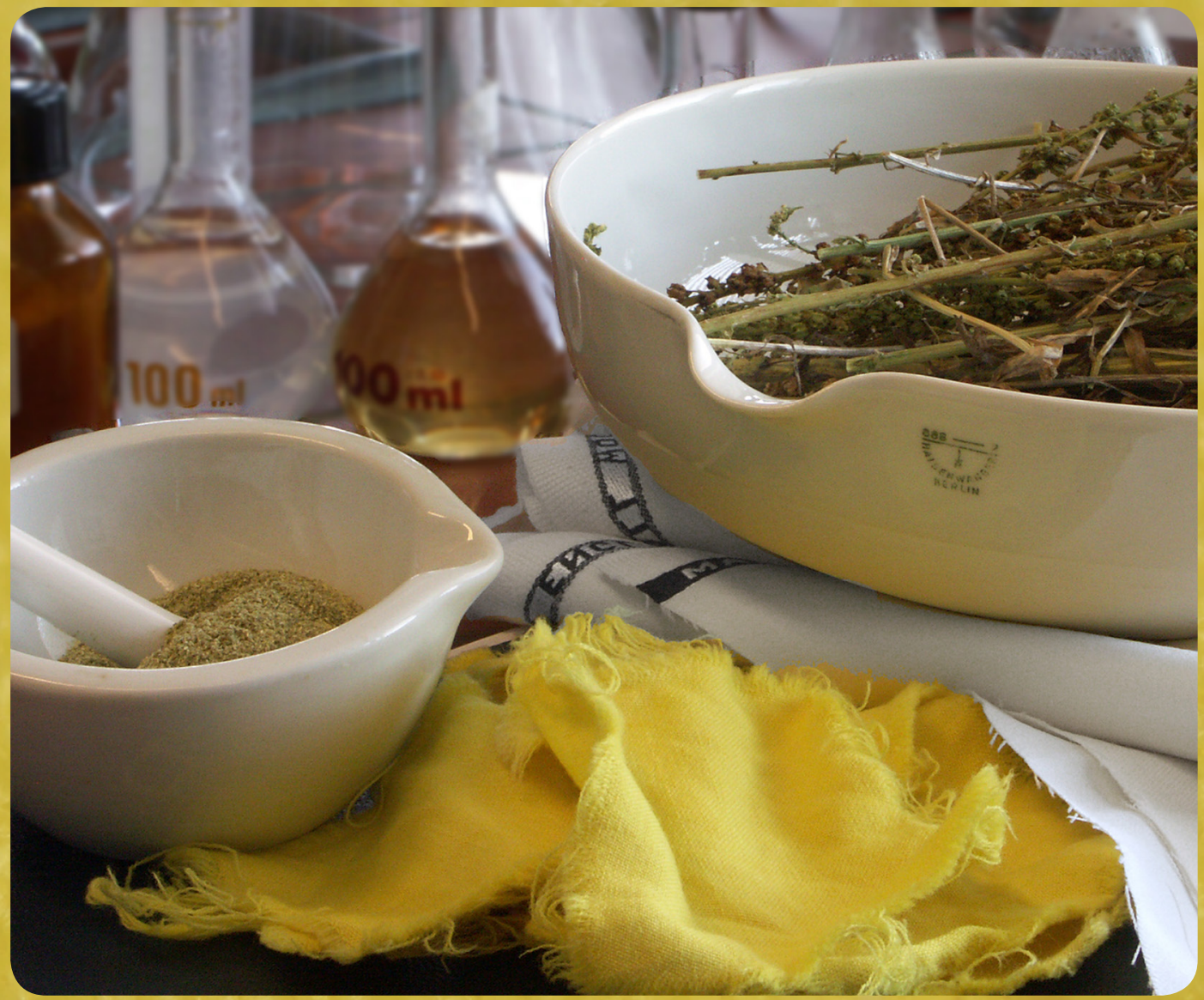




\section{Propositions}

1. There are limitations to the yellow colour of wool dyed with weld.

(this thesis)

2. Using short UHPLC columns on conventional HPLC systems is an economical way of modernising HPLC-based analyses.

(this thesis)

3. People and planet are better taken care of through organic agriculture than through conventional agriculture.

(based on Reganold JP, Wachter JM. Nat. Plants 2016)

4. The release of genetically engineered organisms in natural, rural and urban areas is an ecocide.

5. The pursuit of excellence as human being must precede that of professional excellence.

6. Pride is fruit of short-sightedness.

Propositions belonging to the thesis entitled

Textile dyeing with a flavonoid dye: photo-stability and analytical chemistry methods

Alexandre Villela

Wageningen, 15 April 2020 
Textile dyeing with a flavonoid dye: photo-stability and analytical chemistry methods 


\section{Thesis committee}

\section{Promotor}

Prof. Dr J.T. Zuilhof

Professor of Organic Chemistry

Wageningen University \& Research

\section{Co-promotor}

Dr T.A. van Beek

Assistant professor, Laboratory of Organic Chemistry

Wageningen University \& Research

\section{Other members}

Prof. Dr J.H. Bitter, Wageningen University \& Research

Prof. Dr R. Verpoorte, Leiden University

Prof. Dr P.J. Schoenmakers, University of Amsterdam

Prof. Dr M.H.M. Eppink, Wageningen University \& Research

This research was conducted under the auspices of the graduate school VLAG (Advanced studies in Food Technology, Agrobiotechnology, Nutrition and Health Sciences). 


\title{
Textile dyeing with a flavonoid dye: photo-stability and analytical chemistry methods
}

\author{
Alexandre Villela
}

\section{Thesis}

submitted in fulfilment of the requirements for the degree of doctor at Wageningen University

by the authority of the Rector Magnificus,

Prof. Dr A.P.J. Mol, in the presence of the

Thesis Committee appointed by the Academic Board to be defended in public

on Wednesday 15 April 2020

at 1:30 p.m. in the Aula. 
Alexandre Villela

Textile dyeing with a flavonoid dye: photo-stability and analytical chemistry methods, 168 pages.

PhD thesis, Wageningen University, Wageningen, the Netherlands (2020)

With references, with summary in English

ISBN 978-94-6395-334-4

DOI-link https://doi.org/10.18174/516631 
In memory of my grandmother Pérola (Voca) 



\section{Table of contents}

Chapter 1. General introduction 9

Chapter 2. LC-UV method for the quantitation of the main flavonoids of weld 17

Chapter 3. Spectrophotometric comparison of the content of chlorophylls in weld 33

Chapter 4. Photo-stability of the dye of weld in presence of aluminium ions $\quad 43$

Chapter 5. Analysis of a natural dye: an experiment for analytical organic chemistry

$\begin{array}{ll}\text { Chapter 6. General discussion } & 77\end{array}$

$\begin{array}{ll}\text { Summary } & 87\end{array}$

$\begin{array}{ll}\text { Acknowledgements } & 91\end{array}$

$\begin{array}{ll}\text { Publications and training activities } & 95\end{array}$

Appendix A. Chapter 2: Supplementary information 99

Appendix B. Chapter 3: Supplementary information 103

Appendix C. Chapter 4: Supplementary information 109

Appendix D. Chapter 5: Supplementary information $\quad 147$ 

Chapter 1

General introduction 
The contents of this chapter are, to a large extent, part of the following papers:

Villela A, van der Klift EJC, Mattheussens ESGM, Derksen GCH, Zuilhof H, van Beek TA. Fast chromatographic separation for the quantitation of the main flavone dyes in Reseda luteola (weld). J Chromatogr A 2011; 1218(47): 8544-50

Villela A, Derksen GCH, Zuilhof H, van Beek TA. Spectrophotometric comparison of the content of chlorophylls in weld (Reseda luteola). Anal Methods 2011; 3(6): 1424-7

Villela A, van Vuuren MSA, Willemen HM, Derksen GCH, van Beek TA. Photo-stability of a flavonoid dye in presence of aluminium ions. Dyes Pigments 2019; 162: 222-31

Villela A, Derksen GCH, van Beek TA. Analysis of a natural yellow dye: an experiment for analytical organic chemistry. J Chem Educ 2014; 91(4): 566-9 


\subsection{Introduction}

Coloured textiles have been used by mankind throughout times [1]. Dyes have been obtained from different natural sources, including plants, molluscs and insects [1] and were valuable in the past [2]. Although the use of natural dyes experienced a fast decline from the $1850 \mathrm{~s}$ with the first synthetic dyes entering the market $[3,4]$, there has been a renewed interest. Currently, this is due to innovation-related, economical, personal, and ethical reasons [5]. Figure 1.1 depicts yarns dyed with natural dyes in various colours.

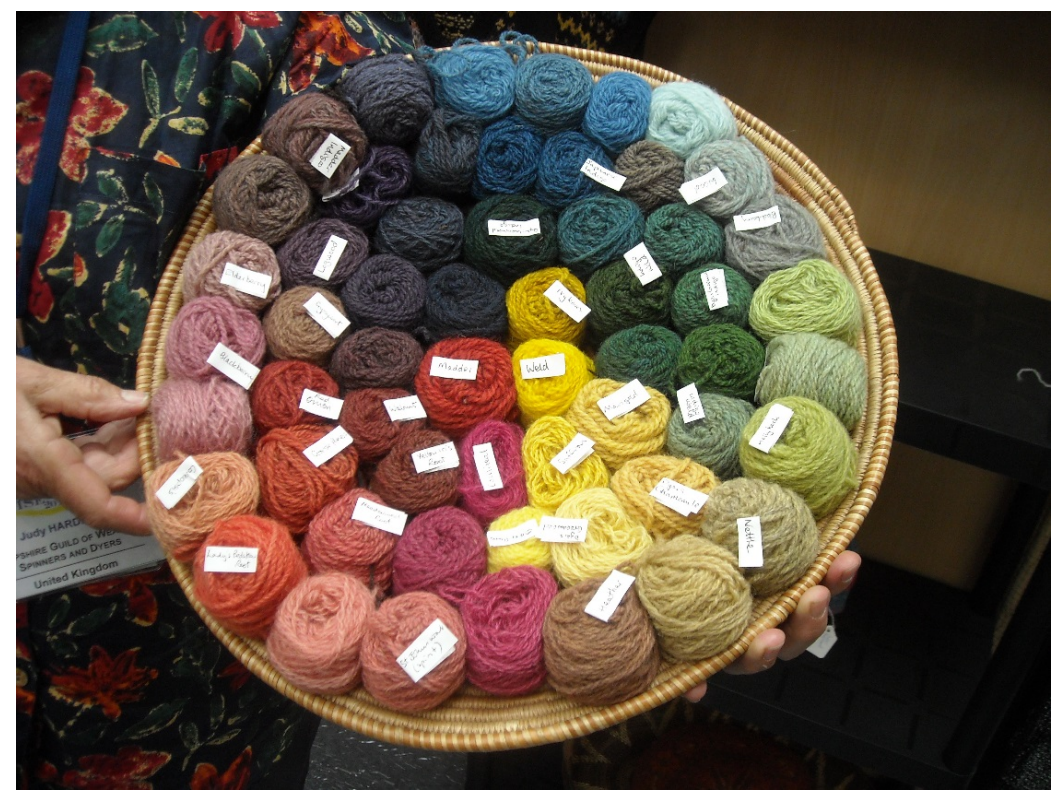

Figure 1.1. Yarns of wool dyed with natural dyes. ${ }^{1}$

In addition, identification of dyestuff of historical textiles is of historical and conservational interest [2]. Figure 1.2 depicts a live mannequin wearing a costume dyed with a natural dye.

\footnotetext{
${ }^{1}$ Dyed by Judy Hardman (United Kingdom); picture taken in La Rochelle/France (2011).
} 


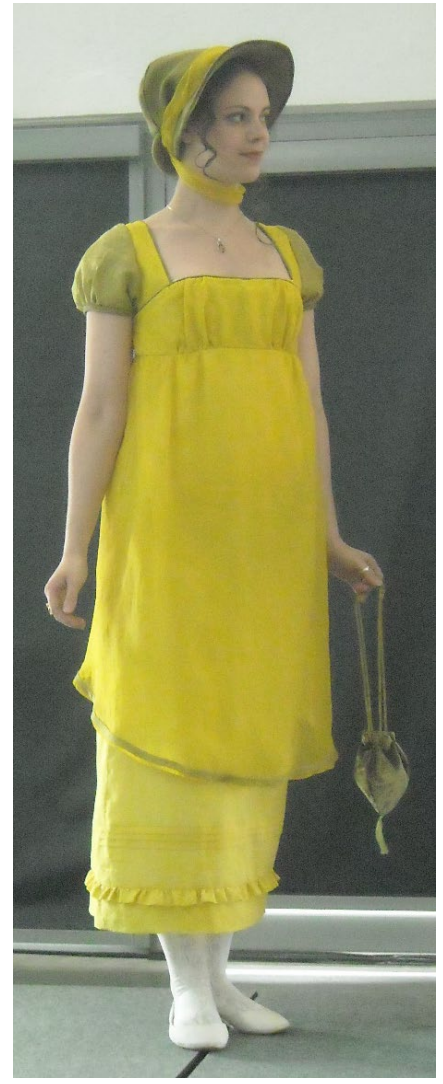

Figure 1.2. Valérie Fischbach acting as a live mannequin wearing a costume in Incroyables et Merveilleuses style dyed with weld (Reseda luteola L.). ${ }^{2}$

It should be noted, however, that the use of natural dyes for textiles is not synonymous with environmentally friendly dyeing [5]. Different factors must be addressed for it to be an ecologically sound industrial activity [6]. Naturally, techno-economic aspects of production also require attention [7].

Weld (Reseda luteola L.) used to be an important vegetable source of dye for textiles in Europe and the Mediterranean area [1]. The main colouring compounds of the plant belong to the class of flavonoids [1]. The flavone luteolin (lut) and two of its glycosyl conjugates, lut-7$O$-glucoside (lut monoglucoside, lmg) and lut-7,3'-O-diglucoside (lut diglucoside, ldg), are the main flavonoids of the plant [8] (Fig. 1.3). Seven other minor ones include the aglycones apigenin and chrysoeriol, together with mono and diglycosides of all three aglycones $[8,9]$.

\footnotetext{
${ }^{2}$ Les Incroyables et Merveilleuses was a French fashion trend of the end of the 18th century; made by students preparing for a degree in arts and crafts at lycée polyvalent Jules Verne de Sartrouville - a high school in France - together with their teachers; picture taken in La Rochelle/France (2011).
} 
<smiles>O=c1cc(-c2ccc(O)c(O)c2)oc2cc(O)cc(O)c12</smiles>

Figure 1.3. Structure of the flavone luteolin (lut), the aglycone of the main flavonoids of weld (Reseda luteola L.).

RP-HPLC-UV (reversed phase high-performance liquid chromatography with spectrophotometric detection in the ultraviolet range of the electromagnetic spectrum) is a very suitable technique for the separation and detection of these non-volatile moderately polar UVactive analytes, and is available in most laboratories. Various assays have been published for the quantitation of flavonoids in weld, by different analytical techniques. RP-HPLC-DAD (RPHPLC-diode-array detector) has been used to quantify the aglycones quercetin, luteolin, and apigenin in weld after simultaneous extraction-hydrolysis of the glycosides [10]. Other groups used RP-HPLC-UV to quantify only luteolin $[11,12]$. Cristea et al. [13] extracted weld with methanol-water 8:2 at room temperature and under reflux and, afterwards, analysed the three main flavones by the same technique with external standardisation. Moiteiro et al. [14] also used methanol-water 8:2, but extracted the flavonoids from weld by $10 \mathrm{~min}$ sonication at room temperature. In addition to $\mathbf{l d g}$, Img, and lut, they also quantified luteolin-4'-O-glucoside. Since there was no simple, validated RP-HPLC-UV method for the quantitation of ldg, Img, and lut in samples of weld, the development of such a method - and its validation for the purposewas aimed at. The method that was developed is described in chapter 2.

According to the industrial partner of the project, one of the problems to overcome was a greenish hue that accompanies the yellow colour after dyeing alum (dodecahydrate aluminium potassium sulphate) pre-treated textiles with weld. Such a greenish hue would be undesirable, and it was hypothesised that chlorophylls $a$ and $b$ are potential sources of it. Thus, for the purposes of raw material characterisation, the development of a simple analytical method for the quantitation of chlorophylls in samples of weld was aimed at. The method that was developed envisages to compare the content of porphyrin ring-containing pigments in different weld plant materials, and is described in chapter 3 .

Weld has been used to dye both animal fibres - such as wool — and vegetable fibres, after they have been treated (mordanted ${ }^{3}$ ) with alum in facultative combination with the dye-assistant tartar [1]. Alum-premordanted wool dyed with weld leads to yellow colours and, generally, the yellow colours of textiles dyed with natural dyes are poorly resistant to light [1]. Considering today's requirement of photo-resistance (light-fastness) of the colours of dyed textiles, this is

\footnotetext{
${ }^{3}$ The word mordant comes from the Latin word mordere, which means "to bite". Metal salts have been referred to as mordants in relation to a classical model of binding of dyes to fibres involving the metals [1].
} 
also the case for the dye of weld. Therefore, the work reported in chapter 4 aimed at finding out whether: ${ }^{4}$

- a progressive decrease of $\left[\mathrm{Al}^{3+}\right]$ would progressively increase the photo-stability of the dye of weld;

- the endogenous glycosidase of weld should be inactivated before extracting the flavonoids of the plant in order to obtain the most photo-stable dye.

Because of its wide applicability, high-performance liquid chromatography (HPLC) is one of the analytical techniques with which the undergraduate student of life sciences should be acquainted. This is also true for the internal standard method [15], which is important in quantitative instrumental analysis $[16,17]$. The experiment described in chapter 5 aims at familiarising students with both. This is accomplished using the real-world application of natural dyes for textiles. Weld, the plant used in the experiment, and wool dyed by students with its extract are depicted in Figure 1.4.

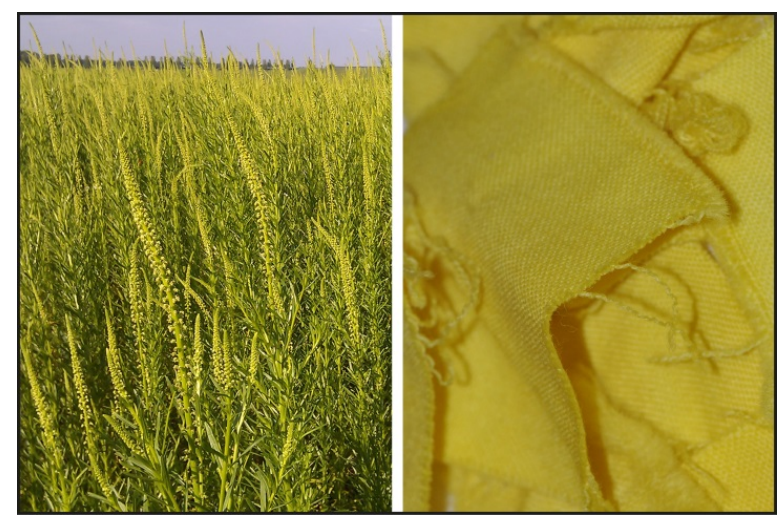

Figure 1.4. Patch of weld (Reseda luteola L.) and alumpretreated wool dyed with extract of weld.

\footnotetext{
${ }^{4}$ The rationale for these aims is presented in section 4.1 .
} 


\subsection{References}

[1] Cardon D. Natural dyes - sources, tradition, technology and science. 1st ed. Archetype Publications: London; 2007.

[2] Ferreira ESB, Hulme AN, McNab H, Quye A. The natural constituents of historical textile dyes. Chem Soc Rev 2004; 33(6): 329-36.

[3] Cardon D. Colours in civilizations of the world and natural colorants: history under tension.

In: Bechtold T, Mussak R, editors. Handbook of natural colorants, John Wiley \& Sons: Chichester; 2009, p. 21-6.

[4] Abel A. The history of dyes and pigments: from natural dyes to high performance pigments.

In: Best J, editor. Colour design - theories and applications, Woodhead Publishing: Cambridge; 2012, p. 433-70.

[5] Mussak RAM, Bechtold T. Natural colorants in textile dyeing. In: Bechtold T, Mussak RAM, editors. Handbook of natural colorants, John Wiley \& Sons: Chichester; 2009, p. 315-37.

[6] Ganglberger E. Environmental aspects and sustainability. In: Bechtold T, Mussak R, editors. Handbook of natural colorants, John Wiley \& Sons: Chichester; 2009, p. 353-66.

[7] Geissler S. Economic aspects of natural dyes. In: Bechtold T, Mussak RAM, editors. Handbook of natural colorants, John Wiley \& Sons: Chichester; 2009, p. 367-84.

[8] Marques R, Sousa MM, Oliveira MC, Melo MJ. Characterization of weld (Reseda luteola L.) and spurge flax (Daphne gnidium L.) by high-performance liquid chromatography-diode array detection-mass spectrometry in Arraiolos historical textiles. J Chromatogr A 2009; 1216(9): 1395-402.

[9] Peggie DA, Hulme AN, McNab H, Quye A. Towards the identification of characteristic minor components from textiles dyed with weld (Reseda luteola L.) and those dyed with Mexican cochineal (Dactylopius coccus Costa). Microchim Acta 2008; 162(3-4): 371-80.

[10] Hartl A, Vogl CR. Faser-und Färbepflanzen aus Ökologischem Landbau. Anbauversuche Färbepflanzen. Endbericht zur Projekterweiterung Teil B (Ertragsleistung und Farbstoffgehalt von Färber-Resede (Reseda luteola L.), Färberkamille (Anthemis tinctoria L.) und Färberknöterich (Polygonum tinctorium Ait.) auf Biobetrieben in Niederösterreich im Vergleich mit praxis-und handelsüblichen Warenpartien). Project L 1043/96, Ministry of Agriculture, Forestry, Environment and Water Management and Environment \& Ministry for Education, Science and Research: Vienna; 2000.

[11] Cerrato A, De Santis D, Moresi M. Production of luteolin extracts from Reseda luteola and assessment of their dyeing properties. J Sci Food Agric 2002; 82(10): 1189-99.

[12] Angelini LG, Bertoli A, Rolandelli S, Pistelli L. Agronomic potential of Reseda luteola L. as new crop for natural dyes in textiles production. Ind Crops Prod 2003; 17(3): 199-207.

[13] Cristea D, Bareau I, Vilarem G. Identification and quantitative HPLC analysis of the main flavonoids present in weld (Reseda luteola L.). Dyes Pigments 2003; 57(3): 267-72.

[14] Moiteiro C, Gaspar H, Rodrigues AI, Lopes JF, Carnide V. HPLC quantification of dye flavonoids in Reseda luteola L. from Portugal. J Sep Sci 2008; 31(21): 3683-7. 
[15] Magee JA, Herd AC. Internal standard calculations in chromatography. J Chem Educ 1999; 76(2): 252.

[16] Barrows RD. Quantitative comparison of three standardization methods using a one-way ANOVA for multiple mean comparisons. J Chem Educ 2007; 84(5): 839-41.

[17] Harvey D. Analytical Chemistry 2.0. http://www.asdlib.org/onlineArticles/ecourseware/Analytical\%20Chemistry\%202.0/Text_File s.html [accessed August 2013]. 


\section{Chapter 2}

\section{LC-UV method for the quantitation of the main flavonoids of weld}

The content of this chapter is largely that of the following paper:

Villela A, van der Klift EJC, Mattheussens ESGM, Derksen GCH, Zuilhof H, van Beek TA. Fast chromatographic separation for the quantitation of the main flavone dyes in Reseda luteola (weld). J Chromatogr A 2011; 1218(47): 8544-50. 
A simple validated industrially-usable quantitative method to assess the flavone content of $R$. luteola samples is described in this chapter. The flavones were overnight-extracted from the dried and ground aerial parts of the plant at room temperature via maceration with methanolwater 8:2. Afterwards, they were quantified through internal standardisation against chrysin by RP-HPLC-UV at $345 \mathrm{~nm}$. The efficiency of the one-step extraction was $95 \%$. The limits of detection (LOD) and quantitation (LOQ) were $\leq 1 \mathrm{ng}$ and $\leq 3 \mathrm{ng}$, respectively, providing ample sensitivity for the purpose. The precision expressed as relative standard deviation of the entire method was $<6.5 \%$ for the combined content of luteolin-7,3'-O-diglucoside, luteolin-7-Oglucoside, and luteolin. The average absolute recovery (accuracy) at three spiking levels was $102 \%$ (range: $98-107 \%$ ) and the relative recovery ranged from 99 to $102 \%$. The separation was initially carried out on a traditional $250 \mathrm{~mm} \times 4.6 \mathrm{~mm} 5 \mu \mathrm{m}$-particle size HPLC column (80 min run time, $35.9 \mathrm{~mL} \mathrm{MeOH}$ ). It was then speeded up by the use of a $50 \mathrm{~mm} \times 3.0 \mathrm{~mm} 1.8$ $\mu \mathrm{m}$-particle size UHPLC column ( $5 \mathrm{~min}$ run time, $1.4 \mathrm{~mL} \mathrm{MeCN}$ ), while still using a conventional HPLC system. Whereas the retention times on the UHPLC column were relatively less reproducible, cross-validation showed that the quantitation of luteolin-7,3'-O-diglucoside, luteolin-7-O-glucoside, and luteolin was not statistically significantly different, with comparable precision. The method is more sensitive when using the UHPLC column than when using the HPLC column. The analytical method described meets the demand for a very small manpower input per sample and uses standard laboratory equipment. Using a UHPLC column on a conventional HPLC system is a way of modernising HPLC-based phytochemical analyses inexpensively. 


\subsection{Introduction}

In view of the expectation of having to analyse hundreds of samples in the course of the academic and industrial dye research of which this project is part, developing a method suitable for the simultaneous analysis of the three main flavones of the plant with as little manpower input as possible and using standard equipment was aimed at. According to the industrial partner of the project, ldg, Img, and lut constitute about $80 \%$ of the total flavonoid content of $R$. luteola and the ratio between them and the minor flavonoids is fairly constant. Thus, quantifying only these three flavones, while being informative, keeps the LC-based method simple and cheap.

A validated RP-HPLC-UV method for the quantitation of ldg, lmg, and lut that satisfies the demand of the project in terms of low manpower input is reported in this chapter. Moreover, the chromatographic step on a $250 \mathrm{~mm} \times 4.6 \mathrm{~mm} 5 \mu \mathrm{m}$-particle size HPLC column was speeded up and made low in solvent consumption by using a $50 \mathrm{~mm} \times 3.0 \mathrm{~mm} 1.8 \mu \mathrm{m}$-particle size UHPLC column, while still using a conventional HPLC system.

\subsection{Material and methods}

\subsubsection{Plant material, chemicals and reagents}

Five plants were withdrawn from a bunch of dried Reseda luteola L. (cultivar code: H) plants. The plants used were grown in the North of the Netherlands and were harvested on August 2007. A voucher specimen was deposited at the Wageningen branch of the National Herbarium of the Netherlands (Gen. Foulkesweg 37, 6703 BL Wageningen, The Netherlands) and identified as W. Olsder s. n. (WAG, barcodes WAG0248296-WAG0248298). Drying took place by leaving the plants outdoors during daytime and indoors during the nights, for $\sim 10$ days. The aerial parts of the plants were ground with a cutting mill (Retsch GmbH, type SM1, Haan/Germany; $0.25 \mathrm{~mm}$ sieve). This combined sample is henceforth referred to as R. luteola $\mathrm{H}$, and was stored in the dark.

Methanol ("HPLC grade" or similar), DMSO (99.9\% for spectroscopy, Acros Organics), and acetonitrile (HPLC grade or p.a.) were used without further purification. Ultrapure water was prepared with an EasyPure UV system (Barnstead/Thermolyne, Dubuque/USA) or purchased from Merck (Lichrosolv water for chromatography). Demineralised water (Ph. Eur.) was purchased from VWR or prepared with a Seradest SD 2000 ion-exchanger (Seral Erich Alhäuser $\mathrm{GmbH}$, Ransbach-Baumbach/Germany). Formic acid was from Acros Organics (98+\%) and VWR (AnalaR Normapur 99-100\%), ammonium formiate was from Aldrich, Fluka or VWR, EDTA (dihydrate, either di- or tetrasodium) was from either Aldrich or VWR, and luteolin (lut) used for spiking was from Sigma ( $\geq 98 \%$, TLC grade). Standard compounds luteolin-7,3'-di-O-glucoside (luteolin diglucoside, Idg), luteolin-7-O-glucoside (luteolin monoglucoside, lmg), and luteolin (lut) were all of analytical control grade (Extrasynthese). Their purity was determined by ${ }^{1} \mathrm{H}-\mathrm{NMR}$ in DMSO- $d 6(99.5+$ atom $\% \mathrm{D}$, Aldrich) with a 400 MHz NMR spectrometer (Bruker, Avance III, Fällanden/Switzerland) as 88, 94, and 98 and 94\% for Idg, Img, and lut (Extrasynthese and Sigma, respectively), respectively. Maleic acid (puriss., $\geq 99.0 \%$ by HPLC, Fluka) was used as internal standard for the analyses by NMR [1]. Chrysin (97\% grade) was from Aldrich. G24 Environmental and Innova 4080 Incubator Shakers (New Brunswick Scientific Co. Inc., Edison/USA) were used. A 15-stirring points 
magnetic stirrer (Variomag Poly 15, H+P Labortechnik, Munich/Germany) was used. The sonication bath used was from Elma, type T 700 (Germany).

\subsubsection{Sample preparation}

$(200.0 \pm 0.9) \mathrm{mg}$ of dried $R$. luteola $\mathrm{H}$ were weighed (Mettler AE 260 balance) in $50 \mathrm{~mL}$ Erlenmeyer flasks. A magnetic stir bar and $20 \mathrm{~mL}$ of methanol-water 8:2 (v/v) were added to each flask, after which they were closed with a rubber stopper. The flasks were placed either on a 15-stirring point magnetic stirrer or on individual magnetic stirrers. Samples were extracted for $16 \mathrm{~h}$ at room temperature, at $300 \mathrm{rpm}$. Then, $5.00 \mathrm{~mL}$ of chrysin stock solution were added to the Erlenmeyer flask and stirring continued for another 10-14 min. Subsequently, an aliquot of the solution was filtered via a $0.45 \mu \mathrm{m}$ syringe filter (Minisart RC4, Sartorius Stedim Biotech, Goettingen/Germany)/polypropylene syringe (with rubber stopper) to a glass HPLC autosampler vial, discarding the first drops.

\subsubsection{LC I (HPLC column)}

HPLC analyses in Wageningen were performed on a Waters system consisting of a binary pump $(1525 \mu)$, a photodiode array detector (DAD) (996) and an autosampler (717 plus), and equipped with a column oven model $5 \mathrm{CH}$. An Alltima $250 \mathrm{~mm} \times 4.6 \mathrm{~mm} \mathrm{C18} 5 \mu \mathrm{m}$-particle size column was used, in combination with a $\mathrm{C} 18$ guard column. The volumes of the syringe and loop installed were 250 and $200 \mu \mathrm{L}$, respectively. The system was controlled by Waters Empower 2 software. The draw rate of the autosampler was $1 \mu \mathrm{L} \mathrm{sec}^{-1}$ and the injected volume, $20 \mu \mathrm{L}$. Mixtures of methanol-water and methanol only were used as needle wash solvent (the latter is preferred for keeping sample carryover below 1\%). One of the relative recovery experiments was carried out in Steenbergen, on an analogous system (see section SI A.1.1, Appendix A). At both locations, a pH 3 buffer of $160 \mathrm{mM}$ formic acid, $40 \mathrm{mM}$ ammonium formiate and $0.04 \mathrm{mM}$ of EDTA in water (A), and methanol (B) were used as solvents. The flow was $1.00 \mathrm{~mL} \mathrm{~min}^{-1}$ and the following linear gradient was used: $85-60 \% \mathrm{~A}(0-35 \mathrm{~min})$, $60-36 \%$ A (35-47 min), 36-23\% A (47-60 min), 23-0\% A (60-65 min), 0\% A (65-70 min). Subsequent injections could be made after $10 \mathrm{~min}$ of re-equilibration. The column was kept at $40{ }^{\circ} \mathrm{C}$. The DAD was set to scan from 245 to $500 \mathrm{~nm}$ (Wageningen) and 200 to $595 \mathrm{~nm}$ (Steenbergen). The peak areas were based on the absorbance at $345 \mathrm{~nm}$. LC-DAD-MS for peak purity checking was performed in Wageningen with the same column on a Thermo Scientific system consisting of an Eppendorf CH-30 column oven, a Finnigan Surveyor autosampler plus, MS pump plus, DAD plus, and a Finnigan LXQ linear ion trap MS with ESI probe working in $(+)$-ionisation mode in combination with Xcalibur software (version 2.0.5). Conditions were basically the same as above, except that solvent A contained no EDTA. About $10 \%$ of the flow was directed to the MS.

\subsubsection{LC II (UHPLC column)}

Analyses were performed on an Agilent system consisting of a binary pump (Agilent 1200 Series), a diode array detector (DAD), an autosampler, and a column oven (all Hewlett-Packard, Series 1100). An Agilent XDB-C18 $50 \mathrm{~mm} \times 3.0 \mathrm{~mm} 1.8 \mu \mathrm{m}$-particle size column without guard column was used. The system was controlled by HP ChemStation for LC 3D (Rev. A.06.03) software. The following modifications were done to reduce the internal volume of the system: (i) the mixer was replaced by a $7.5 \mathrm{~mm} \times 3.0 \mathrm{~mm}$ Alltima C18 ( $5 \mu \mathrm{m}$-particle size $)$ pre- 
column, which now acted as the mixer and connected damper and injector; and (ii) shortening of the tubing from the injection system to the column and from the column to the detector. The injected volume was $2 \mu \mathrm{L}$. The column temperature was $35{ }^{\circ} \mathrm{C}$ (measured with a digital thermometer, model 3150, PeakTech). The DAD scan range was 245-500 nm and detection was carried out at $345 \mathrm{~nm}$ (bandwidth $4 \mathrm{~nm}$ ), having $470 \mathrm{~nm}$ (bandwidth $40 \mathrm{~nm}$ ) as reference $\lambda$. The following solvents were used as eluent: solvent A was the same as for the HPLC column, whereas solvent $\mathrm{B}$ was acetonitrile. The flow was $0.90 \mathrm{~mL} \mathrm{~min} \mathrm{~m}^{-1}$ and the following linear gradient was used: $85-45 \%$ A $(0-4.00 \mathrm{~min}), 45-85 \% \mathrm{~A}(4.00-4.01 \mathrm{~min})$ and $85 \% \mathrm{~A}$, isocratic (4.01-5.00 $\mathrm{min})$. Injections were made every $5 \mathrm{~min}$.

\subsubsection{Calibration curves, linearity and determination of relative response factors (RRFs)}

For the HPLC column, the stock solutions were prepared as follows: (i) $125 \mathrm{mg}$ of chrysin (internal standard, i.s.; MW: $\left.254.24 \mathrm{~g} \mathrm{~mol}^{-1}\right)$ were dissolved in methanol $\left(0.5 \mathrm{mg} \mathrm{mL}^{-1} ; 2.0\right.$ $\mathrm{mM}$ ); (ii) $2.0 \mathrm{mg}$ of Idg (MW: $610.52 \mathrm{~g} \mathrm{~mol}^{-1}$ ) were accurately weighed and dissolved in methanol-dimethyl sulfoxide 7:3 (v/v); (iii) $3.6 \mathrm{mg}$ of $\mathbf{I m g}$ (MW: $448.38 \mathrm{~g} \mathrm{~mol}^{-1}$ ) were accurately weighed and dissolved in methanol-dimethyl sulfoxide $7: 3(\mathrm{v} / \mathrm{v})$; and (iv) $2.4 \mathrm{mg}$ of lut (MW: $286.24 \mathrm{~g} \mathrm{~mol}^{-1}$ ) were accurately weighed and dissolved in methanol. In the cases of i.s. and lut, the dissolution was assisted by the use of a shaker at room temperature. Generally, the exposure of the solutions of the flavones to light was minimised. As $10 \mathrm{~mL}$ volumetric flasks were used for ldg, lmg, and lut, the concentration of the stock solutions were $176 \mu \mathrm{g}$ $\mathrm{mL}^{-1}(0.29 \mathrm{mM}), 341 \mu \mathrm{g} \mathrm{mL} \mathrm{L}^{-1}(0.76 \mathrm{mM})$, and $233 \mu \mathrm{g} \mathrm{mL} \mathrm{L}^{-1}(0.81 \mathrm{mM})$, respectively (taking into account the purity determined by NMR). The i.s. stock solution was stored at $4{ }^{\circ} \mathrm{C}$. The dilutions were made by adding $1.00 \mathrm{~mL}$ of the i.s. solution and different volumes of each of the stock solutions to $5 \mathrm{~mL}$ volumetric flasks. Five concentrations for ldg and $\mathbf{l m g}$, and seven for lut (for which a 10x diluted stock solution was additionally required) were prepared by the use of volumetric pipettes, ranging as follows: (i) ldg: 7-141 $\mu \mathrm{g} \mathrm{mL}^{-1}$; (ii) lmg: 14-205 $\mu \mathrm{g} \mathrm{mL}^{-1}$; and (iii) lut: $2-116 \mu \mathrm{g} \mathrm{mL}^{-1}$. This was done separately for each of the flavones. In all cases: (i) only methanol was added to the mark and (ii) each solution was injected once. For the UHPLC column, the stock and diluted solutions were prepared as above, except that $2.4 \mathrm{mg}$ of $\mathbf{I d g}, 3.7$ $\mathrm{mg}$ of $\mathbf{l m g}$, and $2.3 \mathrm{mg}$ of lut were weighed (thus, taking into account the purity determined by NMR, the concentrations of the stock solutions were: $215 \mu \mathrm{g} \mathrm{mL} L^{-1}$ or $0.35 \mathrm{mM}, 340 \mu \mathrm{g} \mathrm{mL}^{-1}$ or $0.76 \mathrm{mM}$, and $230 \mu \mathrm{g} \mathrm{mL}^{-1}$ or $0.80 \mathrm{mM}$, respectively) and the concentrations of the diluted solutions ranged as follows: (i) ldg: $9-150 \mu \mathrm{g} \mathrm{mL}^{-1}$; (ii) lmg: $14-238 \mu \mathrm{g} \mathrm{mL}^{-1}$; and (iii) lut: $2-$ $115 \mu \mathrm{g} \mathrm{mL} \mathrm{m}^{-1}$. In all cases, each solution was injected once.

\subsubsection{Evaluation of the extraction efficiency}

$R$. luteola $\mathrm{H}$ was extracted according to the normal procedure (above). However, the work-up was done differently. The extract was filtered under reduced pressure by the use of an ordinary $60^{\circ}$ filtration funnel and a suction flask. The filtrate was collected in a test tube placed inside the flask. It was then transferred to a $25 \mathrm{~mL}$ volumetric flask and methanol-water 8:2 (v/v) was added to the mark. The solution was syringe-filtered and analysed by HPLC. No i.s. solution was added as the experiment was run on a relative basis and the results were calculated based on the sum of the areas of the Idg, Img, and lut peaks. The filter paper was transferred back to the Erlenmeyer flask. The powder of the plant material was removed from the filter paper with the aid of $20 \mathrm{~mL}$ of freshly added methanol-water $8: 2(\mathrm{v} / \mathrm{v})$. The same extraction and work-up 
procedures were carried out twice more. This experiment was carried out thrice. The extraction times of each cycle were: 1 st $16 \mathrm{~h}$; 2nd 24-26 h; and 3rd 53-56 h.

\subsubsection{Precision of the entire method}

For the HPLC column, three series of seven replicates of the usual extraction were carried out $($ sample $=R$. luteola $\mathrm{H})$. They occurred on days 1,3 and 5 . Those of days 1 and 5 were carried out with a 15-stirring point magnetic stirrer, whereas those of day 3 , by the use of the individual magnetic stirrers. For the UHPLC column, eight replicates of the usual extraction were carried out ( sample $=R$. luteola $\mathrm{H})$. After storage of samples at $4{ }^{\circ} \mathrm{C}$ or $-20^{\circ} \mathrm{C}$, they were analysed on days 5,5 , and 6 .

\subsubsection{Recovery of the method}

\subsubsection{Relative recovery experiments, including evaluation of the stability of the compounds under the extraction conditions}

The relative recovery experiment was conducted similarly to that described earlier [2]. In short: pre-purified samples were subjected anew to the entire analytical procedure. In this case, a 10stirring points magnetic stirrer (RO 10 P, IKA Werke, Staufen/Germany) was used. The areas of the peaks before and after the analytical procedure, including extraction, were compared. Also, extracts were filtered through filter paper Whatman 42 and brought to a final volume of $25.0 \mathrm{~mL}$ with methanol-water 8:2 (v/v). In each case, the area of the peaks of $\mathbf{l d g}, \mathbf{I m g}$, and lut of syringe-filtered and non-syringe-filtered (above) samples were compared $(n=3)$. The experiments were carried out with three different amounts of plant material: $\sim 100,200$, and 300 mg.

\subsubsection{Absolute recovery by spiking experiment (accuracy)}

Known amounts of each flavonoid of interest were added to the plant material (spiking). Then, the extraction and work-up proceeded as usual. Due to the poor solubility of the glycosides (lmg and Idg) in methanol, water, and their mixtures, this required a specific approach. Each flavonoid standard was accurately weighed and transferred to a round-bottom flask with methanol, which was then evaporated in vacuo. Methanol-water 8:2 (v/v) was added to the residue. This was followed by simultaneous agitation and sonication during $10 \mathrm{~min}$. This solution was analysed $(n=3)$ with the internal standard method to determine the absolute amount of each flavone present. Next, $20.00 \mathrm{~mL}$ of the solution was added to $200 \mathrm{mg}$ of plant material, followed by standard extraction, work-up, and analysis (above). The amounts of ldg, Img, and lut present in $200 \mathrm{mg}$ of $R$. luteola $\mathrm{H}$ were $707 \mu \mathrm{g}$ (average) $(3.3 \%=$ relative standard deviation), $1,298 \mu \mathrm{g}(3.9 \%)$, and $195 \mu \mathrm{g}(5.4 \%)$, respectively $(\mathrm{n}=12)$. The spiking was carried out at three levels, as follows: low (two triplicates), medium (triplicate) and high (triplicate). The added absolute amounts of $\mathbf{l d g}$, $\mathbf{l m g}$, and lut in the spiking experiments were:

(i) $392 \mu \mathrm{g}(0.7 \%), 618 \mu \mathrm{g}(0.2 \%)$, and $78.1 \mu \mathrm{g}(0.6 \%)$, respectively, in the first triplicate of level low;

(ii) $341 \mu \mathrm{g}(0.2 \%), 623 \mu \mathrm{g}(0.6 \%)$, and $118.2 \mu \mathrm{g}(0.5 \%)$, respectively, in the second triplicate of level low;

(iii) $726 \mu \mathrm{g}(0.5 \%), 1,369 \mu \mathrm{g}(0.4 \%)$, and $232.7 \mu \mathrm{g}(0.4 \%)$, respectively, in the level medium;

(iv) $929 \mu \mathrm{g}(0.4 \%), 1,923 \mu \mathrm{g}(0.2 \%)$ and $290.8 \mu \mathrm{g}(0.3 \%)$, respectively, in the level high. 
Thus, the spiking levels were: 40-61\% (low), 103-119\% (medium), and 131-149\% (high), roughly corresponding to 50,110 , and $140 \%$ of the flavonoid content that is present in the plant material. The recovery (in \%) was calculated as [3]:

$\{[($ amount found $)-($ amount in plant $)] /$ amount spiked $\} \times 100 \%$

\subsubsection{Stability of samples ready for analysis}

All extracts of series 1 of the HPLC column precision experiment (above) were collected in four HPLC vials. One set of vials was loaded for analysis in the HPLC shortly after the workup procedure. The second set of vials was also placed in the auto-sampler (room temperature and dark), but analysed $24 \mathrm{hrs}$ after the previous series. The third set was placed at $4{ }^{\circ} \mathrm{C}$, and the fourth, at $-20{ }^{\circ} \mathrm{C}$. They were analysed $72 \mathrm{~h}$ and 15 days after the first set of vials, respectively.

\subsubsection{Data/statistical analysis}

Values of the results presented were generally rounded up according to their uncertainties (standard deviation values), expressed with one significant digit. Unless stated otherwise, statistical analyses were carried out using the Mann-Whitney $U$-test ( $\alpha=5 \%$, two-sided test) [4].

\subsection{Results and discussion}

\subsubsection{Extraction}

As the assay was expected to be used in an industrial setting for hundreds of samples during many years, the amount of labour per sample was of eminent importance. Earlier, a slow maceration-type extraction with introduction of i.s. before sampling followed by RP-HPLC proved itself very labour-efficient in the analysis of 750 Taxus samples [5, 6]. A similar approach (overnight maceration with stirring) was evaluated for $R$. luteola flavones.

Next, the solvent for extraction had to be selected. Cristea et al. [7] compared different solvents for the extraction of Idg, Img, and lut from the aerial parts of $R$. luteola, with methanolwater $8: 2(\mathrm{v} / \mathrm{v})$ giving the highest yield. The same authors observed $10-30 \%$ lower extraction yields of the flavonoids after extraction with methanol-water $8: 2(\mathrm{v} / \mathrm{v})$ for $4 \mathrm{~h}$ at room temperature than after $15 \mathrm{~min}$ of refluxing [7]. This is consistent with our preliminary observations using a solvent-sample ratio of 20 , with which - even after $\sim 18 \mathrm{~h}$ of extraction at room temperature-lower yield of the flavones were obtained than after $15 \mathrm{~min}$ of reflux. However, when using a solvent-sample ratio of 100, the yields were observed not to be statistically significantly different (Mann-Whitney $U$-test, $\alpha=10 \%$ ). This fits with the observation by Cerrato et al. [8] that the yield of lut, upon extraction with methanol at room temperature, reaches an equilibrium after $\sim 16 \mathrm{~h}$. Considering that the aim was to develop a method requiring as little as possible manpower input per sample, the overnight extraction at room temperature is clearly advantageous over the 15 min extraction by reflux. The extraction, when carried out overnight and using a solvent-sample ratio of 100 , gave $95 \%$ efficiency. A second and a third extraction yielded 4 and 1\%, respectively. A fourth extraction step with additional sonication yielded no additional flavones. Performing a single extraction in this manner saves time, chemicals, and manpower input. As over $99 \%$ of the flavonoids are extracted in the first two cycles and $s_{\mathrm{r}}$ (relative standard deviation) values are low, it is an option 
to correct the initial outcome by multiplying it by a factor of $100 / 95$ to arrive at the true flavone content. In the tables, uncorrected values are presented. The manual labour input of the whole analytical procedure is minimal, consisting of weighing the previously ground plant material, adding solvent and stir bar, placing the flask on a magnetic stirrer, adding the i.s. solution, and syringe-filtering the sample into the HPLC vial.

\subsubsection{Chromatography}

The validation was performed on a traditional HPLC column. The solvents used with this $5 \mu \mathrm{m}-$ particle size RP-HPLC $250 \mathrm{~mm} \times 4.6 \mathrm{~mm}$ column were: (i) an aqueous buffer of $\mathrm{pH} 3$ (solvent A) [9], and (ii) methanol (solvent B). The detection wavelength was selected to be $345 \mathrm{~nm}$ in view of the absorbance maxima of $\operatorname{ldg}(340 \mathrm{~nm}), \operatorname{lmg}(350 \mathrm{~nm})$, and lut $(350 \mathrm{~nm})$. No sample preparation other than filtration proved necessary (Fig. 1, top). The total run time, including equilibration, was $80 \mathrm{~min}$, and $35.9 \mathrm{~mL}$ of methanol were needed. From the results of the precision experiment, retention times were observed to be precise, varying at most $0.4 \%$ over a period of 5 days. Within one day, the $s_{\mathrm{r}}$ values of the retention times varied from 0.004 to $0.05 \%$.

The use of a $1.8 \mu \mathrm{m}$-particle size UHPLC $50 \mathrm{~mm} \times 3.0 \mathrm{~mm}$ column saves time and solvents. The UHPLC column could be run with a flow of $0.9 \mathrm{~mL} \mathrm{~min}^{-1}$ on a conventional HPLC system after minor adaption of the hardware and tubing, and changing the B solvent to acetonitrile (Fig. 1, bottom). This shortened the run time to $5 \mathrm{~min}$, and only $1.4 \mathrm{~mL}$ of acetonitrile was needed. The resolution between $\mathbf{l d g}$ and $\mathbf{I m g}\left(R_{\mathrm{s}}=5.4\right)$ was lower than on the HPLC column $\left(R_{\mathrm{S}}=9.2\right)$, but still more than sufficient for reliable integrations.

Although in absolute terms the retention time variation was lower on the UHPLC column, relatively (i.e., precision), they were observed to be 25 to $180 \times$ (i.s. and ldg cases, respectively) higher than with the $5 \mu \mathrm{m}$-particle size HPLC column. However, never did this influence the quantitation (Table 2.4). The higher relative retention time variation is likely caused by working near the maximum pressure of the HPLC pump (400 bar) and, additionally, by the much lower absolute retention times (ldg: varying from 0.85 to $0.93 \mathrm{~min}$, and varying from 33.67 to 33.81 min for the 1.8 and $5 \mu \mathrm{m}$-particle size columns, respectively). This was supported by performing some trial analyses on a true UHPLC system. After increasing the flow to $1.4 \mathrm{~mL}$ $\mathrm{min}^{-1}$ and adapting the gradient (max. pressure $525 \mathrm{bar}$ ), the run time was shortened to $2 \mathrm{~min}$ and the retention time variability was reduced to $0.05-0.73 \%$ (data not shown). 

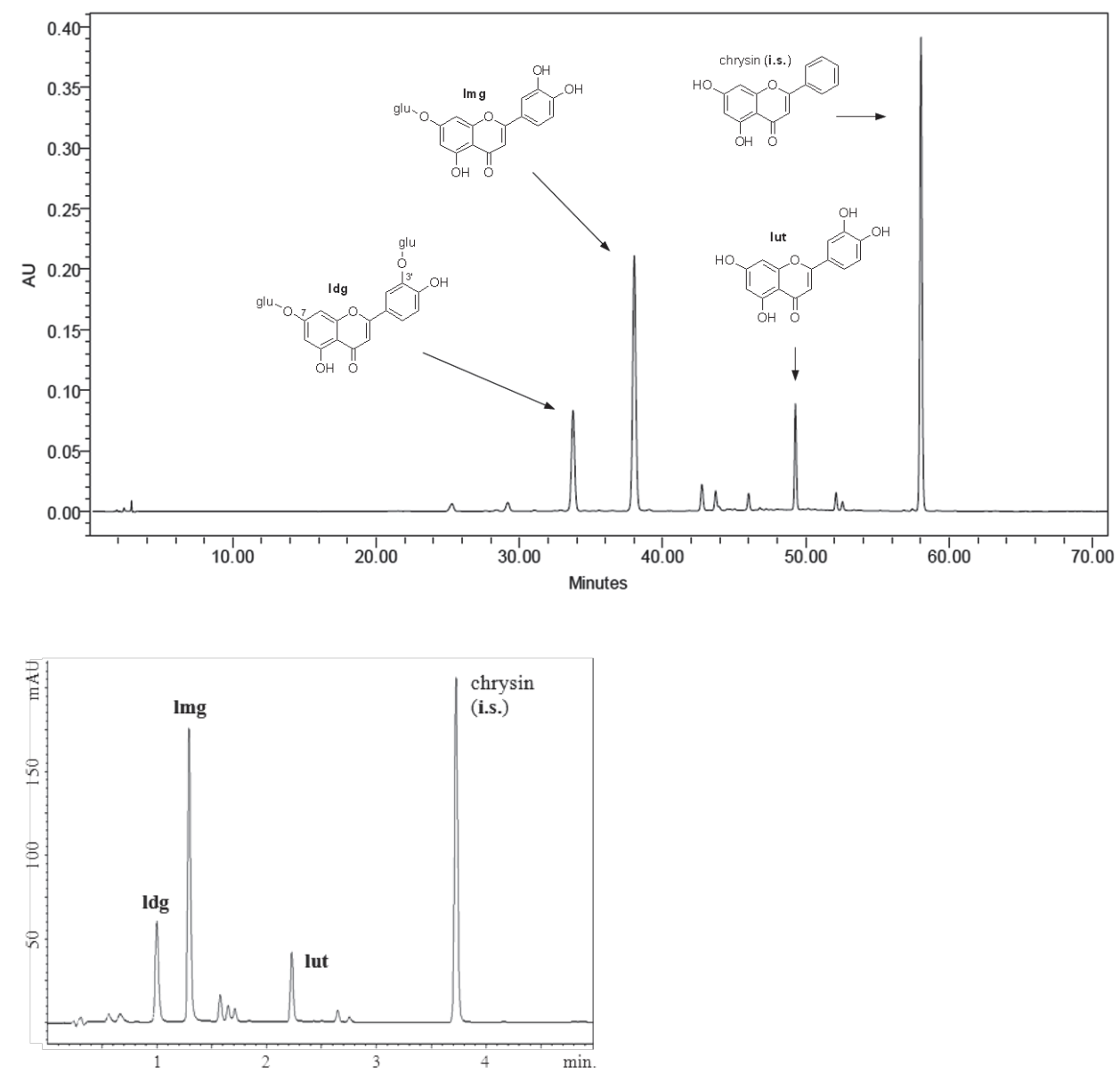

Figure 2.1. Top: HPLC profile of $R$. luteola $\mathrm{H}$ extract on $5 \mu \mathrm{m}$-particle size $250 \mathrm{~mm} \times 4.6 \mathrm{~mm}$ HPLC column. Column temperature was $40{ }^{\circ} \mathrm{C}$ and injected volume was $20 \mu \mathrm{L}$. Identity of the main peaks is indicated: luteolin-7,3'-di- $O$-glucoside (luteolin diglucoside, Idg), luteolin-7-O-glucoside (luteolin monoglucoside, Img), luteolin (lut) and chrysin (internal standard, i.s.). Bottom: Analysis of $R$. luteola $\mathrm{H}$ on $1.8 \mu \mathrm{m}$-particle size $50 \mathrm{~mm} \times 3.0 \mathrm{~mm}$ UHPLC column. Column temperature was $35^{\circ} \mathrm{C}$ and injected volume was $2 \mu \mathrm{L}$. Top and bottom: Detection at $345 \mathrm{~nm}$. 


\subsubsection{Accuracy}

The accuracy of the method was determined by an absolute recovery (spiking) experiment at three levels. Namely, by adding roughly $50 \%, 100 \%$, and $140 \%$ of what is expected in the plant (Table 2.1). The $s_{\mathrm{r}}$ values of the results are equivalent to those of the usual procedure (Table 2.4), except for the low spiking level. The average recovery was not statistically different from $100 \%$ (assuming normal distribution of the results and considering $2 s$ ), indicating good accuracy. To check for any constant zero-order losses due to adsorption on glass and filters which cannot be detected with spiking experiments, relative recovery experiments at three different concentrations were carried out. The stability of the compounds under the extraction conditions was simultaneously evaluated (Table 2.1). At all three concentrations, the relative recovery of the three flavonoids was not statistically different from $100 \%$ (assuming normal distribution of the results and considering $2 s$ ), showing that - as expected - the extraction procedure is mild and that any losses due to sample manipulation, filtration, or adsorption to glass are negligible.

Table 2.1. Relative and absolute recoveries ${ }^{a}$ of $\mathbf{l d g}$, $\mathbf{l m g}$, and lut $(\mathrm{n}=3$; sample $=R$. luteola $\mathrm{H})$.

\begin{tabular}{|c|c|c|c|c|c|c|}
\hline \multirow{2}{*}{ Level } & \multicolumn{3}{|c|}{ Relative $(\%)^{b, c}$} & \multicolumn{3}{|c|}{ Absolute $(\%)^{b, d}$} \\
\hline & ldg & Img & lut & Idg & Img & lut \\
\hline Low & $(102 \pm 2), 2$ & $(99 \pm 2), 2$ & $(100 \pm 3), 3$ & $(99 \pm 8), 8$ & $(103 \pm 7), 7$ & $\begin{array}{l}(106 \pm 15) \\
14\end{array}$ \\
\hline Medium & $\begin{array}{l}(101.0 \quad \pm \\
0.7), 0.7\end{array}$ & $\begin{array}{l}(99.7 \pm 0.2), \\
0.2\end{array}$ & $(101 \pm 1), 1$ & $(98 \pm 6), 6$ & $(101 \pm 6), 6$ & $(107 \pm 8), 7$ \\
\hline High & $(101 \pm 2), 2$ & $(99 \pm 1), 1$ & $(101 \pm 1), 1$ & $\begin{array}{l}(98.7 \pm 0.9), \\
1.0\end{array}$ & $\begin{array}{l}(99.9 \pm 0.2) \\
0.2\end{array}$ & $(102 \pm 4), 4$ \\
\hline
\end{tabular}

${ }^{a}$ Relative recovery is based on subjecting an extract corresponding to 100,200 , or $300 \mathrm{mg}$ of plant material anew to the entire analytical procedure; absolute recovery is based on three spiking experiments at 50,110 , and $140 \%$.

${ }^{\mathrm{b}}$ Expressed as (average \pm standard deviation), $s_{\mathrm{r}}$ (relative standard deviation).

${ }^{c}$ The (relative) recovery of $\mathbf{l d g}$, Img, and lut due to the syringe-filtration also ranged between 99 and $102 \%$, with $s_{\mathrm{r}}$ values ranging between 0.1 and $2.6 \%$.

${ }^{\mathrm{d}}$ Low level: $\mathrm{n}=6$. 


\subsubsection{Identification and peak purity}

The identity of the three main flavonoids of $R$. luteola was confirmed to be ldg, Img, and lut by having identical retention times and on-line UV-vis absorption spectra to those of authentic reference substances, and on-line mass spectrometric experiments (see section SI A.1.2).

Peak purity analysis (see section SI A.1.2) by LC-MS and LC-UV showed there is no significant co-elution of minor compounds absorbing at $345 \mathrm{~nm}$ of $R$. luteola and the $\mathbf{~ I d g}$, $\mathbf{l m g}$, lut, and i.s. peaks (see section SI A.2.1) on either the HPLC or the UHPLC column. Thus, the peak areas on both columns at $345 \mathrm{~nm}$ are representative for Idg, lmg, lut, and i.s.

\subsubsection{Calibration curves and limits of detection and quantitation}

Internal standardisation was the quantitation method selected. Out of four potential internal standards [3',4'-dihydroxyflavone, lut tetramethylether, chrysin (5,7-dihydroxyflavone) and acacetin (apigenin-4'-methylether)], chrysin was selected based on stability issues, price considerations ( $€ 0.01$ assay $\left.^{-1}\right)$, and retention time, in spite of its relatively low absorbance at $345 \mathrm{~nm}$.

The relative response factors (RRFs, slope of $A_{\mathbf{x}} / A_{\mathbf{i} . s .}$ plotted $v s . w_{\mathbf{x}} / W_{\text {i.s. }}$ ) of $\mathbf{l d g}, \mathbf{l m g}$, and lut were determined and the linearity of the concentration of the solutions $v s$. area of the peaks was checked. The RRFs were 1.10 (ldg), 1.51 (lmg), and 2.37 (lut) with the HPLC column and 1.13 (ldg), 1.58 (lmg), and 2.29 (lut) with the UHPLC column. The areas of the peaks were observed to linearly correlate with the concentrations of the solutions over the range of concentrations studied (Table 2.2). These ranges are satisfactory for the quantitation of the compounds of interest at the concentrations in which they are present in $R$. luteola $\mathrm{H}$ and other samples.

Table 2.2. HPLC calibration curves and linearity of Idg, Img, and lut. Ldg and Img: Five point-curves; Lut:

Seven point-curves.

\begin{tabular}{lll}
\hline Compound $[\mathbf{x}]$ & $\begin{array}{l}\text { HPLC column }^{\text {a }} \\
{[\mathbf{x}]\left(\mu \mathrm{gL}^{-1}\right) v s . \mathrm{A}_{\mathbf{x}}\left(\mathrm{R}^{2}\right)}\end{array}$ & $\begin{array}{l}\text { UHPLC column }^{\mathrm{a}} \\
{[\mathbf{x}]\left(\mu \mathrm{gL}^{-1}\right) v s . \mathrm{A}_{\mathbf{x}}\left(\mathrm{R}^{2}\right)}\end{array}$ \\
\hline $\boldsymbol{l d g}$ & $\mathrm{y}=46,517 \mathrm{x}+12,410(0.9995)$ & $\mathrm{y}=4.9919 \mathrm{x}+0.1505(0.9998)$ \\
$\mathbf{l m g}$ & $\mathrm{y}=65,346 \mathrm{x}-19,906(0.9999)$ & $\mathrm{y}=7.044 \mathrm{x}+7.8141(0.9998)$ \\
lut & $\mathrm{y}=101,383 \mathrm{x}+89,417(0.9998)$ & $\mathrm{y}=10.249 \mathrm{x}-2.0982(0.9992)$ \\
\hline
\end{tabular}

${ }^{a}$ Idg, Img, and lut: Each case, $\mathrm{n}=1$.

The limits of detection (LOD) and quantitation (LOQ) of the method were determined based on the slopes of the calibration curves and the $s$ of the baseline noise of analyses of analytical blanks, and on the signal-to-noise ratio of injections of highly diluted solutions (Table 2.3). For more details on the determination of the LOD and LOQ values, see Appendix A. Assuming normal distribution of the results and considering both the $s$ values of the results and, in this case, the uncertainty of the LOD values estimated based on the signal-to-noise ratio, the LOD values using the HPLC column are the same, regardless the procedure used for their estimation. Similarly, using the UHPLC column, except for Idg, the LOD values are also the same. Moreover, the method is more sensitive when using the UHPLC column than when using the HPLC column (Table 2.3). 
Table 2.3. LOD and LOQ values of $\mathbf{l d g}$, Img, and lut using both HPLC and UHPLC columns, based on: (i) the slopes of the calibration curves and the $s$ of the baseline noise of analyses of analytical blanks; and (ii) based on the signal-to-noise ratio.

\begin{tabular}{|c|c|c|c|}
\hline Compound & $\mathrm{LOD} \pm s(\mathrm{ng})$ & $\mathrm{LOQ} \pm s(\mathrm{ng})$ & LOD (ng) \\
\hline & \multicolumn{3}{|c|}{ HPLC column (injection volume of $20 \mu \mathrm{L}$ ) } \\
\hline & \multicolumn{2}{|l|}{$\mathrm{i}(\mathrm{n}=5)$} & ii $(\mathrm{n}=1)$ \\
\hline $\operatorname{ldg}$ & $1.1 \pm 0.3$ & $3 \pm 1$ & 0.9 \\
\hline $\operatorname{lmg}$ & $0.7 \pm 0.2$ & $2.2 \pm 0.7$ & 0.8 \\
\hline \multirow[t]{3}{*}{ lut } & $0.25 \pm 0.08$ & $0.8 \pm 0.2$ & 0.4 \\
\hline & \multicolumn{3}{|c|}{ UHPLC column (injection volume of $2 \mu \mathrm{L}$ ) } \\
\hline & \multicolumn{2}{|l|}{$\mathrm{i}(\mathrm{n}=6)$} & ii $(n=1)$ \\
\hline Idg & $0.29 \pm 0.05$ & $0.9 \pm 0.1$ & 0.1 \\
\hline $\operatorname{lmg}$ & $0.21 \pm 0.04$ & $0.6 \pm 0.1$ & 0.2 \\
\hline lut & $0.14 \pm 0.02$ & $0.41 \pm 0.07$ & 0.1 \\
\hline
\end{tabular}

The LOD and LOQ values of this method are low compared with those of earlier methods. Plazonić et al. and Kočevar et al. $[10,11]$ determined LOD and LOQ values for Img and lut that are 6-20× higher than the values reported here, when using the HPLC column, and 20 $50 \times$ higher than the values reported here, when using the UHPLC column. Gaspar et al. [12] determined LOD values $<7 \mathrm{ng}$ and LOQ values $\leq 11 \mathrm{ng}$ for $\mathbf{~ I d g}$, Img, and lut, which are 6-12× (LOD) and 4-10× (LOQ) higher than the values reported here, using the HPLC column, and are 20-60× (LOD) and 10-20× (LOQ) higher than the values reported here, using the UHPLC column. The baselines of the UV detectors used in the work reported here were highly stable. On average, the $s$ values of the baseline noise over large time intervals were only $0.04 \pm 0.01$ mAU (HPLC column) and $0.09 \pm 0.01 \mathrm{mAU}$ (UHPLC column) (see Appendix A for details). Baselines in earlier studies were possibly less stable. In addition, different methods were used to estimate those limits, as Plazonić et al. [10] used the residual $s$ of the regression line and slope, and Kočevar et al. and Gaspar et al. [11, 12] based it on the signal-to-noise ratio.

\subsubsection{Stability of samples}

The stability of the samples ready for HPLC analysis was evaluated to verify whether the residence time in the autosampler would influence the outcome. This could, for example, be the case when analysing a large sample set. Moreover, it was evaluated whether the samples are stable upon storage at $4{ }^{\circ} \mathrm{C}$ for 3 days and at $-20{ }^{\circ} \mathrm{C}$ for 15 days. Upon storage of the samples ready for HPLC analysis, the area of the chrysin peak was not statistically significantly different than that of the samples analysed shortly after the work-up procedure, indicating that neither precipitation of the i.s. nor sample concentration took place. Assuming normal distribution of the results and considering the $s$, the amounts of the flavones remained the same in all analysed sets of vials. Thus, the compounds in samples are stable upon storage under the aforementioned conditions. 


\subsubsection{Quantitative results and precision}

The concentrations of Idg, Img, and lut in $R$. luteola $\mathrm{H}$, as determined on the $5 \mu \mathrm{m}$-particle size column, were $3.5 \mathrm{mg} \mathrm{g}^{-1}, 6.5 \mathrm{mg} \mathrm{g}^{-1}$, and $1.0 \mathrm{mg} \mathrm{g}^{-1}$, respectively. For the $1.8 \mu \mathrm{m}$-particle size column, these figures were $3.6 \mathrm{mg} \mathrm{g}^{-1}, 6.5 \mathrm{mg} \mathrm{g}^{-1}$, and $1.0 \mathrm{mg} \mathrm{g}^{-1}$ (Table 2.4). These results are not statistically significantly different (Idg). This indicates that the HPLC system copes well with the small UHPLC injection volumes $(2 \mu \mathrm{L})$. Furthermore, major advantages of the use of the UHPLC column are, of course, the $16 \times$ faster analysis and the $25 \times$ lower solvent consumption.

The precision of the entire method on the HPLC column was evaluated in terms of repeatability and intermediate precision. The $s_{\mathrm{r}}$ values for the whole analytical procedure were $\sim 5 \%$ with the HPLC column, except for series 3 (Table 2.4). Still, the larger $s_{\mathrm{r}}$ values of series 3 did not influence the average outcome. The type of stirrer used (15-point, which heats itself up by $3{ }^{\circ} \mathrm{C}$ during operation, for series 1 and $3 v s$. individual ones for series 2 ) does not seem to have any influence on the outcome, which suggests robustness of the method regarding small temperature variations. The $s_{\mathrm{r}}$ values of the quantitations carried out with the UHPLC column were $7 \%$ (ldg), $7 \%$ (lmg), and 10\% (lut) (Table 2.4). These values are comparable to those of the analyses of the same samples carried out with the HPLC column, 7\% (Idg), $7 \%$ (Img), and $11 \%$ (lut) (footnote $d$, Table 2.4). Kočevar et al. and Plazonić et al. [11] [10] reported $s_{\mathrm{r}}$ values for the repeatability and intermediate precision of the areas of Img and lut peaks ranging from 0.9 to $4.3 \%$, respectively, when analysing standard solutions. When analysing extracts, Kočevar et al. [11] observed slightly higher $s_{r}$ values, up to 5.4\% for lmg. Gaspar et al. [12] evaluated the repeatability of the whole analytical procedure using two samples of $R$. luteola of extreme (high and low) contents of flavonoids. The observed average $s_{r}$ values were $5.1 \%$ (ldg), 3.9\% (lmg), and $4.9 \%$ (lut). The $s_{r}$ values reported here are slightly higher than those of the aforementioned works. Possible reasons include the different experimental designs and data processing. Still, the proposed method determines the combined content of Idg, Img, and lut with $s_{\mathrm{r}}<6.5 \%$, which is fine for the intended purpose. 
Table 2.4. Precision of the entire method, and that of the analyses using the UHPLC column, for the quantitation of ldg, lmg, and lut in Reseda luteola (sample $=$ R. luteola $\mathrm{H}$ ).

\begin{tabular}{|c|c|c|c|}
\hline Series & Compound & $\begin{array}{l}\text { HPLC column } \\
\text { Concentration }\left(\mathrm{mg} \mathrm{g}^{-1}\right)^{\mathrm{a}, \mathrm{b}}\left(S_{\mathrm{r}} \text { in } \%\right)\end{array}$ & $\begin{array}{l}\text { UHPLC column } \\
\text { Concentration }\left(\mathrm{mg} \mathrm{g}^{-1}\right)^{\mathrm{c}, \mathrm{d}}\left(s_{\mathrm{r}} \text { in } \%\right)\end{array}$ \\
\hline \multirow{3}{*}{1} & Idg & $3.6(5.3)$ & $3.6(7.1)$ \\
\hline & Img & $6.7(5.2)$ & $6.5(7.2)$ \\
\hline & lut & $1.01(5.8)$ & $1.0(10.4)$ \\
\hline \multirow{3}{*}{2} & ldg & $3.5(3.8)$ & $3.6(6.2)$ \\
\hline & $\operatorname{lmg}$ & $6.5(3.6)$ & $6.5(6.5)$ \\
\hline & lut & $1.00(4.9)$ & $1.01(9.0)$ \\
\hline \multirow{3}{*}{3} & Idg & $3.5(6.1)$ & $3.6(8.8)$ \\
\hline & Img & $6.4(6.5)$ & $6.5(8.5)$ \\
\hline & lut & $1.01(8.5)$ & $1.0(11.5)$ \\
\hline
\end{tabular}

${ }^{a}$ Extractions were carried out on three non-consecutive days (each day, $\mathrm{n}=7$ ).

${ }^{\mathrm{b}}$ Series 3: $s$ of the quantitation of $\mathbf{l d g}$, Img, and lut were 0.2, 0.4 and 0.09, respectively; thus, the $s_{\mathrm{r}}$ of their combined amounts was $6.3 \%$.

${ }^{c}$ Extractions were carried out once $(\mathrm{n}=8)$; then, stored samples were analysed in three series (see section 2.2.7).

${ }^{\mathrm{d}}$ Analysis of same samples $(\mathrm{n}=8)$ using the HPLC column: Amount $=3.6 \mathrm{mg} \mathrm{g}^{-1}, \mathrm{~s}_{\mathrm{r}}=6.8 \%(\mathbf{l d g}) ; 6.5 \mathrm{mg} \mathrm{g}^{-1}$, $7.2 \%$ (lmg); and $1.0 \mathrm{mg} \mathrm{g}^{-1}, 10.7 \%$ (lut); for that, the following RRFs (determined anew for HPLC column, details not presented) were used: 1.09 (ldg); 1.51 (lmg); and 2.28 (lut).

\subsection{Conclusion}

The analytical method reported here is suitable for the quantitation of $\mathbf{l d g}$, $\mathbf{l m g}$, and lut in the aerial parts of $R$. luteola. According to the extensive validation (extraction efficiency, recovery, accuracy, precision, sensitivity, peak purity, sample stability), this is accomplished accurately. The precision reported $(<6.5 \%)$ is adequate for the purpose. The industrial partner of the project reported, in daily practice, a standard deviation $<4 \%$ when analysing over $120 \mathrm{R}$. luteola samples using this method. The method meets the need for very little manpower input per sample and uses standard laboratory equipment. Although the analytical method was developed for the quantitation of flavones in R. luteola, it is expected that, after additional validation, it could be applied on other flavone-rich plant materials too.

Two types of columns were used: For the validation, a traditional $4.6 \mathrm{~mm}$ column with $5 \mu \mathrm{m}$ particles; then, the chromatographic step was speeded-up by the use of a short UHPLC column, while still using a conventional HPLC system. The use of the UHPLC column reduced the run time by a factor of 16 and the organic solvent consumption by a factor of 26 . Retention times were relatively less reproducible with the UHPLC column than with the HPLC column. This could be remedied by either lowering the flow to $0.6 \mathrm{~mL} \mathrm{~min}^{-1}$ or using a true UHPLC pump. Cross-validation showed that the quantitation of $\mathbf{l d g}$, Img, and lut was not statistically significantly different, with comparable precision. Moreover, the method is more sensitive with the UHPLC column than with the HPLC column. Using a UHPLC column on a conventional HPLC system is, thus, a way of modernising HPLC-based (phytochemical) analyses inexpensively. 


\subsection{Supplementary material}

Appendix A contains information supplementary to that in this chapter. Sections material and methods, results and discussion, and reference are available.

\subsection{References}

[1] van Beek TA, van Veldhuizen A, Lelyveld GP, Piron I. Quantitation of bilobalide and ginkgolides $\mathrm{A}, \mathrm{B}, \mathrm{C}$ and $\mathrm{J}$ by means of nuclear magnetic resonance spectroscopy. Phytochem Anal 1993; 4(6): 261-8.

[2] van Beek TA, Scheeren HA, Rantio T, Melger WC, Lelyveld GP. Determination of ginkgolides and bilobalide in Ginkgo biloba leaves and phytopharmaceuticals. J Chromatogr A 1991; 543(2): 375-87.

[3] Gao X-Y, Jiang Y, Lu J-Q, Tu P-F. One single standard substance for the determination of multiple anthraquinone derivatives in rhubarb using high-performance liquid chromatographydiode array detection. J Chromatogr A 2009; 1216(11): 2118-23.

[4] Massart DL, Vandeginste BGM, Buydens LMC, De Jong S, Lewi PJ, Smeyers-Verbeke J. Handbook of chemometrics and qualimetrics: part A. Elsevier Science: Amsterdam; 1997.

[5] van Rozendaal ELM, Kurstjens SJL, van Beek TA, van den Berg RG. Chemotaxonomy of Taxus. Phytochemistry 1999; 52(3): 427-33.

[6] van Rozendaal ELM, Lelyveld GP, van Beek TA. A simplified method for the determination of taxanes in yew needles by reversed-phase $(\mathrm{C} 18)$ high pressure liquid chromatography. Phytochem Anal 1997; 8(6): 286-93.

[7] Cristea D, Bareau I, Vilarem G. Identification and quantitative HPLC analysis of the main flavonoids present in weld (Reseda luteola L.). Dyes Pigments 2003; 57(3): 267-72.

[8] Cerrato A, De Santis D, Moresi M. Production of luteolin extracts from Reseda luteola and assessment of their dyeing properties. J Sci Food Agric 2002; 82(10): 1189-99.

[9] Derksen GCH, Niederlander HAG, van Beek TA. Analysis of anthraquinones in Rubia tinctorum L. by liquid chromatography coupled with diode-array UV and mass spectrometric detection. J Chromatogr A 2002; 978(1-2): 119-27.

[10] Plazonić A, Bucar F, Maleš Ž, Mornar A, Nigović B, Kujundžić N. Identification and quantification of flavonoids and phenolic acids in burr parsley (Caucalis platycarpos L.), using high-performance liquid chromatography with diode array detection and electrospray ionization mass spectrometry. Molecules 2009; 14: 2466-90.

[11] Kočevar N, Glavač I, Injac R, Kreft S. Comparison of capillary electrophoresis and high performance liquid chromatography for determination of flavonoids in Achillea millefolium. $\mathrm{J}$ Pharm Biomed Anal 2008; 46(3): 609-14.

[12] Gaspar H, Moiteiro C, Turkman A, Coutinho J, Carnide V. Influence of soil fertility on dye flavonoids production in weld (Reseda luteola L.) accessions from Portugal. J Sep Sci 2009; 32(23-24): 4234-40. 


\section{Chapter 3}

\section{Spectrophotometric comparison of the content of chlorophylls in weld}

The content of this chapter is largely that of the following paper:

Villela A, Derksen GCH, Zuilhof H, van Beek TA. Spectrophotometric comparison of the content of chlorophylls in weld (Reseda luteola). Anal Methods 2011; 3(6): 1424-7. 
An analytical method for the comparison of the content of chlorophylls and their structurally similar breakdown products in weld is described. 


\subsection{Introduction, material and methods, results and discussion, and conclusion}

The greenish hue to which reference is made in the introductory chapter of this thesis could be caused by one of the two factors elaborated upon in this paragraph. First, it could be an intrinsic property of the use of the flavone-based dye; the colours of textiles dyed with mordant dyes are influenced by the metal salt used as mordant [1]. Second, chlorophylls $a$ and $b$ (the main and intensely green pigments of terrestrial plants) are present in the aerial parts of weld and it was hypothesised that they could bind to metal-treated fibres due to Lewis acidLewis base interactions. Based on this hypothesis, quantitation of chlorophylls in weld samples was of interest as part of the characterization of the raw material for production of the dye-extract. With this as background, the development of a simple analytical method to compare the relative amounts of chlorophylls and their breakdown products in different weld samples was aimed at. Because of the expected large number of samples, low manpower input was of paramount importance.

A first consideration in such a development is the observation that chlorophylls are unstable and can be broken down, e.g., by enzymatic activity, light exposure or under acidic conditions [2, 3]. As harvested weld is dried under fairly rough conditions, it not only contains chlorophylls $a$ and $b$ (chls $a$ and $b$ ), but also their breakdown products, including pheophytins (magnesium atom replaced by two hydrogen atoms), chlorophyllides (no phytyl chain) and pheophorbides (magnesium atom replaced by two hydrogen atoms and no phytyl chain) $[4,5]$. To minimally modify the composition of chls and breakdown products of dried weld plant material, precautions should be taken during the analysis. The extraction needs to be fast, carried out in dim light, and use cold solvents of neutral $\mathrm{pH}[2,3,5]$ The quantitation step either immediately follows the extract preparation $[2,3]$ or the compounds should be stable in the extract [5].

Chls can be detected by spectrophotometry, spectrofluorimetry or mass spectrometry $[4,6]$. Whereas spectrofluorimetry is more sensitive than spectrophotometry, quenching of fluorescence takes place in highly concentrated solutions [7] and spectrophotometry (without a preceding HPLC step) is simpler and faster to use. In addition, it is expected that only chls and some of their breakdown products in weld absorb light at wavelengths $>630 \mathrm{~nm}$.

Chls $a$ and $b$, chlorophyllides $a$ and $b$, pheophytins $a$ and $b$, and pheophorbides $a$ and $b$ display two main absorption bands: The blue one (Soret), at wavelengths $<500 \mathrm{~nm}$ and the red one, between 640 and $670 \mathrm{~nm}$ [5]. Despite the main blue bands being more intense than red ones, the latter must be used due to increased selectivity. The red bands of chls and chlorophyllides are centered at nearly the same wavelength $[5,8]$. Those of pheophytins and pheophorbides are 4 to $11 \mathrm{~nm}$ red-shifted and the molar absorption coefficients are about $40 \%$ smaller relative to chls $[5,8]$. Thus, the red absorption band of extracts of weld (Figure SI B.1, appendix B) comprises the red bands of multiple compounds. The absorbance at its maximum was used to compare different samples. ${ }^{1}$

\footnotetext{
${ }^{1}$ Although not done during this work, it could be tested whether weld samples containing different chls/chlorophyllides-to-"pheopigments" ratios could be compared after conversion of chls and chlorophyllides to corresponding "pheopigments" using $\mathrm{HCl}$ (see section "Pheophytinization under Defined Conditions"- and two preceding sections - of ref. 3 for elaboration on the conversion of chls to pheophytins using the acid).
} 
The method for analysing of chls and their breakdown products in weld was evaluated. Simultaneous extraction of 20 samples followed by sequential absorbance measurements was observed to be unsuitable, as the absorbance of identical samples gradually increased going from sample 1 to sample 20 (appendix B). Absorbances of the extracts of samples that were put to steep (soak) for $2 \mathrm{~h}\left(4{ }^{\circ} \mathrm{C}\right)$ after dynamic extraction with acetone were higher than of those in which the measurements immediately followed the extraction (entries 1 through 4 of Table 3.1), indicating an on-going extraction. The $5 \mathrm{~min}$ centrifugation step after the extraction also increased the yield (appendix B). Thus, for a suitable comparison of the content of chls and breakdown products in weld samples, the contact time between sample and solvent has to remain constant. ${ }^{2}$ Centrifugation followed by transfer of the supernatant to the cuvette without filtration was unsuitable. Results suggested scattering of light due to turbidity of the extracts (data not shown), ${ }^{3}$ indicating the need for sample filtration.

The yield of the 3 min vortexing extraction with acetone at room temperature is about $50 \%$ of what can be extracted after $24 \mathrm{~h}$ with this - for chlorophyll-not very efficient solvent (entries 5 and 7). Regarding the choice of solvent: Absolute ethanol extracts about $75 \%$ of what the superior $\mathrm{DMF}^{4}$ extracts but is more efficient than acetone (entries 7, 9, and 12). In addition, among the tested extraction procedures, vortexing is the fastest and probably mildest, and ethanol has the advantage of low toxicity and being environmentally friendly. Finally, the presence of water in the solvent leads to formation of hydroxylated allomers [11]. Also, water in the solvent leads to a red-shift of the main absorption bands of chls and reduction of their molar absorption coefficients [3]. ${ }^{5}$ Thus, the final analytical procedure consists of a 3 min extraction with absolute ethanol by vortexing at room temperature, followed by syringefiltration of the extract and absorbance measurement. ${ }^{6}$

\footnotetext{
${ }^{2}$ No difference in extraction efficiency among weld samples from different plant parts is expected. This is indicated by the linearity of the relation seen ahead (Figure 3.1 and preceding discussion).

${ }^{3}$ Optical clarity of solutions was checked at $700 \mathrm{~nm}[9]$.

${ }^{4}$ Toxicity of DMF has hampered its recommendation for routine work [5]. DMF is also viscous and has a "faint amine odour" [10].

${ }^{5}$ Ethanol absolute is: (i) $3 \times$ more expensive than ethanol $96 \%$, but still $\sim 10 \%$ cheaper than methanol and (ii) highly hygroscopic [10].

${ }^{6}$ Final analytical procedure: $(125.0 \pm 0.9) \mathrm{mg}$ of sample are weighed in centrifuge tube $(10 \mathrm{~mL}$, Oak Ridge, PPCO, Thermo Scientific, Rochester/USA); $5 \mathrm{~mL}$ of absolute ethanol added via a $10 \mathrm{~mL}$ graduated cylinder; 3 min vortexing (MS2 Minishaker, IKA Works-Wilmington/USA; 2,500 $\mathrm{min}^{-1}$ ) of each sample individually; syringe-filtration $(5 \mathrm{~mL}$ PP syringe; syringe-filter, PTFE, $13 \mathrm{~mm}, 0.45$ $\mu \mathrm{m}$, Grace Davison Discovery Science) of extracts into either a $2 \mathrm{~mm}$-pathlength disposable plastic cuvette (Eppendorf) or a $10 \mathrm{~mm}$-pathlength disposable plastic cuvette (Greiner Bio-One); use of disposable plastic cuvette caps; absorbance of subsequent extracts was measured at 3 min intervals (Cary 100 Scan UV-Visible spectrophotometer-Varian/Australia; double beam mode; $\lambda \mathrm{s}: 665 \mathrm{~nm}$ and $750 \mathrm{~nm}$; spectral bandwidth: $1.5 \mathrm{~nm}$; signal averaging time: $1 \mathrm{~s}$; light beam: $10 \mathrm{~mm}$ high, starting at $15 \mathrm{~mm}$ from bottom of cuvette holder). Note: (i) Centrifuge tube: held in place during extraction with supports and clamps. (ii) First drops of syringe-filtered solutions: discarded to prevent possible changes in concentration. (iii) The $2 \mathrm{~mm}$-pathlength plastic cuvette needs to be lifted up with the lever of the cuvette holder of the spectrophotometer and to be filled over the $500 \mu \mathrm{L}$-mark, as its optical surface is only $3 \mathrm{~mm}$ high and starts $7 \mathrm{~mm}$ from the base. (iv) Procedures were conducted under reduced light. (v) Possibility of further simplification by using an automatic pipette for the addition of the solvent - most likely with a concomitant gain in precision — and a vortex mixer equipped with a tube holder.
} 
Table 3.1. Absorbance of extracts of weld samples due to chlorophylls and their structurally similar breakdown products obtained with different solvents and methods of extraction, using three types of cuvettes. ${ }^{\mathrm{a}, \mathrm{b}}$

\begin{tabular}{|c|c|c|c|c|c|}
\hline Entry & $\begin{array}{l}\text { Plant } \\
\text { material }\end{array}$ & $\mathrm{n}$ & $\begin{array}{l}\text { Extraction procedure; }{ }^{c} \text { sample treatment and } \\
\text { series of measurements }\end{array}$ & Solvent ${ }^{\mathrm{d}}$ & $\begin{array}{l}\text { Absorbance (AU) } \\
\text { and } s_{\mathrm{r}}(\%) \mathrm{e}^{\mathrm{e}}\end{array}$ \\
\hline \multicolumn{6}{|c|}{10 mm-pathlength quartz cuvette } \\
\hline 1 & B & 4 & 3 min vortexing; 5 min centrifugation & Acetone & $0.146(2.6)$ \\
\hline 2 & B & 4 & 3 min vortexing; 5 min centrifugation; $2 \mathrm{~h}\left(4{ }^{\circ} \mathrm{C}\right)$ & Acetone & $0.161(2.3)$ \\
\hline 3 & B & 4 & 10 min sonication & Acetone & $0.162(1.2)$ \\
\hline 4 & B & 4 & $10 \mathrm{~min}$ sonication; $2 \mathrm{~h}\left(4^{\circ} \mathrm{C}\right)$ & Acetone & $0.177(3.0)$ \\
\hline 5 & B & 4 & $16 \mathrm{~h}$ shaking & Acetone & $0.241(0.7)$ \\
\hline 6 & B & 4 & $16 \mathrm{~h}$ shaking; $2 \mathrm{~h}\left(4^{\circ} \mathrm{C}\right)$ & Acetone & $0.227(1.5)$ \\
\hline 7 & B & 3 & 3 min vortexing & Acetone & $0.125(4.9)$ \\
\hline 8 & B & 3 & 3 min vortexing & $\begin{array}{l}\mathrm{MeOH}-\mathrm{H}_{2} \mathrm{O} \\
(9: 1)\end{array}$ & $0.150(6.0)$ \\
\hline 9 & B & 2 & 3 min vortexing & Abs EtOH & $0.163(0.5)$ \\
\hline 10 & B & 3 & 3 min vortexing & EtOH 96\% & $0.168(0.7)$ \\
\hline 11 & B & 3 & 3 min vortexing & $\mathrm{MeOH}$ & $0.183(4.8)$ \\
\hline 12 & B & 3 & 3 min vortexing & DMF & $0.215(0.6)$ \\
\hline \multicolumn{6}{|c|}{$2 \mathrm{~mm}$-pathlength plastic cuvette } \\
\hline 13 & $\mathbf{A}$ & 1 & 3 min vortexing; day 1 & Abs EtOH & 0.022 \\
\hline 14 & $\mathbf{A}$ & 3 & 3 min vortexing; day 7 (morning) & Abs EtOH & $0.023(3.5)$ \\
\hline 15 & $\mathbf{A}$ & 4 & 3 min vortexing; day 7 (afternoon) & $\mathrm{Abs} \mathrm{EtOH}$ & $0.021(2.5)$ \\
\hline 16 & $\mathbf{E}$ & 1 & 3 min vortexing; day 1 & Abs EtOH & 0.128 \\
\hline 17 & $\mathbf{E}$ & 4 & 3 min vortexing; day 7 (morning) & $\mathrm{Abs} \mathrm{EtOH}$ & $0.129(3.3)$ \\
\hline 18 & $\mathbf{E}$ & 4 & 3 min vortexing; day 7 (afternoon) & Abs EtOH & $0.120(1.4)$ \\
\hline 19 & $\mathbf{F}$ & 1 & 3 min vortexing; day 1 & $\mathrm{Abs} \mathrm{EtOH}$ & 0.424 \\
\hline 20 & $\mathbf{F}$ & 4 & 3 min vortexing; day 7 (morning) & Abs EtOH & $0.420(5.0)$ \\
\hline 21 & $\mathbf{F}$ & 3 & 3 min vortexing; day 7 (afternoon) & $\mathrm{Abs} \mathrm{EtOH}$ & $0.427(2.8)$ \\
\hline 22 & G & 1 & 3 min vortexing; day 1 & Abs EtOH & 0.982 \\
\hline 23 & G & 4 & 3 min vortexing; day 7 (morning) & Abs EtOH & $0.936(4.5)$ \\
\hline 24 & G & 4 & 3 min vortexing; day 7 (afternoon) & Abs EtOH & $0.931(2.4)$ \\
\hline 25 & $\mathbf{H}$ & 1 & 3 min vortexing; day 1 & Abs EtOH & 1.048 \\
\hline 26 & $\mathbf{H}$ & 4 & 3 min vortexing; day 7 (morning) & Abs EtOH & $0.976(7.4)$ \\
\hline 27 & $\mathbf{H}$ & 4 & 3 min vortexing; day 7 (afternoon) & $\mathrm{Abs} \mathrm{EtOH}$ & $0.957(5.8)$ \\
\hline \multicolumn{6}{|c|}{$1 \mathrm{~mm}$-pathlength quartz cuvette } \\
\hline 28 & $\mathbf{A}$ & 3 & 3 min vortexing; day $2(n=1)$ and day $9(n=2)$ & $\mathrm{DMF}$ & $0.015(2.6)$ \\
\hline 29 & $\mathbf{E}$ & 3 & 3 min vortexing; day $2(n=1)$ and day $9(n=2)$ & DMF & $0.108(2.1)$ \\
\hline 30 & $\mathbf{F}$ & 4 & $\begin{array}{l}3 \text { min vortexing; day } 2(n=1) \text {, day } 9(n=2) \text {, and } \\
\text { day } 9(n=1)\end{array}$ & DMF & $0.363(7.3)$ \\
\hline 31 & $\mathbf{G}$ & 3 & 3 min vortexing; day $2(n=1)$ and day $9(n=2)$ & DMF & $0.695(1.1)$ \\
\hline 32 & $\mathbf{H}$ & 3 & 3 min vortexing; day $2(n=1)$ and day $9(n=2)$ & DMF & $0.765(0.2)$ \\
\hline
\end{tabular}

${ }^{a} \lambda$ of detection: Entries 1 through 12 and 28 through 32, absorbance at $664 \mathrm{~nm}$ minus absorbance at $750 \mathrm{~nm}(664$

$-750 \mathrm{~nm}$ ); entries 13 through 27, $665-750 \mathrm{~nm}$. Note: 1) Subtraction of absorbance at $750 \mathrm{~nm}$ needed due to 
large cuvette-to-cuvette variation of $2 \mathrm{~mm}$-pathlength plastic cuvettes (range of readings at $750 \mathrm{~nm}$ : $-53-89$ mAU); 2) Red-absorption maxima: Abs EtOH, $665 \mathrm{~nm}$; other solvents, $664 \mathrm{~nm}$.

${ }^{\mathrm{b}} \mathbf{A}, \mathbf{B}, \mathbf{E}, \mathbf{F}, \mathbf{G}$, and $\mathbf{H}$ are the codes of (dried and ground-sieved) weld samples in increasing concentration of chls and breakdown products. Note: 1) Differences among samples include cultivar and plant parts used; ${ }^{7} 2$ ) Results of analyses of samples $\mathbf{C}$ and $\mathbf{D}$ are displayed in appendix B.

${ }^{\mathrm{c}}$ Always at room temperature and under reduced light.

${ }^{\mathrm{d}} \mathrm{MeOH}=$ methanol, $\mathrm{Abs}$ EtOH $=$ absolute ethanol, and DMF $=N, N$-dimethylformamide.

e Average absorbance ( $s_{\mathrm{r}}=$ relative standard deviation).

The repeatability \{"precision under the same operating conditions over a short interval of time" [12]\} of the method was assessed based on the relative standard deviation $\left(s_{\mathrm{r}}\right)$ of analyses of weld samples $\mathbf{A}, \mathbf{E}, \mathbf{F}, \mathbf{G}$, and $\mathbf{H}$. Literature data from a study on the extraction of pigments from phytoplankton showed sonication in DMF to be a suitable reference method, as that method displayed excellent $s_{\mathrm{r}}$ values $(0.4-6.0 \%$, depending on the pigment) and fulfils nearly all criteria for a suitable extraction technique, including precision [5]. The $s_{\mathrm{r}}$ values of the assay presented here are typically $2-5 \%$, and in all cases $<7.5 \%$ (entries 13 through 27 ). Thus, the method displays good repeatability, more than meeting the demands for the intended purpose.

The results of the two series of measurements of each weld sample were compared (entries 14 vs. 15,17 vs. 18,20 vs. 21,23 vs. 24 , and 26 vs. 27). In the cases of samples $\mathbf{F}, \mathbf{G}$, and $\mathbf{H}$, the difference was $\leq 2 \%$. This is smaller than that observed for samples $\mathbf{A}(13 \%)$ and $\mathbf{E}(7 \%)$. However, the absolute differences in absorbance of these samples are very low (A: $2 \mathrm{mAU}$ and E: $9 \mathrm{mAU}$ ). The $s_{\mathrm{r}}$ values are higher than those of samples $\mathbf{F}, \mathbf{G}$, and $\mathbf{H}$ due to the low absolute absorbance of the extracts of samples $\mathbf{A}$ and $\mathbf{E}$. If increased precision is required for samples with absorbance $\leq 190 \mathrm{mAU}, 10 \mathrm{~mm}$-pathlength plastic cuvettes should be used (appendix B).

Based on the analysis of 81 weld samples, with the highest absorbance being $1.165 \mathrm{AU}$ (results not shown), sample $\mathbf{H}$ is expected to be near the upper practically occurring limit of concentration of chls and breakdown products in weld samples. Because the absorbance of the

\footnotetext{
${ }^{7}$ Dried weld samples:

A: Part of the plants: stems; cultivar: G; place of growth: Zeeland, SW of the Netherlands; harvested in: 2008; pore size of sieve used during grinding-sieving: $0.25 \mathrm{~mm}$;

B: aerial parts; H; Groningen, $\mathrm{N}$ of the Netherlands; 2007; plants were placed outdoors during daytimes and indoors during night times for $\sim 10$ days; $0.25 \mathrm{~mm}$;

C: stems; G; Zeeland; 2009; 0.25, 0.50, or $0.75 \mathrm{~mm}$. Note: grown in another field as $\mathbf{A}$;

D: reproductive parts, leaves, and upper parts of the stems; rest, as $\mathbf{B}$;

E: leaves and reproductive parts; G; Zeeland; 2008; $0.25 \mathrm{~mm}$;

F: leaves and reproductive parts; G; Noord Brabant, S of the Netherlands; 2010; $0.25 \mathrm{~mm}$;

G: leaves and reproductive parts; G; Zeeland; 2010; $0.2 \mathrm{~mm}$;

$\mathbf{H}$ : leaves; G; Noord Brabant; 2010; $0.2 \mathrm{~mm}$. Note: harvested 3 weeks earlier than $\mathbf{F}$.

Note: Samples $\mathbf{A}, \mathbf{C}$, and $\mathbf{E}$ though $\mathbf{H}$ were supplied by the industrial partner of the project. The general drying procedure used by them was: (root-removed) plants were placed indoors (roughly $30^{\circ} \mathrm{C}$; dark) for 2-2.5 weeks, on average.
} 
extracts of sample $\mathbf{H}$ is $\leq 1.0 \mathrm{AU}$ (entries 25 through 27), ${ }^{8}$ the method covers the entire range of concentrations of chls in weld samples.

Chls are situated inside the thylakoids of the chloroplasts of plant tissues, bound to apoproteins through different types of bonding, including Lewis acid-Lewis base interactions $[2,5]$. DMF is a better solvent than absolute ethanol for the extraction of chls and their breakdown products (entries 9 and 12). Furthermore, there is only $\sim 10 \%$ difference between the absorbance of the extracts of weld in acetone obtained by shaking overnight (entry 5), assumed to fully extract the chls and their breakdown products, ${ }^{9}$ and that of the extracts in DMF obtained by vortexing for 3 min (entry 12). Thus, to ascertain whether extraction with absolute ethanol was selective regarding the "types" of chls and plant parts being extracted, the extraction of different samples of weld using absolute ethanol was compared with that using DMF (Figure 3.1).

\footnotetext{
${ }^{8}$ If sample $\mathbf{H}$ would be ground-sieved using a $0.25 \mathrm{~mm}$ sieve, the absorbance of its extracts would be lower than that seen in Table 3.1 (see also entries 10-12 of Table SI B.1, appendix B).

${ }^{9}$ Extraction does not seem to continue upon steeping $\left(2 \mathrm{~h} / 4{ }^{\circ} \mathrm{C}\right)$ (entries 5 and 6$)$. This is not the case for the other extraction procedures (entries 1 through 4 ). An extraction efficiency experiment would be needed to check this assumption.
} 


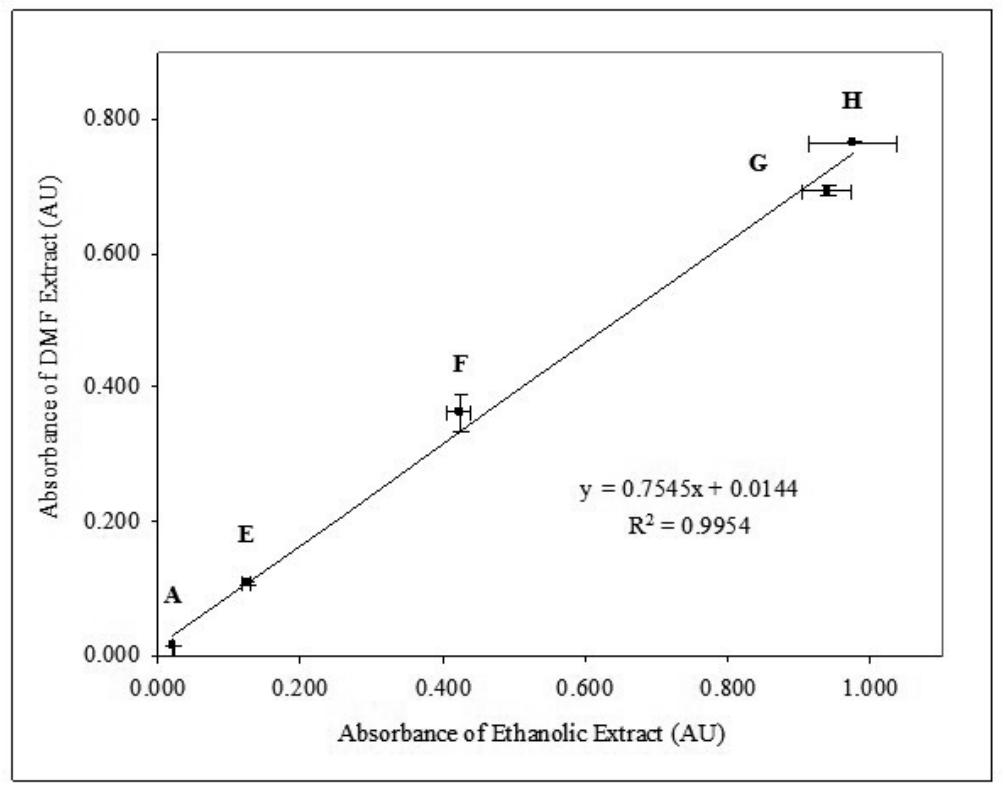

Figure 3.1. Correlation between absorbance of ethanolic and DMF extracts of weld. Average absorbances are plotted; error bars $=1 \times$ standard deviation. Ethanolic extracts: 2 mm-pathlength plastic cuvette; $\mathrm{n}=8(\mathbf{A}$ and $\mathbf{F})$ and $\mathrm{n}=9$ (E, G, and $\mathbf{H})$. DMF extracts: 1 mm-pathlength quartz cuvette; $\mathrm{n}=3(\mathbf{A}, \mathbf{E}, \mathbf{G}$, and $\mathbf{H})$ and $\mathrm{n}=4(\mathbf{F})$.

The linear relation between the extracted amounts of chls and breakdown products by absolute ethanol and by DMF indicates that the extraction with absolute ethanol is not selective and, thus, that absolute ethanol can be suitably used as solvent for the comparative method described here. Additionally, it suggests that the ethanolic solution is not saturated throughout the possible range of concentration of chls and breakdown products in weld samples.

The method at hand rapidly compares the total absorbance of porphyrin ring-containing pigments (chls and their structurally similar breakdown products) in different weld samples. It is expected to minimally modify the composition of chls and breakdown products of samples and displays acceptable precision. Analysis of forty samples - including data processingcould be carried out in one working day, requiring a total amount of $200 \mathrm{~mL}$ of ethanol $(5 \mathrm{~mL}$ per sample). Moreover, the method covers the entire range of occurring concentrations, uses ethanol as a mild, non-toxic extraction solvent - that is not selective regarding the "types" of chls and plant tissues being extracted - and is simple. Finally, although developed for the comparison of the chlorophyll content in weld, it is expected that-after additional validation - it could be applied on other plant materials too. 


\subsection{Supplementary material}

Appendix B contains information supplementary to that in this chapter.

\subsection{References}

[1] Ferreira ESB, Hulme AN, McNab H, Quye A. The natural constituents of historical textile dyes. Chem Soc Rev 2004; 33(6): 329-36.

[2] Harborne JB. Phytochemical methods - a guide to modern techniques of plant analysis. 2nd ed. Chapman and Hall: London/New York; 1984.

[3] Lichtenthaler HK. Chlorolphylls and carotenoids: pigments of photosynthetic biomembranes. In: Packer L, Douce R, editors. Plant cell membranes, Academic Press: San Diego/New York/etc.; 1987, p. 350-82.

[4] Holden M. Chlorophylls. In: Goodwin TW, editor. Chemistry and biochemistry of plant pigments. 2nd ed, Academic Press: London; 1976, p. 1-37.

[5] Jeffrey SW, Mantoura RFC, Wright SW, editors. Phytoplankton pigments in oceanography: guidelines to modern methods. 1st ed. UNESCO Publishing: Paris; 1997.

[6] Schoefs B. Chlorophyll and carotenoid analysis in food products. Properties of the pigments and methods of analysis. Trends Food Sci Technol 2002; 13: 361-71.

[7] In vitro determination of chlorophyll $a$ and pheophytin $a$ in marine and freshwater algae by fluorescence. National Exposure Research Laboratory — USEPA: Cincinnati; 1997.

[8] White RC, Jones ID, Gibbs E. Determination of chlorophylls, chlorophyllides, pheophytins, and pheophorbides in plant material. J Food Sci 1963; 28(4): 431-6.

[9] Vernon LP. Spectrophotometric determination of chlorophylls and pheophytins in plant extracts. Anal Chem 1960; 32(9): 1144-50.

[10] O’Neil MJ, Smith A, Heckelman PE, Obenchain Jr. JR, Gallipeau JAR, D’Arecca MA, Budavari S, editors. The merck index - an encyclopedia of chemicals, drugs and biologicals. 13th ed. Merck and Co.: Whitehouse Station; 2001.

[11] Woolley PS, Moir AJ, Hester RE, Keely BJ. A comparative study of the allomerization reaction of chlorophyll $a$ and bacteriochlorophyll $a$. J Chem Soc, Perkin Trans 2 1998; (8): 1833-9.

[12] Validation of analytical procedures: text and methodology Q2(R1), comprising Q2A (1994) and Q2B (1996). International Conference on Harmonisation of Technical Requirements for Registration of Pharmaceuticals for Human Use; 2005. 


\section{Chapter 4}

\section{Photo-stability of the dye of weld in presence of aluminium ions}

The content of this chapter is largely that of the following paper:

Villela A, van Vuuren MSA, Willemen HM, Derksen GCH, van Beek TA. Photo-stability of a flavonoid dye in presence of aluminium ions. Dyes Pigments 2019; 162: 222-31 
The main colouring compounds of the dye plant weld (Reseda luteola L.) are the flavones luteolin (lut), lut-7-O-glucoside and lut-7,3'-O-diglucoside. Alum (an aluminium salt)premordanted wool dyed with weld leads to yellow colours that are of low resistance to light. The photo-stability of lut in aerated methanol-water $8: 2(\mathrm{v} / \mathrm{v})$ solution upon irradiation with light above $300 \mathrm{~nm}$ was studied at different lut- $\mathrm{Al}^{3+}$ ratios. Experiments using extracts of weld to dye wool premordanted with increasing quantities of aluminium salts were also carried out. The photo-stability of lut in the polar protic solvent and the photo-resistance (light-fastness) of the colour of weld-dyed wool decrease with increasing concentrations of aluminium ions. Thus, the lower the $\left[\mathrm{Al}^{3+}\right]$ used for mordanting the wool, the more light-fast its colour. Lowering the $\left[\mathrm{Al}^{3+}\right]$ appears to have no negative influence on the wash-fastness of the colour. As the gain in light-fastness by the use of low $\left[\mathrm{Al}^{3+}\right]$ to premordant the wool is not extensive, however, this does not seem to be a way to meet today's requirement of light-fastness of the colours of dyed textiles by itself. Nevertheless, it may be part of a broader strategy to address the need for increased lightfastness of the colour of wool dyed with weld. Implementation of this approach by dyers is expected to clarify whether it results in benefits for textile dyeing practice. 


\subsection{Introduction}

Varying the metal ion mordant changes the colour of the dyed textile and has a major influence on its light-fastness [1, 2]. Increasing concentrations of aluminium ion lead to intensified colours of solutions of lut and the flavonols - 3-hydroxyflavones - kaempferol and quercetin, as seen by the change of their UV-vis absorption spectra [3-5]. However, members of the flavones and flavonols classes of flavonoids have been reported to display diminished photostability in the presence of $\mathrm{Al}^{3+}[6,7]$. Thus, the influence of increasing concentrations of aluminium ion on the photo-stability of the dye of weld was studied to address the issue of whether a compromise between the obtainable colours and their photo-resistance would be a way to meet today's requirement of light-fastness of the colours of textiles. The photo-stability of lut in presence of $\mathrm{Al}^{3+}$ at different lut- $\mathrm{Al}^{3+}$ ratios was studied in solution. Experiments using extracts of weld to dye wool premordanted with increasing quantities of aluminium salts were also carried out.

Glycosylation may confer stability to flavonoid aglycones [8], [9] (chapter 42). For example, the antioxidant activity of flavonoids is diminished by glycosylation [8], [10] (chapter 5). Weld contains an enzyme that breaks the glycosidic bonds of its flavone glucosides ${ }^{1}$ [11]. Lut, Img and Idg are obtained if this glycosidase is inactivated before extracting the flavonoids. In contrast, only lut is obtained if the enzyme is not inactivated. Thus, there is an issue of whether the glycosidase should be inactivated before extracting the flavonoids of weld in order to obtain the most photo-stable dye. Experiments were carried out in the context of such an issue. The relative photo-stability of lut, Img and Idg in solution was studied, and results of the colours of alum-mordanted wool dyed with them are presented.

\footnotetext{
${ }^{1}$ Although there might be enzymes - and not only one enzyme - breaking the glycosidic bonds, the singular form of the word is used in this thesis.
} 


\subsection{Material and methods}

The material and methods of the work is summarised in this section. Readers interested in further procedures and details are referred to section SI C.1 (appendix C).

\subsubsection{Effect of different concentrations of $\mathrm{Al}^{3+}$ and glycosylation pattern of lut (aglycone, monoglucoside, and diglucoside) on its photo-stability in solution}

The following chemical compounds were used for the preparation of stock and working solutions of the flavones, $\mathrm{Al}^{3+}$, and $\mathrm{HNO}_{3}$ used for construction of the calibration lines and preparation of the solutions used for the irradiation experiments described: Lut ( $96 \%$ by NMR; Indofine Chemical Company, Hillsborough/USA); Img (93\% by NMR; Extrasynthese, Genay/France); Idg ( $86 \%$ by NMR; Extrasynthese, Genay/France); aluminium nitrate nonahydrate (99.997\%; Aldrich Chemistry, St. Louis/USA); nitric acid (65\%, extra pure; Merck, Darmstadt/Germany).

Solutions of lut, Img, and ldg — with and without $\mathrm{Al}^{3+}$ — were prepared in aerated methanolwater 8:2 (v/v). Nitric acid was added to all volumetric flasks, except to those containing lut and $\mathrm{Al}^{3+}$ in a ratio $1: 10$, because the lowering of the $\mathrm{pH}$ was due to the Lewis acid $\mathrm{Al}^{3+}$ in this case (rather than to $\mathrm{HNO}_{3}$ or a combination of both). The apparent $\mathrm{pH}$ of all irradiated solutions was 3.6; the term apparent $\mathrm{pH}$ is used as the solvent of the solutions was not water, but the methanol-water mixture. Stirred solutions were irradiated at $32{ }^{\circ} \mathrm{C}$ in glass cuvettes using a phosphor-coated low pressure mercury vapour lamp, which led to irradiation only with light above $300 \mathrm{~nm}$, most importantly in the $300-420 \mathrm{~nm}$ range. The photodecomposition of lut, lmg, and ldg - decrease of [flavone] over time - was monitored by RP-HPLC-UV.

Solutions used for the irradiation experiments were prepared on the day the experiments started, and transferred to the glass cuvettes $(3.5 \mathrm{~mL} ; 10 \mathrm{~mm}$ light path) in which they were irradiated. This was done without using Pasteur pipettes to prevent possible contamination. Slots for four cuvettes were made on the cover plate of a magnetic stirrer. The distance from the front window of the cuvettes to the centre of the lamp was $2.02 \mathrm{~cm}$. Pictures of the set-up are seen in Figure SI C.1. Calibration solutions and solutions used for irradiation experiments were kept in the dark at room temperature not less than $60 \mathrm{~min}$ before use. This was motivated by the fact that flavonoid- $\mathrm{Al}^{3+}$ complexation does not reach equilibrium immediately.

Observations reported were made during five irradiation experiments. They are referred to as $1 \mathrm{a}$ and $1 \mathrm{~b}$ (1st irradiation replicate), $2 \mathrm{a}$ and $2 \mathrm{~b}$ ( $2 \mathrm{nd}$ irradiation replicate), and special irradiation experiment. During the first four irradiation experiments, the eight solutions - $\mathbf{l u t}_{0.10}$, lut $_{0.10}-\mathrm{Al}_{0.02}$, lut $\mathbf{l u}_{0.10}-\mathrm{Al}_{0.10}$, lut $\mathbf{l}_{0.10}-\mathrm{Al}_{1.00}$, lut $\mathbf{l}_{0.05}, \mathbf{l m g}_{0.05}$, $\mathbf{l d g}_{0.05}$, and $\mathbf{l d g}_{0.05}-\mathrm{Al}_{0.05}$ - were irradiated in duplicate. Solutions lut $\mathbf{t}_{0.20}$ and lut $_{0.10}-\mathrm{Al}_{0.99}$ were irradiated during the special irradiation experiment, with a filter blocking radiation of wavelengths shorter than $\sim 420 \mathrm{~nm}$ (420 nm cut-off filter) being placed in front of the cuvette containing lut $\mathbf{t}_{0.10}-\mathrm{Al}_{0.99}$. Notes:

- All solutions-flavones, $\mathrm{Al}^{3+}$, and $\mathrm{HNO}_{3}$ - were prepared anew for use in irradiation experiments $2 \mathrm{a}$ and $2 \mathrm{~b}$, and special irradiation experiment.

- Code of solutions used: flavone $[$ flavone $]-\mathrm{Al}_{[\mathrm{Al}]}$, in which [flavone $]=[\text { flavone }]_{0}, \mathrm{Al}=\mathrm{Al}^{3+}$, and concentrations are expressed in $\mathrm{mM}$.

During the irradiation experiments, $0.05 \mathrm{~mL}$ aliquots of the solutions were collected at $\mathrm{t}=$ $1.0 \mathrm{~h}, 2.0 \mathrm{~h}, 3.0 \mathrm{~h}, 4.0 \mathrm{~h}, 8.0 \mathrm{~h}$, and $24.0 \mathrm{~h}$, as irradiations started on one day (day 1) and finished on the following one (day 2). During the special irradiation experiment, aliquots of the solutions were collected at $\mathrm{t}=2.0 \mathrm{~h}, 4.0 \mathrm{~h}, 8.0 \mathrm{~h}$, and $24.0 \mathrm{~h}$. The photodecomposition of the flavones 
over time was quantified by RP-HPLC-UV using peak areas of the $350 \mathrm{~nm}$ traces (lut and lmg) and of the $340 \mathrm{~nm}$ traces (ldg), and calibration lines. Except for solution lut $\mathbf{t}_{0.20}$, the [flavone] of all samples - $\mathrm{t}_{0}(\mathrm{t}=0 \mathrm{~h})$ through $\mathrm{t}_{24}(\mathrm{t}=24 \mathrm{~h})$ - of each irradiated solution was comprised within the range of concentrations used for construction of the calibration lines. A straight line mathematical model was fit through the experimental data $\{[$ flavone] $(\mathrm{mM}) v s$. time $(\mathrm{min})\}$. This regression analysis was carried out for each of the solutions irradiated during experiments $1 \mathrm{a}-2 \mathrm{~b}$ and special irradiation experiment via the least-squares method.

The photodecomposition of the flavones was described as being of zero-order, in which the rate of reaction equals the rate constant $(\mathrm{d}[$ flavone $] / \mathrm{d} t=k)$. As the integrated form of the zeroorder rate law is [flavone] $=k t+[\text { flavone }]_{0}$, the $k$ values were obtained from the slope of the equations $(k=-$ slope). The relative rates of photodecomposition were calculated through the formula $k_{\mathrm{j}} / k_{\mathrm{i}}$, in which $\mathrm{i}$ was lut in lut $_{0.11}$, lut $_{0.10}$, or lut $\mathrm{t}_{0.05}$, and $\mathrm{j}$ was lut, lmg, or ldg in other solutions. Notes:

- Solution lut - $_{0.20}$ was used for comparison of the rates of photodecomposition of lut in lut $_{0.20}$, lut l. $_{0.1}$ and lut l. $_{05}$. For this purpose, a procedure similar to that outlined above was carried out. Peak areas $v s$. time were used instead of concentrations $v s$. time, however, and the slopes of the equations of the best-fit lines $(y=a x+b)$ were compared;

- All irradiated solutions contained $\mathrm{NO}_{3}{ }^{-}$, originating from $\mathrm{HNO}_{3}, \mathrm{Al}\left(\mathrm{NO}_{3}\right)_{3}$, or from both of them. As the oxidation state of the $\mathrm{N}$-atom of the ion is $+5, \mathrm{NO}_{3}{ }^{-}$may be reduced in different systems/under different conditions [12]. One such condition could be the irradiation with light in the $300-420 \mathrm{~nm}$ range used in the irradiation experiments reported here, even with the $\left[\mathrm{NO}_{3}{ }^{-}\right]$being $\leq 3 \mathrm{mM}$. It does not mean that the ion has necessarily contributed to the photodecomposition of the flavones in the experiments of this study, however. Reasons for this are:

- If reduction of $\mathrm{NO}_{3}{ }^{-}$took place during the irradiation experiments, methanol may have acted as reducing agent instead of the flavones [12]; methanol was present in solution in quantities far larger than those of the flavones, as it was part of the solvent mixture;

- The relative rates of decomposition of the flavones (Table 4.2) do not match the relative $\left[\mathrm{NO}_{3}{ }^{-}\right]$of the solutions: $1.4 \mathrm{vs} .1 .2\left(\mathbf{l u t}_{0.10}-\mathrm{Al}_{0.02}\right), 3.2 \mathrm{vs.} 1.9\left(\mathbf{l u t}_{0.10}-\mathrm{Al}_{0.10}\right)$,

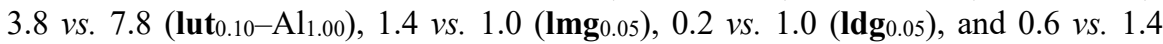
$\left(\mathbf{l d g}_{0.05}-\mathrm{Al}_{0.05}\right)$;

$\circ$ The photo-stability of lut and $\mathbf{l d g}$ in solution (in presence of $\mathrm{NO}_{3}{ }^{-}$) decreases with increasing $\left[\mathrm{Al}^{3+}\right]$ (Table 4.2). This matches the results of the experiments in which wool was dyed with extracts of weld (experimental details in sections SI C.1.13 and SI C.1.15): The light-fastness of the colours of dyed wool decreases with increasing quantities of $\mathrm{Al}^{3+}$ used to premordant the wool (Tables 4.4 and 4.5);

O In preliminary experiments, the photodecomposition of lut in nitric acid-acidified aerated methanol-water $8: 2(\mathrm{v} / \mathrm{v})$ solution was observed to be 35 to $55 \%$ slower than in non-acidified solution (section SI C.2.2).

Additionally, Img and ldg appear to be stable upon overnight heating in presence of $\mathrm{NO}_{3}{ }^{-}$ at a concentration of $0.35 \mathrm{mM}$ (sections SI C.1.12 and SI C.2.10).

Spectrophotometric analyses were carried out using quartz cuvettes. On day 1, the remainders of the solutions used for irradiation were diluted $5 \times$ with aerated methanol-water 8:2 (v/v). On 
day $2, \mathrm{t}_{24}$ solutions were diluted and analysed in the same way. In the case of lut $\mathbf{t}_{0.20}, \mathrm{t}_{0}$ and $\mathrm{t}_{24}$ solutions were diluted $10 \times$.

Calibration solutions and samples used for irradiation experiments 1a-special irradiation experiment were analysed by RP-HPLC-UV undiluted. Analyses were carried out on a Waters system, equipped with C18 $5 \mu \mathrm{m}$-particle size column. Further details of the HPLC system and column used are described in publication by Villela et al. [13] (p. 8545, method using the HPLC column). See the referred publication also for information on: Eluent, its flow rate and composition (solvents and gradient); volume of injection; and temperature of the column oven. The photodiode array detector scan range was $245-500 \mathrm{~nm}$.

\subsubsection{Effect of increasing quantities of $\mathrm{Al}^{3+}$ bound to mordanted wool on the photo- stability of the dye of weld}

The following material/chemical compounds were used as wool, mordants, and source of dye: Ready-to-dye wool [Kova Wool Sateen White (part number W110); Whaleys (Bradford), Bradford/United Kingdom]; alum (puriss. p.a. grade; Sigma-Aldrich, Steinheim/Germany); aluminium sulphate tetradecahydrate (ViVoChem, Almelo/The Netherlands); tartaric acid (Brenntag, Dordrecht/The Netherlands); sample of the aerial parts of dried and ground weld \{described by Villela et al. [13]\}; commercial extract of weld (Rubia Yellow; Rubia Pigmenta Naturalia, later Rubia Natural Colours, Steenbergen/The Netherlands).

\subsubsection{Experiment using alum}

Ready-to-dye wool was mordanted with a $10 \mathrm{~g} \mathrm{~L}^{-1}$ aqueous (deionised water) solution of alum [ $\mathrm{KAl}\left(\mathrm{SO}_{4}\right)_{2} \cdot 12 \mathrm{H}_{2} \mathrm{O}$ ] through heating to $90+{ }^{\circ} \mathrm{C}$ during $0.5-1 \mathrm{~h}$, followed by a $1 \mathrm{~h}$-period at $\sim 95$ ${ }^{\circ} \mathrm{C}$ [14]. Essentially the same procedure was also carried out with deionised water only (no alum; blank-mordanting), and with $2 \mathrm{~g} \mathrm{~L}^{-1}$ aqueous solution of alum. In each case, four of the obtained $\sim 5 \times 5 \mathrm{~cm}$-pieces of mordanted wool were dyed with a $96 \%$ ethanol-deionised water $3: 1(\mathrm{v} / \mathrm{v})$ extract of the aerial parts of weld in deionised water at $80{ }^{\circ} \mathrm{C}$ for $15 \mathrm{~min}$ [14]. $L^{*}, a^{*}$ and $b^{*}$ quantities (CIELAB colour space) were measured for each piece of dyed wool, and their chroma $\left[C^{*} \mathrm{ab}=\left(a^{* 2}+b^{* 2}\right)^{1 / 2}\right]$ and hue angle $\left[h_{\mathrm{ab}}=\arctan \left(b^{*} / a^{*}\right)\right]$ were calculated [15]. The data were processed as follows: Standard deviation values were expressed with one significant digit, and average values were rounded up accordingly.

The light-fastness of the colours was determined according to the ISO 105-B02 norm. Two pieces of dyed wool were irradiated in a weathering tester in each of the three cases (dyed blankmordanted wool, and dyed wool that had been mordanted with $2 \mathrm{~g} \mathrm{~L}^{-1}$ and $10 \mathrm{~g} \mathrm{~L}^{-1}$ aqueous solutions of alum). The scale 1 (poor)-8 (excellent) — with 3 being the acceptable lower limitwas used for reporting the results [16]. Colour difference $\left\{\Delta E^{*}{ }_{\mathrm{ab}}=\left[\left(\Delta L^{*}\right)^{2}+\left(\Delta a^{*}\right)^{2}+\left(\Delta b^{*}\right)^{2}\right]^{1 / 2}\right\}$ values were calculated from the average values of the $L^{*}, a^{*}$, and $b^{*}$ quantities (CIELAB colour space) measured before and after irradiation [15]. The wash-fastness of the colours of the pieces of dyed wool was determined according to the ISO 105-C06 norm at $40{ }^{\circ} \mathrm{C}$ for $30 \mathrm{~min}$. Two pieces of wool were used-with only one of them being washed (thus, $n=1$; one pair of samples) - in each of the three cases. Afterwards, both pieces were visually compared and $L^{*}$, $a^{*}$, and $b^{*}$ quantities (CIELAB colour space) were measured. The scale 1 (poor)-5 (excellent) — with 3-4 being the acceptable lower limit—was used for reporting the results [16]. 


\subsubsection{Experiment using aluminium sulphate and tartaric acid}

Ready-to-dye wool was pretreated with an aqueous solution of a textile auxiliary agent aiming at protecting the fibre from fibre-to-fibre and fibre-to-metal action. The wool was then mordanted with an aqueous (tap water) solution of aluminium sulphate and tartaric acid at 95 ${ }^{\circ} \mathrm{C}$ during $1.75 \mathrm{~h}$. This procedure was carried out with $0.2,2,10$ and $25 \mathrm{~g} \mathrm{~L}^{-1}$ solutions of aluminium sulphate tetradecahydrate, with the concentration of tartaric acid being $1.3 \mathrm{~g} \mathrm{~L}^{-1}$ in all cases. Each piece of mordanted wool was dyed with an aqueous (tap water) solution of a commercial extract of weld $[2.5 \%(\mathrm{w} / \mathrm{w})$ extract-wool $]$ at $100{ }^{\circ} \mathrm{C}$ during $1.75 \mathrm{~h}$. The dyed wool was rinsed at $95^{\circ} \mathrm{C}$ using detergent and, then, rinsed further with tap water at the same temperature. $L^{*}, a^{*}$, and $b^{*}$ quantities (CIELAB colour space) were measured for each piece of dyed wool, and their chroma $\left(C^{*}{ }_{\mathrm{ab}}\right)$ and hue angle $\left(h_{\mathrm{ab}}\right)$ were calculated as above. The lightfastness of the colours was determined at TO2C (University College Ghent, Belgium) according to the ISO 105-B02 norm. Also in this case, the scale 1 (poor)-8 (excellent) was used for reporting the results. 


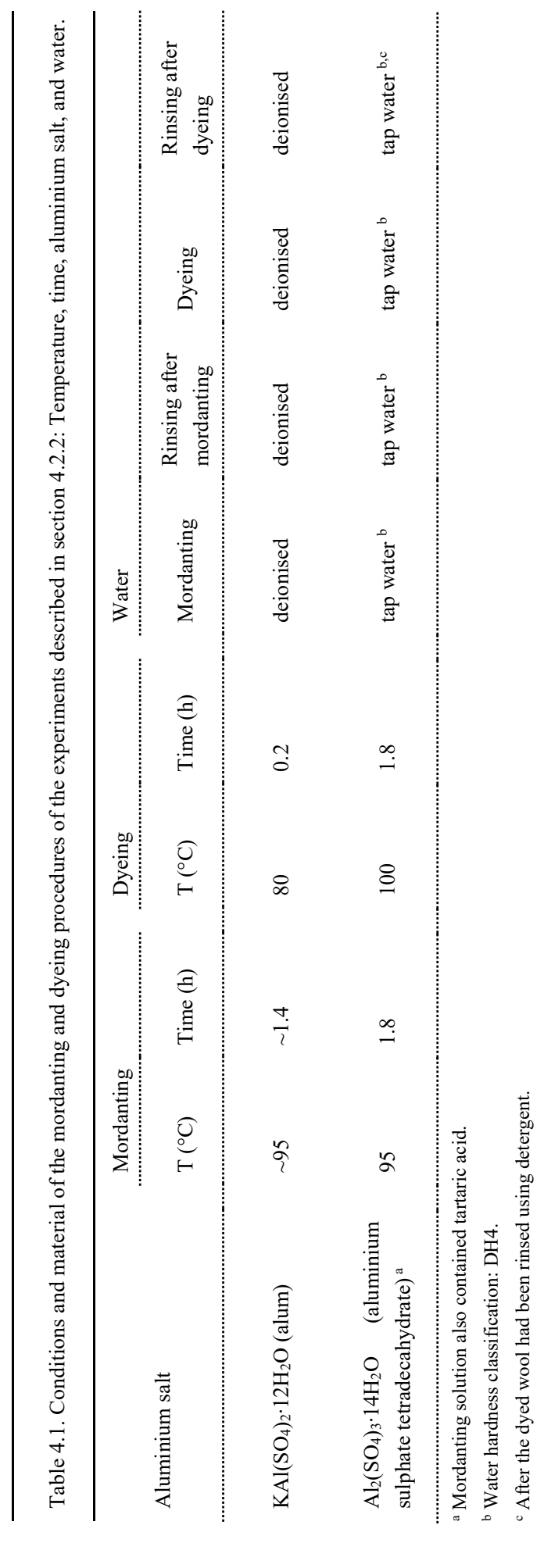


4.2.3. Effect of the glycosylation pattern of lut (aglycone, monoglucoside, and diglucoside) on the colours of alum-mordanted wool dyed with it

The following chemical compounds and material were used for dyeing the alum-mordanted wool: Lut ( $96 \%$ by NMR; Indofine Chemical Company, Hillsborough/USA); Img (95\% by NMR; Extrasynthese, Genay/France); Idg ( $86 \%$ by NMR; Extrasynthese, Genay/France); sample of the aerial parts of dried and ground weld \{described by Villela et al. [13]\}.

Single pieces of the wool mordanted with a $10 \mathrm{~g} \mathrm{~L}^{-1}$ aqueous solution of alum described above were dyed at $80^{\circ} \mathrm{C}$ for $15 \mathrm{~min}$ - according to procedures adapted from that described by Villela et al. [14] (Supporting Information, page 2) —with:

- $11.5 \mu \mathrm{mol}$ of lut, lmg, or ldg;

- A 96\% ethanol-water 3:1 (v/v) extract of $420 \mathrm{mg}$ of a sample of the aerial parts of dried and ground weld.

A blank-without-wool was carried out similarly. The dyeing baths were sampled after removal of the pieces of dyed wool — while still warm and stirring - followed by $5 \times$ dilution with DMSO. Later, these samples were analysed by RP-HPLC-UV (as above). The percentages of leftover flavones in the dyeing baths were calculated as follows:

- Individual flavones: Using calibration curves, with that of Img having to be extrapolated due to low [Img] in the sample;

- Extract of weld: The areas of lut, Img, and ldg peaks of the wool-dyeing were compared with those of the blank-without-wool.

$L^{*}, a^{*}$, and $b^{*}$ quantities (CIELAB colour space) were measured for the dyed wool, and their chroma $\left(C^{*}\right.$ ab $)$ and hue angle $\left(h_{\mathrm{ab}}\right)$ were calculated as above. For this, only a part of about $5 \times 1$ $\mathrm{cm}$ of the piece of wool was used in each of the four cases. 


\subsection{Theory}

This section provides theoretical background for the discussion in the chapter. Its first paragraph consists of a brief overview of photophysical processes often taking place upon irradiation of organic molecules in solution, based on the book by Gilbert and Baggott [17].

Organic molecules may be excited from the electronic ground singlet state $\left(\mathrm{S}_{0}\right)$ to electronic excited states upon irradiation in the portion(s) of the UV-vis range of the electromagnetic spectrum in which they absorb light. This excitation may be to the lowest vibrational level of the first electronic excited singlet state $\left(S_{1}\right)$. If the excitation is to a vibrationally excited level of $\mathrm{S}_{1}$, this excess vibrational energy is quickly dissipated through vibrational relaxation (VR) by collisions of the excited molecule with solvent molecules. This leads to heat generation. Molecules that are excited to higher electronic excited singlet states may reach the lowest vibrational level of $\mathrm{S}_{1}$ through the nonradiative transition internal conversion (IC) - e.g., $\mathrm{S}_{2} \rightarrow \mathrm{S}_{1}$ - followed by VR. Then, the molecules may return to $\mathrm{S}_{0}$ with or without emission of light. If this transition is nonradiative, it takes place through $\mathrm{S}_{1} \rightarrow \mathrm{S}_{0}$ IC followed by VR. If it is radiative, it is referred to as fluorescence. From $\mathrm{S}_{1}$, the organic molecules may also proceed to the first electronic excited triplet state $\left(\mathrm{T}_{1}\right)$ through intersystem crossing (ISC). Also from the vibrationless level of $\mathrm{T}_{1}$, they may return to $\mathrm{S}_{0}$ with or without emission of light. If the transition is nonradiative, it takes place, again, through ISC - this time $\mathrm{T}_{1} \rightarrow \mathrm{S}_{0}$ - followed by VR. If it is radiative, it is referred to as phosphorescence. These transitions can be schematically visualised in a Jablonski diagram. ${ }^{2}$

Depending on the structure, flavones and flavonols undergo tautomerism. In the case of the flavone lut, this takes place through proton transfer at the 5-hydroxyl and 4-carbonyl groups (pseudo-carboxyl group) (Fig. 4.1). Amat et al. studied photophysical processes taking place upon irradiation of lut [18]. In the electronic singlet ground state $\left(\mathrm{S}_{0}\right)$, the O5-bound tautomer was calculated to be energetically favourable over the O4-bound tautomer. In the first electronic singlet excited state $\left(\mathrm{S}_{1}\right)$, it is the opposite.<smiles>CC(C)(C)c1cc(-c2ccc(O)c(O)c2)cc(=O)c2c(O)cc(O)cc12</smiles>

O5-bound tautomer<smiles>O=c1cc(O)cc2oc(-c3ccc(O)c(O)c3)cc(O)c1-2</smiles>

O4-bound tautomer

Figure 4.1. Tautomerism of lut, through proton transfer at the 5-hydroxyl and 4-carbonyl groups (pseudo-carboxyl group).

\footnotetext{
${ }^{2}$ Singlet (S) and triplet (T) refer to the electronic state of molecules, which relates to the spin of their electrons [17]. There is no need for further elaboration on them for the discussion in this thesis.
} 
After photon absorption, lut loses some of the energy gained by planarization of its structure. Although the B-ring is $18^{\circ}$ out of the plane of rings $\mathrm{A}-\mathrm{C}$ in the $\mathrm{S}_{0}$, this decreases to only $1^{\circ}$ in the $S_{1}[18]$. Charge transfer from the B-ring towards rings $C$ and $A$ could be the reason for such planarization [19]. After that, lut is expected to undergo tautomerism, or excited state intramolecular proton transfer (ESIPT).

The main processes through which lut returns to $\mathrm{S}_{0}$ are nonradiative, as its fluorescence quantum yield $\left(\phi_{\mathrm{f}}\right)$ is $<10^{-4}$ in methanol [5]. The reason for this may be a high rate of $\mathrm{S}_{1} \rightarrow \mathrm{S}_{0}$ IC. As the $\mathrm{S}_{0}-\mathrm{S}_{1}$ energy gap of lut is $2.810^{4} \mathrm{~cm}^{-1}$ - i.e., larger than $2.510^{4} \mathrm{~cm}^{-1}$ - the efficiency of the transition could be due to an acceleration by charge transfer from the B-ring, ESIPT, or both of them $[18,19]$. After the IC, VR leads to the lowest vibrational level of $S_{0}[17]$.

Solvent participates in the proton transfer at the $\mathrm{S}_{0}$ in methanol-water 8:2- the solvent used for evaluating the photo-stability of lut in the study reported here-as it is a polar protic solvent [20]. This may be the case at the $\mathrm{S}_{1}$ too. Polar protic solvents lessen ESIPT [21, 22]. Thus, as the proton transfer at the $\mathrm{S}_{1}$ might be mediated by the solvent - and possibly also by component partners of lut dimers/aggregates [21] — it is henceforth referred to as excited state proton transfer (ESPT).

\subsection{Results and discussion}

\subsubsection{Effect of different concentrations of $\mathrm{Al}^{3+}$ on the photo-stability of the dye of weld} 4.4.1.1. Photo-stability of lut in solution as a function of different concentrations of $\mathrm{Al}^{3+}$ The photo-stability of lut in aerated methanol-water 8:2 (v/v) solution upon its irradiation with light above $300 \mathrm{~nm}$ at different $\mathrm{t}_{0}$ concentrations $-0.20 \mathrm{mM}\left(\mathbf{l u t}_{0.20}\right), 0.11 \mathrm{mM}\left(\mathbf{l u t}_{0.11}\right)$ and 0.05 $\mathrm{mM}\left(\right.$ lut $_{0.05}$ ) - was compared. Straight lines were fit through the experimental data; the slopes of the equations of the best-fit lines range from $-1.810^{-14}$ to $-2.310^{-14} \mathrm{AU}$. These, and the number of molecules decomposed in $24 \mathrm{~h}$ of irradiation-evidenced by the change in peak area-are very similar (Fig. SI C.11). This suggests that the rate of photodecomposition of lut is independent of its concentration, following a zero-order rate law under the conditions used in this study.

In the same set of experiments, the photo-stability of lut in presence of $\mathrm{Al}^{3+}$ at different lut$\mathrm{Al}^{3+}$ ratios-5:1 ( $\left.\mathbf{l u t}_{0.10}-\mathrm{Al}_{0.02}\right), 1: 1\left(\mathbf{l u t}_{0.10}-\mathrm{Al}_{0.10}\right)$, and 1:10 (lut $\mathbf{l}_{0.10}-\mathrm{Al}_{1.00}$ ) —was studied in duplicate. The experimental data were treated as above, with the photodecomposition of lut being described by the zero-order integrated rate law ([lut $\left.]=k t+[\mathbf{l u t}]_{0}\right)$. As the rate of photodecomposition is equal to the rate constant $(k)$ in zero-order reactions $(\mathrm{d}[\mathbf{l u t}] / \mathrm{d} t=k)$, the relative rates of the photodecomposition of lut could be obtained. The photo-stability of lut in solution decreased with increasing $\left[\mathrm{Al}^{3+}\right]$, with the relative rates of its photodecomposition

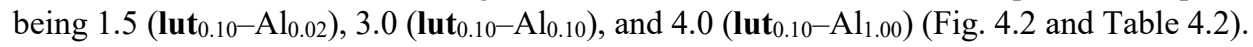




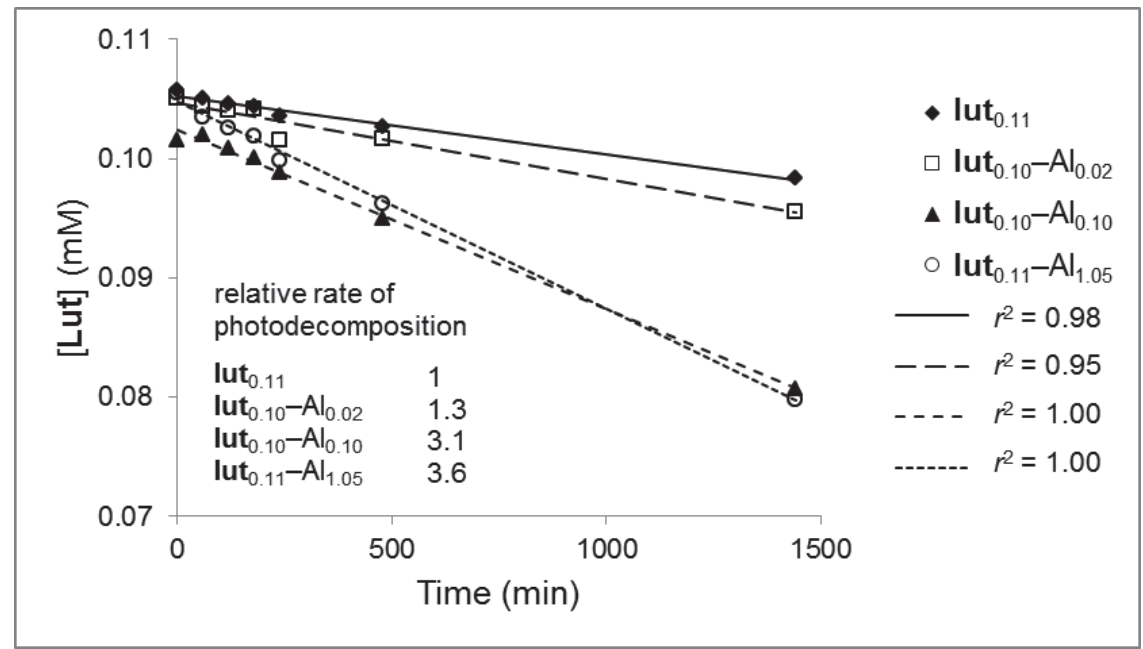

Figure 4.2. Effect of increasing $\left[\mathrm{Al}^{3+}\right]$ on the photo-stability of lut in solution. Note: Subscripts of code of solutions denote [lut $]_{0}$ and $\left[\mathrm{Al}^{3+}\right]$, in $\mathrm{mM}$; Solvent: aerated methanolwater $8: 2(\mathrm{v} / \mathrm{v}) ; r^{2}=$ quality of description of the photodecomposition of lut by the zeroorder integrated rate law ([lut $\left.]=k t+[\text { lut }]_{0}\right)$; Duration of irradiation of solutions $=24.0 \mathrm{~h}$ $(1,440 \mathrm{~min})$; Data from $1^{\text {st }}$ irradiation replicate. 
Table 4.2. Relative rate of photodecomposition of lut in solution as a function of different concentrations of $\mathrm{Al}^{3+}$ and glycosylation pattern (aglycone, monoglucoside, and diglucoside).

\begin{tabular}{|c|c|c|c|c|}
\hline Solution $^{\mathrm{a}}$ & $\begin{array}{l}\text { Flavone decomposed in } \\
24 \text { h of irradiation }(\%)\end{array}$ & $r^{2 \mathrm{~b}}$ & $\begin{array}{l}\text { Rate constant, } k \\
\left(10^{-3} \mathrm{~mol} \mathrm{~L}^{-1} \mathrm{~min}^{-1}\right)\end{array}$ & $\begin{array}{l}\text { Relative rate of } \\
\text { photodecomposition }^{c}\end{array}$ \\
\hline \multicolumn{5}{|c|}{$1^{\text {st }}$ irradiation replicate } \\
\hline lut $_{0.11}$ & 7 & 0.98 & $4.910^{-6}$ & 1 \\
\hline lut $_{0.10}-\mathrm{Al}_{0.02}$ & 9 & 0.95 & $6.410^{-6}$ & 1.3 \\
\hline lut $_{0.10}-\mathrm{Al}_{0.10}$ & 21 & 1.00 & $1.510^{-5}$ & 3.1 \\
\hline lut $_{0.11}-\mathrm{Al}_{1.05}$ & 24 & 1.00 & $1.710^{-5}$ & 3.6 \\
\hline lut $_{0.05}$ & 12 & 0.99 & $4.410^{-6}$ & 1 \\
\hline $\operatorname{lmg}_{0.05}$ & 16 & 0.99 & $5.710^{-6}$ & 1.3 \\
\hline $\operatorname{ldg}_{0.04}{ }^{\mathrm{d}}$ & 1 & 0.48 & $3.510^{-7}$ & 0.1 \\
\hline $\mathbf{l d g}_{0.05}-\mathrm{Al}_{0.05}{ }^{\mathrm{d}}$ & 8 & 0.69 & $2.910^{-6}$ & 0.6 \\
\hline \multicolumn{5}{|c|}{$2^{\text {nd }}$ irradiation replicate } \\
\hline lut $_{0.10}$ & 6 & 1.00 & $4.310^{-6}$ & 1 \\
\hline lut $_{0.10}-\mathrm{Al}_{0.02}$ & 10 & 0.98 & $6.710^{-6}$ & 1.6 \\
\hline lut $_{0.10}-\mathrm{Al}_{0.10}$ & 22 & 0.99 & $1.410^{-5}$ & 3.3 \\
\hline lut $_{0.10}-\mathrm{Al}_{0.99}$ & 26 & 1.00 & $1.810^{-5}$ & 4.0 \\
\hline lut $_{0.05}$ & 11 & 0.97 & $3.910^{-6}$ & 1 \\
\hline $\operatorname{lmg}_{0.05}$ & 17 & 0.99 & $5.810^{-6}$ & 1.5 \\
\hline $\operatorname{ldg}_{0.05}{ }^{\mathrm{d}}$ & 4 & 0.62 & $1.310^{-6}$ & 0.3 \\
\hline $\mathbf{l d g}_{0.05}-\mathrm{Al}_{0.05}{ }^{\mathrm{d}}$ & 9 & 0.46 & $2.310^{-6}$ & 0.6 \\
\hline
\end{tabular}

${ }^{a}$ Subscripts of code of solutions denote [flavone $]_{0}$ and $\left[\mathrm{Al}^{3+}\right]$, in $\mathrm{mM}$; Solvent: aerated methanol-water 8:2 (v/v); $\mathrm{b} r^{2}=$ quality of description of the photodecomposition of the flavones by the zero-order integrated rate law ([flavone $\left.]=k t+[\text { flavone }]_{0}\right) ;{ }^{\mathrm{c}}$ Relative rates of photodecomposition $=k_{\mathrm{j}} / k_{\mathrm{i}}$-as d[flavone $] / \mathrm{d} t=k$ in zero-order reactions - in which $\mathrm{i}$ is lut in $\mathbf{l u t}_{0.11}$, lut $\mathbf{l}_{0.10}$, or $\mathbf{l u t}_{0.05}$, and $\mathrm{j}$ is lut, lmg, or ldg in other solutions; ${ }^{\mathrm{d}} \mathrm{The}^{\mathrm{T}}$ photodecomposition of $\mathbf{l d g}$ over time — with and without $\mathrm{Al}^{3+}$ — is plotted in Figures SI C.12-15. 
An explanation for the decrease of the photo-stability of lut with increasing $\left[\mathrm{Al}^{3+}\right]$ is suggested. As discussed in the Theory section, the main processes through which electronic excited state lut returns to $\mathrm{S}_{0}$ are nonradiative, possibly through an $\mathrm{S}_{1} \rightarrow \mathrm{S}_{0}$ IC accelerated by charge transfer from the B-ring towards rings $\mathrm{C}$ and $\mathrm{A}, \mathrm{ESPT}$, or by both of them. ${ }^{3}$ In lut- $\mathrm{Al}^{3+}$ complexes, the charge transfer from the B-ring of lut after electronic excitation might diminish. Furthermore, the possibility of ESPT at the pseudo-carboxyl group decreases with increasing $\left[\mathrm{Al}^{3+}\right.$ ], up to the point in which all lut molecules are forming a complex with $\mathrm{Al}^{3+}$ and ESPT becomes impossible. These two possibilities are elaborated upon in the remaining of this section.

The dihedral angle between the plane of ring $\mathrm{B}$ and that of rings $\mathrm{A}-\mathrm{C}$ decreases upon complexation with $\mathrm{Al}^{3+}$ at the pseudo-carboxyl group [4, 23]. This planarization is linked to increased electronic delocalization [4, 23], which is consistent with the lowest UV-vis absorption bands of lut- $\mathrm{Al}^{3+}$ complexes being red-shifted relative to that of lut [Fig. SI C.7, and [5] (Fig. 7)]. Thus, the charge transfer from the B-ring of lut in lut- $\mathrm{Al}^{3+}$ complexes after electronic excitation might be less pronounced than that of free lut.

Complexation at the pseudo-carboxyl group is favoured over that at the 3'- and 4'-hydroxyl groups (catechol group) in a neutral environment [4]. In an acidic environment-methanolwater 9:1 acidified to an apparent $\mathrm{pH}$ of 2.5-flavonol- $\mathrm{Al}^{3+}$ complexation at the catechol group did not even take place [4]. The environment in which the experiments reported in this section were carried out was also acidic (methanol-water 8:2 at an apparent $\mathrm{pH}$ of 3.6). Consequently, complexation between lut and $\mathrm{Al}^{3+}$ is expected to have taken place primarily-if not solelyat lut's pseudo-carboxyl group. Therefore, the decrease of the photo-stability of lut with increasing $\left[\mathrm{Al}^{3+}\right]$ is also consistent with a corresponding decreasing possibility of ESPT at the pseudo-carboxyl group [6,7].

This can be understood by knowing which complexes are formed at different lut- $\mathrm{Al}^{3+}$ ratios. ${ }^{4}$ Amat et al. studied it theoretically, with experimental data in methanol obtained by Favaro et al. as benchmark [5, 23]. The following - also represented in Figure 4.3 - is based on their report:

- At a lut- $\mathrm{Al}^{3+} 3: 1$ ratio, lut is both free and as the lut $-\mathrm{Al}^{3+} 2: 1$ complex involving the pseudo-carboxyl group;

- At a lut- $\mathrm{Al}^{3+} 1: 2$ ratio, lut is largely present in the form of the lut- $\mathrm{Al}^{3+} 1: 1$ complex, also involving the pseudo-carboxyl group;

- At a lut- $\mathrm{Al}^{3+} 1: 10$ ratio, a mixture of the complexes lut- $\mathrm{Al}^{3+} 1: 2$ involving the pseudocarboxyl group and the catechol group, and lut $-\mathrm{Al}^{3+} 1: 1$ (as in the previous bullet point) is likely.

\footnotetext{
${ }^{3}$ Deprotonation at the 7-OH group of lut could also play a role in acceleration of the $\mathrm{S}_{1} \rightarrow \mathrm{S}_{0}$ IC. This is further elaborated upon in section 4.4.2.1.

${ }^{4}$ The rationale presented for the decreasing possibility of ESPT at the pseudo-carboxyl group with increasing $\left[\mathrm{Al}^{3+}\right]$ is qualitative on the possible lut- $\mathrm{Al}^{3+}$ complexes present in solution, not involving the formation constants of the complexes.
} 
i) without $\mathrm{Al}^{3+}$<smiles>O=c1cc(-c2ccc(O)c(O)c2)oc2cc(O)cc(O)c12</smiles>

iii) lut-Al| $\left.\right|^{3+}$ 1:2<smiles>C[C+](C)C</smiles>

ii) lut- $\mathrm{Al}^{3+}$ s:1

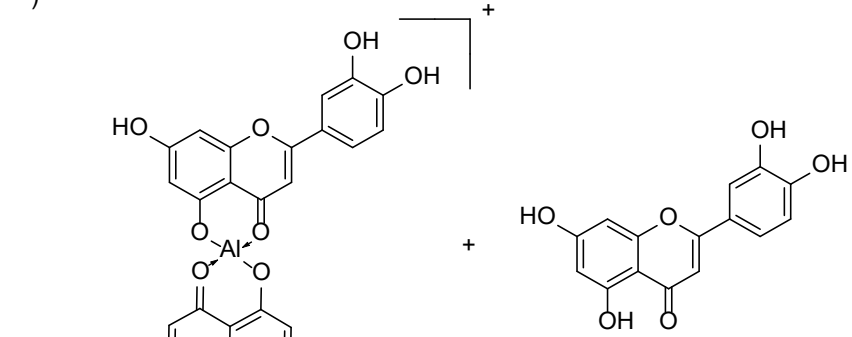<smiles></smiles>
iv) lut- $\left.A\right|^{3+}$ 1:10<smiles></smiles><smiles>CC[C+](C)C</smiles>

Figure 4.3. Lut- $\mathrm{Al}^{3+}$ complexes formed at different lut- $\mathrm{Al}^{3+}$ ratios in methanol [23].

Water in the solvent seems to be unfavourable for lut- $\mathrm{Al}^{3+}$ complexation. Because of this, the main species in methanol-water 8:2 solution at a lut- $\mathrm{Al}^{3+} 1: 10$ ratio is expected to be the same as that in methanol at a lut- $\mathrm{Al}^{3+} 1: 2$ ratio \{Table SI C.1 and ensuing discussion, [5] (Fig. 7), and $[23]\}$. Therefore, the decrease of the photo-stability of lut with increasing $\left[\mathrm{Al}^{3+}\right]$ reported here is consistent with ESPT being:

- Possible at a lut- $\mathrm{Al}^{3+} 5: 1$ ratio, due to the main species in solution being the lut- $\mathrm{Al}^{3+} 2: 1$ complex and free lut, as represented in situation ii of Figure 4.3;

- Still possible at a lut- $\mathrm{Al}^{3+} 1: 1$ ratio-but to a much smaller extent than in the previous case-due to the main species in solution being the same as in the previous bullet point, but with an increased number of lut molecules forming a complex with $\mathrm{Al}^{3+}$;

- Impossible at a lut- $\mathrm{Al}^{3+} 1: 10$ ratio, due to the main species in solution being the lut- $\mathrm{Al}^{3+}$ 1:1 complex represented in situation iii of Figure 4.3.

The reported fluorescence in a situation in which all lut molecules are forming a complex with $\mathrm{Al}^{3+}$ evidences a process for the $\mathrm{S}_{1} \rightarrow \mathrm{S}_{0}$ transition other than accelerated IC. Fluorescence is nearly the only process through which the lut $-\mathrm{Al}^{3+}$ complex(es) release(s) absorbed energy, as $\phi_{\mathrm{f}} \approx 1$ in methanol [5]. Thus, there is a change of the preferred process through which lut releases absorbed energy at high $\left[\mathrm{Al}^{3+}\right]$. As charge transfer from the B-ring of lut after 
electronic excitation may diminish and the possibility of ESPT decreases, the possible accelerated $\mathrm{S}_{1} \rightarrow \mathrm{S}_{0}$ transition via IC could be progressively replaced by an $\mathrm{S}_{1} \rightarrow \mathrm{S}_{0}$ transition via fluorescence.

The rate constant of accelerated $\mathrm{S}_{1} \rightarrow \mathrm{S}_{0}$ transition via IC $\left(k_{\mathrm{IC}}\right)$ of lut in methanol-water 8:2 might be of the order of magnitude of $10^{11} \mathrm{~s}^{-1}$, by analogy to that of the O-3-glycosylated flavonol rutin in methanol, also a polar protic solvent [19]. Fluorescence lifetimes are typically of the order of magnitude of $10^{-9} \mathrm{~s}$ and the measured fluorescence lifetime $\left(\tau_{\mathrm{f}}\right)$ is the reciprocal of the rate constant of fluorescence $\left(k_{\mathrm{f}}\right)$ if $\phi_{\mathrm{f}}=1$, i.e., $\tau_{\mathrm{f}}=k_{\mathrm{f}}^{-1}$ [17] (chapter 4). Thus, the electronic excited state lifetime of free lut might be about two orders of magnitude shorter than that of lut molecules engaged in complex formation with $\mathrm{Al}^{3+}$. Since molecules are more reactive in the electronic excited state than in the electronic ground state, this would account for the decrease of the photo-stability of the compound with increasing $\left[\mathrm{Al}^{3+}\right]$.

\subsubsection{Effect of mordanting wool with different quantities of $\mathrm{Al}^{3+}$ before its dyeing with extracts of weld on the colour and on its light-fastness}

Two experiments using extracts of weld to dye wool premordanted with increasing quantities of $\mathrm{Al}^{3+}$ were carried out. In one of them wool was mordanted using alum [ $\mathrm{KAl}\left(\mathrm{SO}_{4}\right)_{2} \cdot 12 \mathrm{H}_{2} \mathrm{O}$ ], and in the other, aluminium sulphate and tartaric acid. $L^{*}, a^{*}$, and $b^{*}$ quantities (CIELAB colour space) were measured for the pieces of dyed wool, and their light-fastness was determined. As CIELAB chroma $\left(C^{*}\right.$ ab $)$ and hue angle $\left(h_{\mathrm{ab}}\right)$ approximately correlate to chroma and hue [15], the $C^{*}$ ab quantities are henceforth referred to as the chroma of the colours, and the $h_{\mathrm{ab}}$ quantities, as their hue.

The dyed wool becomes more colourful \{saturated [24]\}- displays higher chroma-with increasing $\left[\mathrm{Al}^{3+}\right]$, with a plateau seeming to be reached at some point (Fig. 4.4 and Table 4.3). This takes place at nearly constant lightness $\left(L^{*}\right)$ and hue (Table 4.3 and Table SI C.4). It is also worth noting that the colour of the dyed blank-mordanted wool-in which the wool had been pretreated as in the other cases, except that the mordanting bath had no alum-was pale, with a chroma value of only 15 (Fig. 4.4 and Table SI C.4). To some extent, the results of colourfulness contrast with those of an earlier report by Vinod et al. (2010), as the chroma of alum-premordanted silk - also a proteinaceous fibre-dyed with a flavonoid dye remained constant with increasing $\left[\mathrm{Al}^{3+}\right][25]$. The $\mathrm{K} / \mathrm{S}$ value increased, however, suggesting increased dye uptake [26]. Thus, the increase in colourfulness of the dyed wool with increasing $\left[\mathrm{Al}^{3+}\right]$ reported here could be - at least in part — due to larger quantities of dye in the fibre. 


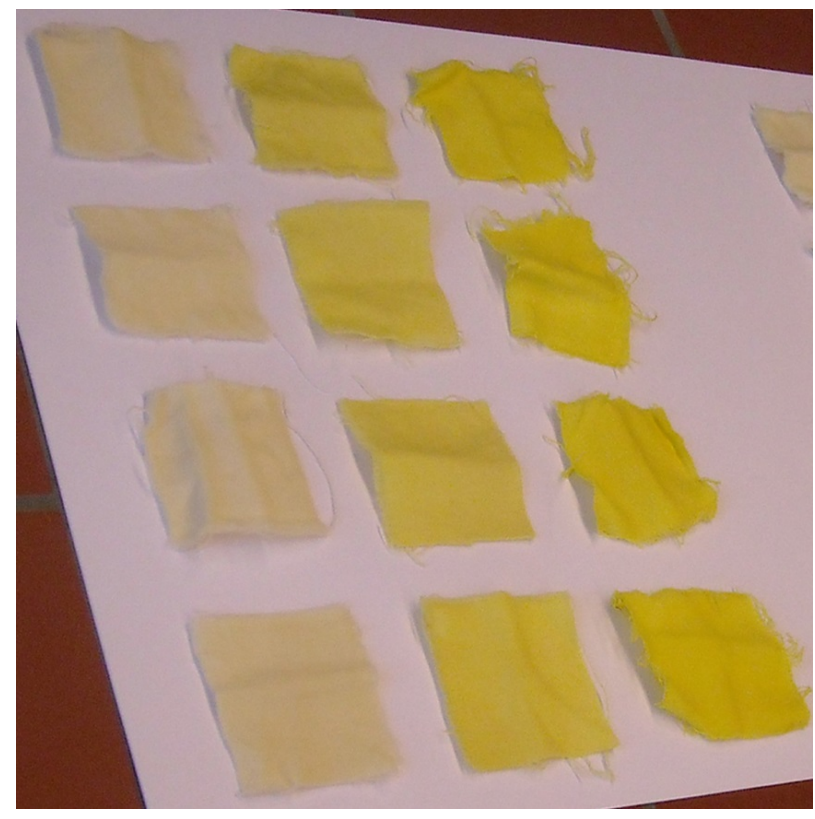

Figure 4.4. Weld-dyed wool premordanted with varying quantities of $\mathrm{Al}^{3+}$ (experiment using alum). Pieces of dyed wool in columns, from right to left $(n=4$, each case): Wool that had been premordanted with $10 \mathrm{~g} \mathrm{~L}^{-1}$ and $2 \mathrm{~g} \mathrm{~L}^{-1}$ aqueous solutions of alum, and blank-mordanted wool (wool that had been pretreated as in the other cases, except that the mordanting bath had no alum).

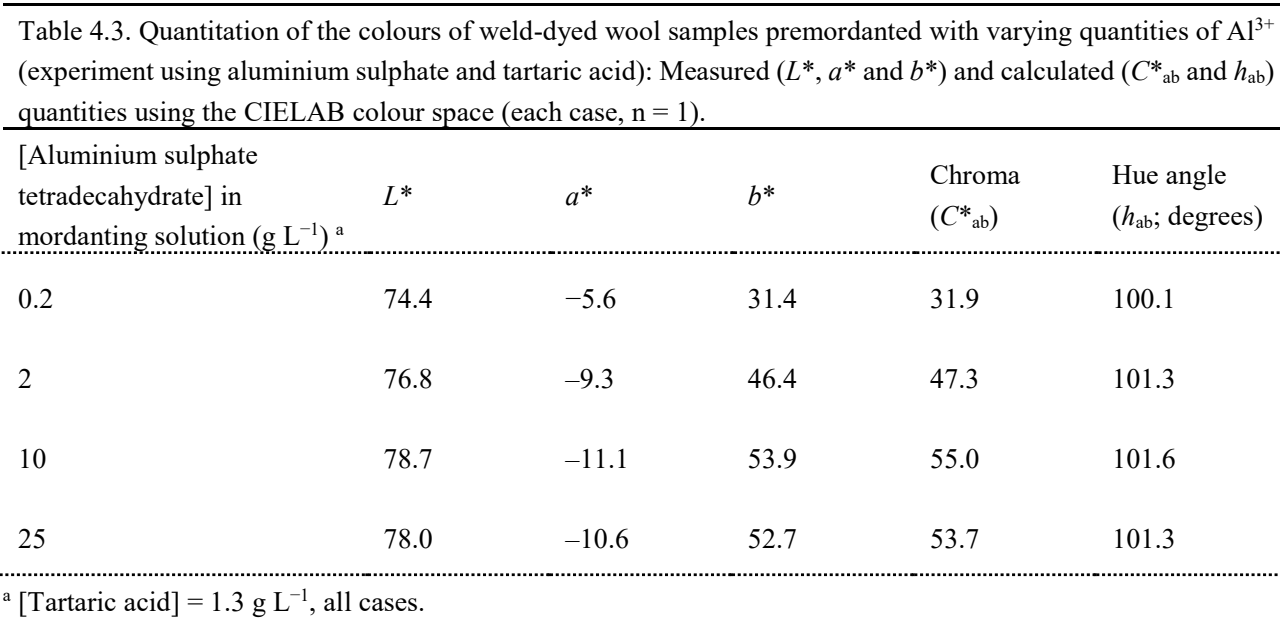


The light-fastness of the colours of the wool in both experiments was below 3, the acceptable lower limit using the scale 1 (poor)-8 (excellent) [16]. However, that of all samples decreased with increasing $\left[\mathrm{Al}^{3+}\right]$. In the experiment in which alum was used, the colour difference values calculated from the $L^{*}, a^{*}$, and $b^{*}$ quantities before and after irradiation increased at higher $\left[\mathrm{Al}^{3+}\right]$ (Table 4.4). In the experiment in which aluminium sulphate and tartaric acid were used, the light-fastness of the colours of the samples themselves decreased with increasing $\left[\mathrm{Al}^{3+}\right]$ (Table 4.5). This contrasts with earlier reports in which the colours of $\mathrm{Al}^{3+}$-mordanted proteinaceous fibres dyed with flavonoid dyes have been reported as more or equally light-fast as those of non-mordanted fibres [16, 25, 27].

The wash-fastness of the colours of the samples of the experiment in which alum was used was also determined. On the scale 1 (poor) -5 (excellent), wash-fastness values of 3-4 are the acceptable lower limit [16]. The wash-fastness of all colours either matched or surpassed this limit (Table SI C.5). Although replicate samples would be needed for increased accuracy of the description of the phenomenon, the colour of dyed blank-mordanted wool (no alum) appears to be more wash-fast than that of dyed $\mathrm{Al}^{3+}$-mordanted wool. This would contrast with earlier reports too. The colours of $\mathrm{Al}^{3+}$-mordanted proteinaceous fibres dyed with flavonoid dyes have been reported as more wash- or water-fast than those of non-mordanted fibres [16, 25, 27].

Table 4.4. Light-fastness of the colours of weld-dyed wool premordanted with varying quantities of $\mathrm{Al}^{3+}$ (experiment using alum; samples of Figure 4.4), and CIELAB colour difference $\left(\Delta E^{*}\right.$ ab) values calculated from the $L^{*}, a^{*}$, and $b^{*}$ quantities before and after irradiation.

\begin{tabular}{lll}
\hline [Alum] in mordanting solution $\left(\mathrm{g} \mathrm{L}^{-1}\right)$ & Light-fastness of the colour & $\Delta E^{*}{ }_{\mathrm{ab}}^{\mathrm{b}}$ \\
Blank (no alum) & $<1 / 1$ & 4.78 \\
2 & $<1$ & 4.90 \\
10 & $<1$ & 6.25 \\
&
\end{tabular}


Table 4.5. Light-fastness of the colours of weld-dyed wool premordanted with varying quantities of $\mathrm{Al}^{3+}$ (experiment using aluminium sulphate and tartaric acid; samples of Table 4.3; each case, $\mathrm{n}=1$ ).

\begin{tabular}{ll}
\hline $\begin{array}{l}\text { [Aluminium sulphate tetradecahydrate] in mordanting } \\
\text { solution }\left(\mathrm{g} \mathrm{L}^{-1}\right)^{\mathrm{a}}\end{array}$ & Light- \\
0.2 & $1-2$ \\
2 & $<1 / 1$ \\
10 & $<1$ \\
25 & $<1$ \\
& \\
& \\
& \\
& \\
&
\end{tabular}

The two experiments in which wool was mordanted with different quantities of $\mathrm{Al}^{3+}$ before its dyeing differed in a number of ways. Several of these differences are displayed in Table 4.1. The short heating time of the dyeing process of the alum-experiment is likely to have been positive for the wool in terms of its physical properties. This is due to the loss of soluble proteins from the wool upon high-temperature heating, which increases with the duration of the process [28]. Nevertheless, long, high-temperature heating is required for the dye molecules to arrive at the regions within the wool fibres where interaction of the dyes with the proteins is thermodynamically favoured [29]. Thus, the long, high-temperature heating of the dyeing process of the aluminium sulphate/tartaric acid-experiment is expected to have been positive in terms of the quality of the dyeing. A potential negative effect of the short, lower-temperature heating used in the alum-experiment would be low wash-fastness of the colour, as the dye molecules - not at the regions of thermodynamically favoured interactions yet - could have been extracted from the fibre with relative ease [29]. As mentioned above, however, the washfastness of the obtained colours either matched or surpassed the acceptable lower limit.

In spite of these and other differences between the two experiments, the light-fastness of the colours of weld-dyed wool decreased with increasing $\left[\mathrm{Al}^{3+}\right]$ in both cases. As mentioned earlier in this section, more dye may have been taken up by wool mordanted with larger quantities of $\mathrm{Al}^{3+}$. Light-fastness of the colour generally increases with the increase of the quantity of dye in the fibre $[30,31]$. If this is the case also for the system dye of weld- $\mathrm{Al}^{3+}-$ wool, the detrimental effect of $\mathrm{Al}^{3+}$ on the light-fastness of the colours is even larger than that seen in Tables 4.4 and 4.5.

A similar explanation to that suggested in the previous section for the decrease of the photostability of lut with increasing $\left[\mathrm{Al}^{3+}\right]$ is given here. That is, the decrease of the photo-stability of the flavones - main components of the dye of weld $\{[14]$ (p.7 of SI) $\}$ - with increasing $\left[\mathrm{Al}^{3+}\right]$ may be due to a change of their preferred process for releasing absorbed energy. The $\mathrm{S}_{1} \rightarrow \mathrm{S}_{0}$ transition could increasingly proceed via fluorescence rather than via IC accelerated by a photophysical process(es). This could lead to longer electronic excited state lifetimes of the flavones engaged in complex formation with $\mathrm{Al}^{3+}$ than those of the free flavones, accounting for the decrease of the photo-stability of the compounds. However, the picture here differs from 
that of lut in solution due to additional geometrical constraints and changes in electronic distribution. These relate to the chemical structures of the flavones themselves-which differ from that of lut, with most of them containing sugar moieties - and to their interaction with the proteins of wool. Van der Waals forces are one of the important ways through which dye molecules interact with the proteins of wool [29]. Naturally, interactions such as this influence the electronic distribution of the flavones.

4.4.2. Effect of glycosylation pattern of lut (aglycone, monoglucoside, and diglucoside) on its photo-stability in solution and colours of alum-mordanted wool dyed with it 4.4.2.1. Photo-stability of lut in solution as a function of its glycosylation pattern The photo-stability of lut in solution was studied in duplicate as a function of its glycosylation pattern: Aglycone, lut-7-O-glucoside (lut monoglucoside, Img) and lut-7,3'-O-diglucoside (ldg). This was done in the same set of the experiments discussed in section 4.4.1.1, in aerated methanol-water 8:2 (v/v) solution with light above $300 \mathrm{~nm}$. Also the experimental data were treated as done for lut in solution in the presence of $\mathrm{Al}^{3+}$, with the relative rates of photodecomposition being obtained. Whereas Img photodecomposed $1.4 \times$ faster than lut, the photodecomposition of Idg was much slower (Table 4.2 and Fig. 4.5). Although this increased reactivity of Img upon irradiation relative to lut was also observed by Smith et al. [6], it seems counter-intuitive at first, due to the possibility of glycosylation to confer stability to flavonoid aglycones [8], [9] (chapter 42), [10] (chapter 5). Possible explanations for the effect of the glycosylation pattern on the photo-stability of lut in solution are elaborated upon in this section. 


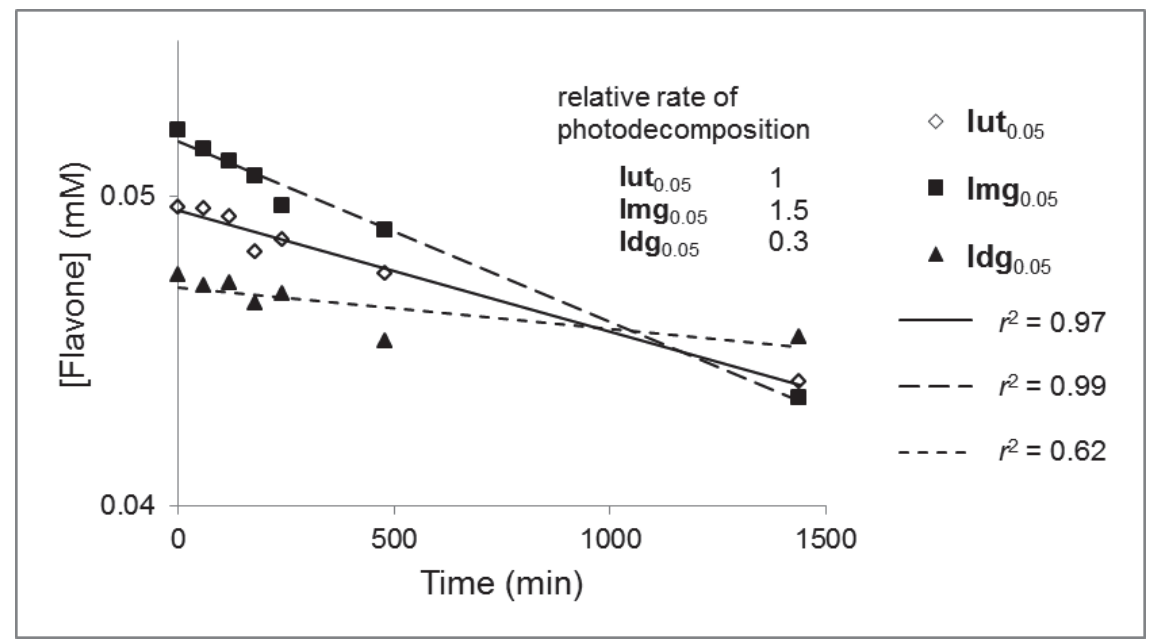

Figure 4.5. Effect of glycosylation pattern - aglycone, monoglucoside, and diglucosideon the photo-stability of lut in solution. Note: Subscripts of code of solutions denote [flavone] $]_{0}$, in $\mathrm{mM}$; Solvent: aerated methanol-water $8: 2(\mathrm{v} / \mathrm{v}) ; r^{2}=$ quality of description of the photodecomposition of the flavones by the zero-order integrated rate law ([flavone] $\left.=k t+[\text { flavone }]_{0}\right) ;$ Duration of irradiation of solutions $=24.0 \mathrm{~h}(1,440 \mathrm{~min}) ;$ Data from $2^{\text {nd }}$ irradiation replicate.

The possibility of lut to increase the electronic density of the A-ring through deprotonation at the 7-OH group may account for the difference between its rate of photodecomposition and that of Img. The electronic distributions of lut and apigenin - 3'-deoxy lut - are similar [18]. The $\mathrm{S}_{0} \rightarrow \mathrm{S}_{1}$ transition of apigenin is accompanied by a shift of electron density from ring A to ring $\mathrm{C}$ [18]. Upon irradiation with light above $300 \mathrm{~nm}$, lut mainly undergoes an $\mathrm{S}_{0} \rightarrow \mathrm{S}_{1}$ transition [18] (Table 4.2 and Fig. 4.3). Thus, in the experiments reported here, lut is expected to have undergone a change in electronic distribution equivalent to that of apigenin; importantly for this discussion, a lowering of the electron density of ring A.

With a $\mathrm{p} K_{\mathrm{a}}<9$, the 7-OH is one of the two most acidic groups of lut $[5,32]$. The tendency for deprotonation at this hydroxyl group should only increase in the $\mathrm{S}_{1}$ because of the change in electronic distribution [22]. Thus, such a deprotonation could be a way for excited state lut to compensate part of the loss of electron density of ring A. This is impossible in the case of Img because it has an $O$-glucose moiety instead of a hydroxyl group at C-7. Such an impossibility could lead to a change in the preferred process through which absorbed energy is released, causing the electronic excited state lifetime of Img to be longer than that of lut and, in this way, account for the reduced photo-stability of Img.

Stabilization of the transition state of the formation of the flavonoxyl radical of lut by intramolecular $\mathrm{H}$-bond could explain the difference between the rates of photodecomposition of lut and ldg. The flavonoxyl radical of quercetin - a lut-like flavonoid having an additional hydroxyl group at C-3 - is formed through high-energy irradiation (radiolysis) [33]. Flavonoxyl 
radicals are formed under milder conditions too, since phenoxyl radicals are formed via irradiation of phenols in the UV-vis range of the electromagnetic spectrum [34]. Kozlowski et al. calculated the unpaired electron of the radical species to be delocalized, with $\mathrm{C}-2$ bearing high spin density if the radical was to be formed at the 3-OH group [33]. Those authors expect molecular oxygen to react with the flavonoxyl radical of quercetin precisely at C-2, before the formed peroxyl radical reacts as the decomposition of the flavonoid continues. Thus, the formation of the flavonoxyl radical is expected to be the first step of the photo-oxidative degradation-referred to as photodecomposition throughout this chapter-of lut and its glycosyl conjugates too.

In flavones that have a catechol group, the energy of the flavonoxyl radical is lowered by intramolecular $\mathrm{H}$-bond involving the $\mathrm{O}$-atom bearing the unpaired electron and the neighbouring hydroxyl group [33,35], [10] (chapter 5). This is why the flavonoxyl radical of lut is expected to be formed at the catechol group; with that formed at the 4'-OH group having been calculated to be the most stable [35]. The H-bond at 3'-OH/4'-O may stabilize not only the radical, but also the transition state of its formation. Such a stabilization could not take place in the case of Idg since it has an $O$-glucose group instead of a hydroxyl group at C-3'. A lower energy of the transition state of the formation of the flavonoxyl radical of lut would cause the activation energy barrier for the formation of the radical of lut to be smaller than that for the formation of the radical of $\mathbf{l d g}$, resulting in a faster formation of the radical of lut.

The rate of photodecomposition of $\mathbf{l d g}$ in presence of $\mathrm{Al}^{3+}$ in aerated methanol-water 8:2 $(\mathrm{v} / \mathrm{v})$ solution was also obtained through the set of the experiments discussed in section 4.4.1.1; thus, with light above $300 \mathrm{~nm}$. As seen in Table 4.2, ldg engaged in complex formation with $\mathrm{Al}^{3+}\left(\mathbf{I d g}_{0.05}-\mathrm{Al}_{0.05}\right)$ photodecomposed at least $2 \times$ faster than free $\mathbf{l d g}$. By analogy to lut, the main species in solution at a $\mathbf{l d g}-\mathrm{Al}^{3+} 1: 1$ ratio are expected to be the $\mathbf{l d g}-\mathrm{Al}^{3+} 2: 1$ complex and free ldg (Fig. 4.3 and ensuing discussion). As previously discussed, lut in presence of $\mathrm{Al}^{3+}$ also photodecomposes faster than free lut. Similarly to lut, the faster photodecomposition of ldg in presence of $\mathrm{Al}^{3+}$ could have resulted from a smaller possibility of accelerated $\mathrm{S}_{1} \rightarrow \mathrm{S}_{0}$ transition via $\mathrm{IC}$ due to diminished charge transfer from the B-ring towards rings $\mathrm{C}$ and $\mathrm{A}$, diminished possibility of ESPT, or both of them being diminished. This possible change in the process of the $\mathrm{S}_{1} \rightarrow \mathrm{S}_{0}$ transition of part of the Idg molecules could have led to their electronic excited state lifetime being longer, accounting for the decreased photo-stability of $\mathbf{l d g}$ in presence of $\mathrm{Al}^{3+}$.

\subsubsection{Colours of alum-mordanted wool dyed with lut as a function of the glycosylation pattern of the compound}

Two experiments were carried out in which $\mathrm{Al}^{3+}$-mordanted wool was dyed with different dyes. In one of them, alum-mordanted wool was dyed at $80^{\circ} \mathrm{C}$ for $15 \mathrm{~min}$. The percentages of leftover flavones in the dyeing baths were calculated after analysis by RP-HPLC-UV. This experiment consists of the following two parts:

- Wool was dyed with the individual flavones. In each case, a piece of mordanted wool was dyed with lut, lmg, or ldg;

- A piece of mordanted wool was dyed with an extract of weld (thus, with all three flavones simultaneously).

In the other experiment — not further described — wool mordanted with aluminium sulphate and tartaric acid was dyed at $100{ }^{\circ} \mathrm{C}$ for $1 \mathrm{~h}$ with the individual flavones. Thus, also in this case, pieces of mordanted wool were dyed with lut, Img, or ldg. Then, the percentages of leftover 
flavones in the dyeing baths and rinsing waters were calculated with RP-HPLC-UV calibration curves after their y-intercepts had been set to zero. A picture of the dyed pieces of wool of the first experiment is seen in Figure 4.6, and the percentages of leftover flavones after dyeing from both experiments are listed in Table 4.6.

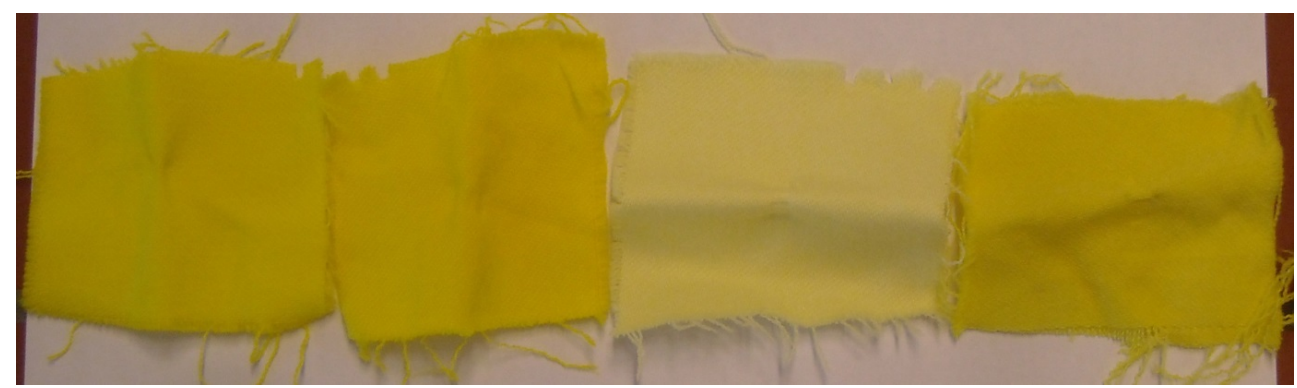

Figure 4.6. Pieces of alum-mordanted wool dyed with the individual flavones - lut, lmg, or Idg — and with an extract of weld (from left to right).

Table 4.6. Leftover flavones after dyeing $\mathrm{Al}^{3+}$-mordanted wool with lut, lmg, ldg, or an extract of weld (each case, $\mathrm{n}=1)$.

\begin{tabular}{|c|c|c|c|c|}
\hline \multirow{2}{*}{ Dye } & \multirow{2}{*}{ Dyeing conditions } & \multicolumn{3}{|c|}{ Leftover flavones in dyeing baths $(\%)^{a}$} \\
\hline & & Lut & Lmg & Ldg \\
\hline Lut, Img, or Idg & $80^{\circ} \mathrm{C}, 15 \min ^{\mathrm{b}}$ & 5 & 16 & 63 \\
\hline Extract of weld & $80^{\circ} \mathrm{C}, 15 \min ^{\mathrm{b}}$ & 6 & 18 & 66 \\
\hline Lut, Img, or Idg & $100^{\circ} \mathrm{C}, 1 \mathrm{~h}$ & 5 & 13 & 58 \\
\hline
\end{tabular}

a In dyeing baths and rinsing waters, in experiment in which dyeing processes were carried out at $100{ }^{\circ} \mathrm{C}$ for $1 \mathrm{~h}$.

${ }^{\mathrm{b}}$ Dyeing processes of samples of Fig. 4.6.

The colours of alum-mordanted wool dyed with lut or Img seem to be similar, but different from those in which either an extract of weld or Idg are used (Fig. 4.6 and Table SI C.6). The wool dyed with the latter two dyes was much less colourful — chroma 60 and 30, respectivelythan that dyed with either lut or Img (chroma 80-85).

In the case of Idg, this is possibly due to the quantity of flavone binding to the wool. Table 4.6 lists the percentages of leftover flavones in the dyeing baths. The uptake of lut, Img, and Idg by the $\mathrm{Al}^{3+}$-mordanted wool is estimated from them. The data suggest lut to be extensively taken up by the mordanted wool, as well as most lmg, but this to be the case only for one-third of Idg molecules. The lack of a free catechol group could be a reason for a limited binding of Idg to the mordanted wool. This could also be due to steric hindrance-bulkiness of the glucose moiety-and solubility in the dyeing bath (Idg is more hydrophilic than both Img and lut), 
equivalently to suggestion by Mouri et al. when reporting a preferential binding of flavonol aglycones to silk relative to that of the glycosides [36].

\subsection{Conclusion}

The photo-stability of lut in solution - polar protic solvent - and the light-fastness of the colour of weld-dyed wool decrease with increasing $\left[\mathrm{Al}^{3+}\right]$. Thus, the lower the $\left[\mathrm{Al}^{3+}\right]$ used for mordanting the wool, the more light-fast its colour. Lowering the $\left[\mathrm{Al}^{3+}\right]$ appears to have no negative influence on the wash-fastness of the colour. As the gain in light-fastness by the use of low $\left[\mathrm{Al}^{3+}\right]$ to premordant the wool is limited, however, this does not seem to be a way to meet today's requirement of light-fastness of the colours of dyed textiles by itself. Nevertheless, it may be part of a broader strategy to address the need for increased light-fastness of the colour of wool dyed with weld. Implementation of this approach by dyers is expected to clarify whether it results in benefits for textile dyeing practice. On one hand, lowering the $\left[\mathrm{Al}^{3+}\right]$ to mordant the wool has the drawback of limiting the obtainable yellow colour, as its saturation increases with increasing $\left[\mathrm{Al}^{3+}\right]$. On the other hand, reduction of the quantity of mordant should increase the needed environmental friendliness of the dyeing of textiles with natural dyes, and have financial benefits.

\subsection{Supplementary material}

Appendix C contains information supplementary to that in this chapter. Sections material and methods, results and discussion, author contributions and references are available. Reference is made in this chapter only to part of the information in appendix C. Thus, readers are referred to it for further details on the work.

\subsection{References}

[1] Duffield PA. Dyeing wool with acid and mordant dyes. In: Lewis DM, Rippon JA, editors. The coloration of wool and other keratin fibres, John Wiley \& Sons/Society of Dyers and Colourists: Electronic format; 2013, p. 205-28.

[2] Crews PC. The influence of mordant on the lightfastness of yellow natural dyes. J Am Inst Conserv 1982; 21(2): 43-58.

[3] Deng H, van Berkel GJ. Electrospray mass spectrometry and UV/visible spectrophotometry studies of aluminum(III)-flavonoid complexes. J Mass Spectrom 1998; 33: 1080-7.

[4] Cornard JP, Merlin JC. Comparison of the chelating power of hydroxyflavones. J Mol Struc 2003; 651-653: 381-7.

[5] Favaro G, Clementi C, Romani A, Vickackaite V. Acidichromism and ionochromism of luteolin and apigenin, the main components of the naturally occurring yellow weld: a spectrophotometric and fluorimetric study. J Fluoresc 2007; 17(6): 707-14.

[6] Smith GJ, Thomsen SJ, Markham KR, Andary C, Cardon D. The photostabilities of naturally occurring 5-hydroxyflavones, flavonols, their glycosides and their aluminium complexes. J Photochem Photobiol, A 2000; 136(1-2): 87-91. 
[7] Malathy R, Rajendran M. Study on photochemically and chemically generated singlet oxygen quenching rate constant of quercetin. Int J Green Herb Chem 2013; 2(3): 631-40.

[8] Heim KE, Tagliaferro AR, Bobilya DJ. Flavonoid antioxidants: chemistry, metabolism and structure-activity relationships. J Nutr Biochem 2002; 13: 572-84.

[9] Clayden J, Greeves N, Warren S. Organic chemistry. 2nd ed. Oxford University Press: New York; 2012.

[10] Larson RA. Naturally ocurring antioxidants. 1st ed. Lewis Publishers: Boca Raton/New York; 1997.

[11] Zhang X, Cardon D, Cabrera JL, Laursen R. The role of glycosides in the light-stabilization of 3-hydroxyflavone (flavonol) dyes as revealed by HPLC. Microchim Acta 2010; 169(3-4): 327-34.

[12] Fanning JC. The chemical reduction of nitrate in aqueous solution. Coord Chem Rev 2000; 199(1): 159-79.

[13] Villela A, van der Klift EJC, Mattheussens ESGM, Derksen GCH, Zuilhof H, van Beek TA. Fast chromatographic separation for the quantitation of the main flavone dyes in Reseda luteola (weld). J Chromatogr A 2011; 1218(47): 8544-50.

[14] Villela A, Derksen GCH, van Beek TA. Analysis of a natural yellow dye: an experiment for analytical organic chemistry. J Chem Educ 2014; 91(4): 566-9.

[15] Goodman TM. International standards for colour. In: Best J, editor. Colour design theories and applications, Woodhead Publishing/The Textile Institute: Oxford/Cambridge/etc.; 2012, p. 177-218.

[16] Bechtold T, Mahmud-Ali A, Mussak R. Natural dyes from food processing wastes. In: Waldron $\mathrm{K}$, editor. Handbook of waste management and co-product recovery in food processing, CRC Press/Woodhead Publishing: Boca Raton/Boston/etc.; 2007, p. 502-33.

[17] Gilbert A, Baggott J. Essentials of molecular photochemistry. 1st ed. Blackwell Science: Oxford; 1991.

[18] Amat A, Clementi C, De Angelis F, Sgamellotti A, Fantacci S. Absorption and emission of the apigenin and luteolin flavonoids: a TDDFT investigation. J Phys Chem A 2009; 113(52): 15118-26.

[19] Bondarev SL, Knyukshto VN, Tikhomirov SA, Buganov OV. Mechanism for highly efficient non-radiative deactivation of electronic excitation in rutin. J Appl Spectrosc 2016; 82(6): 929-35.

[20] Smail K, Tchouar N, Barj M, Marekha B, Idrissi A. Luteolin organic solvent interactions. A molecular dynamics simulation analysis. J Mol Liq 2015; 212: 503-8.

[21] Smith GJ, Markham RK. Tautomerism of flavonol glucosides: relevance to plant UV protection and flower color. J Photochem Photobiol, A 1998; 118(2): 99-105.

[22] Huvaere K, Skibsted LH. Flavonoids protecting food and beverages against light. J Sci Food Agr 2015; 95(1): 20-35. 
[23] Amat A, Clementi C, Miliani C, Romani A, Sgamellotti A, Fantacci S. Complexation of apigenin and luteolin in weld lake: a DFT/TDDFT investigation. Phys Chem Chem Phys 2010; 12(25): 6672-84.

[24] Hanson AR. What is colour? In: Best J, editor. Colour design - theories and applications, Woodhead Publishing/The Textile Institute: Oxford/Cambridge/etc.; 2012, p. 3-23.

[25] Vinod KN, Puttaswamy, Gowda KN, Sudhakar R. Extraction, identification and adsorption-kinetic studies of a natural color component from G. sepium. Nat Sci 2010; 2(5): 469-75.

[26] Kanazawa H, Mori J. Relation between dye uptake and K/S value in the dyeing of natural fiber. Sci Rep Fukushima Univ 1995; 57: 17-24.

[27] Vankar PS, Shanker R, Wijayapala S. Dyeing of cotton, wool and silk with extract of Allium cepa. Pigm Resin Technol 2009; 38(4): 242-7.

[28] Rippon JA. The structure of wool. In: Lewis DM, Rippon JA, editors. The coloration of wool and other keratin fibres, John Wiley \& Sons/Society of Dyers and Colourists: Electronic format; 2013, p. 1-42.

[29] Rippon JA. The chemical and physical basis for wool dyeing. In: Lewis DM, Rippon JA, editors. The coloration of wool and other keratin fibres, John Wiley \& Sons/Society of Dyers and Colourists: Electronic format; 2013, p. 43-74.

[30] Cristea D, Vilarem G. Improving light fastness of natural dyes on cotton yarn. Dyes Pigments 2006; 70(3): 238-45.

[31] Giles CH. The fading of colouring matters. J Appl Chem 1965; 15: 541-50.

[32] Ramešová Š, Sokolová R, Degano I, Bulíčková J, Žabka J, Gál M. On the stability of the bioactive flavonoids quercetin and luteolin under oxygen-free conditions. Anal Bioanal Chem 2012; 402(2): 975-82.

[33] Kozlowski D, Marsal P, Steel M, Mokrini R, Duroux JL, Lazzaroni R, Trouillas P. Theoretical investigation of the formation of a new series of antioxidant depsides from the radiolysis of flavonoid compounds. Radiat Res 2007; 168(2): 243-52.

[34] Rayne S, Forest K, Friesen KJ. Mechanistic aspects regarding the direct aqueous environmental photochemistry of phenol and its simple halogenated derivatives. A review. Environ Int 2009; 35(2): 425-37.

[35] Leopoldini M, Russo N, Toscano M. The molecular basis of working mechanism of natural polyphenolic antioxidants. Food Chem 2011; 125(2): 288-306.

[36] Mouri C, Mozaffarian V, Zhang X, Laursen R. Characterization of flavonols in plants used for textile dyeing and the significance of flavonol conjugates. Dyes Pigments 2014; 100: 13541. 


\section{Chapter 5}

\section{Analysis of a natural dye: an experiment for analytical organic chemistry}

The content of this chapter is largely that of the following paper:

Villela A, Derksen GCH, van Beek TA. Analysis of a natural yellow dye: an experiment for analytical organic chemistry. J Chem Educ 2014; 91(4): 566-9. 
This experiment exposes second-year undergraduate students taking a course in analytical organic chemistry to high performance liquid chromatography (HPLC) and quantitative analysis using the internal standard method. This is accomplished using the real-world application of natural dyes for textiles. The extracted flavonoids of the plant weld are responsible for the yellow colour of the dyed wool. Dried and ground weld is extracted for dyeing wool and quantifying the plant's three main flavonoids. The students also mimic the work of chemists investigating historical textiles by carrying out a small scale extraction of the dyed wool. Twenty-one students carried out the experiment and their samples were analysed using either a traditional $5 \mu \mathrm{m}$-particle size HPLC column or a modern $1.8 \mu \mathrm{m}$-particle size ultrahigh-pressure liquid chromatography (UHPLC) column mounted in a conventional HPLC system. 


\subsection{Introduction}

Undergraduate students of molecular life sciences and biotechnology programs of Wageningen University take the course Analytical Methods in Organic Chemistry (AMOC) at the beginning of the second year. AMOC has both theoretical and practical components. Its practical component is divided into spectroscopy and chromatography. During the latter, students perform experiments individually and become acquainted with a range of techniques used for the analysis of organic compounds. The experiment reported here was used in 2011, 2012, and 2013.

\subsection{Description of the experiment}

\subsubsection{Introduction}

The compounds of weld that are responsible for the yellow colour of dyed alum-treated wool belong to the class of flavonoids [1]. The three main compounds are 2-(3,4-dihydroxyphenyl)5,7-dihydroxy-4H-1-benzopyran-4-one (luteolin, lut), lut-7-O-glucoside (lut monoglucoside, Img), and lut-7,3'-O-diglucoside (lut diglucoside, ldg) [2, 3]. The compound used as internal standard (i.s.) for their quantitation in weld is 5,7-dihydroxy-2-phenyl-4H-1-benzopyran-4-one (chrysin) [4]. The structures of these four compounds are depicted in Figure 5.1.
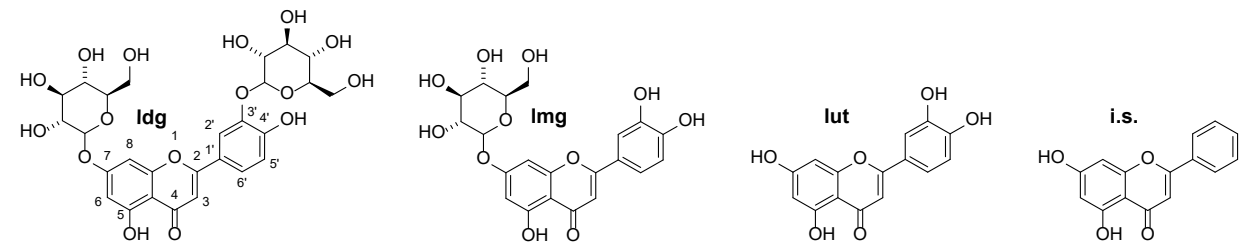

Figure 5.1. Structures of the three main flavonoids of weld and the compound used as internal standard (i.s.) for their quantitation in weld. Their identities are luteolin-7,3'-O-diglucoside (luteolin diglucoside, Idg), luteolin-7-O-glucoside (luteolin monoglucoside, Img), luteolin (lut), and chrysin (i.s.).

Since the first use of the experiment, the protocol of the experiment has undergone modifications. Both student and teaching assistants' feedback contributed to this. Students who carried out the experiment in 2012 and 2013 were busy with its practical part for $\sim 4 \mathrm{~h}$. An updated version of the protocol of the experiment handed out to students is available in Appendix D. 


\subsubsection{Practical part}

The students carry out two extractions of dried and ground weld simultaneously: One extract is used for dyeing wool and the other is used for quantifying the plant's three main flavonoids. For the wool dyeing, $1.5 \mathrm{~g}$ of the dried and ground weld is placed in an Erlenmeyer flask with $30 \mathrm{~mL}$ of $96 \%$ ethanol-water 3:1, and stoppered. The mixture is sonicated for $10 \mathrm{~min}$. After filtration through a folded filter paper to a round-bottom flask, the $\sim 20 \mathrm{~mL}$ of $96 \%$ alcohol is removed by a rotatory evaporator. The dyeing bath is prepared by transferring the alcohol-free extract from the round-bottom flask to a $150 \mathrm{~mL}$ beaker using $4 \times 15 \mathrm{~mL}$ portions of deionized water. To quantify the plant's three main flavonoids, $200 \mathrm{mg}$ of the dried and ground weld is placed in a $50 \mathrm{~mL}$ Erlenmeyer flask and is extracted and sonicated as described above, except for using only $20 \mathrm{~mL}$ of $96 \%$ ethanol-water 3:1. After sonication, a magnetic stir bar is added to the Erlenmeyer flask. This is followed by addition of $5.00 \mathrm{~mL}$ of a methanolic solution of the i.s. of known concentration using a volumetric pipette (see Appendix D for the possibility of replacing methanol by $96 \%$ alcohol), and 10 min-stirring. After filtration of the solution via a syringe filter, the sample is ready for HPLC analysis.

The students proceed by soaking four ready-made $\sim 5 \times 5 \mathrm{~cm}$ pieces of wool (pretreated with aluminum potassium sulfate dodecahydrate, alum) in water at $50{ }^{\circ} \mathrm{C}$. The dyeing bath is heated to $80^{\circ} \mathrm{C}$, and the four pieces of wool are added to it. The dyeing step lasts $15 \mathrm{~min}$, after which the dyed wool is rinsed with water. A small piece of a single thread is removed from the dyed wool and the dye is extracted by placing it in $300 \mu \mathrm{L}$ of methanol-water-methanoic acid (formic acid) 80:15:5 in a microcentrifuge tube of $2 \mathrm{~mL}$, and heating via a water bath at $60{ }^{\circ} \mathrm{C}$ for $30 \mathrm{~min}$. Sample is ready for HPLC analysis after filtration of the cooled solution via a syringe filter. The samples from both parts of the experiment are given to one of the teaching assistants so that they can be analysed. This is done by reversed phase (RP)-HPLC-UV at 345 $\mathrm{nm}$ in either $80 \mathrm{~min}$ at $40{ }^{\circ} \mathrm{C}$ (Alltima $250 \times 4.6 \mathrm{~mm} \mathrm{C18} 5 \mu \mathrm{m}$-particle size HPLC column) or $5 \mathrm{~min}$ at $35^{\circ} \mathrm{C}$ [Eclipse XDB-C18 $50 \times 3.0 \mathrm{~mm} 1.8 \mu \mathrm{m}$-particle size ultrahigh-pressure liquid chromatography (UHPLC) column]. In both cases columns are mounted in conventional HPLC systems. The gradient elution separation is carried out with an aqueous buffer $\mathrm{pH} 3$ and either methanol (HPLC column) or methyl cyanide (acetonitrile) (UHPLC column). The chromatograms with the data needed are given to the students for data processing. Although this procedure was typically followed, involvement of the students in running the analyses would be preferable; e.g., by accompanying the teaching assistant in preparing and starting the sequence of analyses and receiving a brief explanation of HPLC. Even though all students participate in a demonstration on HPLC at the beginning of the chromatography part of AMOC, the additional exposure to the instrument could be beneficial to the students' learning. In Appendix D, different parts of the protocol are discussed and material and methods for the preparation of the experiment are detailed. 


\subsubsection{Data processing}

With the chromatogram of the weld sample containing peak areas and retention times, the students start by assigning the peaks corresponding to ldg, lmg, lut, and i.s. on the basis of the retention times. Then, using the equation that relates peak area to the quantity of compound in a sample and predetermined relative response factors (RRFs), the students calculate the concentration of the three main flavonoids in the weld sample. This is done using the following equation:

$\mathrm{w}_{\mathrm{x}}=\frac{\mathrm{A}_{\mathrm{x}}}{\mathrm{A}_{\text {i.s. }}} \cdot \frac{\mathrm{w}_{\text {i.s. }}}{\mathrm{RRF}}$

in which $\mathrm{A}_{\mathrm{x}}$ is the peak area of compound $x$; $\mathrm{A}_{\text {i.s. }}$ is the peak area of i.s.; Wi.s. is the weight of i.s.; RRF is the relative response factor; and $\mathrm{w}_{\mathrm{x}}$ is the weight of compound $x$. Because the peak areas are obtained from the chromatogram, the quantity (weight) of added i.s. is known, and the RRFs are given, students can calculate the quantity of compound $x$ (ldg, Img, or lut) in the sample. Then, the concentration of compound $x$ in the weld sample can be calculated.

In addition, mimicking the work of chemists investigating historical textiles, the students identify the dye source of the freshly dyed piece of wool. This is done by assigning the peaks corresponding to Idg, lmg, and lut using chromatograms and UV-vis absorption spectra of authentic standards. They also compare the chromatogram of the dyed wool's extract sample with that of the weld's extract sample.

The work of the students is concluded by answering a few questions that include separation principles of RP-HPLC analysis and the relation between structure and UV (345 nm) absorbance of weld's three main flavonoids. Solutions to the assignments and answers to the questions of the protocol handed out to students, including derivation of the equation above, are available in Appendix D.

\subsection{Hazards}

Basic organic chemistry laboratory safety procedures [5] should be observed when carrying out the experiment. Erlenmeyer flasks should not be clamped during sonication, as they may break. There is the risk of implosion (glass breakage) during operation of rotatory evaporators. $96 \%$ alcohol is flammable [6]. Exposure to methanol (flammable, toxic) and formic acid (corrosive) must be minimized [6]. Sample filtration via a syringe filter has the risk of liquid spillage due to an improper connection between both parts. The microcentrifuge tube containing the methanol-water-formic acid extract should be cooled prior to opening because of the pressure build-up during the heating step. The support team should pay special attention:

- during the preparation of the methanol-water-formic acid solution and HPLC solvent A (aqueous buffer $\mathrm{pH} 3$ ) because of handling of formic acid, when the use of protective gloves is recommended [7];

- so that vapours originating from HPLC solvent B (methanol or acetonitrile, toxic) bottle and HPLC waste container are properly exhausted [6]. 


\subsection{Results and discussion}

In 2011, 12 students carried out the experiment. Their samples were analysed using a traditional $25 \mathrm{~cm}$-long, $5 \mu \mathrm{m}$-particle size RP-HPLC column. Five and four students carried out the experiment in 2012 and 2013, respectively. ${ }^{1}$ Their samples were analysed using a modern 5 cm-long, $1.8 \mu \mathrm{m}$-particle size RP-UHPLC column mounted in a conventional HPLC system. Results obtained by a student in 2011 and another student in 2012 are depicted in Figure 5.2. The peaks of the main compounds in the chromatograms are assigned. The compounds responsible for the minor peaks also belong to the class of flavonoids. Their identities are listed in Appendix D. The signal-to-noise ratios of the chromatograms of the dyed wool's extract samples are much smaller than those of the chromatograms of the weld's extract samples because only small pieces of single threads of dyed wool are analysed, resulting in small quantities of flavonoids in the samples. This mimics of the work of chemists investigating historical textiles, in which it is crucial to minimize damage to artifacts.

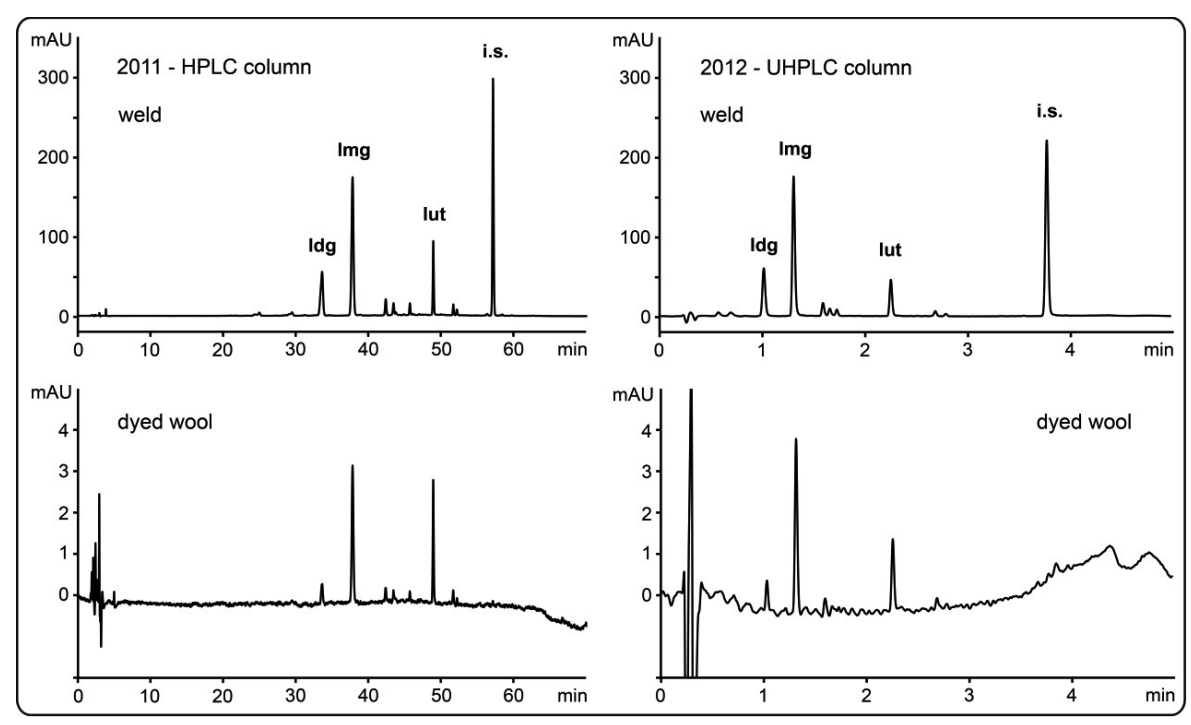

Figure 5.2. Chromatograms of the extracts of weld and dyed wool prepared by two students. All cases: $345 \mathrm{~nm}$ traces. Peaks of the main compounds are assigned.

In 2011, 10 students submitted a report of the experiment. In 2012, this was done by the five students. On the basis of those reports, it was observed that nearly all students understood how separation by reversed phase chromatography works. Furthermore, half of the students knew how to use the internal standard method for quantitative analysis, and one-third of them had

\footnotetext{
${ }^{1}$ In addition to the 21 students who carried out the experiment in 2011-2013, the experiment was also carried out by 10 students in 2014.
} 
difficulty with it. Additional observations on the students' learning regarding the didactic aims and background of the experiment are described in Appendix D.

\subsection{Summary}

Students are exposed to analysis by HPLC and quantitative analysis using the internal standard method by carrying out this experiment. This is accomplished using the real-world application of natural dyes for textiles, which is a current topic in chemistry.

\subsection{Supplementary material}

Appendix D contains information supplementary to that in this chapter. The following material is available:

- Updated version of the protocol of the experiment handed out to students;

- Discussion of different parts of the protocol;

- Material and methods for the preparation of the experiment;

- Instructor notes;

- Additional observations on the students' learning based on 2011 and 2012 reports;

- Updated version of the inventory of specialized material handled by students;

- Example data sets of the HPLC analysis of weld sample.

\subsection{References}

[1] Cardon D. Natural dyes - sources, tradition, technology and science. 1st ed. Archetype Publications: London; 2007.

[2] Cristea D, Bareau I, Vilarem G. Identification and quantitative HPLC analysis of the main flavonoids present in weld (Reseda luteola L.). Dyes Pigments 2003; 57(3): 267-72.

[3] Marques R, Sousa MM, Oliveira MC, Melo MJ. Characterization of weld (Reseda luteola L.) and spurge flax (Daphne gnidium L.) by high-performance liquid chromatography-diode array detection-mass spectrometry in Arraiolos historical textiles. J Chromatogr A 2009; 1216(9): 1395-402.

[4] Villela A, van der Klift EJC, Mattheussens ESGM, Derksen GCH, Zuilhof H, van Beek TA. Fast chromatographic separation for the quantitation of the main flavone dyes in Reseda luteola (weld). J Chromatogr A 2011; 1218(47): 8544-50.

[5] Vogel AI. Vogel's textbook of practical organic chemistry. 5th ed [revised by Furniss BS, Hannaford AJ, Smith PWG, Tatchell AR]. Longman Scientific \& Technical: Essex; 1989.

[6] O’Neil MJ, Smith A, Heckelman PE, Obenchain Jr. JR, Gallipeau JAR, D'Arecca MA, Budavari S, editors. The merck index - an encyclopedia of chemicals, drugs and biologicals. 13th ed. Merck and Co.: Whitehouse Station; 2001.

[7] Safety data sheet of formic acid - revision 08-Jun-2012, Acros Organics: http://www.acros.com; 2012 [accessed August 2013]. 
Chapter 6

General discussion 


\subsection{Introduction}

The work reported in this thesis describes concepts and analytical chemistry methods relevant for the use of natural dyes for textiles. The contents of chapters $\mathbf{2 , 3}$, and $\mathbf{4}$ refer to different aspects of textile dyeing technology. They all relate to the use of the dyestuff of weld (Reseda luteola L.). The analytical method for the analysis of the main colouring compounds of the plant-described in chapter $\mathbf{2}$-was applied to research (chapter 4) and education in chemistry (chapter 5). In this chapter, the works presented in chapters $\mathbf{2}-\mathbf{5}$ are summarised, elements of what they report are discussed, and future prospects of dyeing textiles with natural dyes are briefly elaborated upon.

\subsection{Chapter 2}

A validated RP-HPLC-UV method for the quantitation of ldg, Img, and lut via internal standardisation in samples of weld is described in chapter 2 . The method is simple, requiring very little manpower input per sample. With the exception of the 15-stirring point magnetic stirrer - that, less conveniently, could be replaced by individual magnetic stirrers - only standard laboratory equipment is needed. The analytical method proved fit-for-purpose based on its validation in terms of extraction efficiency, stability and losses of the compounds, accuracy, precision, and sensitivity.

As the method was developed using only one batch of weld $(R$. luteola $\mathrm{H})$ plant material, it has the potential drawback of not being suitable for analysing samples of weld having a concentration of the three flavones much lower or much higher than that of $R$. luteola $\mathrm{H}$. The industrial partner of the project analysed $120+$ batches of weld plant material. No samples were encountered with such low concentrations of Idg, Img, and lut that they could not be analysed using the method as described in chapter $\mathbf{2}$ (that is, samples leading to injected quantities smaller than the smallest injected quantities of the calibration curves). However, there were samples having concentrations of the flavones that were too high. For the analyses of such samples, the industrial partner of the project modified the method by simply weighing $100 \mathrm{mg}$ - instead of $200 \mathrm{mg}$ - of sample. Such an adaptation of the method is expected to lead to:

- no major change in extraction efficiency even with the solvent-sample ratio increasing to 200 , as it is already high $(95 \%)$ with a solvent-sample ratio of 100 ;

- no change in accuracy; neither in terms of stability of the flavones or losses due to adsorption on glass and filters (the relative recovery experiments were also carried out using $100 \mathrm{mg}$ of plant material), or in absolute terms (as there is even less plant material to which the flavones could bind);

- no major loss of precision as, if a $0.1 \mathrm{mg}$-least division balance is used, the weighing error remains $<1 \%$.

The validity of this approach would need testing. This could be done, for example, by comparing the results of the analyses of a small number of replicates of 100 and $200 \mathrm{mg}$ of a few samples.

After the publication of a validated RP-HPLC-DAD method for the quantitation of Idg, Img, apigenin-7-O-glucoside, luteolin-4'-O-glucoside, lut and apigenin in samples of weld by Gaspar et al. [1], the chromatographic separation using a $5 \mu \mathrm{m}$-particle size RP-HPLC column was speeded up by using a short sub- $2 \mu \mathrm{m}$-particle size (RP-UHPLC) column. This 
was done while still using a conventional HPLC system, after minor hardware adaptation. The method using the UHPLC column proved fit-for-purpose through comparison of accuracy and precision of the quantitation of Idg, Img, and lut in $R$. luteola $\mathrm{H}$ with those achieved by using the HPLC column. Large gains in analysis time and eluent consumption were obtained. Thus, the use of short UHPLC columns on conventional HPLC systems is an economical way of modernising HPLC-based analyses.

\subsection{Chapter 3}

An analytical method for the comparison of the content of porphyrin ring-containing pigments - chlorophylls (chls) and their structurally similar breakdown products - in different samples of weld is described in chapter 3. The method:

- uses ethanol as a mild, non-toxic extraction solvent (that is not selective regarding the "types" of chls and plant tissues being extracted);

- covers the entire range of occurring concentrations;

- displays acceptable precision;

- is simple.

Nevertheless, the manpower input required by the method is not low. One working day was needed for the analyses and data processing of 40 samples. It is expected, however, that more samples can be analysed in the same time through implementation of the following:

- weighing accurately $\sim 125 \mathrm{mg}$ instead of (125.0 \pm 0.9$) \mathrm{mg}$, with a correction factor (125 divided by amount weighed) being used in the calculations. This would speed up the weighing of the samples;

- having 60 centrifuge tubes available instead of 20. This would speed up the analysis of the samples, as no tubes would need to be washed during the data-acquisition day.

Footnote 1 of chapter 3 relates to a limitation of the method. Comparison of the content of porphyrin ring-containing pigments in samples of weld having different chls/chlorophyllidesto-"pheopigments" ratios is hampered, as the optical molar absorption coefficients of pheophytins and pheophorbides are $\sim 40 \%$ smaller than those of the corresponding chls and chlorophyllides $[2,3]$. Possibly, this can be fixed by conversion of chls and chlorophyllides to the corresponding "pheopigments" through addition of one drop of a $25 \%$ aqueous $\mathrm{HCl}$ solution to $5 \mathrm{~mL}$ of an extract of the pigments, as outlined by Lichtenthaler [4]. The conversion is expected to be rather fast, as chls are generally fully converted to pheophytins in $\leq 1 \mathrm{~min}$ [4]. Thus, one could test whether the same procedure described in chapter 3 can be used with the extraction solvent being $\mathrm{HCl}$-acidified ethanol instead of absolute ethanol.

One could test the usefulness of the method reported in chapter 3 for the intended purposes and the hypothesis that chlorophylls $a$ and $b$ are the sources of the greenish hue that accompanies the yellow colour after dyeing alum pre-treated textiles with weld. This could be done by seeing whether there is a relation between the optical absorbance values - due to chls and their structurally similar breakdown products - of extracts of samples of weld and the chroma (saturation) of the greenish hue of alum-mordanted wool dyed with the same plant materials. However, although many samples would be needed, the presence of such a relation 
would only be suggestive. This is because the chroma of the greenish hue could be due to something else. For example, it could be correlated to the total content of flavonoids.

\subsection{Chapter 4}

The effect of different concentrations of aluminium ion on the photo-stability of the dye of weld, and the relative photo-stability of lut, $\mathbf{l m g}$ and $\mathbf{l d g}$ in solution are reported in chapter 4 . Results of the colours obtained by dyeing alum-mordanted wool with the three flavones are also presented.

The observed order of photo-stability of the flavones in solution was ldg $>>$ lut $>$ Img. However, alum-mordanted wool dyed with Idg (or with an extract of weld) was much less colourful than that dyed with either lut or Img. At least in part, this could be due to a reduced uptake of $\mathbf{l d g}$ by $\mathrm{Al}^{3+}$-mordanted wool relative to that of lut or Img. These observations should support answering the question whether it is preferable for the endogenous glycosidase of weld to be inactivated before extraction of the flavonoids in order to obtain the most photostable dye, but are not conclusive. A dye containing flavonoid glycosides and aglycones is obtained if this glycosidase is inactivated before extracting the flavonoids of the plant. Conversely, a dye containing only the aglycones is obtained if the enzyme is not inactivated before the extraction process. Comparison of the light-fastness of the colour of $\mathrm{Al}^{3+}$ mordanted wool dyed with a glycosidase-hydrolysed extract of weld with that of $\mathrm{Al}^{3+}$ mordanted wool dyed with an extract in which the glycosidase has been inactivated before extracting the flavonoids is expected to be decisive.

The light-fastness of the colour of weld-dyed wool decreased with increasing $\left[\mathrm{Al}^{3+}\right]$ used for premordanting the wool. As the gain in light-fastness by the use of low $\left[\mathrm{Al}^{3+}\right.$ ] was limited, this cannot be a way to meet today's requirement of light-fastness of the colours of dyed textiles by itself. In chapter $\mathbf{4}$, reference is made to a broader strategy of which using low $\left[\mathrm{Al}^{3+}\right]$ for premordanting the wool is but one part in order to address the need for increased light-fastness of the colour of wool dyed with weld. Such a strategy-largely based on information in different publications [5-8] — could also include:

- Using slightly more dyestuff than one would normally use;

- Using the preferable approach regarding the use of a dyestuff that is flavonoid glycoside-rich or flavonoid glycoside-poor. This relates to the optional inactivation of the endogenous glycosidase before extracting the flavonoids of weld;

- Adding antioxidants - such as gallic acid - to the dyed textile, preferably, with the antioxidants being obtained from agricultural/food processing residues (as an example, gallic acid and many other polyhydroxyphenols can be obtained from pistachio green hull). ${ }^{1}$

\footnotetext{
${ }^{1}$ The antioxidants could also be generated through the photodecomposition of part of the components of the dyestuff. For example, $\mathrm{Al}^{3+}$-mordanted wool could be dyed with both outer scales of onions (onion skins) and weld. This could lead to a characteristic change in the yellow colour over time as, upon exposition to light, textiles dyed with onion skins appear to fade $[9,10]$ and $\mathrm{Al}^{3+}$-mordanted wool dyed with weld darkens and becomes redder [11] (Fig. 6). Lightening of the fabric would be expected to precede its darkening/reddening since the flavonol quercetin is the main flavonoid aglycone of onion skins $\{[10,12]$ and data not shown $\}$ and quercetin appears to be less stable upon exposition to light than luteolin, the main flavonoid aglycone of weld [9]. The photo-oxidative
} 
The use of such a strategy limits the range of colours that can be obtained upon dyeing textiles with weld. However, each of its elements could lead to a small gain in light-fastness of the colour. Combined, such gains might be a way of meeting today's requirement of the property.

\subsection{Chapter 5}

Chapter 5 reports a work on education in chemistry at undergraduate level. Students of molecular life sciences and biotechnology of Wageningen University had the opportunity to deepen their knowledge on HPLC and quantitative analysis using the internal standard method while working on a "natural dyes for textiles"-themed experiment. Their assignment was to quantify ldg, Img, and lut in a sample of weld, and to dye alum-mordanted wool with an extract of the same sample. Based on 15 reports by students, it was observed that nearly all of them understood how separation by reversed phase chromatography works. Furthermore, half of the students knew how to use the internal standard method for quantitative analysis, and one-third of them had difficulty with it.

Students also mimicked the work of chemists investigating historical textiles. For that, they had the assignment of performing a small-scale extraction of the dyed wool. After analysis of the sample by HPLC, each student was asked to compare the retention times and UVabsorption spectra of the three main flavonoids of the chromatogram of the wool sample with those of pre-analysed authentic standards of Idg, Img and lut, and to compare the chromatographic profile of the wool sample with that of the weld sample.

The dyeing bath was prepared with deionised water in this experiment and in part of the experiments reported in chapter 4. Although it is expected that the extract of weld with which the bath was prepared contained ions, it could have been preferable to use a bath richer in ions. Osmotic pressure is developed as water enters the wool fibre, and electrolytes in the dyeing bath lead to a decrease in the difference between the $\mathrm{pH}$ inside the fibres and that of the bath [13]. The $\mathrm{pH}$ equilibration relate to the flow of ions through the dyeing bath-fibre interface. If the presence of electrolytes in the dyeing bath also influences the flow of the dye molecules through the dyeing bath-fibre interface, it might be preferable to prepare the dyeing bath with electrolytes-rich water.

A procedure for extracting dye molecules from the wool was developed for the experiment described in this chapter. A small piece of a single thread of dyed wool is extracted with methanol-water-formic acid $80: 15: 5$ at $60{ }^{\circ} \mathrm{C}$ for $30 \mathrm{~min}$. The development of this procedure was based on:

- the fact that methanol-water 8:2 is a good solvent for the extraction of the flavonoids of weld \{Cristea et al. reported one of the works using this solvent for the purpose; they observed it to be the most efficient among five different solvents [14]\};

- the work by Zhang et al., in which samples of dyed textile fabrics were extracted with methanol-formic acid $95: 5$ at $60{ }^{\circ} \mathrm{C}$ for $30 \mathrm{~min}$ [9].

The extraction conditions are mild, with the chromatogram of the extract of the dyed wool being very similar to that of the extract of weld (Fig. 5.2). The larger ratios lmg-ldg and lut-

degradation of quercetin leads to at least one compound that displays antioxidant activity, 3,4dihydroxybenzoic acid (protocatechuic acid) [10]. 
Img of the chromatogram of the extract of the dyed wool relative to that of the extract of weld are expected to be due to the following reasons:

- lower uptake of the diglycosides relative to the monoglycosides and of the monoglycosides relative to the aglycones by the $\mathrm{Al}^{3+}$-mordanted wool (this is in agreement with the data discussed in section 4.4.2.2);

- worse extraction of the diglycosides relative to the monoglycosides and of the monoglycosides relative to the aglycones from the $\mathrm{Al}^{3+}$-mordanted wool the latter is in line with results published by Willemen et al. [11] (left panel of Fig. 5 and preceding discussion)\}.

As the difference between the chromatograms in terms of relative quantities of the flavonoids is small, the reported procedure is suitable for the intended purposes. It may also be used for research purposes, as done_-in an adapted form_-by Willemen et al. [11].

\subsection{Concluding remarks}

The work reported in this thesis is focused on the use of dyestuff of weld (R. luteola L.) for textile dyeing. Obtaining dyes from crops cultivated as dye plants may not be environmentally friendly [15]. Advantageously from the environmental impact point of view, natural dyes for large-scale use can be obtained from sources such as residues of food production [16, 17]. Therefore, the large-scale use of weld as a dye plant might be something of the past. If that is the case, then the methods described in chapters $\mathbf{2}$ and $\mathbf{3}$ could be used for analysing other sources of dyes after adaptation and additional validation. On what concerns the chromatographic separation of flavonoids, further improvement might be achieved by the use of a column packed with a sub-2 $\mu \mathrm{m}$ superficially porous stationary phase on UHPLC instrumentation [18].

More research on understanding the photodecomposition of natural dyes and on improving the light-fastness of the colours of textiles dyed with many such dyes is needed [19]. Therefore, the discussion in chapter 4 and above is expected to contribute to ongoing or future works in the field of textile dyeing with natural dyes. The experiment for use in education in chemistry elaborated upon in chapter $\mathbf{5}$ may be used as is, as well as the procedure for extracting dye molecules from wool described in the same chapter. The latter may also be used for research purposes. Finally, cultivation of dye plants-weld includedremains important for production of goods at a handicraft level in relation to biological diversity and cultural conservation. 


\subsection{References}

[1] Gaspar H, Moiteiro C, Turkman A, Coutinho J, Carnide V. Influence of soil fertility on dye flavonoids production in weld (Reseda luteola L.) accessions from Portugal. J Sep Sci 2009; 32(23-24): 4234-40.

[2] Jeffrey SW, Mantoura RFC, Wright SW, editors. Phytoplankton pigments in oceanography: guidelines to modern methods. 1st ed. UNESCO Publishing: Paris; 1997.

[3] White RC, Jones ID, Gibbs E. Determination of chlorophylls, chlorophyllides, pheophytins, and pheophorbides in plant material. J Food Sci 1963; 28(4): 431-6.

[4] Lichtenthaler HK. Chlorolphylls and carotenoids: pigments of photosynthetic biomembranes. In: Packer L, Douce R, editors. Plant cell membranes, Academic Press: San Diego/New York/etc.; 1987, p. 350-82.

[5] Giles CH. The fading of colouring matters. J Appl Chem 1965; 15: 541-50.

[6] Cristea D, Vilarem G. Improving light fastness of natural dyes on cotton yarn. Dyes Pigments 2006; 70(3): 238-45.

[7] Mouri C, Mozaffarian V, Zhang X, Laursen R. Characterization of flavonols in plants used for textile dyeing and the significance of flavonol conjugates. Dyes Pigments 2014; 100 : $135-41$.

[8] Seifzadeh N, Sahari MA, Barzegar M, Gavlighi HA, Calani L, Del Rio D, Galaverna G. Evaluation of polyphenolic compounds in membrane concentrated pistachio hull extract. Food Chem 2019; 277: 398-406.

[9] Zhang X, Cardon D, Cabrera JL, Laursen R. The role of glycosides in the lightstabilization of 3-hydroxyflavone (flavonol) dyes as revealed by HPLC. Microchim Acta 2010; 169(3-4): 327-34.

[10] Ferreira ESB, Quye A, McNab H, Hulme AN. Photo-oxidation products of quercetin and morin as markers for the characterisation of natural flavonoid yellow dyes in ancient textiles. Dyes History Archaeol 2002; 18: 63-72.

[11] Willemen H, van den Meijdenberg GJP, van Beek TA, Derksen GCH. Comparison of madder (Rubia tinctorum L.) and weld (Reseda luteola L.) total extracts and their individual dye compounds with regard to their dyeing behaviour, colour, and stability towards light. Color Technol 2019; 135(1): 40-7.

[12] Takahama U, Hirota S. Deglucosidation of quercetin glucosides to the aglycone and formation of antifungal agents by peroxidase-dependent oxidation of quercetin on browning of onion scales. Plant Cell Physiol 2000; 41(9): 1021-9.

[13] Rippon JA. The chemical and physical basis for wool dyeing. In: Lewis DM, Rippon JA, editors. The coloration of wool and other keratin fibres, John Wiley \& Sons/Society of Dyers and Colourists: Electronic format (doi: 10.1002/9781118625118.ch2); 2013, p. 43-74.

[14] Cristea D, Bareau I, Vilarem G. Identification and quantitative HPLC analysis of the main flavonoids present in weld (Reseda luteola L.). Dyes Pigments 2003; 57(3): 267-72.

[15] Duffield PA. Dyeing wool with acid and mordant dyes. In: Lewis DM, Rippon JA, editors. The coloration of wool and other keratin fibres, John Wiley \& Sons/Society of Dyers 
and Colourists: Electronic format (doi: 10.1002/9781118625118.ch7); 2013, p. 205-28.

[16] Ganglberger E. Environmental aspects and sustainability. In: Bechtold T, Mussak R, editors. Handbook of natural colorants, John Wiley \& Sons: Chichester; 2009, p. 353-66.

[17] Bechtold T, Mahmud-Ali A, Mussak R. Natural dyes from food processing wastes. In: Waldron K, editor. Handbook of waste management and co-product recovery in food processing, CRC Press/Woodhead Publishing: Boca Raton/Boston/etc.; 2007, p. 502-33.

[18] de Villiers A, Venter P, Pasch H. Recent advances and trends in the liquidchromatography-mass spectrometry analysis of flavonoids. J Chromatogr A 2016; 1430: 1678.

[19] Shahid-ul-Islam, Sun G. Thermodynamics, kinetics, and multifunctional finishing of textile materials with colorants extracted from natural renewable sources. ACS Sustainable Chem Eng 2017; 5(9): 7451-66. 
Summary 
Coloured textiles have been used by mankind throughout times. The use of natural dyes experienced decline when synthetic dyes entered the market. Although dyeing textiles with natural dyes is not synonymous with environmentally friendly dyeing, there has been a renewed interest in natural dyes. Weld (Reseda luteola L.) used to be an important vegetable source of dye for textiles in Europe and the Mediterranean area. Alum (an aluminium salt)-premordanted wool dyed with weld leads to yellow colours, with the main colouring compounds of the plant belonging to the class of the flavonoids. The flavone luteolin (lut) and two of its glycosyl conjugates-lut-7- $O$-glucoside (lut monoglucoside, Img) and lut-7,3'- $O$-diglucoside (lut diglucoside, ldg) - are the main flavonoids of the plant. The research described in this thesis is part of an academic and industrial project focusing on the use of dyestuff of weld for textile dyeing.

A reversed phase-high-performance liquid chromatography with UV detection (RP-HPLCUV) analytical method was developed and validated for the quantitation of Idg, Img, and lut via internal standardisation in weld plant material. This was done in connection with the expectation of having to analyse hundreds of samples in the course of the dye research of which this project is part. The method-described in chapter $\mathbf{2}$ - is simple, requiring very little manpower input per sample. With the exception of the 15-stirring point magnetic stirrer-that, less conveniently, could be replaced by individual magnetic stirrers - only standard laboratory equipment is needed. The analytical method proved fit-for-purpose based on its validation in terms of extraction efficiency, stability and losses of the compounds, accuracy, precision, and sensitivity. Weld plant material having high concentrations of the flavones could be analysed through a slightly modified version of the method, using $100 \mathrm{mg}$ instead of $200 \mathrm{mg}$ of sample. Analyses of a small number of replicates of 100 and $200 \mathrm{mg}$ of a few samples of the plant are expected to be sufficient to test the validity of this approach.

The analytical method was validated using a $5 \mu \mathrm{m}$-particle size RP-HPLC column. Then, the chromatographic separation was speeded up by using a sub- $2 \mu \mathrm{m}$-particle size (RP-UHPLC) column. This was done while still using a conventional HPLC system, after minor hardware adaptation. The method using the UHPLC column proved fit-for-purpose through comparison of accuracy and precision of the quantitation of Idg, Img, and lut with those achieved by using the HPLC column. Large gains in analysis time and eluent consumption were obtained in this way.

According to the industrial partner of the project, one of the problems to overcome was a greenish hue that accompanies the yellow colour after dyeing alum-premordanted textiles with weld. Such a greenish hue would be undesirable, and it was hypothesised that chlorophylls $a$ and $b$ are potential sources of it. In relation to this, an analytical method was developed for the comparison of the content of porphyrin ring-containing pigments - chlorophylls (chls) and their structurally similar breakdown products - in different samples of weld. The method, that is described in chapter 3:

i. uses ethanol as a mild, non-toxic extraction solvent (that is not selective regarding the "types" of chls and plant tissues being extracted);

ii. covers the entire range of occurring concentrations;

iii. displays acceptable precision;

iv. is simple.

The method has the drawback that the manpower input required is not low and displays a limitation. Comparison of the content of porphyrin ring-containing pigments in batches of weld 
plant material having different chls/chlorophyllides-to-"pheopigments" ratios is hampered due to differences in optical molar absorption coefficients. One could test if this limitation can be overcome by conversion of chls and chlorophyllides to the corresponding "pheopigments" by using HCl-acidified ethanol — instead of absolute ethanol—as extraction solvent.

Alum-premordanted wool dyed with weld leads to yellow colours that are of low resistance to light. The work described in chapter 4 was carried out in the context of such an issue. The effect of different concentrations of aluminium ion on the photo-stability of the dye of weld, and the relative photo-stability of lut, Img and Idg in solution are reported. Results of the colours obtained by dyeing alum-mordanted wool with the three flavones are also presented.

On one hand, the observed order of photo-stability of the flavones in solution was ldg $>>$ lut $>$ Img. On the other hand, alum-mordanted wool dyed with ldg (or with an extract of weld) was much less colourful than that dyed with either lut or lmg. The light-fastness of the colour of weld-dyed wool decreased with increasing $\left[\mathrm{Al}^{3+}\right]$ used for premordanting the wool. As the gain in light-fastness by the use of low $\left[\mathrm{Al}^{3+}\right]$ was limited, this cannot be a way to meet today's requirement of light-fastness of the colours of dyed textiles by itself. Nevertheless, it could be part of a broader strategy to address the need for increased light-fastness of the colour of wool dyed with weld.

Undergraduate students of life sciences should be acquainted with HPLC and internal standard method for the quantitation of compounds. Students of molecular life sciences and biotechnology of Wageningen University had the opportunity to deepen their knowledge on both while working on a "natural dyes for textiles"-themed experiment. This experiment is reported in chapter 5 .

Their assignment was to quantify ldg, Img, and lut in a batch of weld plant material, and to dye alum-mordanted wool with an extract of the same batch. Based on 15 reports by students, it was observed that nearly all of them understood how separation by reversed phase chromatography works. Furthermore, half of the students knew how to use the internal standard method for quantitative analysis, and one-third of them had difficulty with it.

Students also mimicked the work of chemists investigating historical textiles. For that, they had the assignment of performing a small-scale extraction of the dyed wool. After analysis of the sample by HPLC, each student was asked to compare the retention times and UVabsorption spectra of the three main flavonoids of the chromatogram of the wool sample with those of pre-analysed authentic standards of Idg, Img and lut, and to compare the chromatographic profile of the wool sample with that of the weld sample.

The procedure for extracting dye molecules from the wool used by the students was developed for the experiment described in this chapter. A small piece of a single thread of dyed wool is extracted with methanol-water-formic acid 80:15:5 at $60{ }^{\circ} \mathrm{C}$ for $30 \mathrm{~min}$. These conditions are mild, with the chromatogram of the extract of the dyed wool being very similar to that of an extract of weld. Thus, the procedure is suitable for the intended purposes, and was used - in an adapted form - for research purposes.

The work reported in this thesis is focused on the use of dyestuff of weld ( $R$. luteola L.) for textile dyeing. From an environmental impact point of view, obtaining natural dyes for largescale use from sources such as residues of food production might be advantageous over obtaining dyes from crops cultivated as dye plants. Although the large-scale use of weld as a dye plant might be something of the past, what is reported in this thesis remains relevant either "as is" (chapters $\mathbf{4}$ and 5) or after adaptation/additional validation for analysing compounds in 
other biological material (chapters 2 and 3). Finally, cultivation of dye plants-weld included-remains important for production of goods at a handicraft level in relation to biological diversity and cultural conservation. 
Acknowledgements 
The future has a long history

Stadszegel, Zwolle/The Netherlands 
I feel happy and grateful for having arrived at the stage of the PhD work in which I now am. The work is nearly complete. That is, the reading copy of the thesis has been submitted, the moment of defending it and graduating is at sight. As the final bits and pieces of the thesis are put together, it is my pleasure to write this very section. I mention few names, but I would like you to feel thanked for your contribution to this journey of mine regardless of its extent. If we have not met during this journey — or have not met yet - you can have an idea of those who were important to it by reading this section.

I am thankful for those who took care of me as I grew up and supported me on the journey. This is not limited to but importantly, includes my family and friends. I would like to particularly mention Dani - a good friend - with whom I walked a good length of the journey, lived abundance and experienced scarcity; Ciro - my father here on Earth — in whom I had an example of endurance in adversity; and Josely - my mother - who did a PhD herself over the last years, in whom I had unyielding encouragement to keep studying.

I am grateful to all those who - directly or indirectly - contributed to making the beginning of this $\mathrm{PhD}$ journey possible. This includes teachers and supervisors during my education in chemistry, internships, MSc thesis work, and jobs.

Different people contributed to the work of this thesis. I am grateful to all of them for the input. The political, conceptual and technical contribution to my $\mathrm{PhD}$ work of Eric, Monique, Hendra and Dorien (Rubia Natural Colours), and Elbert, Jacob, Barend, Han and Teris (Laboratory of Organic Chemistry) was of particular importance. I grew professionally considerably through working under the supervision of Han and Teris. Both of them are committed professionals, and the knowledge of Teris on analytical organic chemistry is vast.

My professional development during the large time span of working on this thesis also encompasses that which took place during activities that ran in parallel to it. Different people contributed to my growth as I worked as teaching assistant at Wageningen University and analytical chemist at Entomology. I am grateful to the input of all of them too. Working with Erik and Frank (Laboratory of Organic Chemistry), and Marcel (Laboratory of Entomology) was encouraging and inspiring.

The interaction with different colleagues with whom I worked during the professional activities mentioned above was also important to me. Some became friends. I grew personally through these interactions, and am grateful for our time together.

I was involved on a number of activities besides work. Two particularly important ones were the Dutch language course, and the tennis trainings and competitions. I am thankful for the time I had together with many people during those activities. Mates and those who served as organizers and teachers - professionally or as volunteers - contributed substantially to my development.

My spiritual development was of extreme importance to me. It was supported and facilitated by a number of people and organizations. I am thankful to all of them. In particular, participating in various activities organized by the International Christian Fellowship and the Student Chaplaincy — and the community that remained after its official end-was joyful, instructive, and of spiritual significance.

God-my father in Heaven - did great things to me. All what He did allowed me to be where I now am, including being at this point of concluding the PhD work. I am very thankful to Him for the nearness, for everything. 
During the whole process, I have seen many people much less often that I would have liked to. I would be glad to see many of them-both those I knew before this very journey started and others I got to know along the way-much more often in the future. With Fefo and Leka - my brother and sister - and many others, I look forward to - to varying degreesshare many adventures to come. 


\section{Publications and training activities}




\section{$\mathrm{PhD}$ work-related publications: full-text papers in peer-reviewed journals}

Villela A, van Vuuren MSA, Willemen HM, Derksen GCH, van Beek TA. Photo-stability of a flavonoid dye in presence of aluminium ions. Dyes Pigments 2019; 162: 222-31

Villela A, Derksen GCH, van Beek TA. Analysis of a natural yellow dye: an experiment for analytical organic chemistry. J Chem Educ 2014; 91(4): 566-9

Villela A, van der Klift EJC, Mattheussens ESGM, Derksen GCH, Zuilhof H, van Beek TA. Fast chromatographic separation for the quantitation of the main flavone dyes in Reseda luteola (weld). J Chromatogr A 2011; 1218(47): 8544-50

Villela A, Derksen GCH, Zuilhof H, van Beek TA. Spectrophotometric comparison of the content of chlorophylls in weld (Reseda luteola). Anal Methods 2011; 3(6): 1424-7 


\section{Overview of completed training activities}

If no geographic reference is made, it is because the activity took place in Wageningen or its surroundings.

\section{Discipline-specific activities}

KNCV (Royal Netherlands Chemical Society) Annual Spring Meeting:

- Advances in hyphenated MS; 17 Apr 2008

- New developments in separation methods; 20 Apr 2012

7th Joint Meeting of AFERP, ASP, GA, PSE \& SIF on Natural Products with pharmaceutical, nutraceutical, cosmetic and agrochemical interest (Athens/Greece); 04-07 Aug 2008

Annual NWO Meeting on Analytical Chemistry (Lunteren/The Netherlands):

- 2008 edition; 03-04 Nov 2008

- 2009 edition; 02-03 Nov 2009

- 2010 edition; 01-02 Nov 2010

Annual NWO Meeting on Organic Chemistry (Lunteren/The Netherlands); 20-21 Oct 2009

Advanced Organic Chemistry; 2009-2010 (VLAG and Laboratory of Organic Chemistry, WUR)

International Symposium and Exhibition on Natural Dyes (La Rochelle/France); 25-29 Apr 2011 (ARRDHOR CRITT HORTICOLE and CIHAM UMR 5648)

46th International Symposium on Essential Oils (Lublin/Poland); 13-16 Sep 2015 (Medical University of Lublin, Department of Pharmacognosy with Medicinal Plant Unit of Medical University of Lublin, and Polish Academy of Sciences)

19th Congress of the International Society for Ethnopharmacology (Dresden/Germany); $12-14$ Jun 2019

Advances in Plant and Food Metabolomics (3rd WURomics Symposium); 12 Dec 2019 (EPS and WUR)

\section{General courses}

Information Literacy for PhD Including Introduction to EndNote; 27-28 May 2008 (Library. WUR)

20th VLAG PhD Week (Bergeijk/The Netherlands); 27-30 Oct 2008 (VLAG)

Training “Study Skills”; 10 Oct 2009 (Purple Monkey and WUR) 
Techniques for Writing and Presenting a Scientific Paper; 29 Jun-02 Jul 2010 (Wageningen Graduate Schools, WUR)

Mini-Symposium “How to Write a World-Class Paper”; 26 Oct 2010 (Library, WUR)

Advanced Course Guide to Scientific Artwork; 07-08 Nov 2011 (Library, WUR)

Adobe InDesign; 09 Nov 2011 (Library, WUR)

Coaching of ACT (Academic Consultancy Training) Groups; 25 and 28 Mar 2013 (Educational Staff Development, WUR)

Workshop “Scientific Integrity”; 05 Jun 2013 (Wageningen Graduate Schools, WUR)

Teachers' Lounge: (The Teacher's Lounge, WUR)

- Kick-off event; 26 Apr 2016

- Café themed "Can we measure the quality of education?"; 15 Mar 2018

Workshop "Distinguishing Science and Metaphysics in Evolution and Religion" (Leiden/The Netherlands); 28-29 Aug 2018 (Lorentz Center)

\section{Optional activities}

Preparing PhD research proposal; submitted to VLAG on 29 May 2008

Spectroscopy (BIP 31306); Sep-Oct 2008 (Laboratory of Biophysics, WUR)

ORC PhD Study Trip (Beijing and Shanghai/China); 11-21 May 2009 (PhD students of the Laboratory of Organic Chemistry, WUR)

YELREM (Yearly Entomology Laboratory Research Exchange Meeting): (Laboratory of Entomology, WUR)

- 2016 edition; 01 Jun 2016

- 2018 edition; 24 May 2018

- 2019 edition; 07 Jun 2019

Plant-Soil-Microbe Interactions for Crop and Pest Management Workshop; 30 Jun 2016 (NIOO-KNAW, NWO, and PE\&RC)

NEV (Nederlandse Entomologische Vereniging) Entomologendag:

- 28th edition; 16 Dec 2016

- 30th edition; 14 Dec 2018

12th Plant-Insect Interaction Workshop; 07 Nov 2017 (group of PhD students of the Laboratory of Entomology, WUR) 


\section{Appendix A}

\section{Chapter 2: Supplementary information}

The content of this appendix is essentially that of the supplementary material of the following paper:

Villela A, van der Klift EJC, Mattheussens ESGM, Derksen GCH, Zuilhof H, van Beek TA. Fast chromatographic separation for the quantitation of the main flavone dyes in Reseda luteola (weld). J Chromatogr A 2011; 1218(47): 8544-50. 


\section{Table of contents}

SI A.1. Supplementary material and methods 100

SI A.1.1. HPLC

SI A.1.2. Identification of the three main flavonoids of $R$. luteola and peak purity assessment

SI A.1.3. Determination of the limits of detection (LOD) and quantitation (LOQ) 101

SI A.2. Supplementary results and discussion $\quad 101$

$\begin{array}{ll}\text { SI A.2.1. Peak purity } & 101\end{array}$

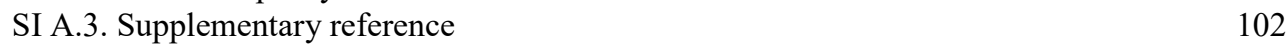

\section{SI A.1. Supplementary material and methods}

SI A.1.1. HPLC

HPLC analyses carried out in Steenbergen: Performed on a system from Dionex Corporation consisting of a low pressure gradient pump (P680 LPG-4), a DAD (UVD340U) and an autosampler (ASI-100), and equipped with a column oven (TCC-100). An Alltima $250 \mathrm{~mm} \times$ $4.6 \mathrm{~mm} \mathrm{C} 185 \mu \mathrm{m}$-particle size column in combination with a $\mathrm{C} 18$ guard column was used. The volume of both, syringe and loop, was $250 \mu \mathrm{L}$. The draw rate of the autosampler was $10 \mu \mathrm{L}$ $\mathrm{sec}^{-1}$. The system was controlled by Chromeleon Client 6.70 SP6 build 1935 software.

\section{SI A.1.2. Identification of the three main flavonoids of $R$. luteola and peak purity assessment}

Through preliminary experiments, the identity of the three main flavonoids of $R$. luteola was verified by: (i) comparing the RP-LC-DAD retention times and UV-vis absorption spectra of the peaks of authentic standards to those of the main peaks of an extract; (ii) spiking that extract with Idg, Img, and lut standards, followed by HPLC analysis; and (iii) MS and MS/MS data, via LC-(DAD-)MS analyses.

HPLC column: The purity of Idg, Img, and lut peaks was assessed through: (i) DAD peak purity analysis (comparison of the purity and threshold angles of the chromatographic peaks by Empower 2 software); and (ii) LC-DAD-MS analysis of an extract of R. luteola (MS data and inspection of the UV-vis contour plots of the peaks). UHPLC column: Samples of $R$. luteola $\mathrm{H}$ were extracted and treated as usual, stored in freezer for six days, and analysed using the UHPLC column. One of the results was used for evaluation of the purity of ldg, lmg, and lut peaks. This was done using the system's software (see section 2.2.4, Chapter 2) in two ways: (i) the peaks were integrated (discarding what was below 5\% of their maximum heights) and all spectra within the limits of integration were automatically selected and overlaid, followed by their visual inspection; and (ii) inspection of their UV-vis contour plots.

Internal standard peak purity: $R$. luteola $\mathrm{H}$ samples $(\mathrm{n}=8)$, as well as analytical blanks $(\mathrm{n}=$ 6)-i.e., samples lacking the plant material that were subjected to the whole analytical procedure - were extracted as usual. Each sample (ready for analysis) was placed in four vials. Part of them was analysed on the same day (overnight, HPLC column), part was stored at $4{ }^{\circ} \mathrm{C}$, and the rest was stored at $-20^{\circ} \mathrm{C}$. [Note: These were the same samples used for the evaluation of the precision of the analysis using the UHPLC column (see section 2.2.7)]. After five days, the samples stored at $4{ }^{\circ} \mathrm{C}$ were analysed using the UHPLC column. In both cases, HPLC 
column and UHPLC column, the average area of the i.s. peak of samples was compared with that of the blanks.

\section{SI A.1.3. Determination of the limits of detection (LOD) and quantitation (LOQ)}

HPLC column: They were estimated based on the slopes of the calibration curves and the $s$ of the baseline noise of analyses of blank samples [1]. The relation concentration vs. peak area was converted to concentration $v s$. peak height for Idg, lmg, and lut and the intercepts of the equations were set to zero. Analytical blanks $(\mathrm{n}=5)$ were injected and the $s$ of the baseline noise at $345 \mathrm{~nm}$ over the range 40.0-45.0 min was calculated, using all data points (ASCII files). The average of the $s$ values was $0.043 \pm 0.014 \mathrm{mAU}$. The LOD and LOQ values were equal to the concentration of $\mathbf{I d g}$, Img, and lut solutions that corresponded with 3.3 and $10 \times$ the $s$ values of the baseline, respectively. The LOD values were additionally estimated based on the signalto-noise ratio [1]. Using the $s$ of the baseline noise value of $0.043 \mathrm{mAU}$, $\mathbf{l d g}$, Img, and lut standard solutions leading to signal-to-noise ratios of $2: 1$ or $3: 1$ were injected in triplicate. The stock solutions of Idg $\left(90 \mu \mathrm{g} \mathrm{mL}^{-1}\right)$ and $\mathbf{~ I m g ~}\left(128 \mu \mathrm{g} \mathrm{mL} \mathrm{m}^{-1}\right)$ were prepared in methanoldimethyl sulfoxide $7: 3(\mathrm{v} / \mathrm{v})$, and that of lut $\left(138 \mu \mathrm{g} \mathrm{mL}^{-1}\right)$ was prepared in methanol. Dilutions: In all cases, only methanol was used. UHPLC column: Generally, determined as described for the HPLC column, except that analytical blanks $(\mathrm{n}=6)$ were injected and the $s$ of the baseline noise was calculated at $345 \mathrm{~nm}$ (having $470 \mathrm{~nm}$ as reference $\lambda$ ) over the range 1.50-2.00 min, using all data points (CSV files). The average of the $s$ values was $0.086 \pm 0.014 \mathrm{mAU}$.

\section{SI A.2. Supplementary results and discussion}

\section{SI A.2.1. Peak purity}

For the chromatographic separation described here (HPLC column), it was observed by (LC-)MS analysis that no other compound of $R$. luteola co-elute with lut, whereas an unknown compound was observed to partially co-elute with Img and Idg. Nevertheless, the contour plots of the Idg and Img peaks indicated that there is no co-elution with any other UV-vis absorbing compounds with significantly different spectral profile at appreciable amounts. The same was observed for the peaks of all three flavones, ldg, Img, and lut, via peak purity analysis. Moreover, there is no significant co-elution between i.s. and minor compounds of $R$. luteola as the change in the i.s. peak area due to such co-elution is $<1 \%$. Thus, the peak areas at $345 \mathrm{~nm}$ are representative for $\mathbf{l d g}$, $\mathbf{l m g}$, lut, and i.s.

UHPLC column: Evaluation of the spectral homogeneity of Idg and Img peaks and inspection of their UV-vis contour plots indicated that there is no co-elution with any other compound with significantly different spectral profile at appreciable amounts. Although the same holds true regarding the UV-vis contour plot of the lut peak, the spectra at its front display different characteristics from the other ones recorded during the elution of the peak. Also using the UHPLC column, there is no significant co-elution between the i.s. and minor compounds of $R$. luteola as the change in the i.s. peak area due to such co-elution is $<1 \%$. The spectral inhomogeneity of the lut peak was observed not to interfere with its quantitation, as the quantitation of $\mathbf{l d g}, \mathbf{l m g}$, and lut using the UHPLC column was statistically the same as that carried out using the HPLC column (see section 2.3.7). Thus, also using the UHPLC column, the peak areas at $345 \mathrm{~nm}$ are representative for $\mathbf{l d g}$, $\mathbf{l m g}$, lut, and i.s. 
Table SI A.1. Results of the estimation of the LOD and LOQ values of ldg, lmg, and lut using both columns (HPLC and UHPLC) based on the slopes of the calibration curves and the $s$ of the baseline noise of analyses of analytical blanks.

\begin{tabular}{lllll}
\hline $\begin{array}{l}\text { Compound } \\
(\mathbf{z})\end{array}$ & Relation $[\mathbf{z}]\left(\mu \mathrm{g} \mathrm{mL} L^{-1}\right) v s . \mathrm{H}_{\mathbf{z}}$ & $\begin{array}{l}\text { Relation }[\mathbf{z}](\mu \mathrm{g} \\
\left.\mathrm{mL}^{-1}\right) v s . \mathrm{H}_{\mathbf{z}}^{\mathrm{a}}, \text { with } \\
\mathrm{b}^{\mathrm{b}}=0\left(\mathrm{R}^{2}\right)\end{array}$ & $\begin{array}{l}\text { LOD } \\
\left(\mathrm{ng} \mathrm{mL} \mathrm{mL}^{-1}\right)\end{array}$ & $\begin{array}{l}\text { LOQ } \\
\left(\mathrm{ng} \mathrm{mL} \mathrm{mL}^{-1}\right)\end{array}$ \\
\hline
\end{tabular}

$\begin{array}{lllll}\text { HPLC column (analytical blanks: } \mathrm{n}=5) & & & \\ \operatorname{ldg} & \mathrm{y}=0.0028 \mathrm{x}-0.004(0.9987) & \mathrm{y}=0.0027 \mathrm{x}(0.9984) & 50(20) & 160(50) \\ \operatorname{lmg} & \mathrm{y}=0.004 \mathrm{x}-0.0037(0.9998) & \mathrm{y}=0.004 \mathrm{x}(0.9998) & 40(10) & 110(40) \\ \text { lut } & \mathrm{y}=0.0113 \mathrm{x}+0.0101 & \mathrm{y}=0.0114 \mathrm{x}(0.9996) & 12(4) & 40(10)\end{array}$

UHPLC column (analytical blanks: $\mathrm{n}=6$ )

\begin{tabular}{llllll} 
Idg & $\begin{array}{l}\mathrm{y}=1.9244 \mathrm{x}+1.3292 \\
(0.9999)\end{array}$ & & $\mathrm{y}=1.9364 \mathrm{x}(0.9998)$ & $150(20)$ & $440(70)$ \\
Img & $\begin{array}{l}\mathrm{y}=2.5681 \mathrm{x}+16.178 \\
(0.9878)\end{array}$ & & $\mathrm{y}=2.6656 \mathrm{x}(0.9854)$ & $110(20)$ & $320(50)$ \\
lut & $\begin{array}{l}\mathrm{y}=4.1341 \mathrm{x}+2.7314 \\
(0.9996)\end{array}$ & & $\mathrm{y}=4.1672 \mathrm{x}(0.9995)$ & $70(10)$ & $210(30)$ \\
\hline
\end{tabular}

a Peak height.

${ }^{\mathrm{b}}$ Intercept of the $[\mathbf{z}]$ vs. $\mathrm{H}_{\mathbf{z}}$ line.

\section{SI A.3. Supplementary reference}

[1] Validation of analytical procedures: text and methodology Q2(R1), comprising Q2A (1994) and Q2B (1996). International Conference on Harmonisation of Technical Requirements for Registration of Pharmaceuticals for Human Use; 2005. 


\section{Appendix B}

\section{Chapter 3: Supplementary information}

The content of this appendix is essentially that of the supplementary material of the following paper:

Villela A, Derksen GCH, Zuilhof H, van Beek TA. Spectrophotometric comparison of the content of chlorophylls in weld (Reseda luteola). Anal Methods 2011; 3(6): 1424-7. 
The absorption spectrum of an absolute ethanol extract of weld sample B (see footnote 7 of chapter 3) is presented in Figure SI B.1. The absorbance at the main red absorption band at $\sim 665 \mathrm{~nm}$ was used to compare different samples.

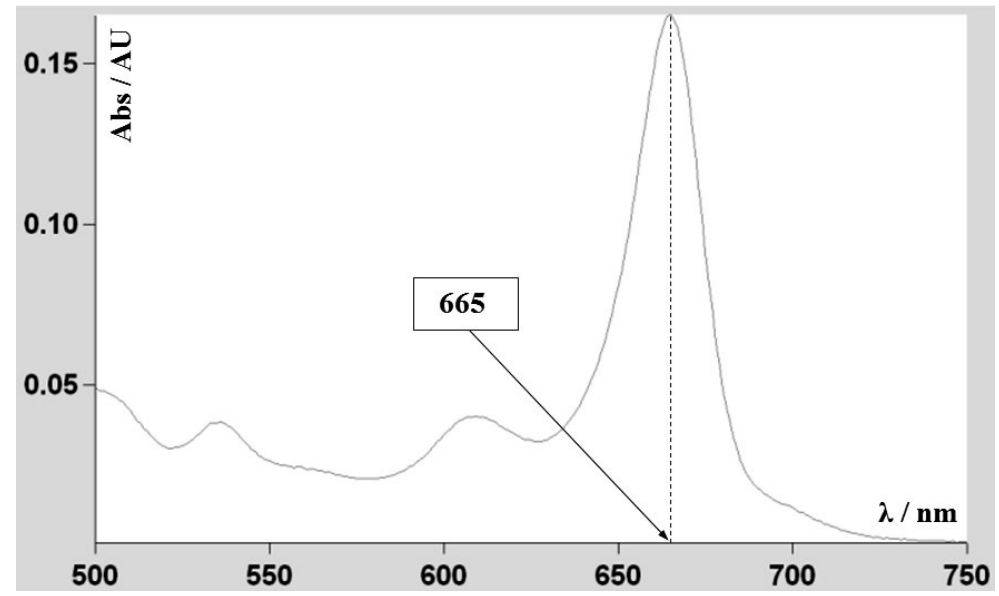

Figure SI B.1. Absolute ethanol extract of weld sample B (see footnote 7 of chapter 3 ) in $10 \mathrm{~mm}$-pathlength quartz cuvette. The wavelength of the main red absorption band is indicated.

Precision of the analytical method using absolute ethanol and $10 \mathrm{~mm}$-pathlength plastic cuvettes (see footnote 6 of chapter 3) was evaluated. The dependence of the extraction efficiency on the particle size of the samples and the correlation between the absorbance of ethanolic and DMF extracts of different $R$. luteola samples using $10 \mathrm{~mm}$-pathlength cuvettes were verified. Results are presented below. 


\begin{tabular}{|c|c|c|c|c|c|}
\hline Entry & $\begin{array}{l}\text { Plant } \\
\text { material } \\
\end{array}$ & $\mathrm{n}$ & Extraction procedure ${ }^{\mathrm{c}}$ and series of measurements & Solvent ${ }^{\mathrm{d}}$ & $\begin{array}{l}\text { Absorbance }(\mathrm{AU}) \\
\text { and } s_{\mathrm{r}}(\%)^{\mathrm{e}}\end{array}$ \\
\hline \multicolumn{6}{|c|}{$10 \mathrm{~mm}$-pathlength plastic cuvette } \\
\hline 1 & $\mathbf{A}$ & 3 & 3-min vortexing & Abs EtOH & $0.096(4.4)$ \\
\hline 2 & B & 3 & 3-min vortexing; day $a$ & Abs EtOH & $0.159(0.3)$ \\
\hline 3 & B & 3 & 3-min vortexing; day $a$ & Abs EtOH & $0.164(2.5)$ \\
\hline 4 & B & 3 & 3-min vortexing; day $a$ & Abs EtOH & $0.160(3.8)$ \\
\hline $5^{\mathrm{f}}$ & B & 9 & 3-min vortexing; day $a$ & Abs EtOH & $0.161(2.7)$ \\
\hline 6 & B & 3 & 3-min vortexing; day $(a+3)$ & Abs EtOH & $0.158(3.1)$ \\
\hline 7 & B & 3 & 3-min vortexing; day $(a+3)$ & Abs EtOH & $0.157(1.1)$ \\
\hline 8 & B & 3 & 3-min vortexing; day $(a+3)$ & Abs EtOH & $0.164(1.7)$ \\
\hline $9^{\mathrm{f}}$ & B & 9 & 3-min vortexing; day $(a+3)$ & Abs EtOH & $0.159(2.9)$ \\
\hline 10 & C 0.75 & 3 & 3-min vortexing & Abs EtOH & $0.149(6.1)$ \\
\hline 11 & C 0.50 & 3 & 3-min vortexing & Abs EtOH & $0.180(4.6)$ \\
\hline 12 & C 0.25 & 3 & 3-min vortexing & Abs EtOH & $0.216(1.5)$ \\
\hline 13 & D & 3 & 3 -min vortexing; day $a(\mathrm{n}=2)$ and day $(a+3)(\mathrm{n}=1)$ & Abs EtOH & $0.271(2.7)$ \\
\hline 14 & $\mathbf{E}$ & 3 & 3-min vortexing & Abs EtOH & $0.643(0.6)$ \\
\hline \multicolumn{6}{|c|}{$10 \mathrm{~mm}$-pathlength quartz cuvette } \\
\hline 15 & B & 3 & 3-min vortexing & DMF & $0.215(1.8)$ \\
\hline 16 & C 0.25 & 3 & 3-min vortexing & DMF & $0.287(1.3)$ \\
\hline 17 & D & 3 & 3-min vortexing & DMF & $0.390(3.2)$ \\
\hline 18 & $\mathbf{E}$ & 3 & 3-min vortexing & DMF & $1.026(1.1)$ \\
\hline
\end{tabular}

a $\lambda$ of detection: entries 1 through 14, $665 \mathrm{~nm}-750 \mathrm{~nm}$ (i.e., absorbance at $750 \mathrm{~nm}$ subtracted from that at 665 $\mathrm{nm}$ ); entries 15 through 18, $664 \mathrm{~nm}-750 \mathrm{~nm}$. $N B$ Subtraction of absorbance at $750 \mathrm{~nm}$ was only done for consistency with data in chapter 3. In all cases the absorbance at $750 \mathrm{~nm}$ varied between -6 and $10 \mathrm{mAU}$.

${ }^{\mathrm{b}} \mathbf{A}$ through $\mathbf{E}$ are the codes of (dried and ground-sieved) weld samples in order of increasing concentration of chls and breakdown products. Note: 1) Differences among samples include cultivar and plant parts used; ${ }^{20} 2$ )

Numbers behind $\mathbf{C}$ : Pore size of sieves used during the grinding-sieving process (in $\mathrm{mm}$ ).

${ }^{\mathrm{c}}$ Always at room temperature and under reduced light.

${ }^{\mathrm{d}} \mathrm{Abs} \mathrm{EtOH}=$ absolute ethanol and $\mathrm{DMF}=N, N$-dimethylformamide.

e Average absorbance ( $s_{\mathrm{r}}=$ relative standard deviation).

${ }^{\mathrm{f}}$ Combining results of previous 3 entries.

Precision: Repeatability was assessed by analysis of sample $\mathbf{B}(\mathrm{n}=9$; entry 5 of Table SI B.1): $s_{\mathrm{r}}<3.0 \%$. Sample $\mathbf{B}$ was analysed again on another day $(\mathrm{n}=9$; entry 9$)$. The difference between both results was $1 \%$. Based on the results seen in entries 15 and 18 of Table 3.1 (chapter 3), and 1 and 14 of Table SI B.1, samples with absorbance of $190 \mathrm{mAU}$ using $2 \mathrm{~mm}$ pathlength plastic cuvettes should display absorbance $\leq 1.0$ AU using 10 mm-pathlength plastic cuvettes. Thus, users having many samples with absorbance $\leq 190 \mathrm{mAU}$ (with $2 \mathrm{~mm}$ pathlength cuvettes) may use the $10 \mathrm{~mm}$-pathlength cuvettes for increased precision. 
Dependence of extraction efficiency on particle size: An increase of absorbance with decreasing particle size is seen (entries 10 through 12). Additionally, as expected, $s_{\mathrm{r}}$ decreases with the decrease of the particle size. This suggests that it is harder to obtain representative samples from coarse plant materials than from fine ones.

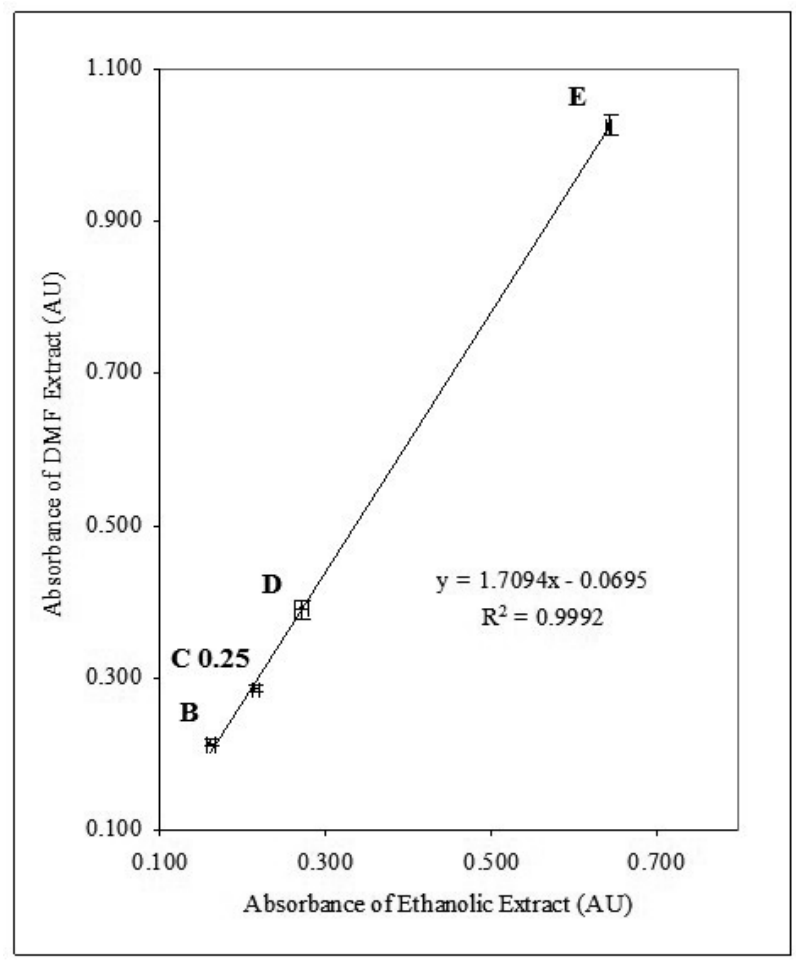

Figure SI B.2. Correlation between absorbance of ethanolic and DMF extracts of $R$. luteola. Average absorbances are plotted; error bars $=1 \times$ standard deviation. Ethanolic extracts: 10 mm-pathlength plastic cuvette; $\mathrm{n}=3(\mathbf{C ~ 0 . 2 5}, \mathbf{D}$, and E) and $\mathrm{n}=9$ (B). DMF extracts: $10 \mathrm{~mm}$-pathlength quartz cuvette; $\mathrm{n}=3$ (all).

As also seen previously, the absorbance of ethanolic and DMF extracts linearly correlate. Note: The slopes of the lines seen in Figure 3.1 (chapter 3) and in Figure SI B.2 are different due to different pathlengths of the cuvettes used.

A gradual increase in absorbance from sample 1 to 20 after simultaneous extraction of 20 samples (Vortex Genie-2; set to maximum speed) followed by sequential absorbance measurements was observed. The results (entries 1, 3, and 5 of Table SI B.2) indicate that the 
extraction of chls and their breakdown products continues statically if the plant material is left in contact with the extraction solvent. Simultaneously, there is evidence that the five-minute centrifugation step at 13,000 rpm enhanced the extraction efficiency. In spite of the observed gradual increase in absorbance, the absorbance of the extracts seen in entry 2 is lower than those seen in entries 1 and 3, and the absorbance of the extracts seen in entry 4 is lower than those seen in entries 3 and 5 .

Table SI B.2. Absorbance of acetone extracts of weld sample B obtained with two methods of extraction, after simultaneous extraction of 20 samples followed by sequential absorbance measurements. ${ }^{\text {a }}$

\begin{tabular}{|c|c|c|c|c|}
\hline Entry & $\mathrm{n}$ & $\begin{array}{l}\text { Extraction procedure and } \\
\text { sample treatment }{ }^{b}\end{array}$ & $\begin{array}{l}\text { Position of the samples } \\
\text { within a series }^{\mathrm{c}}\end{array}$ & $\begin{array}{l}\text { Absorbance (AU) and } \\
\mathrm{S}_{\mathrm{r}}(\%)^{\mathrm{d}}\end{array}$ \\
\hline \multicolumn{5}{|c|}{$10 \mathrm{~mm}$-pathlength quartz cuvette } \\
\hline 1 & 3 & 3-min vortex; 5-min centrifuge & $1-3$ & $0.158(3.5)$ \\
\hline 2 & 4 & 3-min vortex & $4-7$ & $0.149(5.3)$ \\
\hline 3 & 3 & 3-min vortex; 5-min centrifuge & $8-10$ & $0.170(2.6)$ \\
\hline 4 & 4 & 3-min vortex & $14-17$ & $0.160(4.4)$ \\
\hline 5 & 3 & 3-min vortex; 5-min centrifuge & $18-20$ & $0.184(4.6)$ \\
\hline \multicolumn{5}{|c|}{$\lambda$ of detection: $664-740 \mathrm{~nm}$. Note: Range of readings at $740 \mathrm{~nm}: 1-4 \mathrm{mAU}$. } \\
\hline
\end{tabular}




\section{Appendix C}

\section{Chapter 4: Supplementary information}

The content of this appendix is equal to that of the supplementary material of the following paper:

Villela A, van Vuuren MSA, Willemen HM, Derksen GCH, van Beek TA. Photo-stability of a flavonoid dye in presence of aluminium ions. Dyes Pigments 2019; 162: 222-31 


\section{Table of contents}

SI C.1. Supplementary material and methods $\quad 111$

SI C.1.1. General material $\quad 111$

SI C.1.2. Preparation of aerated methanol-water 8:2 (v/v) 112

SI C.1.3. Determination of purity of lut, lmg, and ldg by NMR spectroscopy 112

SI C.1.4. Preparation of stock and working solutions of the flavones, $\mathrm{Al}^{3+}$, and $\mathrm{HNO}_{3}$ used for construction of the calibration lines and preparation of the solutions used for the $\begin{array}{ll}\text { described irradiation experiments } & 113\end{array}$

SI C.1.5. Calibration lines $\quad 113$

SI C.1.6. Solutions used for the irradiation experiments 114

SI C.1.7. Irradiation experiments $\quad 114$

SI C.1.8. Spectrophotometric analyses $\quad 117$

SI C.1.9. HPLC analyses $\quad 118$

SI C.1.10. Recording of the emission spectrum of the lamp used for the irradiation $\begin{array}{ll}\text { experiments } & 118\end{array}$

SI C.1.11. Apparent $\mathrm{pH}$ measurements $\quad 118$

SI C.1.12. Assessment of the stability of $\mathbf{I m g}$ and $\mathbf{l d g}$ in presence of $\mathrm{HNO}_{3}$

SI C.1.13. Experiment on the effect of increasing quantities of $\mathrm{Al}^{3+}$ (alum) bound to mordanted wool on the photo-stability of the dye of weld - part A (carried out in $\begin{array}{lr}\text { Wageningen) } & 120\end{array}$

SI C.1.14. Experiment on the effect of increasing quantities of $\mathrm{Al}^{3+}$ (alum) bound to mordanted wool on the photo-stability of the dye of weld - part B (carried out in $\begin{array}{lr}\text { Steenbergen) } & 121\end{array}$

SI C.1.15. Another experiment on the effect of increasing quantities of $\mathrm{Al}^{3+}$ (using aluminium sulphate and tartaric acid this time) bound to mordanted wool on the photo$\begin{array}{ll}\text { stability of the dye of weld (carried out in Steenbergen) } & 122\end{array}$

SI C.1.16. Colours of alum-mordanted wool dyed with lut, lmg, and ldg 122

$\begin{array}{ll}\text { SI C.2. Supplementary results and discussion } & 124\end{array}$

$\begin{array}{ll}\text { SI C.2.1. Choice of solvent } & 124\end{array}$

SI C.2.2 pH adjustment $\quad 124$

SI C.2.3. Purity of lut, Img, and ldg, as determined by NMR spectroscopy 125

SI C.2.4. Effect of $\mathrm{Al}^{3+}$ on the absorption of light by solutions of lut and ldg 129

SI C.2.5. Irradiation experiments: Light with which solutions were irradiated 130

SI C.2.6. Effect of different concentrations of $\mathrm{Al}^{3+}$ and glycosylation pattern of lut (aglycone, monoglucoside, and diglucoside) on its photo-stability in solution 131

SI C.2.7. Effect of concentration of lut on its photo-stability in solution 136

SI C.2.8. Evaluation of the contribution of light above $420 \mathrm{~nm}$ to the photodecomposition $\begin{array}{ll}\text { processes studied } & 137\end{array}$

SI C.2.9. Photodecomposition of ldg-with and without $\mathrm{Al}^{3+}$ - and lut in lut $\mathbf{l}_{0.10}-\mathrm{Al}_{0.99}$ only with light $>420 \mathrm{~nm}$ - over time 138

SI C.2.10. Stability of $\mathbf{~} \mathbf{m g}$ and $\mathbf{l d g}$ in presence of $\mathrm{HNO}_{3} \quad 141$

SI C.2.11. Effect of increasing quantities of $\mathrm{Al}^{3+}$ of mordanted wool-using alum — on the $\begin{array}{ll}\text { photo-stability of the dye of weld } & 141\end{array}$

SI C.2.12. Effect of the glycosylation pattern of lut (aglycone, monoglucoside, and diglucoside) on the colour of alum-mordanted wool dyed with the individual flavones 143 


\section{SI C.1. Supplementary material and methods}

\section{SI C.1.1. General material}

This section lists some of the compounds/material to which reference is made below (not necessarily explicitly). Additional compounds/material used are listed in the sections in which they are specifically referred to.

\section{$\underline{\text { Solvents }}$}

- $96 \%$ ethanol (for general laboratory use grade; VWR International, Fontenay-sousBois/France)

- Distilled methanol: HPLC grade methanol was distilled

- Water was deionized using a Seradest SD 2000 ion-exchanger (Seral Erich Alhäuser, Ransbach-Baumbach/Germany), an EasyPure UV system (Barnstead/Thermolyne, USA), or a Milli-Q Integral 3 system (Millipore, Molsheim/France)

\section{Compounds}

- Alum [KAl $\left(\mathrm{SO}_{4}\right)_{2} \cdot 12 \mathrm{H}_{2} \mathrm{O}$; puriss. p.a. grade; Sigma-Aldrich, Steinheim/Germany]

- Aluminium sulphate tetradecahydrate (ViVoChem, Almelo/The Netherlands)

- Tartaric acid (Brenntag, Dordrecht/The Netherlands)

\section{$\underline{\text { Equipment }}$}

- Type K thermocouple PeakTech TF-50 connected to a digital thermometer PeakTech 3150 (PeakTech Prüf- und Messtechnik, Ahrensburg/Germany)

- $45 \mathrm{kHz}$ ultrasonic cleaner (model USC $300 \mathrm{~T}$; produced for VWR International in Malaysia)

- Balances: i) $0.1 \mu$ g-least division balance (type UM 3; Mettler-Toledo, Greifensee/Switzerland), ii) $5 \mu$ g-least division balance (Mettler Instrumente, Greifensee/Switzerland), iii) type AE 260 balance operating in $0.1 \mathrm{mg}$-least division mode (Mettler-Toledo, Greifensee/Switzerland), iv) 0.01 g-least division balance (type PM 600; Mettler-Toledo, Greifensee/Switzerland), and v) ABS 220-4 (Kern \& Sohn, Balingen/Germany)

- Centrifuge (WS 235; Bauknecht Hausgeräte, Stuttgart/Germany)

- Incubator shakers: G24 Environmental and Innova 4080, both from New Brunswick Scientific (Edison/USA)

- Spectrophotometer used for measuring $L^{*}, a^{*}$, and $b^{*}$ quantities (CIELAB colour space): Macbeth Color-Eye 7000 (X-Rite, Michigan/USA)

\section{Miscellaneous}

- Phosphor-coated low pressure mercury vapour lamp (84-2094-2 - Jelight, Irvine/USA) charged through a $220 \mathrm{~V}, 50 \mathrm{~Hz}$ power supply (PS-2004-20 - Jelight, Irvine/USA). Note: The emission profile of the lamp is depicted in Figure SI C.9

- Folded filter paper (597 1/2, Ø 150 mm; Whatman, Dassel/Germany) 
- Detergent SARABID PAW (CHT R. Beitlich, Tübingen/Germany)

- Ready-to-dye wool [Kova Wool Sateen White (part number W110); Whaleys (Bradford), Bradford/United Kingdom]

- Sample of the aerial parts of dried and ground weld \{described by Villela et al. [1]\}

\section{SI C.1.2. Preparation of aerated methanol-water 8:2 (v/v)}

Aerated methanol-water 8:2 (v/v) was prepared on the day of use, from methanol and water freshly aerated during $30 \mathrm{~min}$. Such aerated solvents - methanol, water, or the mixture-were used for the preparation of stock and working solutions of the flavones, $\mathrm{Al}^{3+}$ and $\mathrm{HNO}_{3}$. The freshly prepared aerated methanol-water 8:2 (v/v) was also used for filling the volumetric flasks of calibration solutions and solutions used for the irradiation experiments described below up to the marks.

Distilled methanol and deionized water (EasyPure UV system) were used. These solvents were aerated simultaneously, but separately, each in its bottle. This was done by the bubbling of air filtered through active charcoal (coarse particles) for $30 \mathrm{~min}$, on the day of use. The solvent-mixture was prepared using such aerated solvents. Quality of the aerated methanolwater 8:2 (v/v) was monitored by recording its UV-vis absorption spectrum against air at every irradiation experiment event described below, and comparing it with previous ones. Notes:

- The solvents were added to the aeration bottles - or replaced - from time to time.

- Details of the spectrophotometric analyses: See section SI C.1.8.

\section{SI C.1.3. Determination of purity of lut, lmg, and ldg by NMR spectroscopy}

Material and method of the determination of the purity by NMR spectroscopy of the flavones referred to in section SI C.1.4 are briefly reported in this section. The analyses were carried out by the use of the $0.1 \mu \mathrm{g}$-least division balance, maleic acid (grade: puriss., $\geq 99.0 \%$ by HPLC; actual purity: $100.0 \%$, according to certificate of analysis; Fluka) [2], DMSO-d6 (99.5+ atom $\%$ D, Aldrich), and a 400 MHz NMR spectrometer (Avance III; Bruker, Fällanden/Switzerland). Notes:

- All cases: Flavones in vials with lids partially unscrewed were placed in a desiccator under reduced pressure on the day before use, or earlier. Exposure of the vials to light during the process was minimised.

- The following quantities were accurately weighed:

○ Lut: $\sim 0.7 \mathrm{mg}$ (lut) and $\sim 0.6 \mathrm{mg}$ (maleic acid)

○ Lmg: $\sim 0.4 \mathrm{mg}$ (lmg) and $\sim 0.2 \mathrm{mg}$ (maleic acid)

○ Ldg: 0.1-0.4 mg (ldg) and $\sim 0.1 \mathrm{mg}$ (maleic acid); carried out twice, using separate potions of Idg of the same batch

- ${ }^{1} \mathrm{H}-\mathrm{NMR}$ experiments $\left(30^{\circ}\right.$ pulse, 2 s relaxation delay) were used. The number of scans was either 512 (lut) or 1,024 (lmg and ldg). 
SI C.1.4. Preparation of stock and working solutions of the flavones, $\mathrm{Al}^{3+}$, and $\mathrm{HNO}_{3}$ used for construction of the calibration lines and preparation of the solutions used for the described irradiation experiments

Lut stock solutions $\left(292 \mu \mathrm{g} \mathrm{mL} \mathrm{mL}^{-1} ; 1.02 \mathrm{mM}\right)$, Img stock solutions $\left(192 \mu \mathrm{g} \mathrm{mL}^{-1} ; 0.42 \mathrm{mM}\right)$, and Idg stock solutions ( $47 \mu \mathrm{g} \mathrm{mL}^{-1} ; 0.08 \mathrm{mM}$ ) were prepared using either the $0.1 \mu \mathrm{g}$-least division balance or the $5 \mu \mathrm{g}$-least division balance. In each case, the flavone was transferred to a volumetric flask using a syringe and aerated methanol-water $8: 2(\mathrm{v} / \mathrm{v})$. For completion of the dissolution of Img and Idg, the partially filled flasks were wrapped in aluminium foil and placed in an incubator shaker (130-160 rpm) at room temperature for 1-1.5 day. Working solutions were prepared by dilution of stock solutions using volumetric pipettes, and volumetric flasks. In all cases:

- Aerated methanol-water 8:2 (v/v) was added to the marks.

- Solutions were stored in a refrigerator.

- Flavones in vials with lids partially unscrewed were placed in a desiccator under reduced pressure on the day before use, or earlier. Exposure of the vials to light during the process was minimised.

The following chemical compounds were used: Lut $(96 \%$ by NMR; Indofine Chemical Company, Hillsborough/USA); Img (93\% by NMR; Extrasynthese, Genay/France); Idg (86\% by NMR; Extrasynthese, Genay/France).

Aluminium nitrate nonahydrate (99.997\%; Aldrich Chemistry, St. Louis/USA) was used (Note: Although the crystals of the salt are deliquescent[3] and seemed to have taken up some water, no special handling procedure was adopted; the salt was easy to handle throughout the work). Stock solutions were prepared by weighing $124 \mathrm{mg}$ of the salt in a $25 \mathrm{~mL}$ volumetric flask using the balance operating in 0.1 mg-least division mode. Working solutions were prepared by subsequent dilutions of $\mathrm{Al}^{3+}$ stock solution using volumetric pipettes and volumetric flasks. In all cases, aerated methanol-water 8:2 (v/v) was added to the marks. Solutions were stored in a refrigerator.

$\mathrm{HNO}_{3}(65 \%$, extra pure; Merck, Darmstadt/Germany) stock solutions in water were prepared using aerated water (as described above), a $1 \mathrm{~mL}$ volumetric pipette, and a $100 \mathrm{~mL}$ volumetric flask. $\mathrm{HNO}_{3}$ stock solutions in methanol-water 8:2 (v/v) were prepared by dilution of the $\mathrm{HNO}_{3}$ stock solution in water using a $2 \mathrm{~mL}$ volumetric pipette, aerated methanol (as described above), and a $10 \mathrm{~mL}$ volumetric flask. After cooling down the flask, aerated methanol was added to the mark. Working solutions were prepared by dilution of the $\mathrm{HNO}_{3}$ stock solution in methanolwater 8:2 (v/v) using volumetric pipettes and volumetric flasks. Aerated methanol-water 8:2 $(\mathrm{v} / \mathrm{v})$ was added to the marks. Solutions were stored in a refrigerator.

General note: All solutions (flavones, $\mathrm{Al}^{3+}$, and $\mathrm{HNO}_{3}$ ) were prepared anew for use in irradiation experiments $2 \mathrm{a}$ and $2 \mathrm{~b}$, and special irradiation experiment (see section SI C.1.7).

\section{SI C.1.5. Calibration lines}

Stock and working solutions of the flavones, $\mathrm{Al}^{3+}$, and $\mathrm{HNO}_{3}$ were used for preparing the calibration solutions with volumetric pipettes and $5 \mathrm{~mL}$ volumetric flasks. In all cases, freshly prepared aerated methanol-water 8:2 (v/v) was added to the marks of those flasks. After homogenization, solutions were kept in the dark at room temperature for more than 60 min prior to transferring aliquots to HPLC vials. Leftovers of the calibration solutions were stored in a 
refrigerator. Vials with calibration solutions were placed in an HPLC autosampler for RPHPLC-UV analysis (see section SI C.1.9 below) on the same day of their preparation. In all cases, they were analysed $\leq 18 \mathrm{~h}$ after the start of the HPLC sample sequences.

The calibration lines were constructed using peak areas of the $350 \mathrm{~nm}$ traces (lut and $\mathbf{l m g}$ ) and of the $340 \mathrm{~nm}$ traces (ldg). A straight line mathematical model with intercept set to zero was fit through the experimental data. Equations of the best-fit lines were obtained together with coefficient of determination $\left(r^{2}\right)$ values. These regression analyses were carried out via the least-squares method using Microsoft Excel.

\section{SI C.1.6. Solutions used for the irradiation experiments}

This section reports the preparation of the solutions irradiated in experiments $1 \mathrm{a}, 1 \mathrm{~b}, 2 \mathrm{a}, 2 \mathrm{~b}$, and special irradiation experiment (see section SI C.1.7). These solutions were prepared on the day each irradiation experiment started (day 1; see section SI C.1.7). After being let come to room temperature in the dark, stock and working solutions of the flavones, $\mathrm{Al}^{3+}$, and $\mathrm{HNO}_{3}$ were used for preparing the solutions with volumetric pipettes and volumetric flasks. The concentration of $\mathrm{HNO}_{3}$ of the irradiated solutions was $0.35 \mathrm{mM}$. This was achieved by adding working solution of $\mathrm{HNO}_{3}$ to all flasks, except to those containing lut and $\mathrm{Al}^{3+}$ in a ratio 1:10. In this case, the lowering of the $\mathrm{pH}$ was due to the Lewis acid $\mathrm{Al}^{3+}$, rather than to the $\mathrm{HNO}_{3}$ or to a combination of both. Aerated methanol-water 8:2(v/v) was added to the marks in all cases. After homogenization, solutions were kept in the dark at room temperature not less than 60 min before the cuvettes in which they were irradiated were filled (not using Pasteur pipettes to prevent possible contamination), and aliquots were transferred to HPLC vials. Furthermore, aliquots of these solutions were used for the spectrophotometric analyses (see section SI C.1.8). Unnecessary exposure of solutions to light was avoided at all times. Notes:

- The 60 min-interval between the preparation of the solutions and their use was an arbitrary choice motivated by the fact that flavonoid- $\mathrm{Al}^{3+}$ complexation does not reach equilibrium immediately. This has been monitored spectrophotometrically by Surowiec et al. [4] and visually observed during this work. The intensity of the colour of $\mathrm{HNO}_{3}$ containing solutions of lut and $\mathrm{Al}^{3+}$ (ratios 5:1 and 1:1) seemed to increase over time in a preliminary experiment.

- Code of solutions used: flavone $\left[\right.$ flavone] $-\mathrm{Al}_{[\mathrm{Al}]}$, in which [flavone] $=[\text { flavone }]_{0}, \mathrm{Al}=\mathrm{Al}^{3+}$, and concentrations are expressed in $\mathrm{mM}$.

\section{SI C.1.7. Irradiation experiments}

The solutions prepared as described above were irradiated using a set-up consisting of a magnetic stirrer (RCT basic, IKA Labortechnik; setting of stirring rate: 5), a phosphor-coated low pressure mercury vapour lamp, and an air blower $(220 \mathrm{~V}, 700 \mathrm{~W})$ for cooling down the system. All this was placed inside a box prepared from cardboard boxes. The system was generally well closed, apart from a large opening at the front, and two smaller openings at the back and top. The front opening, used for sampling, had a removable cardboard cover. The two other openings had the functions of: i. making room for all cables and pole of the retort stand, and ii. dissipation of heat. The surroundings of the set-up were further protected from radiation originating from the lamp by covering the box with cloth of black colour. Adhesive tapes and 
small pieces of cardboard were used for making slots for the cuvettes on the cover plate of the magnetic stirrer. The distance from the front window of the cuvettes to the centre of the lamp was $2.02 \pm 0.04 \mathrm{~cm}$ (3/4-inch). Considering the diameter of the lamp, the distance from the front window of the cuvettes to the closest edge of the lamp was 1/2-inch. Pictures of the setup are seen in Figure SI C.1.

The lamp was aligned equidistantly from the cuvettes prior to irradiations. The lamp, air blower, and magnetic stirrer were switched on 1.0-1.3 h before the beginning of each irradiation experiment for warm-up of the lamp and system. The observations reported were chiefly made during five irradiation experiments. They are referred to as $1 \mathrm{a}$ and $1 \mathrm{~b}$ (1st irradiation replicate), $2 \mathrm{a}$ and $2 \mathrm{~b}$ (2nd irradiation replicate), and special irradiation experiment. During the first four irradiation experiments, the eight solutions - lut $_{0.10}, \mathbf{l u t}_{0.10}-\mathrm{Al}_{0.02}, \mathbf{l u t}_{0.10}-\mathrm{Al}_{0.10}, \mathbf{l u t}_{0.10}-\mathrm{Al}_{1.00}$, lut $_{0.05}, \mathbf{~ I m g}_{0.05}, \mathbf{I d g}_{0.05}$, and $\mathbf{l d g _ { 0 . 0 5 }}-\mathrm{Al}_{0.05}$-were irradiated in duplicate. Solutions lut $\mathbf{l}_{0.20}$ and lut $_{0.10}-\mathrm{Al}_{0.99}$ were irradiated during the special irradiation experiment, with a filter blocking radiation of wavelengths shorter than $\sim 420 \mathrm{~nm}$ (420 nm cut-off filter) being placed in front of the cuvette containing lut $\mathrm{l}_{0.10}-\mathrm{Al}_{0.99}$ (Figs. SI C.1 and SI C.5).

The temperature inside the cardboard box — next to the irradiation site - was measured at different time-points during irradiation experiments $1 \mathrm{a}-2 \mathrm{~b}$ using a thermocouple. The recorded temperatures ranged from 29 to $34{ }^{\circ} \mathrm{C}$. Note: Due to fluctuation of the temperature readings $\left(\sim 0.5^{\circ} \mathrm{C}\right)$, a small Erlenmeyer with water was placed inside the cardboard box-also next to the irradiation site - for use during the special irradiation experiment. The Erlenmeyer was closed with a rubber stopper having a hole in it, through which a mercury thermometer was passed. The temperature at which the irradiation took place was measured at five time-points using both devices, with the outcome being $30-34{ }^{\circ} \mathrm{C}$ (thermocouple, with the fluctuation of the readings being only $0.1{ }^{\circ} \mathrm{C}$ this time) and $31-35^{\circ} \mathrm{C}$ (mercury thermometer).

Four solutions were irradiated simultaneously during irradiation experiments $1 \mathrm{a}-2 \mathrm{~b}$, as there were places for four cuvettes on the magnetic stirrer. Four glass cuvettes of $3.5 \mathrm{~mL}-$ with round PTFE tight-fit stoppers - having light paths of $10.00 \mathrm{~mm}$ and nearly identical UV-vis absorption spectra were used (Fig. SI C.9). The place in the set-up and the cuvette in which each solution was going to be irradiated were assigned randomly. A small magnetic stir bar was placed in each cuvette. As described in section SI C.1.6, no Pasteur pipettes were used to transfer the solutions from the volumetric flasks to the cuvettes. Notes:

- As the cuvettes were not at the centre of the cover plate, stirring of the solutions was not optimal.

- The ISO 105-B02 norm contributed to the ideas of having an air blower in the set-up and no radiation of wavelengths shorter than $\sim 300 \mathrm{~nm}$.

- In a preliminary experiment, cuvettes with square openings - and the corresponding disposable plastic caps-were observed to be unsuitable for use due to loss of solvent during the irradiation.

The photodecomposition of lut, lmg, and ldg was monitored by RP-HPLC-UV (see section SI C.1.9). Prior to the beginning of the irradiation experiments, aliquots of the solutions were transferred from the volumetric flasks to HPLC vials. These aliquots were referred to as having been collected at $\mathrm{t}_{0}(\mathrm{t}=0 \mathrm{~h})$. Furthermore, $0.05 \mathrm{~mL}$ aliquots of the solutions were collected at $\mathrm{t}$ $=1.0 \mathrm{~h}, 2.0 \mathrm{~h}, 3.0 \mathrm{~h}, 4.0 \mathrm{~h}, 8.0 \mathrm{~h}$, and $24.0 \mathrm{~h}$, as irradiations started on one day (day 1) and finished on the following one (day 2). Samplings were carried out as follows: Cuvettes were removed from the set-up, and aliquots of the solutions were transferred to HPLC vials of 
maximal residual volume of $6 \mu \mathrm{L}$ using Pasteur pipettes. Once closed, the cuvettes were placed back to their positions in the set-up. Each sampling took 4-6 min. For increased stability of the irradiation, the system was kept running during each sampling, i.e., lamp, air blower, and magnetic stirrer remained on. For safety reasons, special safety glasses (Laser 2 000; nearly no transmission of light in the range 190-534 nm) were worn - and the removable cardboard cover was placed at the front opening of the box-during sampling. Notes:

- Special irradiation experiment: Aliquots of the solutions were collected at $\mathrm{t}=2.0 \mathrm{~h}, 4.0$ $\mathrm{h}, 8.0 \mathrm{~h}$, and $24.0 \mathrm{~h}$, i.e., as irradiation experiments $1 \mathrm{a}-2 \mathrm{~b}$, except for $\mathrm{t}=1.0 \mathrm{~h}$, and $3.0 \mathrm{~h}$.

- In all cases, samples were analysed by HPLC undiluted.

- Irradiation experiments $1 \mathrm{a}-2 \mathrm{~b}$ and special irradiation experiment: All solutions - $\mathrm{t}_{0}$ through $\mathrm{t}_{24}$-were injected in the HPLC $24 \mathrm{~h}$ or less after sampling.

The photodecomposition of the flavones over time was quantified by RP-HPLC-UV (see section SI C.1.9) using peak areas of the $350 \mathrm{~nm}$ traces (lut and $\mathbf{I m g}$ ) and of the $340 \mathrm{~nm}$ traces (ldg), and the calibration lines described above. Except for solution lut $\mathbf{l}_{0.20}$, the [flavone] of all samples - $\mathrm{t}_{0}(\mathrm{t}=0 \mathrm{~h})$ through $\mathrm{t}_{24}(\mathrm{t}=24 \mathrm{~h})$ - of each irradiated solution was comprised within the range of concentrations used for construction of the calibration lines. A straight line mathematical model was fit through the experimental data $\{[$ flavone $](\mathrm{mM}) v$ s. time $(\mathrm{min})\}$. This regression analysis was carried out for each of the solutions irradiated during experiments $1 \mathrm{a}-2 \mathrm{~b}$ and special irradiation experiment via the least-squares method using Microsoft Excel. Alike for the calibration lines, equations of the best-fit lines were obtained together with coefficient of determination $\left(r^{2}\right)$ values.

The photodecomposition of the flavones was described as being of zero-order, in which the rate of reaction equals the rate constant $(\mathrm{d}[$ flavone $] / \mathrm{d} t=k)$. As the integrated form of the zeroorder rate law is [flavone] $=k t+[\text { flavone }]_{0}$, the $k$ values were obtained from the slope of the equations $(k=-$ slope). The relative rates of photodecomposition were calculated through the formula $k_{\mathrm{j}} / k_{\mathrm{i}}$, in which i was lut in lut $\mathbf{t}_{0.11}$, lut $\mathbf{t}_{0.10}$, or $\mathbf{l u t}_{0.05}$, and $\mathrm{j}$ was lut, lmg, or ldg in other solutions.

The comparison of the rates of photodecomposition of lut in lut $\mathbf{t}_{0.20}$, lut $\mathbf{l}_{0.11}$ and lut $_{0.05}$ was carried out similarly (see section SI C.2.7). As the highest [lut] used to construct its calibration line in presence of $\mathrm{HNO}_{3}$ was $0.13 \mathrm{mM}$, however, peak areas $\left(10^{-2} \mathrm{AU} \mathrm{s}\right) v s$. time (h) were used instead of concentrations $v s$. time. The slopes of the equations of the best-fit lines $(\mathrm{y}=\mathrm{ax}+$ b) - as well as the changes in peak areas after $24.0 \mathrm{~h}$ of irradiation, relative to those at $\mathrm{t}_{0}$-were compared. Notes:

- Data used for this purpose were acquired during irradiation experiments 1a (lut $\left.\mathbf{l}_{0.11}\right)$ and $1 \mathrm{~b}\left(\mathbf{l u t}_{0.05}\right)$, and special irradiation experiment (lut $\left.\mathbf{l}_{0.20}\right)$.

- The label lut $t_{0.20}$ was based on the weighed quantity of lut, and not on its concentration measured by RP-HPLC-UV using the calibration line, as the case of lut - as well as that of Img and ldg - in all other solutions. 

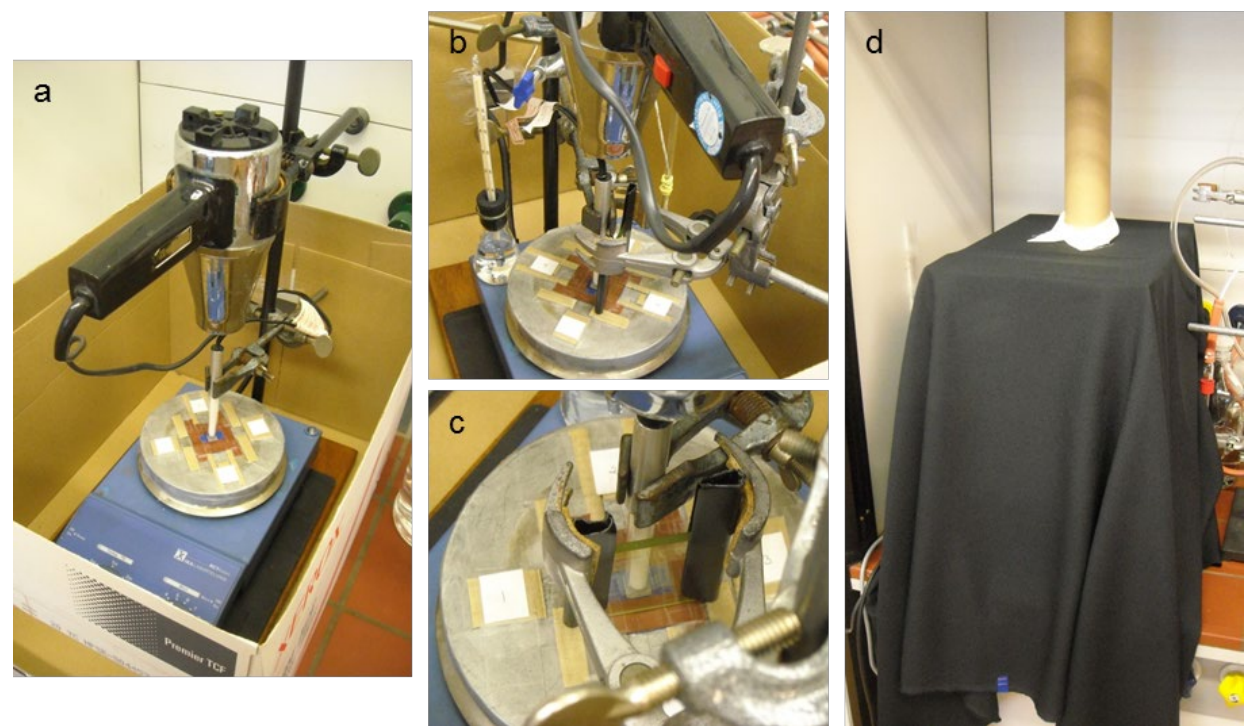

Figure SI C.1. Irradiation set-up: a) open, without the thermocouple; b) as used in the special irradiation experiment, with both temperature-measuring devices-mercury thermometer and thermocouple (attached to a glass rod using a rubber band) - visible; c) close-up of the $420 \mathrm{~nm}$ cutoff filter (special irradiation experiment); d) closed.

\section{SI C.1.8. Spectrophotometric analyses}

Spectrophotometric analyses were carried out using a Cary 100 Scan UV-vis spectrophotometer (Varian). Conditions: Double-beam mode, $1.0 \mathrm{~nm}$ spectral bandwidth, 800 $\mathrm{nm}$ to $200 \mathrm{~nm}$ in $1 \mathrm{~min}$. Lamp warm-up prior to first measurement: Not less than $1 \mathrm{~h}$. Quartz cuvettes of $3.5 \mathrm{~mL}$ having a light path of $10.00 \mathrm{~mm}$ were used. On day $\mathbf{1}$, the remainders of the solutions used for irradiation - temporarily kept at room temperature in the dark-were diluted $5 \times$ using volumetric pipettes and volumetric flasks. Volumes were completed with aerated methanol-water 8:2 (v/v). The UV-vis absorption spectra of these diluted samples were recorded against aerated methanol-water 8:2 (v/v). On day 2, $\mathrm{t}_{24}$ solutions were diluted and analysed in the same way. Notes:

- In the case of lut $\mathbf{t}_{0.20}, \mathrm{t}_{0}$ and $\mathrm{t}_{24}$ solutions were diluted $10 \times$.

- The UV-vis absorption spectra of the glass cuvettes mentioned in section SI C.1.7 were measured against air.

- The UV-vis absorption spectrum of the $420 \mathrm{~nm}$ cut-off filter was measured against air. The filter was not washed before measurement; only nitrogen gas was blown onto it. 


\section{SI C.1.9. HPLC analyses}

Calibration solutions and samples used for irradiation experiments 1a-special irradiation experiment were analysed by RP-HPLC-UV undiluted. Analyses were carried out on a Waters system, equipped with C18 $5 \mu \mathrm{m}$-particle size column. Further details of the HPLC system and column used are described in publication by Villela et al. [1] (p. 8545, method using the HPLC column). See the referred publication also for information on: Eluent, its flow rate and composition (solvents and gradient); volume of injection; and temperature of the column oven. The photodiode array detector scan range was $245-500 \mathrm{~nm}$. Peak areas of lut and $\mathbf{l m g}$ were obtained using $350 \mathrm{~nm}$ traces, and for those of $\mathbf{l d g}, 340 \mathrm{~nm}$ traces were used. Chemicals used for preparing solvent A of the HPLC eluent were: Formic acid (98+\%; Acros Organics); ammonium formate ( $\geq 99.0 \%$; Fluka Analytical); EDTA 4Na $2 \mathrm{H}_{2} \mathrm{O}(98 \%$; Aldrich-Chemie).

Valid "positive" sample(s) were analysed during every sample sequence for monitoring the performance of the HPLC system (quality of the column and functioning of the lamp). They were prepared using the sample of aerial parts of dried and ground weld described by Villela $e t$ $a l$. [1]. Such samples were prepared according to the procedure described in section 2.2 of that publication. "Positive" samples had been observed to be stable (remain valid) upon storage for three days in the refrigerator or 15 days in the freezer [1]. Solvent was analysed after a "positive" sample, for evaluation of the magnitude of sample carry-over. Notes:

- Measured quantities of lut, Img, and Idg in the plant material remained similar (agreement $\geq 87 \%$; exception were the results of one sample, which is regarded as an outlier) to those obtained more than one year earlier, referred to in the publication by Villela et al. [1] (Table 4, footnote d).

- Sample carryovers were $<0.1 \%$.

- Retention times of the four compounds (incl. i.s.) differed $\leq 1.2 \%$ from those observed in analyses carried out more than one year earlier.

\section{SI C.1.10. Recording of the emission spectrum of the lamp used for the irradiation experiments}

The emission spectrum of the phosphor-coated low pressure mercury vapour lamp used was recorded using an absorption spectrometer (LP920 - Edinburgh Instruments, Livingston/United Kingdom), equipped with a flashlamp pumped Q-switched Nd:Yag laser (Brilliant - Quantel, Les Ulis/France). The instrument was calibrated with radiation of $355 \mathrm{~nm}$, and $710 \mathrm{~nm}$ (second harmonic). The lamp was charged through the $220 \mathrm{~V}, 50 \mathrm{~Hz}$ power supply. In this way, the emission spectra of two lamps (same model; one old and one new) were recorded. This was done using two power supplies (same model; one old and one new).

\section{SI C.1.11. Apparent pH measurements}

Measurements were carried out by the use of an InoLab pH 720 (WTW; Weilheim/Germany) $\mathrm{pH}$ meter and a SenTix 20 (WTW; Weilheim/Germany) pH combination electrode. Technical buffers $\mathrm{pH} 4.01,7.00$ and 10.00 (WTW; Weilheim/Germany) were used for calibration of the electrode prior to measurements, and for checking the calibration afterwards. In the case of buffer solutions $\mathrm{pH} 4.01$ and 7.00, the difference between the $\mathrm{pH}$ values measured after the 
apparent $\mathrm{pH}$ measurements and the nominal $\mathrm{pH}$ values was $\leq 0.03$ units. The apparent $\mathrm{pH}$ of the following solutions are reported:

- Calibration solutions. These solutions were stored in the refrigerator, and the measurements were carried out the day after their preparation. Note: Lut calibration solutions were not kept refrigerated as the other ones. They were at room temperature part of the time. As expected, however, this was of no influence on the measurements (Tables SI C.1 and SI C.2).

- Solutions used for the irradiation experiments at $\mathrm{t}_{0}$ ( 2 nd irradiation replicate, and lut $\mathbf{l}_{0.20}$ ). Also these solutions were stored in the refrigerator, and the measurements were carried out the day after their preparation (day 2).

Notes:

- The term apparent $\mathrm{pH}$ is used as the solvent of these solutions was not water, but methanol-water 8:2 (v/v).

- Remarks concerning the measurements (someone from WTW's technical personnel, personal communication; March 31, 2014):

○ Due to the low percentage of water in the samples, the readings fluctuated considerably. Although this could be improved by the use of another type of electrode, it is assumed that measured apparent $\mathrm{pH}$ values can be reliably compared. Comparison of the measured apparent $\mathrm{pH}$ values of the calibration solutions with those of the solutions used for the irradiation experiments at $\mathrm{t}_{0}$ supports this assumption (Tables SI C.1 and SI C.2).

O Although the use of the technical buffer $\mathrm{pH} 10.00$ for calibration of the electrode was incorrect, this was of no influence on the calibration in the range of 3-7 $\mathrm{pH}$ units. All reported apparent $\mathrm{pH}$ values ranged between 3.4 and 3.7.

\section{SI C.1.12. Assessment of the stability of $1 \mathrm{mg}$ and $\mathrm{ldg}$ in presence of $\mathrm{HNO}_{3}$}

Aliquots of $\sim 1 \mathrm{~mL}$ of each of the five Img calibration solutions were placed in $25 \mathrm{~mL}$ screwcap test-tubes on the day of their preparation, and heated at $60-65{ }^{\circ} \mathrm{C}$ overnight using an oil bath. The concentration of $\mathrm{HNO}_{3}$ of the solutions was $0.35 \mathrm{mM}$ (Table SI C.2). Vials with the heat-treated solutions were placed in an HPLC autosampler for RP-HPLC-UV analysis - as described in section SI C.1.9 - on the day the experiment ended. They were analysed within 11 $\mathrm{h}$ from the start of the HPLC sample sequence. The same was done with the $\operatorname{ldg}$ (without $\mathrm{Al}^{3+}$ ) calibration solutions. All described regarding Img calibration solutions holds true also for those of Idg, with the exception that the solutions were kept at $\sim 65^{\circ} \mathrm{C}$. Percentages of the areas of the peaks of the flavones after the heating treatment relative to the original areas of the peaks (section SI C.1.5) were calculated. 
SI C.1.13. Experiment on the effect of increasing quantities of $\mathrm{Al}^{3+}$ (alum) bound to mordanted wool on the photo-stability of the dye of weld - part A (carried out in Wageningen)

\section{Mordanting step}

Ready-to-dye wool was mordanted with a $10 \mathrm{~g} \mathrm{~L}^{-1}$ aqueous (deionised water) solution of alum-liquid-wool quotient: $17 \mathrm{~mL} \mathrm{~g}^{-1}$ - through heating to $90+{ }^{\circ} \mathrm{C}$ during $0.5-1 \mathrm{~h}$, followed by a $1 \mathrm{~h}$-period at $\sim 95^{\circ} \mathrm{C}$ [5] (Supporting Information, page 9). The average of the weights of the obtained $\sim 5 \times 6 \mathrm{~cm}$ pieces of mordanted wool was $0.9 \mathrm{~g}$.

Essentially the same procedure was carried out three more times: With deionised water only (no alum, blank-mordanting), and with $2 \mathrm{~g} \mathrm{~L}^{-1}$ and $15 \mathrm{~g} \mathrm{~L}^{-1}$ aqueous solutions of alum. In each case, the average of the weights of the obtained $\sim 5 \times 5 \mathrm{~cm}$ pieces of mordanted wool was 0.8 g. Note:

- In the case of the $2 \mathrm{~g} \mathrm{~L}^{-1}$ aqueous solution of alum, there was poor stirring of the wool during the mordanting process. However, this did not influence the measurements of $L^{*}$, $a^{*}$, and $b^{*}$ quantities (CIELAB colour space) for the pieces of weld-dyed wool (see part $\mathrm{B}$ below, and the relative standard deviation values in Table SI C.4).

- Differently from the published procedure, the rinsing of the mordanted wool was split in two: A minor rinsing was carried out after the mordanting step, and an additional one was carried out at a later stage.

\section{Dyeing step}

Four $\sim 5 \times 6 \mathrm{~cm}$ pieces of wool mordanted with the $10 \mathrm{~g} \mathrm{~L}^{-1}$ aqueous solution of alum were dyed with a $96 \%$ ethanol-deionised water $3: 1(\mathrm{v} / \mathrm{v})$ extract of the sample of the aerial parts of dried and ground weld at $80{ }^{\circ} \mathrm{C}$ for $15 \mathrm{~min}$. This was done according to the procedure described by Villela et al.[5] (Supporting Information, page 2), with the following relevant exceptions: After filtration of the extract into a $250 \mathrm{~mL}$ round-bottom flask and removal of the $96 \%$ ethanol, $60 \mathrm{~mL}$ of deionised water were added to the flask, with the dyeing process taking place in the round-bottom flask itself. A reflux condenser was connected to this flask, which was heated using a water-bath. Deionised water was used to rinse the pieces of dyed wool, which were, then, hung to dry. The dried pieces of dyed wool were handled with gloves, and stored in the dark. Essentially the same procedure was carried out three more times: For dyeing pieces of blank-mordanted wool, and of wool mordanted with $2 \mathrm{~g} \mathrm{~L}^{-1}$ and $15 \mathrm{~g} \mathrm{~L}^{-1}$ aqueous solutions of alum. Notes:

- All cases: Differently from the published procedure, no aluminium foil was used to cover the dyeing baths.

- In the case of the dyeing of the wool mordanted with $10 \mathrm{~g} \mathrm{~L}^{-1}$ aqueous solution of alum, the ratio of volume of extraction solvent to weight of weld sample was $18 \mathrm{~mL} \mathrm{~g}^{-1}$, whereas in all other cases this ratio was $20 \mathrm{~mL} \mathrm{~g}^{-1}$, as in the published procedure.

- Dyeing of the blank-mordanted wool: One of the pieces fell outside the $250 \mathrm{~mL}$ roundbottom flask while being transferred to the dyeing bath. Although it was immediately resoaked in the deionised water used for the pre-treatment of the mordanted wool, this could have led to inhomogeneity of the colour, as part of the piece of wool touched the tap water of the water-bath. In spite of the relative standard deviation of the measured $b^{*}$ 
quantities of the pieces of dyed wool (CIELAB colour space; part B below) being $6.3 \%$, those of the calculated chroma $\left(C^{*}\right.$ ab) and hue angle $\left(h_{\mathrm{ab}}\right)$ were $\leq 6.0 \%$ (Table SI C.4).

- No proper dyeing took place in the case of the dyeing of the wool mordanted with $15 \mathrm{~g}$ $\mathrm{L}^{-1}$ aqueous solution of alum. The pieces of "dyed wool" looked similar to those of the dyed blank-mordanted wool. The reason for this could neither be traced back to the mordanting process nor to the dyeing process. Thus, these pieces of wool were discarded.

\section{SI C.1.14. Experiment on the effect of increasing quantities of $\mathrm{Al}^{3+}$ (alum) bound to mordanted wool on the photo-stability of the dye of weld - part B (carried out in Steenbergen)}

The following specific compounds/material were used: Detergent solution used for determining the wash-fastness of colours contained ECE phosphate detergent B (SDC, Bradford/UK) and sodium perborate $\left(\mathrm{NaBO}_{2} \cdot \mathrm{H}_{2} \mathrm{O}_{2} \cdot 3 \mathrm{H}_{2} \mathrm{O}\right.$; BDH Laboratory, Poole/England); weathering tester used for determining the light-fastness of the colours [QUV Accelerated Weathering Tester (QPanel Company, Cleveland/USA)].

\section{Colours of the weld-dyed samples of wool}

$L^{*}, a^{*}$ and $b^{*}$ quantities (CIELAB colour space) were measured. Each of the three cases (dyed blank-mordanted wool, and dyed wool that had been mordanted with $2 \mathrm{~g} \mathrm{~L}^{-1}$ and $10 \mathrm{~g} \mathrm{~L}^{-1}$ aqueous solutions of alum): Four pieces of wool $(n=4)$. The light-beam of the spectrophotometer was used in "one large spot"-mode. Afterwards, chroma $\left(C^{*}\right.$ ab $)$ and hue angle $\left(h_{\mathrm{ab}}\right)$ were calculated for each of the pieces via the equations $C^{*} \mathrm{ab}=\left(a^{* 2}+b^{* 2}\right)^{1 / 2}$ and $h_{\mathrm{ab}}$ $=\arctan \left(b^{*} / a^{*}\right)[6]$. Data were processed as follows: Standard deviation values were expressed with one significant digit, and average values were rounded up accordingly.

Light-fastness of the colours, including measurement of $L^{*}, a^{*}$, and $b^{*}$ quantities (CIELAB colour space) for the irradiated samples

The light-fastness of the colours of the pieces of dyed wool was determined according to the ISO 105-B02 norm. Each of the three cases: Two pieces of wool were irradiated in the weathering tester $(\mathrm{n}=2)$. The scale 1 (poor) -8 (excellent) - with 3 being the acceptable lower limit—was used for reporting the results [7]. $L^{*}, a^{*}$, and $b^{*}$ quantities (CIELAB colour space) were measured for the irradiated samples as described above, except that the light-beam of the spectrophotometer was used in "one small spot"-mode (measured at five places of each piece of wool). Afterwards, the CIELAB colour difference ( $\Delta E^{*}$ ab) values were calculated from the average values of the measured $L^{*}, a^{*}$, and $b^{*}$ quantities before (Table SI C.4) and after irradiation (not shown) via the equation $\Delta E^{*} \mathrm{ab}=\left[\left(\Delta L^{*}\right)^{2}+\left(\Delta a^{*}\right)^{2}+\left(\Delta b^{*}\right)^{2}\right]^{1 / 2}[6]$.

\section{Wash-fastness of the colours}

The wash-fastness of the colours of the pieces of dyed wool was determined according to the ISO 105-C06 norm. The assay was carried out at $40{ }^{\circ} \mathrm{C}$ for $30 \mathrm{~min}$. Each of the three cases: Two pieces of wool were used - with only one of them being washed (thus, $n=1$; one pair of samples). Afterwards, both pieces were visually compared and $L^{*}, a^{*}$ and $b^{*}$ quantities (CIELAB colour space) were measured. The scale 1 (poor)-5 (excellent) - with 3-4 being the acceptable lower limit—was used for reporting the results [7]. 
SI C.1.15. Another experiment on the effect of increasing quantities of $\mathrm{Al}^{3+}$ (using aluminium sulphate and tartaric acid this time) bound to mordanted wool on the photostability of the dye of weld (carried out in Steenbergen)

The following specific material was used: Commercial extract of weld (Rubia Yellow; Rubia Pigmenta Naturalia, later Rubia Natural Colours, Steenbergen/The Netherlands); textile auxiliary agent Biavin 109 (mixture described as emulsified fatty compound, containing benzyl alcohol; aims at protecting the fibre from fibre-to-fibre and fibre-to-metal action; CHT R. Beitlich, Tübingen/Germany); apparatus that can be used for wool dyeing, mordanting, washing and rinsing (Linitest Original Hanau; Heraeus, Hanau/Germany).

Pieces of ready-to-dye wool weighing $40 \mathrm{~g}$ each were pretreated at room temperature with a $0.3 \mathrm{~g} \mathrm{~L}^{-1}$ aqueous solution of the textile auxiliary agent. The excess solution was removed by centrifugation. The primary function of this step was to wet the wool prior to its mordanting.

The pretreated wool was mordanted with an aqueous (tap water; water hardness classification: DH4) solution of aluminium sulphate and tartaric acid (liquid-wool quotient: 10 $\mathrm{mL} \mathrm{g}^{-1}$ ). This was done at $95^{\circ} \mathrm{C}$ using the Linitest Original Hanau apparatus operating at $2 \mathrm{~kW}$ during $1.75 \mathrm{~h}$. The system was left to cool down to below $50{ }^{\circ} \mathrm{C}$. Then, the mordanted wool was rinsed twice using tap water at room temperature. The excess water was removed by centrifugation. This procedure was carried out with $0.2,2,10$ and $25 \mathrm{~g} \mathrm{~L}^{-1}$ solutions of aluminium sulphate tetradecahydrate. The concentration of tartaric acid was $1.3 \mathrm{~g} \mathrm{~L}^{-1}$ in all cases.

Each piece of mordanted wool was dyed with an aqueous (tap water) solution of the commercial extract of weld [2.5\% (w/w) extract-wool; liquid-wool quotient: $\left.10 \mathrm{~mL} \mathrm{~g}^{-1}\right]$. This was done at $100{ }^{\circ} \mathrm{C}$ using the Linitest Original Hanau apparatus operating at $2 \mathrm{~kW}$ during 1.75 $\mathrm{h}$. The dyed wool was rinsed with a $0.5 \mathrm{~g} \mathrm{~L}^{-1}$ aqueous solution of the SARABID PAW detergent at $95^{\circ} \mathrm{C}$ using the same machine. Tap water at $95^{\circ} \mathrm{C}$ was used to rinse the dyed wool further, which was, then, centrifuged for removal of the excess water.

$L^{*}, a^{*}$ and $b^{*}$ quantities (CIELAB colour space) were measured. The light-beam of the spectrophotometer was used in "one large spot"-mode. In each case, chroma $\left(C^{*}\right.$ ab $)$ and hue angle $\left(h_{\mathrm{ab}}\right)$ were calculated as above. The light-fastness of the colours was determined at $\mathrm{TO}_{2} \mathrm{C}$ (Ghent/Belgium) according to the ISO 105-B02 norm. Also here, the scale 1 (poor)-8 (excellent) was used for reporting the results.

SI C.1.16. Colours of alum-mordanted wool dyed with lut, lmg, and ldg

The following specific compounds/material were used: Lut (used for dyeing the wool; $96 \%$ by NMR; Indofine Chemical Company, Hillsborough/USA); Img (used for dyeing the wool; 95\% by NMR; Extrasynthese, Genay/France); Idg (used for dyeing the wool; $86 \%$ by NMR; Extrasynthese, Genay/France); $\sim 5 \times 6 \mathrm{~cm}$-pieces of wool mordanted with a $10 \mathrm{~g} \mathrm{~L}^{-1}$ aqueous solution of alum weighing $0.9 \mathrm{~g}$ each (described above); DMSO ( $99.9 \%$ for spectroscopy; Acros Organics, Geel/Belgium).

Stock solutions of lut and of Img were brought to room temperature in the dark. Separately, aliquots of the solutions were transferred to $50 \mathrm{~mL}$ round-bottom flasks using volumetric pipettes. In this way, $3.25 \mathrm{mg}(11.4 \mu \mathrm{mol})$ of lut, and $5.11 \mathrm{mg}(11.4 \mu \mathrm{mol})$ of $\mathbf{l m g}$ were transferred to the flasks. Solvents were removed by the use of a rotatory evaporator. Finally, 
flasks were closed with a stopper and stored in refrigerator. Note: Stock solutions of lut and of Img were prepared as described above, with the following relevant exceptions:

- Lut stock solution:

○ Concentration: $232 \mu \mathrm{g} \mathrm{mL}^{-1}(0.81 \mathrm{mM})$.

- Lmg stock solution:

○ All lmg dissolved after storing the partially filled volumetric flask in refrigerator; i.e., there was no need for using the incubator shaker.

○ Concentration: $341 \mu \mathrm{g} \mathrm{mL}^{-1}(0.76 \mathrm{mM})$.

- Both lut and Img stock solutions:

○ Non-aerated methanol-water 8:2 (v/v) was used. This solvent mixture was prepared using deionized water (EasyPure UV system), and was both used on the day of preparation and stored in refrigerator prior to use.

A different procedure was carried out for ldg. The flavone was weighed directly in a $50 \mathrm{~mL}$ round-bottom flask using the balance operating in 0.1 mg-least division mode. In this way, 7.1 $\mathrm{mg}(11.6 \mu \mathrm{mol})$ of $\mathbf{l d g}$ was transferred to the flask. Also in this case, the flask was closed with a stopper and stored in refrigerator. Note: The large weighing error is of little relevance in view of the nature of the experiment.

Wool was dyed with the individual flavones. In each case, one piece of the mordanted wool was dyed in the round-bottom flask containing lut, lmg, or ldg. This was done at $80{ }^{\circ} \mathrm{C}$ for 15 min, generally according to the procedure described by Villela et al. [5] (Supporting Information, page 2). Note: The procedure was further adapted as follows:

- $17 \mathrm{~mL}$ of deionized water (EasyPure UV system) were added to each round-bottom flask. Thus, the liquid-wool ratio remained $\sim 20 \mathrm{~mL} \mathrm{~g}^{-1}$.

- The dyeing baths were heated by the use of a water-bath.

The dyeing baths were sampled after removal of the pieces of dyed wool, while still warm and stirring. Five times dilution of each $1.0 \mathrm{~mL}$ (measuring pipette) dyeing bath sample was done with DMSO (automatic pipette). Vials containing the diluted dyeing bath solutions were stored in the refrigerator. Once at room temperature, these samples were filtered via a syringe filter prior to RP-HPLC-UV analysis (see section SI C.1.9).

Another piece of the mordanted wool was dyed with an extract of weld in a similar way, with $420 \mathrm{mg}$ of the sample of the aerial parts of dried and ground weld being extracted with 96\% ethanol-water 3:1 (v/v) for this [5] (Supporting Information, page 2). Volumes of solvents and glassware were downscaled according to the weight of weld sample used. Finally, a blankwithout-wool was carried out similarly, also with $420 \mathrm{mg}$ of the weld sample. However, as besides the $96 \%$ ethanol, also the water was completely removed by the use of the rotatory evaporator, $17 \mathrm{~mL}$ of deionized water (Seradest SD 2000 ion-exchanger) were added to the round-bottom flask. As in the cases of lut, lmg, and ldg, the dyeing took place in a roundbottom flask. In both cases - wool- and blank-without-wool - samples of the dyeing baths were prepared for HPLC analysis as described in the previous paragraph.

All five dyeing bath samples described in this section were analysed in one HPLC analysis sample sequence, which was completed in $<12 \mathrm{~h}$. Note: Although the sample of the dyeing bath of the wool dyed with weld was in the refrigerator for four weeks, no precipitate was seen. This was also the case for the other four samples, that were in the refrigerator less than one week.

The percentages of leftover flavones in the dyeing baths were calculated. This was done using the following calibration curves: 
- $[$ Lut $]\left(\mu \mathrm{g} \mathrm{mL} \mathrm{mL}^{-1}\right) v s$. peak area at $345 \mathrm{~nm}(\mu \mathrm{AU} \mathrm{s}): \mathrm{y}=98814 \mathrm{x}+49918\left(\mathrm{R}^{2}=0.9999\right)$

- $[\mathbf{L m g}]\left(\mu \mathrm{g} \mathrm{mL} \mathrm{mL}^{-1}\right) v s$. peak area at $345 \mathrm{~nm}(\mu \mathrm{AU} \mathrm{s}): \mathrm{y}=64571 \mathrm{x}+49805\left(\mathrm{R}^{2}=0.9999\right)$

- $[\mathbf{L d g}]\left(\mu \mathrm{g} \mathrm{mL}^{-1}\right) v s$. peak area at $345 \mathrm{~nm}(\mu \mathrm{AU} \mathrm{s}): \mathrm{y}=46221 \mathrm{x}+26160\left(\mathrm{R}^{2}=0.9999\right)$ Although these curves were constructed two years earlier, the HPLC system - checked as described in section SI C.1.9 - was performing well. Areas of lut, lmg, ldg, and i.s. peaks of the "positive" sample agreed $>90 \%$ with those of an identical sample prepared and analysed 10-11 months earlier, and used as a reference. No sample carryover was observed and, compared with this reference sample, retention times of the four compounds varied $\leq 0.1 \mathrm{~min}$. Whereas the areas of lut and Idg peaks fell within the ranges of the calibration curves, Img's calibration curve had to be extrapolated. The concentration of Img in the sample of the dyeing bath was determined to be $10 \mu \mathrm{g} \mathrm{mL} \mathrm{m}^{-1}$, whereas the concentration of the lowest calibration solution was $14 \mu \mathrm{g} \mathrm{mL}^{-1}$.

The percentages of leftover flavones in the dyeing baths were also calculated from the dyeing processes with the extracts of weld. The $345 \mathrm{~nm}$-areas of lut, Img, and ldg peaks of the wooldyeing were compared with those of the blank-without-wool.

$L^{*}, a^{*}$ and $b^{*}$ quantities (CIELAB colour space) were measured for the wool dyed with the individual flavones and with the extract of weld, and for the non-dyed alum-premordanted wool. Chroma $\left(C^{*} \mathrm{ab}\right)$ and hue angle $\left(h_{\mathrm{ab}}\right)$ were calculated as described above. In each of the four cases of dyed wool, only a part of about $5 \times 1 \mathrm{~cm}$ of the piece of wool was used. The light-beam of the spectrophotometer was used in "one small spot"-mode.

\section{SI C.2. Supplementary results and discussion SI C.2.1. Choice of solvent}

The rate of photodecomposition of flavone has been observed to be solvent-dependent, being higher in methanol than in cyclohexane[8]. Kaneta and Sugiyama[9] and Smith et al.[10] studied the photodecomposition of flavones and flavonols in aerated ethanol and methanolwater 1:1. In the work reported here, aerated methanol-water $8: 2(\mathrm{v} / \mathrm{v})$ was used. This solvent mixture has been observed to be the most efficient for the extraction of the main flavonoids of weld, among alcohols, water and mixtures thereof [11].

\section{SI C.2.2 pH adjustment}

The apparent $\mathrm{pH}$ of a $0.12 \mathrm{mM}$ solution of lut in aerated methanol-water 8:2 (v/v) was 6.8 . Upon addition of the Lewis acid $\mathrm{Al}^{3+}$, at a lut- $\mathrm{Al}^{3+} 1: 10$ ratio, it decreased to 3.5. In order to irradiate solutions having approximately the same concentration of protons, the other irradiated solutions reported here were acidified to an apparent $\mathrm{pH}$ of $3.6 \pm 0.2$ (see Table SI C.1). This was done with nitric acid, as nitrate was the counter-ion of the aluminium salt used. Lmg and Idg were observed to be stable in nitric acid-acidified solution at $\sim 65{ }^{\circ} \mathrm{C}$ overnight. In preliminary experiments, the photodecomposition of lut in nitric acid-acidified aerated methanol-water $8: 2(\mathrm{v} / \mathrm{v})$ solution was observed to be 35 to $55 \%$ slower than in non-acidified solution. This is consistent with an increase of the energy releasing tautomerism by an increased concentration of protons in solution. The observed influence of $\mathrm{pH}$ on the photodecomposition of lut is also consistent with the observation that the triplet excited state of flavone-longer- 
lived than the singlet excited state and, thus, having increased chances of reacting - is quenched by the hydrogen donor $p$-methoxyphenol[12, 13].

\section{SI C.2.3. Purity of lut, lmg, and ldg, as determined by NMR spectroscopy}

The outcomes of the determination by NMR spectroscopy of the purity of the flavones used for the preparation of solutions used for construction of the calibration lines and for the irradiation experiments (described in section SI C.1.4) are presented in this section. The origin of the signals seen in the spectra are also briefly elaborated upon.

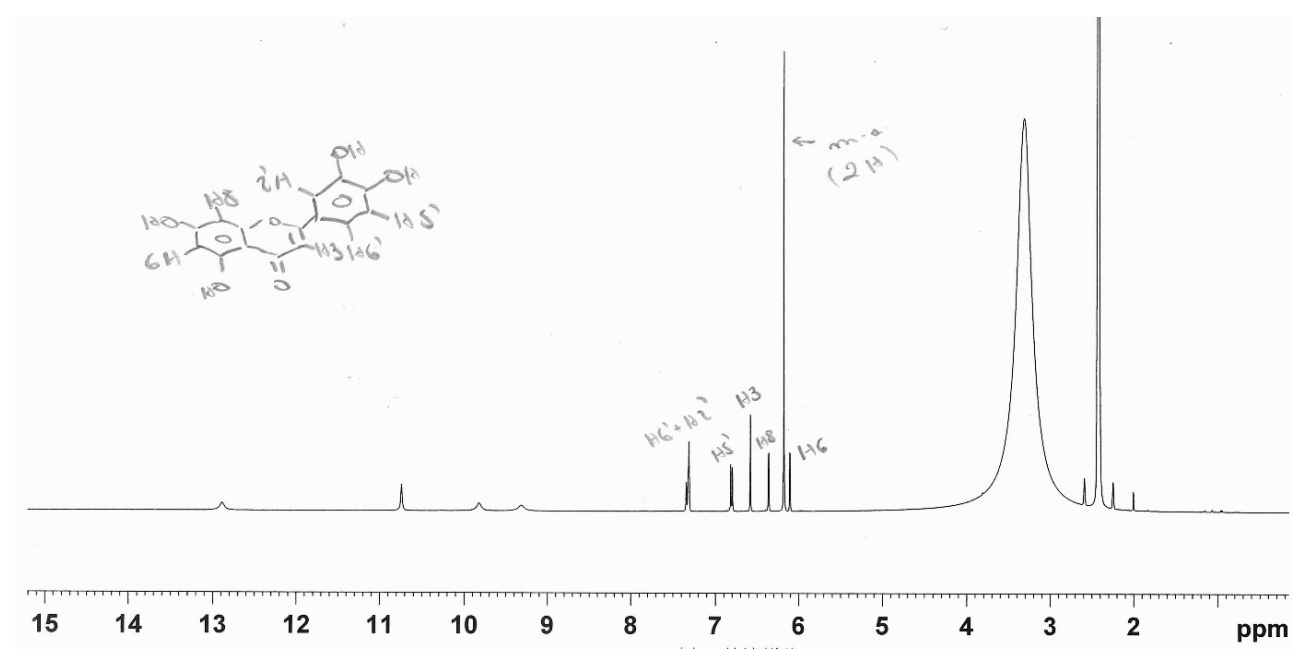

Figure SI C.2. ${ }^{1} \mathrm{H}-\mathrm{NMR}$ spectrum used for the determination of the purity of lut (Indofine Chemical Company) with maleic acid (m.a.). Signals relative to the non-exchangeable $\mathrm{H}$-atoms of the flavone and m.a. are assigned.

In addition to the signals assigned in Figure SI C.2, signals relative to the H-atoms of the following moieties and molecules are also visible: Phenolic and carboxyl groups (9.2-13.0 ppm) [14], water (2.7-4.0 ppm), DMSO and its ${ }^{13} \mathrm{C}$-satellite signals (2.2-2.6 ppm), and unknown compound(s) (0.9-1.2 ppm, $3.8 \mathrm{ppm}$, and signals of low intensity at 5.9-7.9 ppm). Signals at 1.8-2.2 ppm are likely due to $\mathrm{H}$-atoms of residual acetone and its ${ }^{13} \mathrm{C}$-satellite signals [15]. Purity was determined to be $96 \%$. 


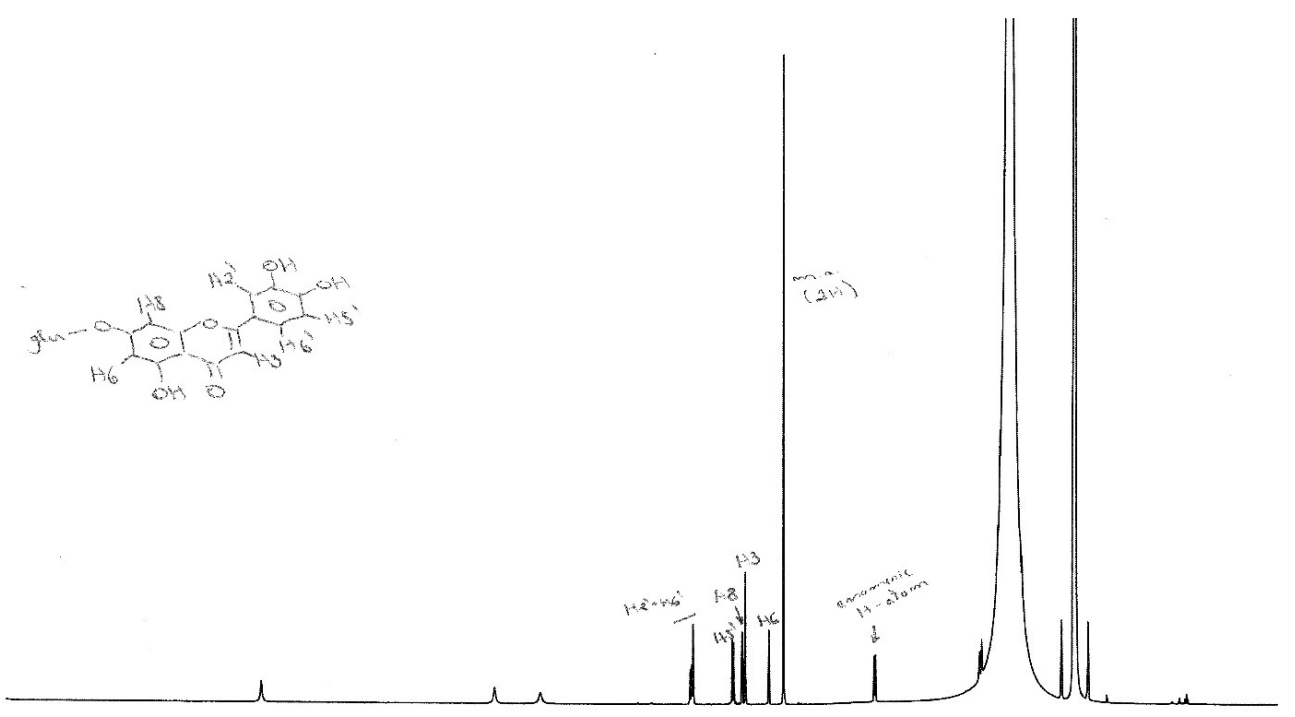

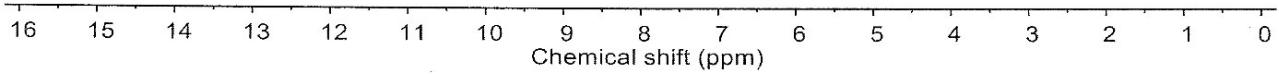

Figure SI C.3. ${ }^{1} \mathrm{H}-\mathrm{NMR}$ spectrum used for the determination of the purity of $\mathbf{I m g}$ (Extrasynthese) with maleic acid (m.a.). Signals relative to the non-exchangeable $\mathrm{H}$-atoms of the aglycone of the flavone and m.a. - as well as the anomeric H-atom of the glucose moiety—are assigned.

In addition to the signals assigned in Figure SI C.3, signals relative to the H-atoms of the following moieties and molecules are also visible: Phenolic and carboxyl groups (9.2-13.0 ppm), water and glucose unit (2.7-3.7 ppm), DMSO and its ${ }^{13} \mathrm{C}$-satellite signals $(2.2-2.7 \mathrm{ppm})$, and unknown compound(s) (0.7-1.2 ppm, $3.8 \mathrm{ppm}$, and signals of low intensity at 5.9-8.2 ppm). Signals at $1.8-2.1 \mathrm{ppm}$ are possibly due to $\mathrm{H}$-atoms of residual acetone and one of its ${ }^{13} \mathrm{C}$ satellite signals. Purity was determined to be $93 \%$. 


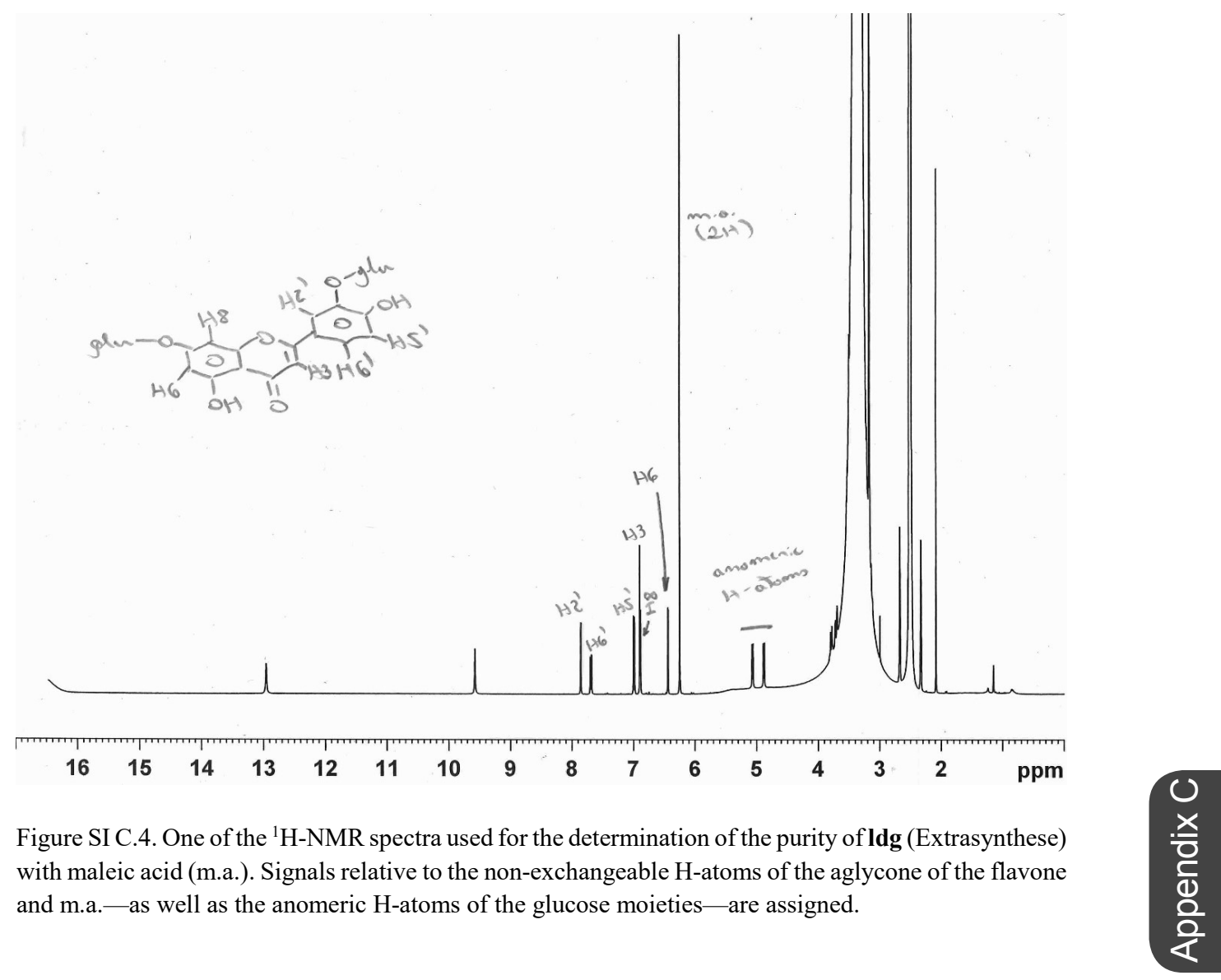




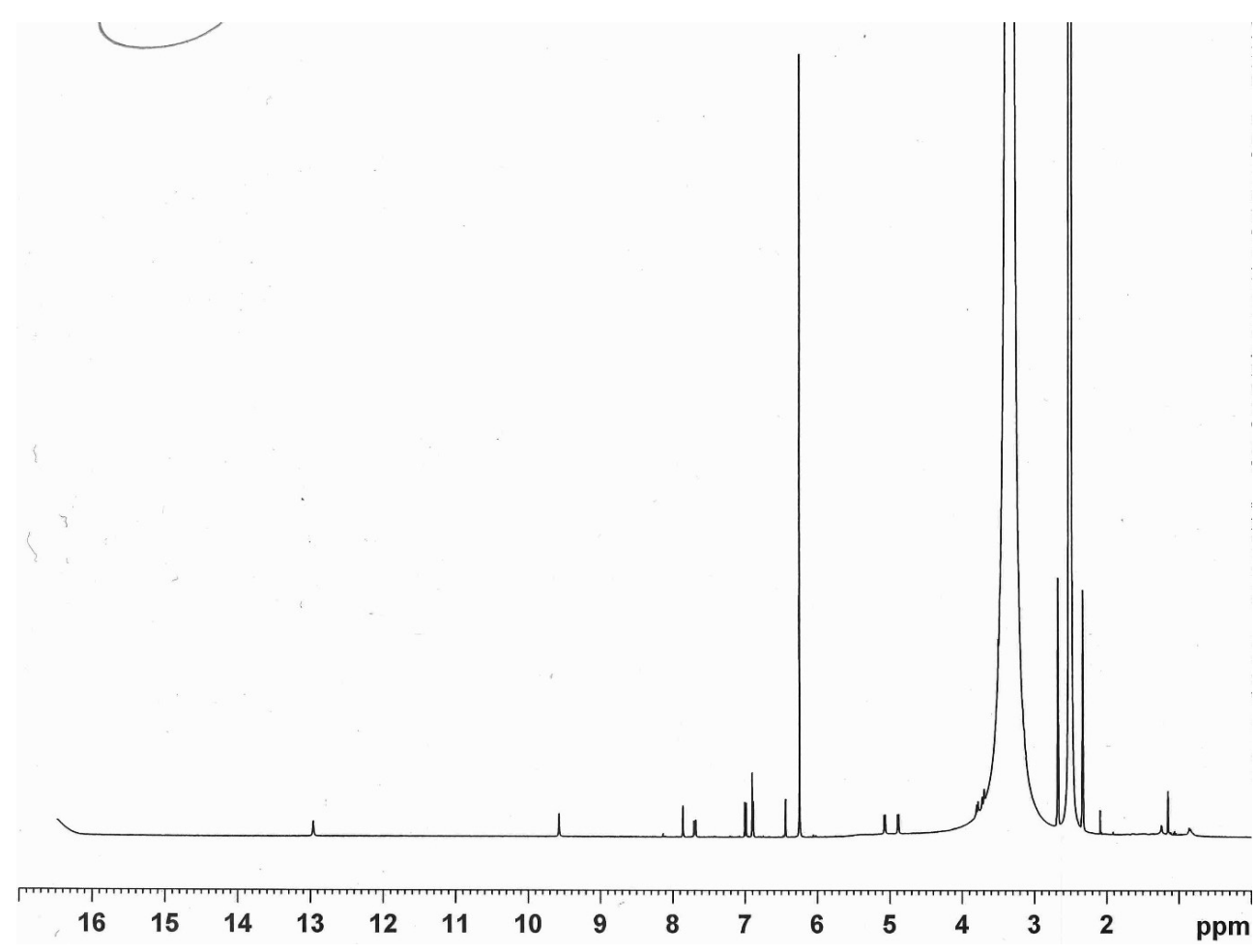

Figure SI C.5. Other ${ }^{1} \mathrm{H}-\mathrm{NMR}$ spectrum used for the determination of the purity of Idg (Extrasynthese) with maleic acid (m.a.).

In addition to the signals assigned in Figure SI C.4, signals relative to the H-atoms of the following moieties and molecules are also visible in Figures SI C.4 and SI C.5: Phenolic and carboxyl groups $(9.5-13.0 \mathrm{ppm})$, water and glucose units $(2.8-4.0 \mathrm{ppm})$, DMSO and its ${ }^{13} \mathrm{C}$ satellite signals (2.3-2.7 ppm), and unknown compound(s) $(0.7-1.3 \mathrm{ppm}$, and signals of low intensity at $5.7-8.2 \mathrm{ppm}$ ). Signals at $1.9-2.3 \mathrm{ppm}$ are likely due to $\mathrm{H}$-atoms of residual acetone and its ${ }^{13} \mathrm{C}$-satellite signals. Signals at 3.0 and $3.2 \mathrm{ppm}$ are likely to be due to $\mathrm{H}$-atoms of an external contaminant (a residual compound in the NMR tube, for example), as they are seen in Figure SI C. 4 but not in Figure SI C.5. Purity was determined to be $86 \%$. 


\section{SI C.2.4. Effect of $\mathrm{Al}^{3+}$ on the absorption of light by solutions of lut and ldg}

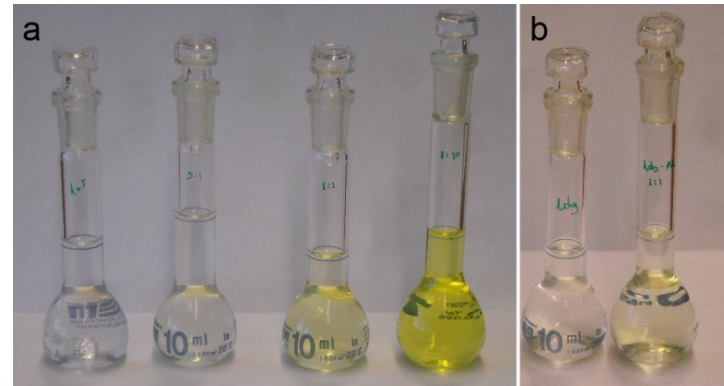

Figure SI C.6. Effect of increasing $\left[\mathrm{Al}^{3+}\right]$ on the colour of solutions of lut and ldg. Solutions at $t_{0}$ from left to right: lut $t_{0.10}$, lut ${ }_{0.10}-\mathrm{Al}_{0.02}$, lut $t_{0.10}-\mathrm{Al}_{0.10}$, lut ${ }_{0.10}-\mathrm{Al}_{0.99}$, $\mathbf{I d g}_{0.05}$, and $\mathbf{l d g}_{0.05}-\mathrm{Al}_{0.05}$. Pictures were taken on day $\mathbf{1}$ of irradiation experiments $2 \mathrm{a}$ (panel $\mathbf{a})$ and $2 \mathrm{~b}$ (panel $\mathbf{b})$.

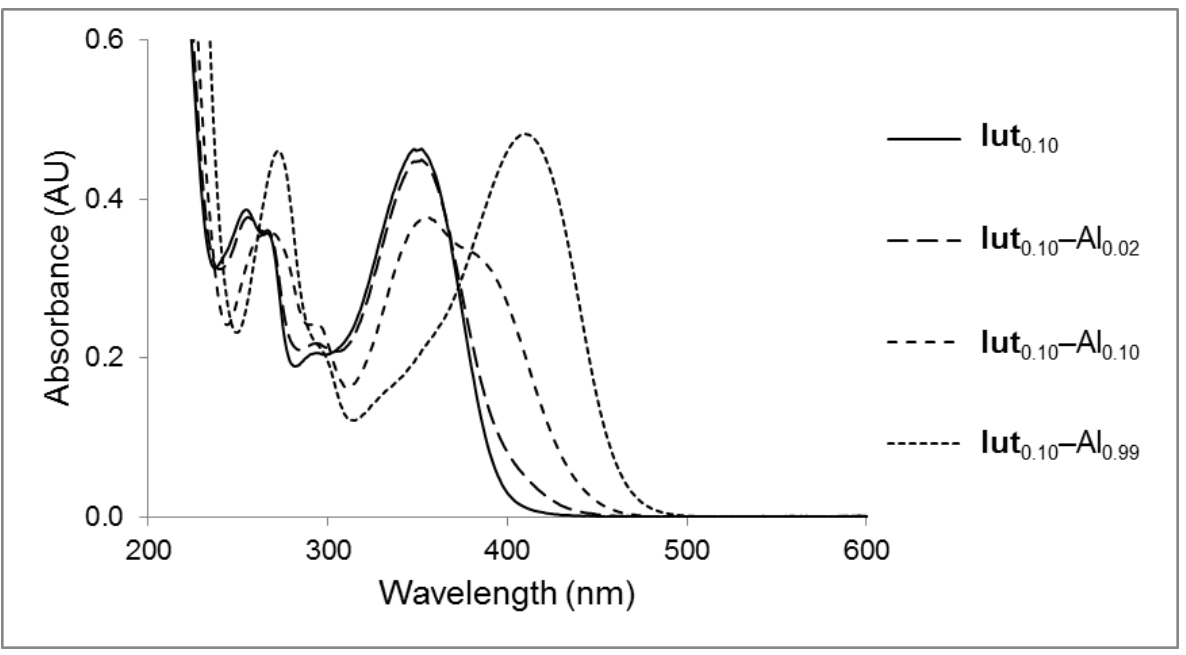

Figure SI C.7. Effect of complexation of lut with $\mathrm{Al}^{3+}$ at increasing $\left[\mathrm{Al}^{3+}\right]$ on the $\mathrm{UV}-\mathrm{vis}$ absorption spectrum of lut. Note: Subscripts of code of solutions denote [lut $]_{0}$ and $\left[\mathrm{Al}^{3+}\right]$, in $\mathrm{mM}$; Solvent: aerated methanol-water 8:2 (v/v); All cases: $\mathrm{t}_{0}$-solutions prepared for the $2 \mathrm{nd}$ irradiation replicate, diluted $5 \times$. 


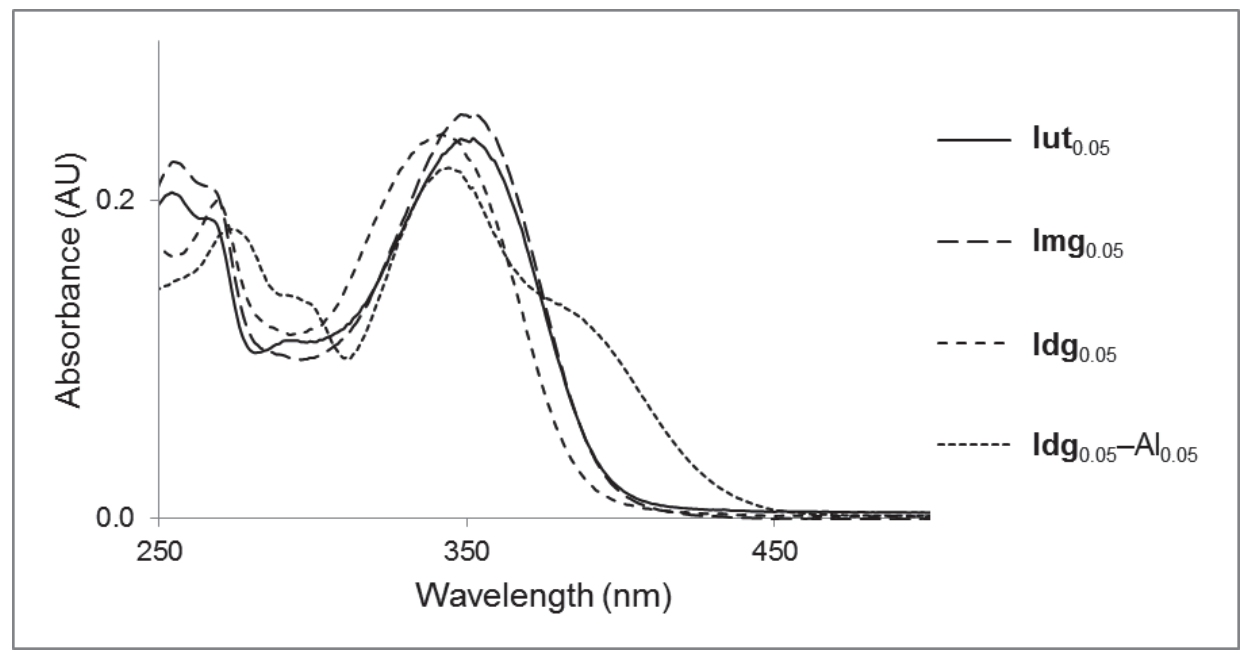

Figure SI C.8. Effects of glycosylation pattern —aglycone, monoglucoside, and diglucoside — on the UV-vis absorption spectrum of lut, and of complexation of $\mathbf{I d g}$ with $\mathrm{Al}^{3+}$ at a 1:1 ratio on the spectrum of Idg. Note: Subscripts of code of solutions denote [flavone $]_{0}$ and $\left[\mathrm{Al}^{3+}\right]$, in $\mathrm{mM}$; Solvent: aerated methanol-water 8:2(v/v); All cases: $t_{0}$-solutions prepared for the 2nd irradiation replicate, diluted $5 \times$.

\section{SI C.2.5. Irradiation experiments: Light with which solutions were irradiated}

The UV-vis spectra of the four glass cuvettes used in the irradiation experiments reported are depicted in Figure SI C.9. The UV-vis absorption spectrum of the $420 \mathrm{~nm}$ cut-off filter recorded is also depicted. The intensity of irradiation varies with the time of use of lamp and power supply; it seems that the newer the lamp and power supply, the higher the intensity of irradiation. The same lamp and power supply were used in the reported irradiation experiments. The emission spectrum resulting of this combination is displayed in Figure SI C.9. Under these conditions, lut mainly undergoes $\mathrm{S}_{0} \rightarrow \mathrm{S}_{1}$ transition [16]. 


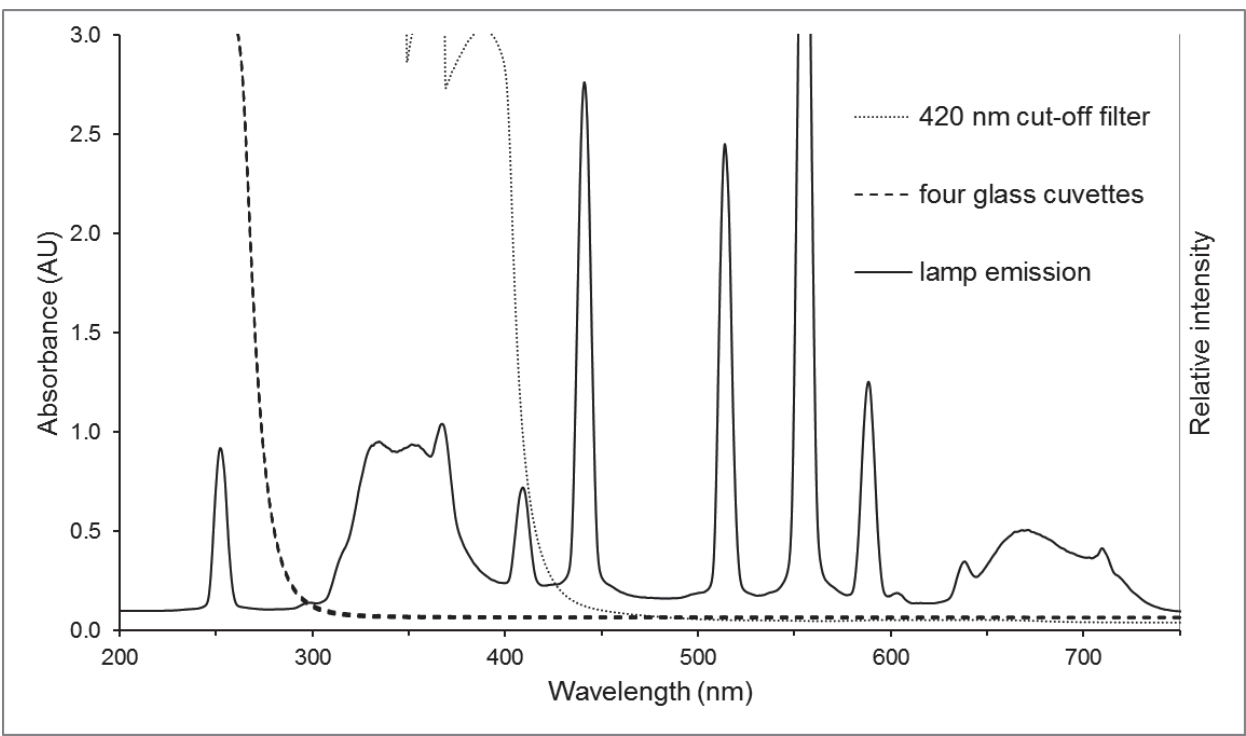

Figure SI C.9. UV-vis absorption spectra: Four glass cuvettes used in the reported irradiation experiments, and $420 \mathrm{~nm}$ cut-off filter (left axis); emission of the lamp (right axis).

SI C.2.6. Effect of different concentrations of $\mathrm{Al}^{3+}$ and glycosylation pattern of lut (aglycone, monoglucoside, and diglucoside) on its photo-stability in solution

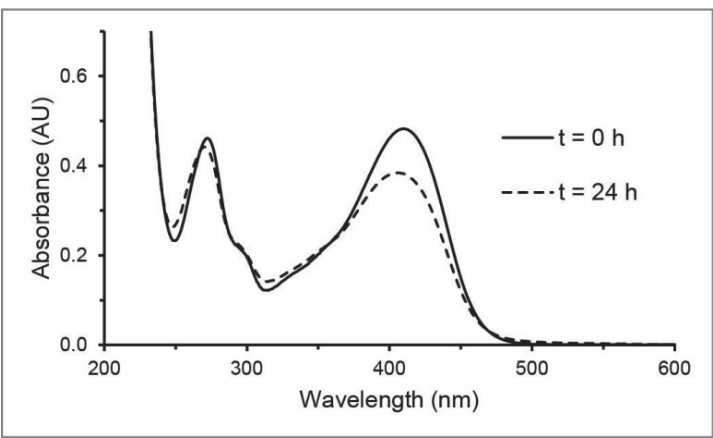

Figure SI C.10. Effect of $24 \mathrm{~h}$ of irradiation on the UV-vis absorption spectrum of lut complexed with $\mathrm{Al}^{3+}$ in lut $_{0.10^{-}}$ $\mathrm{Al}_{0.99}$. Note: Subscripts of code of solution denote [lut $]_{0}$ and $\left[\mathrm{Al}^{3+}\right]$, in $\mathrm{mM}$; Irradiation experiment $2 \mathrm{a}$; Solvent: aerated methanol-water $8: 2(\mathrm{v} / \mathrm{v}) ; \mathrm{t}_{0^{-}}$and $\mathrm{t}_{24}$-solutions were diluted $5 \times$. 
Table SI C.1. Apparent $\mathrm{pH}$ of solutions used for the irradiation experiments and change in absorbance at $\lambda_{\max }$ of the lowest absorption bands of lut, Img, ldg — and complexes of lut and ldg with $\mathrm{Al}^{3+}$ —after $24 \mathrm{~h}$ of irradiation.

\begin{tabular}{|c|c|c|c|c|}
\hline Solution ${ }^{\text {a }}$ & Apparent $\mathrm{pH}$ & $\begin{array}{l}\lambda_{\max } \text { of lowest } \\
\text { absorption band at } \\
\mathrm{t}_{0}(\mathrm{~nm})^{\mathrm{b}}\end{array}$ & $\begin{array}{l}\text { Decrease in } \\
\text { absorbance at } \lambda_{\max } \text { of } \\
\text { lowest absorption band } \\
(\%)^{c}\end{array}$ & $\begin{array}{l}\text { Relative decrease } \\
\text { in absorbance }^{\mathrm{d}}\end{array}$ \\
\hline \multicolumn{5}{|c|}{ 1st irradiation replicate } \\
\hline lut $_{0.11}$ & - & 350 & 5 & 1 \\
\hline lut $_{0.10}-\mathrm{Al}_{0.02}$ & - & 350 & 6 & 1.2 \\
\hline lut $_{0.10}-\mathrm{Al}_{0.10}$ & - & 354 & 16 & 3.2 \\
\hline lut $_{0.11}-\mathrm{Al}_{1.05}$ & - & 410 & 20 & 4.0 \\
\hline lut $_{0.05}$ & - & 350 & 9 & 1 \\
\hline $\operatorname{lmg}_{0.05}$ & - & 350 & 12 & 1.3 \\
\hline $\mathbf{l d g}_{0.04}$ & - & 342 & 2 & 0.2 \\
\hline $\mathbf{l d g}_{0.05}-\mathrm{Al}_{0.05}$ & - & 344 & 6 & 0.7 \\
\hline \multicolumn{5}{|c|}{ 2nd irradiation replicate } \\
\hline lut $_{0.10}$ & 3.6 & 350 & 4 & 1 \\
\hline lut $_{0.10}-\mathrm{Al}_{0.02}$ & 3.6 & 350 & 5 & 1.2 \\
\hline lut $_{0.10}-\mathrm{Al}_{0.10}$ & 3.5 & 355 & 13 & 3.2 \\
\hline lut $_{0.10}-\mathrm{Al}_{0.99}$ & 3.6 & 410 & 20 & 5.0 \\
\hline lut $_{0.05}$ & 3.6 & 350 & 8 & 1 \\
\hline $\operatorname{lmg}_{0.05}$ & 3.6 & 350 & 11 & 1.4 \\
\hline $\operatorname{ldg}_{0.05}$ & 3.7 & 342 & 2 & 0.2 \\
\hline $\mathbf{I d g}_{0.05}-\mathrm{Al}_{0.05}$ & 3.5 & 344 & 8 & 1.0 \\
\hline
\end{tabular}

Special irradiation experiment 


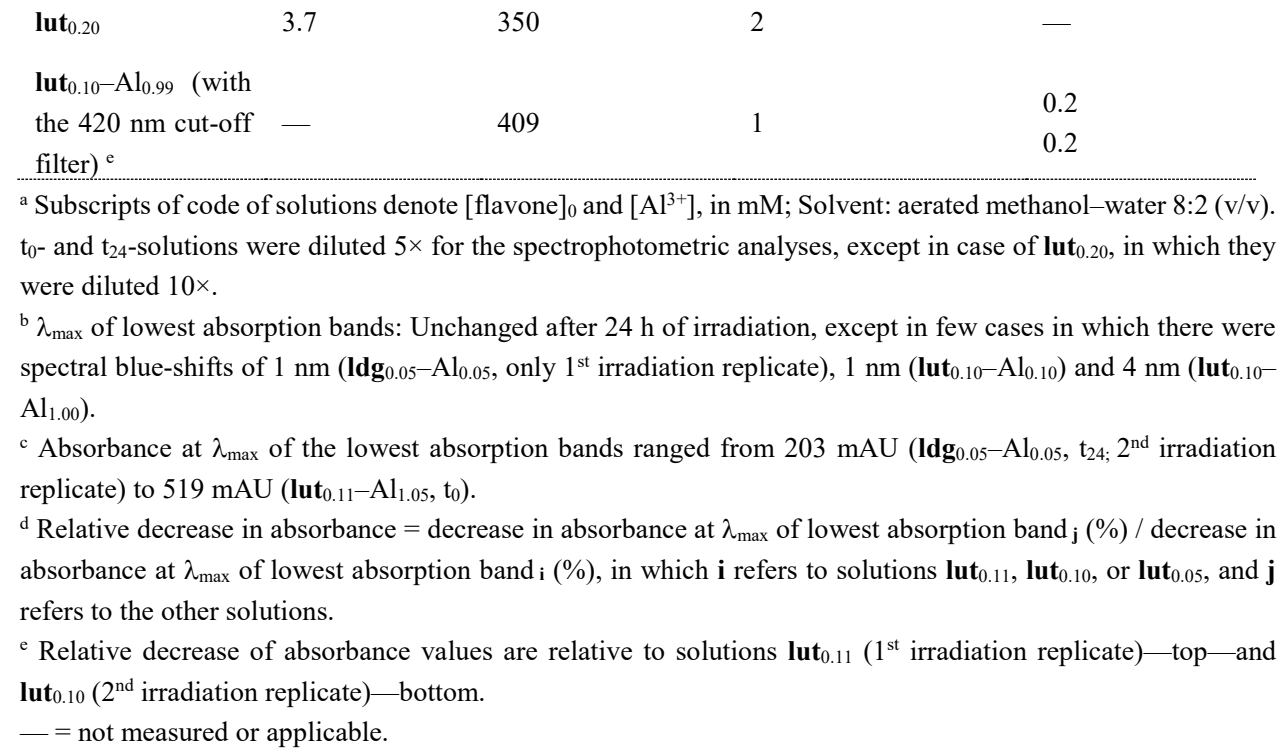

${ }^{\text {a }}$ Subscripts of code of solutions denote [flavone $]_{0}$ and $\left[\mathrm{Al}^{3+}\right]$, in $\mathrm{mM}$; Solvent: aerated methanol-water 8:2 (v/v). $\mathrm{t}_{0}$ - and $\mathrm{t}_{24}$-solutions were diluted $5 \times$ for the spectrophotometric analyses, except in case of lut $\mathrm{t}_{0.20}$, in which they were diluted $10 \times$.

${ }^{\mathrm{b}} \lambda_{\max }$ of lowest absorption bands: Unchanged after $24 \mathrm{~h}$ of irradiation, except in few cases in which there were spectral blue-shifts of $1 \mathrm{~nm}\left(\mathbf{I d g}_{0.05}-\mathrm{Al}_{0.05}\right.$, only $1^{\text {st }}$ irradiation replicate), $1 \mathrm{~nm}\left(\mathbf{l u t}_{0.10}-\mathrm{Al}_{0.10}\right)$ and $4 \mathrm{~nm}_{(\mathbf{l u t}} \mathbf{t}_{0.10}-$ $\left.\mathrm{Al}_{1.00}\right)$.

${ }^{c}$ Absorbance at $\lambda_{\max }$ of the lowest absorption bands ranged from $203 \mathrm{mAU}\left(\mathbf{l d g}_{0.05}-\mathrm{Al}_{0.05}, \mathrm{t}_{24} ; 2^{\text {nd }}\right.$ irradiation replicate) to $519 \mathrm{mAU}\left(\mathbf{l u t}_{0.11}-\mathrm{Al}_{1.05}, \mathrm{t}_{0}\right)$.

${ }^{\mathrm{d}}$ Relative decrease in absorbance $=$ decrease in absorbance at $\lambda_{\max }$ of lowest absorption band $\mathrm{j}_{\mathrm{j}}(\%) /$ decrease in absorbance at $\lambda_{\max }$ of lowest absorption band $\mathbf{i}(\%)$, in which $\mathbf{i}$ refers to solutions lut $\mathbf{t}_{0.11}$, lut $_{0.10}$, or lut $\mathbf{t}_{0.05}$, and $\mathbf{j}$ refers to the other solutions.

e Relative decrease of absorbance values are relative to solutions lut $\mathbf{t}_{0.11}$ ( $1^{\text {st }}$ irradiation replicate) — top —and lut $_{0.10}\left(2^{\text {nd }}\right.$ irradiation replicate $)$ - bottom.

$-=$ not measured or applicable.

Results obtained by analysing the $t_{0^{-}}$and $t_{24}$-solutions by UV-vis spectrophotometry are displayed in Table SI C.1. In the table-and text below-reference is made to the lowest absorption bands of the flavones and their $\mathrm{Al}^{3+}$-complexes. However, there are cases in which two bands next to each other were considered the "lowest absorption band". This can be seen in Figures SI C.7 and SI C.8, in which the UV-vis absorption spectra of the compounds of the 2nd irradiation replicate $t_{0}$-solutions are depicted. This is a simplification. For elaboration on the electronic transitions giving rise to the absorption bands seen in the spectra lut- $\mathrm{Al}^{3+}$ complexes, the reader is referred to the work of Amat et al. [17].

The values of the relative decrease in absorbance at $\lambda_{\max }$ of the lowest absorption bands after $24 \mathrm{~h}$ of irradiation (Table SI C.1) follow the same trend of the relative rates of photodecomposition obtained through RP-HPLC-UV (Table 4.2). However, the values of the percentage of decrease in absorbance at $\lambda_{\max }$ of those bands are - with only one exceptionlower than those of the percentage of flavone decomposed determined by HPLC. This is an indication that using spectrophotometry without prior separation by LC underestimates the extent of the photodecomposition of the flavones, due to the influence of other UV-vis absorbing-compounds.

Upon increasing $\left[\mathrm{Al}^{3+}\right]$, the lowest UV-vis absorption band of the spectrum of lut and $\mathrm{Al}^{3+}$ in solution shifts towards longer $\lambda$ and - after an initial decrease - displays larger intensity (Fig. SI C.7 and Table SI C.1). Lut - as well as the flavonol quercetin-has already been reported to behave in this way in methanolic solution $[18,19]$. However, there is a quantitative difference between this phenomenon as reported here and that reported by Favaro et al. [18]. The ratio between the absorbance at the $\lambda_{\max }$ of the lowest absorption band of the spectrum of lut and $\mathrm{Al}^{3+}$ in solution, with lut and $\mathrm{Al}^{3+}$ present at a 1:10 ratio - considering lut $\mathrm{t}_{0.11}-\mathrm{Al}_{1.05}$ (1 st irradiation replicate, $\mathrm{t}_{0}$ ) and $\mathbf{l u t}_{0.10}-\mathrm{Al}_{0.99}$ (2nd irradiation replicate, $\mathrm{t}_{0}$ ) - and the absorbance at the $\lambda_{\max }$ of 
the lowest absorption band of free lut (without $\mathrm{Al}^{3+}$ ) - considering lut $\mathrm{l}_{0.11}$ (1st irradiation replicate, $\mathrm{t}_{0}$ ) and $\mathbf{l u t}_{0.10}$ (2nd irradiation replicate, $\mathrm{t}_{0}$ ) - was 1.04 , whereas that observed by Favaro et al. was 1.5 [18] (Fig. 7). ${ }^{1}$ Moreover, the ratio between the absorbance at $350 \mathrm{~nm}$ of the spectrum of lut and $\mathrm{Al}^{3+}$ in solution, with lut and $\mathrm{Al}^{3+}$ present at a $1: 10$ ratio-considering lut $_{0.11}-\mathrm{Al}_{1.05}$ (1 $\mathrm{st}$ irradiation replicate, $\mathrm{t}_{0}$ ) and $\mathbf{l u t}_{0.10}-\mathrm{Al}_{0.99}$ (2nd irradiation replicate, $\mathrm{t}_{0}$ ) - and the absorbance at the same wavelength of free lut - considering lut t.11 $_{0.1}$ (1 st irradiation replicate, $\mathrm{t}_{0}$ ) and lut $\mathrm{t}_{0.10}$ (2nd irradiation replicate, $\mathrm{t}_{0}$ ) - was 0.44 , whereas that observed by Favaro et al. was 0.3 [18] (Fig. 7). In addition, the ratio between the absorbance at the $\lambda_{\max }$ of the lowest absorption band of the spectrum of lut and $\mathrm{Al}^{3+}$ in solution, with lut and $\mathrm{Al}^{3+}$ present at a 1:2 ratio — which lay at $405 \mathrm{~nm}$ - and that of free lut was 1.0 [18] (Fig. 7).

This suggests that a decreasing percentage of water in the solvent favours lut$\mathrm{Al}^{3+}$ complexation, as methanol-water 8:2 was used here and non-anhydrous methanol was used by Favaro et al. [18]. ${ }^{2}$ Information on the influence of other solvents on flavonoid-Al ${ }^{3+}$ complexation is also available. Jurd and Geissman reported the lowest absorption band of the spectrum of lut and $\mathrm{Al}^{3+}$ in solution, with lut and $\mathrm{Al}^{3+}$ present at a 1:10 ratio-relative to the lowest absorption band of free lut - to be less shifted towards longer $\lambda$ and of lower intensity than that reported by Favaro et al. $[18,20]$. These differences were even more pronounced than those between the data reported here and the data reported by Favaro et al.. Thus, this suggests that methanol is more favourable for lut $-\mathrm{Al}^{3+}$ complexation than ethanol, as $96 \%$ ethanol was used by Jurd and Geissman [20]. Deng and van Berkel studied the influence of the solvent on the spectrum of the flavonol quercetin — and that of kaempferol—and $\mathrm{Al}^{3+}$ [21]. Methanol was observed to be the most favourable solvent for quercetin- $\mathrm{Al}^{3+}$ complexation, among acetonitrile, isopropanol and a methanol-acetonitrile mixture.

\footnotetext{
${ }^{1}$ The $\lambda_{\max }$ of the lowest absorption band of lut complexed with $\mathrm{Al}^{3+}$, with lut and $\mathrm{Al}^{3+}$ present at a 1:10 ratio was $410 \mathrm{~nm}$ in the work reported here, but $425 \mathrm{~nm}$ in that reported by Favaro et al., whereas the $\lambda_{\max }$ of the lowest absorption band of free lut (without $\mathrm{Al}^{3+}$ ) was $350 \mathrm{~nm}$ in both works.

${ }^{2}$ There might be difference in acidity between the solutions used in the work reported here and those used by Favaro et al.. Whereas the solutions used for the irradiation experiments were acidified to an apparent $\mathrm{pH}$ of 3.6 (Table SI C.1), those used by Favaro et al. for evaluating the influence of increasing $\left[\mathrm{Al}^{3+}\right]$ on the UV-vis absorption spectrum of free lut and lut- $\mathrm{Al}^{3+}$ complexes were not $\mathrm{pH}-$ adjusted. In addition, although the solution of lut and $\mathrm{Al}^{3+}$ in which lut and $\mathrm{Al}^{3+}$ were present at a 1:10 ratio was not $\mathrm{pH}$-adjusted, the percentage of water in the solvent was still different-methanol-water 8:2 vs. non-anhydrous methanol.
} 
Table SI C.2. RP-HPLC-UV calibration lines for the quantitative monitoring of the photodecomposition of lut, lmg, and ldg in solution.

\begin{tabular}{|c|c|c|c|c|c|c|}
\hline Curve & $\begin{array}{l}\text { Calibration } \\
\text { [flavone] } \\
(\mathrm{mM})\end{array}$ & $\begin{array}{l}\text { tions } \\
{\left[\mathrm{Al}^{3+}\right]} \\
(\mathrm{mM})\end{array}$ & $\begin{array}{l}{\left[\mathrm{HNO}_{3}\right]} \\
(\mathrm{mM})\end{array}$ & $\begin{array}{l}\text { Apparent } \\
\mathrm{pH} \text { range }\end{array}$ & $\begin{array}{l}\text { [flavone] }(\mathrm{mM}) \text { vs. peak } \\
\text { area }(\mu \mathrm{AU} \mathrm{s})\end{array}$ & $r^{2}$ \\
\hline lut & $\begin{array}{l}0.01 ; 0.04 ; \\
0.08 ; 0.11 ; \\
0.13\end{array}$ & - & 0.35 & $3.7-3.6$ & $y=2.8010^{7} x$ & 1.00 \\
\hline lut $-\mathrm{Al}_{0.02}$ & $\begin{array}{l}0.01 ; 0.04 ; \\
0.08 ; 0.10 ; \\
0.13\end{array}$ & 0.02 & 0.35 & 3.6 & $y=2.8010^{7} x$ & 1.00 \\
\hline lut $-\mathrm{Al}_{0.10}$ & $\begin{array}{l}0.01 ; 0.04 ; \\
0.08 ; 0.10 ; \\
0.13\end{array}$ & 0.10 & 0.35 & $3.5-3.4$ & $y=2.7910^{7} x$ & 1.00 \\
\hline lut $-\mathrm{Al}_{1.05}$ & $\begin{array}{l}0.01 ; 0.04 ; \\
0.08 ; 0.10 ; \\
0.13\end{array}$ & 1.05 & - & $3.6-3.5$ & $y=2.7910^{7} x$ & 1.00 \\
\hline $\operatorname{lmg}$ & $\begin{array}{l}0.01 ; 0.04 ; \\
0.08 ; 0.10 ; \\
0.13\end{array}$ & - & 0.35 & $3.6-3.5$ & $y=2.8610^{7} x$ & 1.00 \\
\hline Idg & $\begin{array}{l}0.01 ; 0.02 ; \\
0.03 ; 0.04 ; \\
0.06\end{array}$ & - & 0.35 & 3.6 & $y=2.8910^{7} x$ & 1.00 \\
\hline ldg- $\mathrm{Al}_{0.05}$ & $\begin{array}{l}0.01 ; 0.02 ; \\
0.03 ; 0.04 ; \\
0.06\end{array}$ & 0.05 & 0.35 & $3.6-3.5$ & $y=2.7610^{7} x$ & 1.00 \\
\hline
\end{tabular}

Detection: $350 \mathrm{~nm}$ (lut and lmg) and $340 \mathrm{~nm}$ (ldg).

- $=$ absent.

The unit of the [flavone] of some of the calibration curves of the table above was converted from $\mathrm{mM}$ to $\mu \mathrm{g} \mathrm{mL} \mathrm{L}^{-1}$. This was done for comparison with the curves listed earlier, used for calculating the percentages of leftover flavones in dyeing baths. The calibration curves of lut, lmg, and ldg — with $\mathrm{HNO}_{3}$, without $\mathrm{Al}^{3+}$ - then became:

- $\quad[$ Lut $]\left(\mu \mathrm{g} \mathrm{mL}^{-1}\right) v s$. peak area at $350 \mathrm{~nm}(\mu \mathrm{AU} \mathrm{s}): \mathrm{y}=9.7810^{4} \mathrm{x}\left(r^{2}=1.00\right)$

- $\quad[\mathbf{L m g}]\left(\mu \mathrm{g} \mathrm{mL}^{-1}\right) v s$. peak area at $350 \mathrm{~nm}(\mu \mathrm{AU} \mathrm{s}): \mathrm{y}=6.3910^{4} \mathrm{x}\left(r^{2}=1.00\right)$

- $\quad[\mathbf{L d g}]\left(\mu \mathrm{g} \mathrm{mL}^{-1}\right) v s$. peak area at $340 \mathrm{~nm}(\mu \mathrm{AU} \mathrm{s}): \mathrm{y}=4.7310^{4} \mathrm{x}\left(r^{2}=1.00\right)$ 


\section{SI C.2.7. Effect of concentration of lut on its photo-stability in solution}

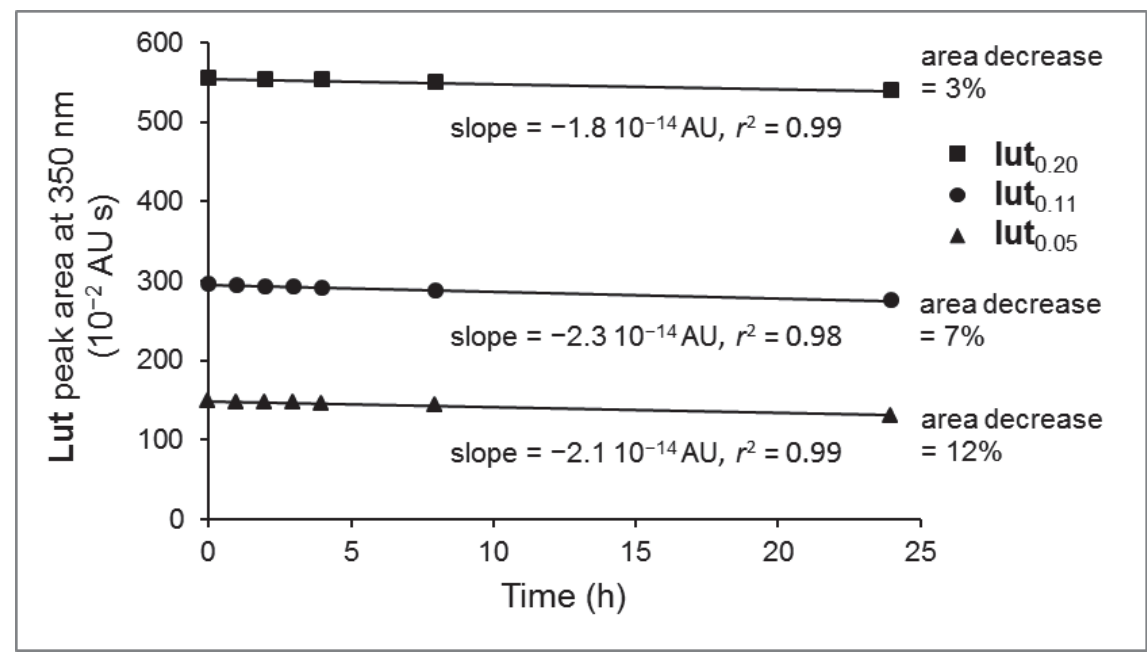

Figure SI C.11. Effect of varying [lut] on its photo-stability in solution. Note: Subscripts of code of solutions denote [lut $]_{0}$, in $\mathrm{mM}$; Solvent: aerated methanol-water 8:2 (v/v); $r^{2}=$ quality of description of the decrease in peak area of lut over time as a straight line; Decrease in lut peak areas reported: After $24 \mathrm{~h}$ of irradiation, relative to those at $\mathrm{t}_{0}$; Duration of irradiation of solutions $=24.0 \mathrm{~h}(1,440 \mathrm{~min})$.

The highest [lut] used to construct its calibration line in presence of $\mathrm{HNO}_{3}$ was $0.13 \mathrm{mM}$ (Table SI C.2). Thus, the photodecomposition of lut in lut $0_{0.20}$, lut l. $_{0.11}$ and lut $t_{0.05}$ is depicted in Figure SI C.11 as peak area vs. time, and not concentration vs. time. However, the relation between the peak area of lut and its concentration is expected to be linear throughout the range of [lut] of the study, as the peak height at $\mathrm{t}_{0}(\mathrm{t}=0 \mathrm{~h})$ in lut $\mathrm{t}_{0.20}$ was $586 \mathrm{mAU}$; well below 1,000 mAU. 
SI C.2.8. Evaluation of the contribution of light above $420 \mathrm{~nm}$ to the photodecomposition processes studied

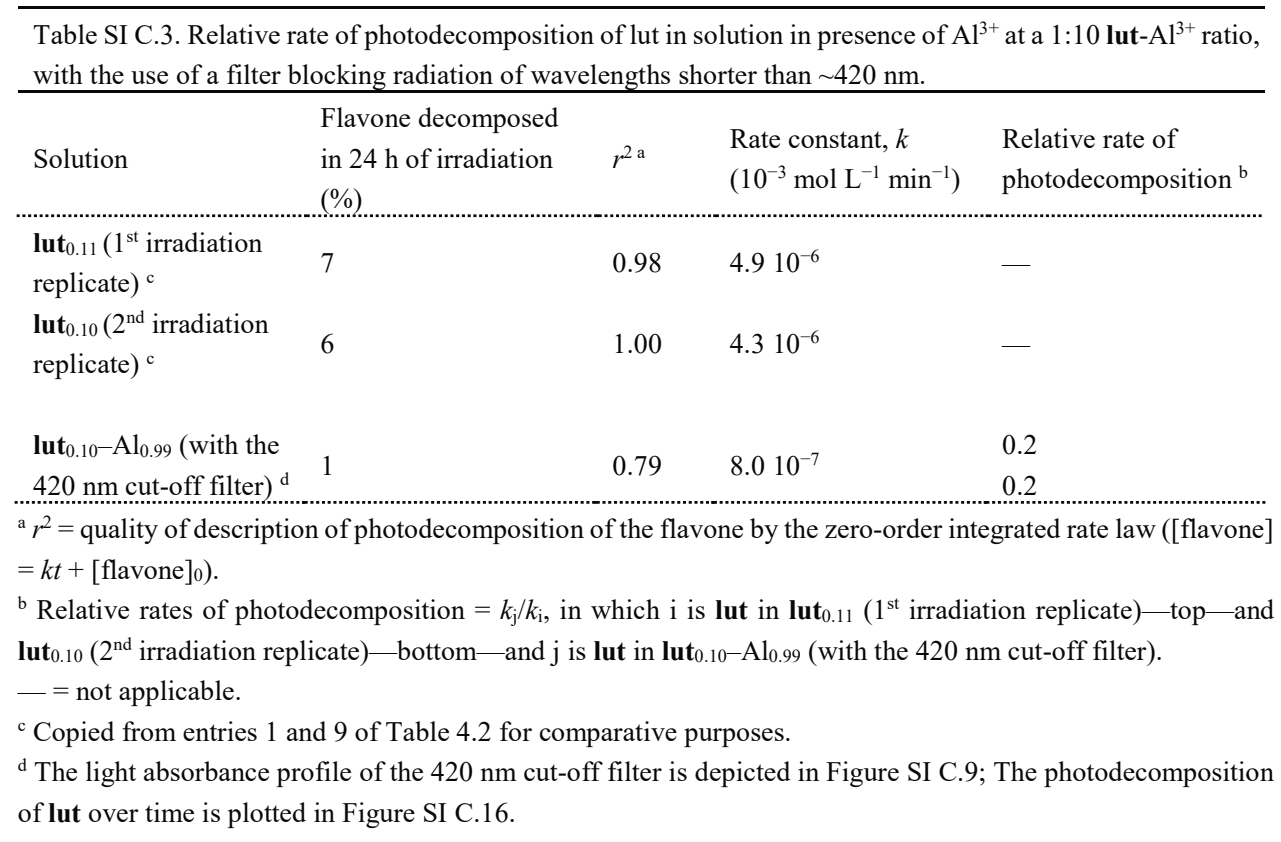

Taking into consideration the UV-vis absorption spectra depicted in Figures SI C.7 and SI C.8, the emission profile of the lamp depicted in Figure SI C.9, and the relative rates of decomposition displayed in Table SI C.3, the contribution of light above $420 \mathrm{~nm}$ to the studied photodecomposition of lut in solution-as a function of different $\left[\mathrm{Al}^{3+}\right]$ and glycosylation pattern - is expected to have been very limited. Thus, the solutions are said to have been irradiated with light, most importantly, in the 300-420 nm range. 
SI C.2.9. Photodecomposition of $\mathrm{ldg}$ - with and without $\mathrm{Al}^{3+}$ —and lut in luto.10-Al0.99—only with light $>420 \mathrm{~nm}-$ over time

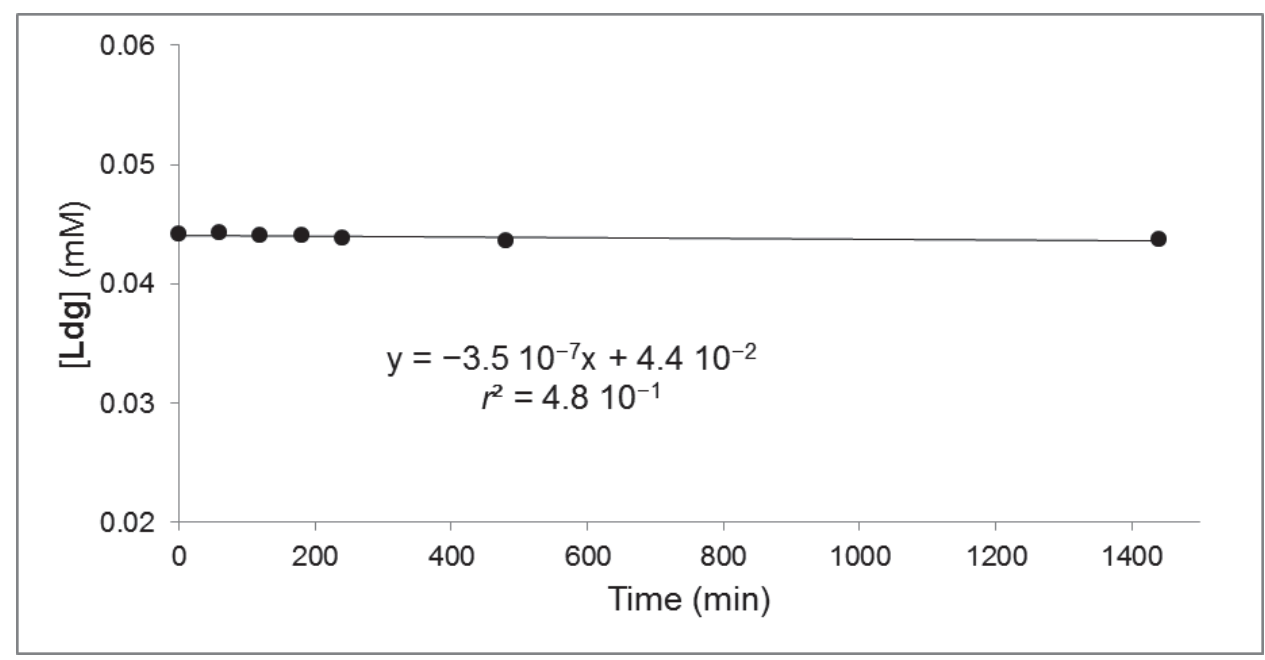

Figure SI C.12. Photodecomposition of Idg in solution upon irradiation of $\mathbf{I d g}_{0.04}$ over $24 \mathrm{~h}$ (1st irradiation replicate). Note: Subscript of code of solution denotes [ldg $]_{0}$; Solvent: aerated methanolwater 8:2 (v/v); Equation of the best-fit line of the description of the photodecomposition of Idg by the zero-order integrated rate law $\left([\mathbf{l d g}]=k t+[\mathbf{I d g}]_{0}\right)$ is displayed, in which $\mathrm{y}=[\mathbf{I d g}]$, slope $=-k$, and $\mathrm{x}=t ; r^{2}$ = quality of this description; Duration of irradiation of solution $=24.0 \mathrm{~h}(1,440 \mathrm{~min})$. 


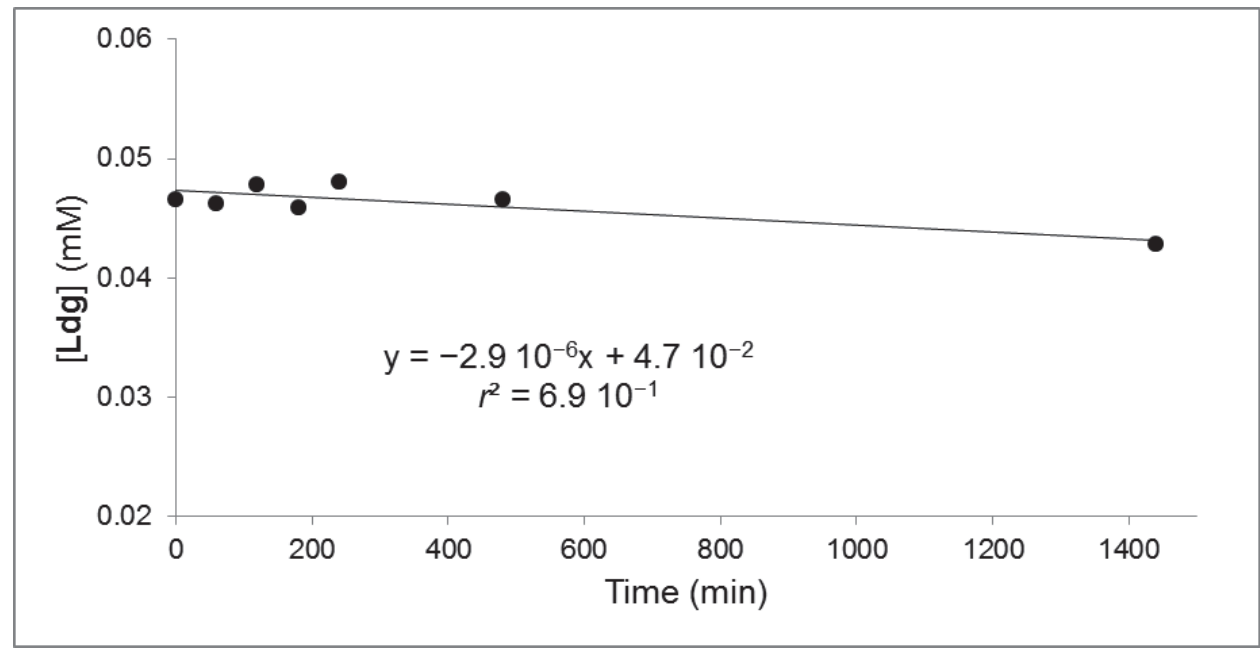

Figure SI C.13. Photodecomposition of Idg in solution upon irradiation of $\mathbf{l d g}_{0.05}-\mathrm{Al}_{0.05}$ over $24 \mathrm{~h}$ (1st irradiation replicate). Note: Subscripts of code of solution denote $[\mathbf{l d g}]_{0}$ and $\left[\mathrm{Al}^{3+}\right]$, in $\mathrm{mM}$; All rest as for Fig. SI C.12.

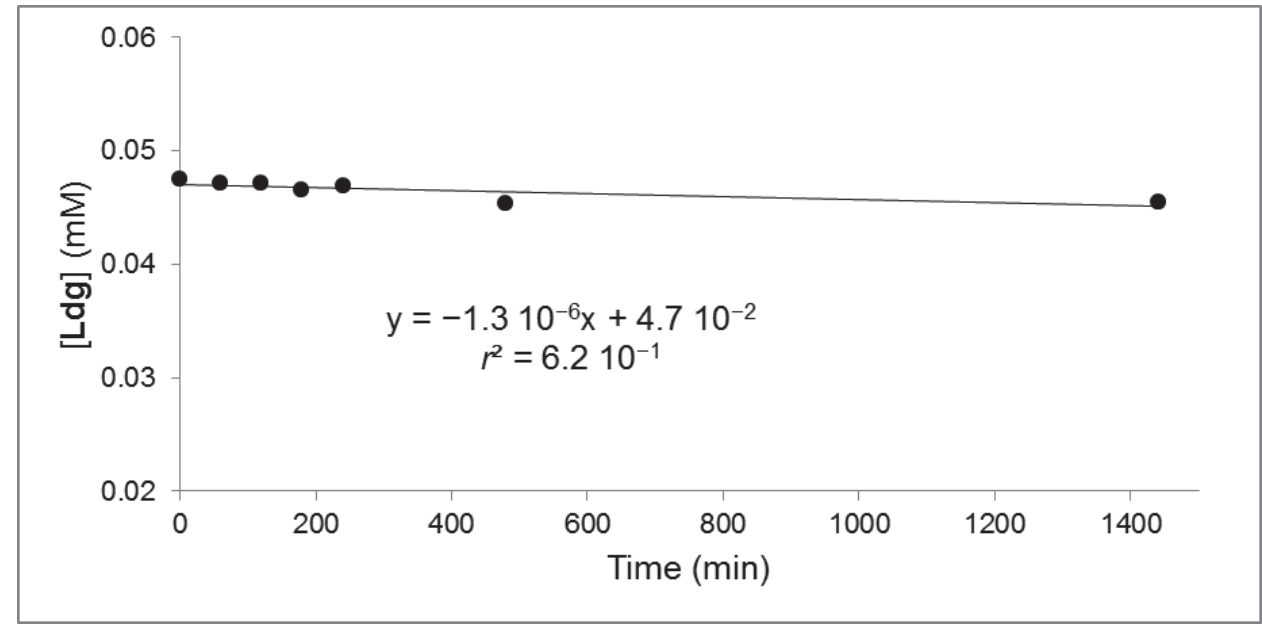

Figure SI C.14. Photodecomposition of $\mathbf{I d g}$ in solution upon irradiation of $\mathbf{I d g}_{0.05}$ over $24 \mathrm{~h}$ (2nd irradiation replicate). Note: All as for Fig. SI C.12. 


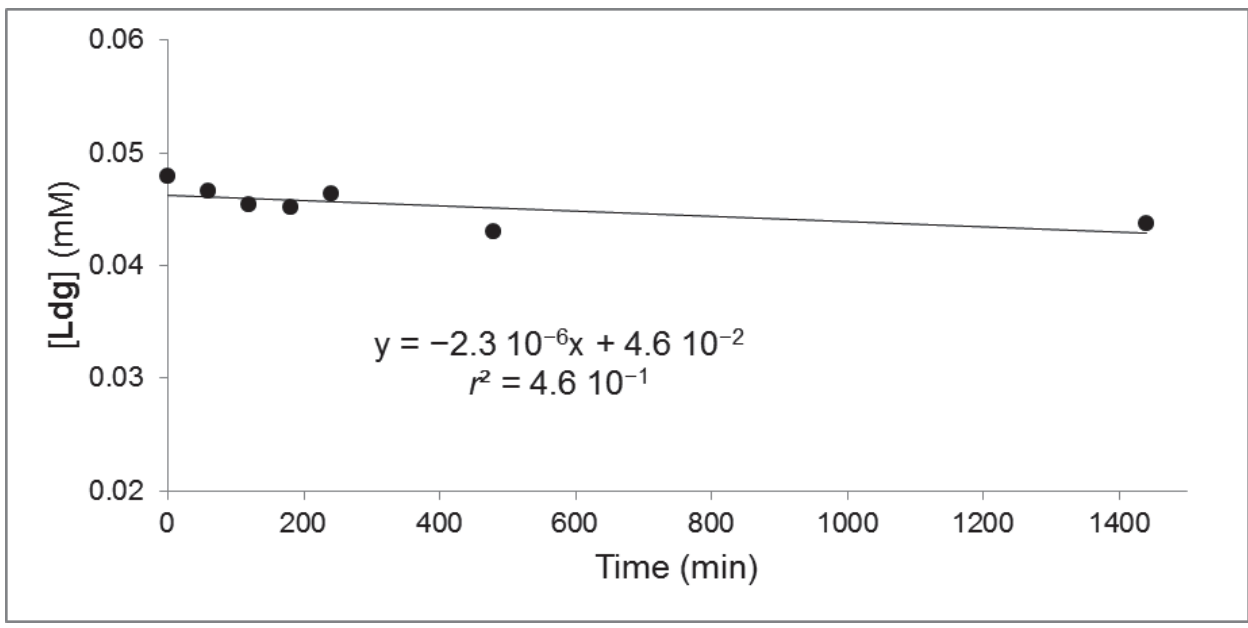

Figure SI C.15. Photodecomposition of $\mathbf{l d g}$ in solution upon irradiation of $\mathbf{l d g}_{0.05}-\mathrm{Al}_{0.05}$ over $24 \mathrm{~h}$ (2nd irradiation replicate). Note: Subscripts of code of solution denote $[\mathbf{l d g}]_{0}$ and $\left[\mathrm{Al}^{3+}\right]$, in $\mathrm{mM}$; All rest as for Fig. SI C.12.

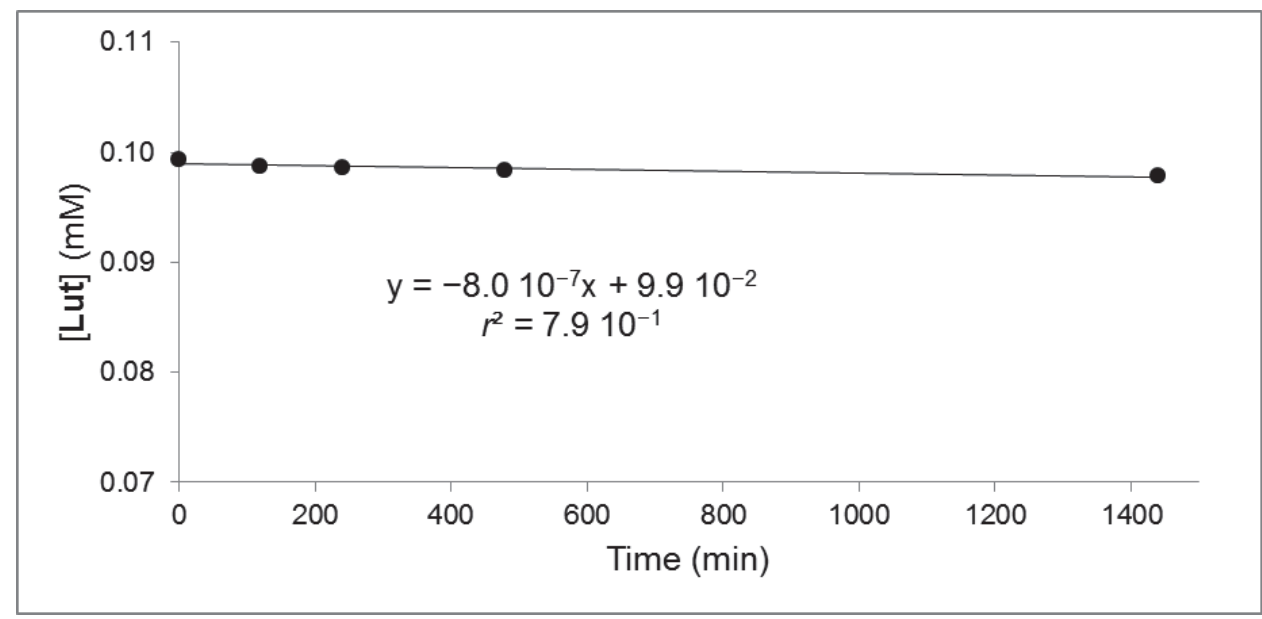

Figure SI C.16. Photodecomposition of lut in solution upon irradiation of $\mathbf{l u t}_{0.10}-\mathrm{Al}_{0.99}(<420 \mathrm{~nm}$ filtered light) over $24 \mathrm{~h}$ (special irradiation experiment). Note: Subscripts of code of solution denote $[\text { lut }]_{0}$ and $\left[\mathrm{Al}^{3+}\right]$, in $\mathrm{mM}$; Equation of the best-fit line of the description of the photodecomposition of lut by the zero-order integrated rate law ([lut $\left.]=k t+[\text { lut }]_{0}\right)$ is displayed, in which $\mathrm{y}=[\mathbf{l u t}]$, slope $=-k$, and $\mathrm{x}=t$; All rest as for Fig. SI C.12. 


\section{SI C.2.10. Stability of $\mathrm{lmg}$ and $\mathrm{ldg}$ in presence of $\mathrm{HNO}_{3}$}

The stability of the glycosyl conjugates of lut - Img and Idg-in presence of $\mathrm{HNO}_{3}$ was assessed. Solutions of each of the flavones at five concentrations containing $\mathrm{HNO}_{3}$ at a concentration of $0.35 \mathrm{mM}$ - the same $\left[\mathrm{HNO}_{3}\right]$ of all $\mathrm{HNO}_{3}$-containing solutions that were used for the irradiation experiments-were heated overnight. Areas of the peaks obtained from the chromatographic analyses of the solutions before and after the heating treatment were compared. The average percentage of Img peak areas after the heating treatment relative to the original peak areas - at five Img concentrations - was 103\% (range: 98-106\%). The average percentage of Idg peak areas after the heating treatment relative to the original peak areas - at five ldg concentrations-was 101\% (range: 98-105\%). These figures-alongside inspection of the corresponding chromatograms - suggest that Img and Idg are stable in presence of $\mathrm{HNO}_{3}$ under the experimental conditions.

\section{SI C.2.11. Effect of increasing quantities of $\mathrm{Al}^{3+}$ of mordanted wool-using alum - on the photo-stability of the dye of weld}

\footnotetext{
Table SI C.4. Colours of weld-dyed wool premordanted with varying quantities of $\mathrm{Al}^{3+}$ (experiment using alum; samples of Figure 4.4): Measured $\left(L^{*}, a^{*}\right.$ and $\left.b^{*}\right)$ and calculated $\left(C^{*}\right.$ ab and $h_{\mathrm{ab}}$ ) quantities using the CIELAB colour space [each case, $\mathrm{n}=4$; data expressed as (average $\pm s), s_{\mathrm{r}}(\%)$, in which $s=$ standard deviation and $s_{\mathrm{r}}=$ relative standard deviation].
}

\begin{tabular}{|c|c|c|c|c|}
\hline$L^{*}$ & $a^{*}$ & $b^{*}$ & $\operatorname{Chroma}\left(C^{*}{ }_{\mathrm{ab}}\right)$ & $\begin{array}{l}\text { Hue angle }\left(h_{\mathrm{ab}} ;\right. \\
\text { degrees })\end{array}$ \\
\hline
\end{tabular}

Blank-mordanted wool (wool pretreated as cases below, except that there was no alum in the mordanting bath)
$(82.9 \pm 0.7), 0.8$
$-(3.26 \pm 0.08), 2.4$
$(14.4 \pm 0.9), 6.3$
$(14.7 \pm 0.9), 6.0$
$(102.8 \pm 0.7), 0.7$

Wool premordanted with $2 \mathrm{~g} \mathrm{~L}^{-1}$ aqueous solutions of alum ${ }^{\text {a }}$
$(82.2 \pm 0.3), 0.4$
$-(10.8 \pm 0.4), 3.4$
$(43.2 \pm 0.6), 1.4$
$(44.6 \pm 0.7), 1.5$
$(104.0 \pm 0.3), 0.3$

Wool premordanted with $10 \mathrm{~g} \mathrm{~L}^{-1}$ aqueous solutions of alum
$(82.0 \pm 0.5), 0.6$
$-(12.9 \pm 0.5), 3.9$
$(60 \pm 2), 3.7$
$(61 \pm 2), 3.6$
$(102.1 \pm 0.6), 0.6$

${ }^{a}$ The colour of one of the pieces of dyed wool was not homogeneous; brief visual inspection before colorimetric measurements. Based on these results, this is of no problem. 
According to Goodman [6], the axes of the CIELAB colour space represent approximately:

- $L^{*} \quad$ lightness

- $a^{*} \quad$ amount of red (positive) or green (negative)

- $b^{*} \quad$ amount of yellow (positive) or blue (negative)

CIELAB chroma $\left(C^{*} \mathrm{ab}\right)$ and hue angle $\left(h_{\mathrm{ab}}\right)$ approximately correlate to chroma and hue, and lightness, chroma and hue together can describe the perception of a colour [6]. Thus, the $L^{*}$, $C^{*}{ }_{\mathrm{ab}}$ and $h_{\mathrm{ab}}$ quantities of the pieces of dyed wool are used in this work as a description of their colours.

Table SI C.5. Wash-fastness of the colours of weld-dyed wool premordanted with varying quantities of $\mathrm{Al}^{3+}$ (experiment using alum; samples of Figure 4.4) based on visual comparison and change in lightness $\left(\Delta L^{*}\right.$, CIELAB colour space) - each case: $\mathrm{n}=1$ (i.e., one pair of samples, with only one of the two of them being washed). ${ }^{\mathrm{a}}$

\begin{tabular}{lcc}
\hline Concentration of alum in mordanting solution & Visual & Based on $\Delta L^{*}$ \\
Blank (no alum) & $4 / 4-5$ & $4-5$ \\
$\mathbf{2} \mathbf{g ~ L}^{-1}$ & $3-4 / 4$ & 4 \\
$\mathbf{1 0 ~} \mathbf{g ~ L}^{-1}$ & $3-4 / 4$ & 4
\end{tabular}

a Scale: 1 (poor)-5 (excellent); wash-fastness values of 3-4 are the acceptable lower limit [7].

The colours of the pieces of weld-dyed wool that were premordanted with $2 \mathrm{~g} \mathrm{~L}^{-1}$ and $10 \mathrm{~g} \mathrm{~L}^{-1}$ aqueous solutions of alum darkened after washing (assay on the wash-fastness of the colours). There are three hypotheses on what could have led to this darkening:

- The anion of the salt could have complexed with an available site - catechol or pseudocarboxyl group - of the flavones bound to the mordanted wool. Reasoning: i. the detergent solution used contained sodium perborate, and ii. boric acid complexes with the free catechol group of rutin - a 3-O-glycoside of the flavonol quercetin-leading to a redshift of the lowest energy absorption band in presence of sodium acetate [22].

- A pH effect. The detergent solution used for washing the dyed wool is basic, and there might have not been full neutralization by the end of the washing procedure. Reasoning: there is a red-shift of the lowest energy absorption band of lut in $95 \%$ ethanol in basic conditions (sodium acetate) [20].

- Possible incomplete removal of flavone diglycosides not bound to the wool through the after-dyeing rinsing, followed by their removal through the more aggressive conditions of the wash fastness assay. Reasoning: alum-mordanted wool dyed with Idg is pale yellow (Fig. 4.6). 
SI C.2.12. Effect of the glycosylation pattern of lut (aglycone, monoglucoside, and diglucoside) on the colour of alum-mordanted wool dyed with the individual flavones

\begin{tabular}{|c|c|c|c|c|c|}
\hline \multicolumn{6}{|c|}{$\begin{array}{l}\text { Table SI C.6. Colours of alum-mordanted w } \\
\text { dyes (samples of Figure 4.6): Measured ( } \\
\text { CIELAB colour space (each case, } n=1 \text { ). }\end{array}$} \\
\hline Dye & $L^{*}$ & $a^{*}$ & $b^{*}$ & $\begin{array}{l}\text { Chroma } \\
\left(C^{*}{ }_{a b}\right)\end{array}$ & $\begin{array}{l}\text { Hue angle } \\
\left(h_{\mathrm{ab}} ; \text { degrees }\right)\end{array}$ \\
\hline None ${ }^{a}$ & 85.4 & -0.9 & 3.4 & 3.5 & 104.2 \\
\hline Lut & 82.6 & -14.9 & 76.6 & 78.1 & 101.0 \\
\hline Lmg & 80.4 & -6.7 & 83.9 & 84.2 & 94.5 \\
\hline Ldg & 85.4 & -10.4 & 27.1 & 29.0 & 110.9 \\
\hline Extract of weld & 82.0 & -13.3 & 58.8 & 60.3 & 102.7 \\
\hline
\end{tabular}

The relative photo-stability of the flavones in solution was $\mathbf{l m g}<\mathbf{l u t}<\mathbf{l d g}$ (section 4.4.2.1). Interestingly, the hue angle values of alum-mordanted wool dyed with these flavones individually follow the same trend, but the chroma values follow the opposite trend (Table SI C.6).

\section{SI C.3. Author contributions}

Alexandre Villela: Formulated the research questions, designed/performed the experiments on the photo-stability of the flavones in solution, designed/performed the experiments on the dyeing of alum-mordanted wool with the flavones/extract of weld, analysed/interpreted all data, and wrote the chapter/supplementary material.

Monique S. A. van Vuuren: Designed/performed the experiments on the dyeing of aluminium sulphate/tartaric acid-mordanted wool with the flavones/extract of weld, carried out the measurement of all $L^{*}, a^{*}$, and $b^{*}$ quantities (CIELAB colour space), performed most assays on the light/wash-fastness of the colours of the dyed wool, and analysed/interpreted the resulting data.

Hendra M. Willemen: Contributed to interpretation of data of the part of the research in which MSAvV was involved, and had input on the writing of the chapter.

Goverdina C. H. Derksen: Coordinated the part of the research in which MSAvV was involved. Teris A. van Beek: Coordinated the part of the research in which AV was involved, and had extensive input on the writing of the chapter/supplementary material. 


\section{SI C.4. Supplementary references}

[1] Villela A, van der Klift EJC, Mattheussens ESGM, Derksen GCH, Zuilhof H, van Beek TA. Fast chromatographic separation for the quantitation of the main flavone dyes in Reseda luteola (weld). J Chromatogr A 2011; 1218(47): 8544-50.

[2] van Beek TA, van Veldhuizen A, Lelyveld GP, Piron I. Quantitation of bilobalide and ginkgolides $\mathrm{A}, \mathrm{B}, \mathrm{C}$ and $\mathrm{J}$ by means of nuclear magnetic resonance spectroscopy. Phytochem Anal 1993; 4(6): 261-8.

[3] O’Neil MJ, Smith A, Heckelman PE, Obenchain Jr. JR, Gallipeau JAR, D'Arecca MA, Budavari S, editors. The merck index - an encyclopedia of chemicals, drugs and biologicals. 13th ed. Merck and Co.: Whitehouse Station; 2001.

[4] Surowiec I, Nowik W, Trojanowicz M. Post-column deprotonation and complexation in HPLC as a tool for identification and structure elucidation of compounds from natural dyes of historical importance. Microchim Acta 2008; 162(3-4): 393-404.

[5] Villela A, Derksen GCH, van Beek TA. Analysis of a natural yellow dye: an experiment for analytical organic chemistry. J Chem Educ 2014; 91(4): 566-9.

[6] Goodman TM. International standards for colour. In: Best J, editor. Colour design - theories and applications, Woodhead Publishing/The Textile Institute: Oxford/Cambridge/etc.; 2012, p. 177-218.

[7] Bechtold T, Mahmud-Ali A, Mussak R. Natural dyes from food processing wastes. In: Waldron K, editor. Handbook of waste management and co-product recovery in food processing, CRC Press/Woodhead Publishing: Boca Raton/Boston/etc.; 2007, p. 502-33.

[8] Monici M, Mulinacci N, Baglioni P, Vincieri FF. Flavone photoreactivity. UV-induced reactions in organic solvents and micellar systems. J Photochem Photobiol, B 1993; 20(2-3): $167-72$.

[9] Kaneta M, Sugiyama N. Light resistance of the flavones and the flavonols. Bull Chem Soc Jap 1971; 44(11): 3211.

[10] Smith GJ, Thomsen SJ, Markham KR, Andary C, Cardon D. The photostabilities of naturally occurring 5-hydroxyflavones, flavonols, their glycosides and their aluminium complexes. J Photochem Photobiol, A 2000; 136(1-2): 87-91.

[11] Cristea D, Bareau I, Vilarem G. Identification and quantitative HPLC analysis of the main flavonoids present in weld (Reseda luteola L.). Dyes Pigments 2003; 57(3): 267-72.

[12] Bhattacharyya K, Ramaiah D, Das PK, Georg MV. A laser flash photolysls study of 2,6dimethyl-3,5-diphenyl-4-pyrone and related chromones. Evidence for triplet state structural relaxation from quenching behaviors. J Phys Chem 1986; 90: 5984-9.

[13] Sisa M, Bonnet Susan L, Ferreira D, van der Westhuizen Jan H. Photochemistry of flavonoids. Molecules 2010; 15(8): 5196-245.

[14] Rundlöf T, Mathiasson M, Bekiroglu S, Hakkarainen B, Bowden T, Arvidsson T. Survey and qualification of internal standards for quantification by ${ }^{1} \mathrm{H}$ NMR spectroscopy. J Pharm Biomed Anal 2010; 52(5): 645-51. 
[15] Fulmer GR, Miller AJM, Sherden NH, Gottlieb HE, Nudelman A, Stoltz BM, et al. NMR chemical shifts of trace impurities: common laboratory solvents, organics, and gases in deuterated solvents relevant to the organometallic chemist. Organometallics 2010; 29(9): 2176 9 .

[16] Amat A, Clementi C, De Angelis F, Sgamellotti A, Fantacci S. Absorption and emission of the apigenin and luteolin flavonoids: a TDDFT investigation. J Phys Chem A 2009; 113(52): 15118-26.

[17] Amat A, Clementi C, Miliani C, Romani A, Sgamellotti A, Fantacci S. Complexation of apigenin and luteolin in weld lake: a DFT/TDDFT investigation. Phys Chem Chem Phys 2010; 12(25): 6672-84.

[18] Favaro G, Clementi C, Romani A, Vickackaite V. Acidichromism and ionochromism of luteolin and apigenin, the main components of the naturally occurring yellow weld: a spectrophotometric and fluorimetric study. J Fluoresc 2007; 17(6): 707-14.

[19] Cornard JP, Merlin JC. Comparison of the chelating power of hydroxyflavones. J Mol Struc 2003; 651-653: 381-7.

[20] Jurd L, Geissman TA. Absorption spectra of metal complexes of flavanoid compounds. J Org Chem 1956; 21: 1395-401.

[21] Deng H, van Berkel GJ. Electrospray mass spectrometry and UV/visible spectrophotometry studies of aluminum(III)-flavonoid complexes. J Mass Spectrom 1998; 33: 1080-7.

[22] Harborne JB. Phytochemical methods - a guide to modern techniques of plant analysis. 2nd ed. Chapman and Hall: London/New York; 1984. 


\section{Appendix D}

\section{Chapter 5: Supplementary information}

The content of this appendix is equal to that of the supplementary material of the following paper:

Villela A, Derksen GCH, van Beek TA. Analysis of a natural yellow dye: an experiment for analytical organic chemistry. J Chem Educ 2014;91(4):566-9. 


\section{Table of contents}

SI D.1. Updated version of the protocol of the experiment handed out to students $\quad 148$

SI D.2. Discussion of different parts of the protocol 152

SI D.3. Material and methods for the preparation of the experiment 155

SI D.4. Instructor notes $\quad 160$

SI D.5. Additional observations on the students' learning based on 2011 and 2012 reports

SI D.6. Updated version of the inventory of specialized material handled by students $\quad 162$

SI D.7. Example data sets of the HPLC analysis of weld sample $\quad 164$

SI D.8. Supplementary references $\quad 166$

\section{SI D.1. Updated version of the protocol of the experiment handed out to students}

\section{ANALYSIS OF A NATURAL YELLOW DYE}

Coloured textiles have been used by mankind throughout times. The dyes have been obtained from different natural sources, including plants, molluscs and insects and were expensive in the past. After the first chemical synthesis of a dye (1856), natural dyes rapidly lost importance to synthetic ones. In the past decades, however, there has been a renewed interest in natural dyes.

Weld (Reseda luteola L.) was a popular source of yellow dye for textiles in Europe. A bright yellow is obtained when it is used for dyeing alum-treated wool (alum = aluminum potassium sulphate dodecahydrate). Flavonoids (phenolic compounds) are the main compounds responsible for the colour in this plant. Its three main flavonoids are luteolin-7,3'-O-diglucoside (luteolin diglucoside, Idg), luteolin-7-O-glucoside (luteolin monoglucoside, Img) and luteolin (lut), whose structures are seen below. Chrysin is used as internal standard (i.s.) in this experiment.
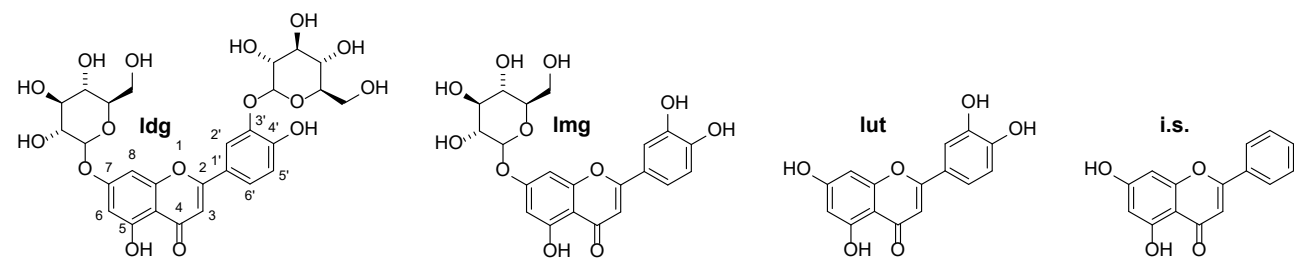

From a historical point of view, for conservation purposes or for forensics, it is of interest to know the dye-source(s) used in historical clothing and objects of art. Small sample sizes, i.e. < $1 \mathrm{mg}$ of textile, are crucial to minimize damage to the artifact. To avoid decomposition during the extraction, mild extraction conditions are needed.

$\underline{\text { Didactic aims }}$

(1) Gaining experience in HPLC analysis and (2) getting acquainted with quantitative analysis using the internal standard method. The field of natural dyes for textiles serves as background. 
Experimental part (for specialized material, see basket)

Part 1: Preparation of the dyeing bath and extraction of weld for HPLC analysis

The extractions described below ( $a$ and $b$ ) are carried out simultaneously:

a) Extraction of weld for wool dyeing:

Weigh $1.5 \mathrm{~g}$ of dried and ground weld in a $100 \mathrm{~mL}$ Erlenmeyer. Add $30 \mathrm{~mL}$ of $96 \%$ alcoholwater $3: 1(\mathrm{v} / \mathrm{v})$, close it with a rubber stopper and place it during $10 \mathrm{~min}$ in an ultrasonic bath (no heat applied) by means of the adapted test-tube rack. Filter the solution through a folded filter paper into a $100 \mathrm{~mL}$ round-bottom flask. Remove only the alcohol using a rotary evaporator, i.e. some water remains. Transfer the extract into a $150 \mathrm{~mL}$ beaker containing a magnetic stir bar with $4 \times 15 \mathrm{~mL}$ of deionized water. This is the dyeing bath.

b) Extraction of weld for HPLC analysis and HPLC-sample preparation:

Weigh accurately $200 \mathrm{mg}$ of dried and ground weld in a $50 \mathrm{~mL}$ Erlenmeyer. Then, carry out the extraction as described above, except for using only $20 \mathrm{~mL}$ of $96 \%$ alcohol-water $3: 1(\mathrm{v} / \mathrm{v})$. After sonication, a magnetic stir bar is added to the Erlenmeyer, followed by addition of 5.00 $\mathrm{mL}$ of i.s. solution in methanol (let it come to room temperature prior to use) and stirring for 10 min at $300 \mathrm{rpm}$. About $1.5 \mathrm{~mL}$ of the solution is filtered by means of a $2 \mathrm{~mL}$ disposable syringe through a $13 \mathrm{~mm} / \varnothing 0.45 \mu \mathrm{m}$ syringe filter into a standard HPLC vial, discarding the first drops and filling $\sim 2 / 3$ of the vial.

\section{Part 2: Wool dyeing and extraction of dyed wool for HPLC analysis}

c.1) Pre-treatment of the wool:

Place a beaker containing a magnetic stir bar and deionized water on a magnetic stirrer-electric hot plate and place a thermo-sensor-first cleaned with acetone - in the water. Add 4 pieces of alum-treated wool of $\sim 5 \times 5 \mathrm{~cm}$ by means of tweezers to the water and heat it to $50{ }^{\circ} \mathrm{C}$. The volume of water should be enough for the wool to be soaked. There is no time requirement for this step, i.e. once the wool is thoroughly wet and the water reaches $50^{\circ} \mathrm{C}$, you can start the next step.

c.2) Dyeing procedure:

Replace the beaker containing the wool by the beaker containing the dyeing bath. Set temperature to $80{ }^{\circ} \mathrm{C}$. Start the stirring and cover the beaker with aluminum foil. When $80{ }^{\circ} \mathrm{C}$ is reached, add the pre-soaked pieces of wool. The dyeing step lasts $15 \mathrm{~min}$. Transfer the wool to a beaker with warm tap water and rinse the pieces of wool. Repeat this with cold tap water. Finally, dry the pieces of dyed wool with a towel. You are welcome to take the pieces of dyed wool home. There are small plastic bags available for that. If you do not want them, remove one thread of wool from one of the pieces (for step d) and hand in the remaining pieces to one of the assistants.

d) Extraction of dyed wool for HPLC analysis and HPLC-sample preparation:

Place $50 \mathrm{~mL}$ of tap water in a $50 \mathrm{~mL}$ beaker and heat it to $60{ }^{\circ} \mathrm{C}$ on an electric hot plate. This is the water bath. Place a small piece $(\sim 0.5 \mathrm{~cm})$ of a single thread of dyed wool in a microcentrifuge tube of $2 \mathrm{~mL}$ and add $300 \mu \mathrm{L}$ of methanol-water-formic acid 80:15:5 (v/v/v) using an automatic pipette. Cap the tube and place it in the water bath for 30 min using the 
floating tube rack. Afterwards, cool the tube with tap water; then, open it. Filter the solution with a $1 \mathrm{~mL}$ disposable syringe through a $4 \mathrm{~mm} / \varnothing 0.45 \mu \mathrm{m}$ syringe filter into an HPLC vial, discarding the first drop. Use a standard HPLC vial with an insert; and fill $\sim 2 / 3$ of the insert.

Part 3: HPLC analysis: quantitation of Idg, $\mathbf{l m g}$ and $\mathbf{l u t}$ in the weld extract using the internal standard method and qualitative analysis of the flavonoids extracted from the dyed wool

e.1) HPLC analysis:

Analyses are carried out on an RP C18 column ( RP = reversed phase; non-polar octadecyl chains chemically bound to silica) in duplicate, with a solvent gradient, as follows:

- Mobile phase: aqueous buffer pH 3 (solvent A) and acetonitrile (B);

- UHPLC column: $1.8 \mu \mathrm{m}$-particle size, $50 \times 3.0 \mathrm{~mm}$ at $35^{\circ} \mathrm{C}$;

- The flow is $0.90 \mathrm{~mL} \mathrm{~min}$ ma $^{-1}$ and the injection volume, $2 \mu \mathrm{L}$;

- Detector continuously scanning from 245 to $500 \mathrm{~nm}$, with chromatograms at 345 $\mathrm{nm}$ being printed;

- The retention times are $1.0 \mathrm{~min}$ (ldg), $1.3 \mathrm{~min}$ (lmg), $2.2 \mathrm{~min}$ (lut) and $3.7 \mathrm{~min}$ (i.s.).

e.2) Determination of the concentration of Idg, Img and lut in the weld sample:

Ask the assistant for the chromatograms containing the retention times and areas of $\mathbf{l d g}$, Img, lut and i.s. peaks. Use the following predetermined relative response factors (RRFs): 1.13 (ldg), 1.58 (lmg) and 2.29 (lut). Calculate the concentration of Idg, Img, and lut in the weld sample, in $\mathrm{mg} \mathrm{g}^{-1}$. Assume $100 \%$ extraction efficiency and $100 \%$ recovery. Check the i.s. solution bottle for the concentration of i.s. and the written material of the course, for slides on the internal standard method.

e.3) Qualitative analysis of the flavonoids extracted from the dyed wool:

Ask the assistant for the chromatograms of the wool sample containing the retention times and UV-vis absorption spectra of Idg, Img and lut peaks. Ask also for chromatograms of preanalysed authentic standards, along with the same data. Compare them. Furthermore, compare the chromatograms of the wool sample with those of the weld sample. $N B$ This is related to questions 3 and 4 .

\section{Questions}

1. Explain the observed order of elution of Idg, lmg and lut (by RP-HPLC).

2. Considering the structures seen on page 1, does it make sense that the RRFs decrease in the order lut $>$ Img $>$ Idg, whereas the molecular weights decrease in the order ldg $\left(611 \mathrm{~g} \mathrm{~mol}^{-1}\right)$ $>\operatorname{lmg}\left(448 \mathrm{~g} \mathrm{~mol}^{-1}\right)>\operatorname{lut}\left(286 \mathrm{~g} \mathrm{~mol}^{-1}\right)$ ? NB Tip: which part of the molecules is responsible for the absorbance at $345 \mathrm{~nm}$ ?

3. Do you think the analytical method used for analysing the dyed wool would be suitable for identifying weld as the dye-source of a yellow historical woolen artifact? Why/Why not?

4. Prior to the HPLC analysis, the flavonoids fixed to the alum-treated fibre were extracted using a $5 \%(\mathrm{v} / \mathrm{v})$ solution of formic acid in methanol-water, at $60{ }^{\circ} \mathrm{C}($ step d). Even under these mild conditions, glycosidic bonds (= chemical bonds between the sugar part and the main flavonoid structure of the sugar-containing flavonoids) are possibly partially broken. 
This is much worsened by the harsh conditions (hydrochloric acid; $100{ }^{\circ} \mathrm{C}$ ) of a traditional procedure as, then, the sugar-containing flavonoids are no longer seen in the chromatograms. What would a chromatogram of the extract look like if the harsh conditions of extraction had been used in step d? Draw it, considering only ldg, Img and lut, and the scale of the y-axis. Which of the two extraction procedures is preferable for identifying weld as the dye-source of a yellow historical woolen artifact? Why?

The protocol ends here. Below, alternative versions of items ( $i$ ) e.1 through e. 3 and (ii) e. 1 and e. 2 are described. This is done in case of using $(i)$ a traditional $250 \times 4.6 \mathrm{~mm} 5 \mu \mathrm{m}$-particle size HPLC column and (ii) retention (or capacity) factors instead of retention times (exemplified when using the UHPLC column).

$i$. In case of using an HPLC column:

e.1) HPLC analysis:

Analyses are carried out on an RP C18 column (RP = reversed phase; non-polar octadecyl chains chemically bound to silica), with a solvent gradient, as follows:

- Mobile phase: aqueous buffer pH 3 (solvent A) and methanol (B);

- HPLC column: $5 \mu \mathrm{m}$-particle size, $250 \times 4.6 \mathrm{~mm}$ at $40{ }^{\circ} \mathrm{C}$;

- The flow is $1.00 \mathrm{~mL} \mathrm{~min}^{-1}$ and the injection volume, $20 \mu \mathrm{L}$;

- Detector continuously scanning from 245 to $500 \mathrm{~nm}$, with chromatograms at 345 $\mathrm{nm}$ being printed;

- The retention times are $34 \mathrm{~min}$ (ldg), $38 \mathrm{~min}$ (lmg), $49 \mathrm{~min}$ (lut) and $57 \mathrm{~min}$ (i.s.).

e.2) Determination of the concentration of ldg, Img, lut in the weld sample:

Ask the assistant for the chromatogram containing the retention times and areas of ldg, lmg, lut and i.s. peaks. Use the following predetermined relative response factors (RRFs): 1.09 (ldg), 1.51 (lmg) and 2.28 (lut). Calculate the concentration of Idg, Img, and lut in the weld sample, in $\mathrm{mg} \mathrm{g}^{-1}$. Assume $100 \%$ extraction efficiency and 100\% recovery. Check the i.s. solution bottle for the concentration of i.s. and the written material of the course, for slides on the internal standard method.

e.3) Qualitative analysis of the flavonoids extracted from the dyed wool:

Ask the assistant for the chromatogram of the wool sample containing the retention times and UV-vis absorption spectra of the ldg, Img and lut peaks. Ask also for chromatograms of pre-analysed authentic standards, along with the same data. Compare them. Furthermore, compare the chromatogram of the wool sample with that of the weld sample. NB This is related to questions 3 and 4 .

$N B$ If needed, change also description of HPLC vials in items $\mathrm{b}$ and $\mathrm{d}$ (see Figures SI D.1a and SI D.1b).

ii. In case of using capacity factors instead of retention times (exemplified when using the UHPLC column): 
e.1) HPLC analysis:

Analyses are carried out on an RP C18 column (RP = reversed phase; non-polar octadecyl chains chemically bound to silica) in duplicate, with a solvent gradient, as follows:

- Mobile phase: aqueous buffer pH 3 (solvent A) and acetonitrile (B);

- UHPLC column: $1.8 \mu \mathrm{m}$-particle size, $50 \times 3.0 \mathrm{~mm}$ at $35^{\circ} \mathrm{C}$;

- The flow is $0.90 \mathrm{~mL} \mathrm{m^{-1 }}$ and the injection volume, $2 \mu \mathrm{L}$;

- Detector continuously scanning from 245 to $500 \mathrm{~nm}$, with chromatograms at 345 $\mathrm{nm}$ being printed;

- The capacity factors $\left(k^{\prime}\right)$ are 3 (ldg), 4 (lmg), 8 (lut) and 14 (i.s.).

e.2) Determination of the concentration of $\mathbf{l d g}$, Img and lut in the weld sample:

Ask the assistant for the chromatograms of:

- solution of uracil in water, for obtaining the void time $\left(t_{\mathrm{m}}\right)$, the time unretained compounds or the eluent take to move through the column. $N B$ Such a solution was analysed under the same conditions as those of your sample;

- weld sample containing the retention times and areas of $\mathbf{l d g}$, Img, lut and i.s. peaks.

Use the following predetermined relative response factors (RRFs): 1.13 (Idg), 1.58 (Img) and 2.29 (lut) [1]. Calculate the concentration of Idg, Img, and lut in the weld sample, in $\mathrm{mg} \mathrm{g}^{-1}$. Assume $100 \%$ extraction efficiency and $100 \%$ recovery $[1,2]$. Check the i.s. solution bottle for the concentration of i.s.. Additionally, see the written material of the course, for slides on $k^{\prime}$ and on the internal standard method.

\section{SI D.2. Discussion of different parts of the protocol}

Below, different parts of the protocol are discussed. This is done for mentioning references used and indicating changes and developments carried out (when applicable), and commenting steps and questions. The procedures related to wool pre-treatment and dyeing used have elements of the procedures described by Colombini et al., Cerrato et al., and Cardon [3-5], as well as those adopted by the company Rubia Natural Colours for wool dyeing with dye obtained from madder roots.

Steps and questions of the protocol of the experiment:

Experimental part

a) Extraction of weld for wool dyeing

- Extraction of weld by sonication for $10 \mathrm{~min}$ was reported by Gaspar et al. [2]. Use of $96 \%$ alcohol-water 3:1 instead of the widely used methanol-water 8:2 aimed at lowering the toxicity of the extraction solvent.

- Assuming $6 \%$ extraction yield, use of $1.5 \mathrm{~g}$ of weld leads to dyeing using $3 \%(\mathrm{w} / \mathrm{w})$ of extract (total extract relative to wool, as the weight of each piece of alum-treated wool of $\sim 5 \times 5 \mathrm{~cm}$ is $\sim 0.8 \mathrm{~g}$ and four of them are dyed in this experiment).

- Use of $60 \mathrm{~mL}$ of water (in four times, for a more efficient transfer of the extract to the beaker) leads to dyeing using a ratio volume of water-weight of wool of $\sim 20$. $N B$ It is 
important not to have too much wool in too little dyeing bath fluid for obtaining an evenly dyed wool [3].

- If needed or wanted, the deionized water may be replaced by rain water (preferably), soft water, or hard water made soft by the addition of acetic acid (or vinegar) [6].

b) Extraction of weld for HPLC analysis and HPLC-sample preparation

- Choice of i.s., its concentration, addition to the sample, homogenization and sample filtration: mostly as described by Villela et al. [1].

$N B$

○ The outcome of a preliminary experiment $(n=1)$ suggests that replacing methanol as the solvent of the i.s. solution by $96 \%$ alcohol is feasible. Additionally, four students carried out the experiment in the 2013 edition of AMOC already using the solution of the i.s. in $96 \%$ alcohol (data not presented). The shapes of the peaks of the main flavonoids in the chromatograms of the weld samples were fine. Thus, due to the same toxicity considerations as above, this replacement is encouraged.

○ Details of sample filtration via disposable syringe and syringe filter: the syringe filter is connected to the syringe after removal of the plunger. Then, the sample is poured into the syringe. Finally, the filtration proceeds by reinsertion of the plunger into the syringe's barrel. Such instruction might be a helpful complement to the information on filtration via syringe filter available in the protocol of the experiment handed out to students.

- Waste handling: the remaining of the content of the Erlenmeyer can be discarded after filtration. The filtrate is disposed in the laboratory's waste container. Finally, the wet paper and plant material are disposed in the trash bin after evaporation of the organic solvents in the fume hood and recovery of the magnetic stir bar.

c.1) Pre-treatment of the wool

- Soaking the alum-pre-treated wool in warm water has the double function of wetting the wool prior to its dyeing - apparently useful for obtaining an even colour - and preventing the wool to go from room temperature to $80{ }^{\circ} \mathrm{C}$ (temperature of the dyeing step) too fast, avoiding possible shrinking and harshening [3], Wulansari D, 2011 (personal communication), and Willemen HM, 2012 (personal communication).

- The pieces of alum-treated wool should be handled by means of tweezers to prevent or minimize touching them with bare hands, which may lead to uneven colour of the dyed wool. This is done at this stage to be on the safe side, as this is the case when handling the wool before the treatment with alum (see section SI D.3).

c.2) Dyeing procedure

- Dyeing at $80{ }^{\circ} \mathrm{C}$ for $15 \mathrm{~min}: 20$ pieces of wool pretreated with a textile auxiliary agent (that aims at minimizing effects of fibre-fibre and fibre-metal contact, Biavin 109; CHT R. Beitlich $\mathrm{GMBH}$ ) and $\mathrm{Al}^{3+}$ were dyed with an extract of weld at $75-80{ }^{\circ} \mathrm{C}$. After different periods of time $(15,30,45$ and $60 \mathrm{~min})$, five pieces of dyed wool were removed from the dyeing bath. After their cooling down and rinsing with water, four of them were washed using conventional laundry soap. Finally, all pieces were hung to dry in the fume hood. The duration of the dyeing step did not influence the outcome. Thus, it is carried out for $15 \mathrm{~min}$. Although it might be that periods of time shorter than 15 min would lead to equally satisfactory results, this was not investigated. 
- In another preliminary experiment, also using wool pretreated with a textile auxiliary agent (as previous bullet point) and $\mathrm{Al}^{3+}$, the resistance of the yellow colour to washing using conventional laundry soap was checked. The pieces of wool that were dyed at 60 $65{ }^{\circ} \mathrm{C}$ remained coloured after washing. Thus, there should be no problem if the dyeing step takes place at a temperature somewhat lower than $80^{\circ} \mathrm{C}$ (although the colour of wool dyed at $60-65{ }^{\circ} \mathrm{C}$ might be less intense than that of wool dyed at $\sim 75^{\circ} \mathrm{C}$ ).

- Rinsing of the dyed wool with (1) warm tap water and (2) cold tap water: an even more gradual temperature transition is described in Dye Plants and Dyeing - a Handbook [6]. This aims at preventing the wool to be subjected to a fast temperature change [3].

- Suggested waste disposal: cooled down dyeing bath and first rinsing water are disposed in the laboratory's waste container.

d) Extraction of dyed wool for HPLC analysis and HPLC-sample preparation

- A piece of $\sim 0.5 \mathrm{~cm}$ of a single thread of dyed wool weighs $\sim 0.2 \mathrm{mg}$.

- The procedure for extracting the dyed wool is based on that described by Zhang et al. [7]. Using $\mathrm{Al}^{3+}$-treated weld-dyed wool, it was observed that methanol-water-formic acid $80: 15: 5$ is better for analysing the flavonoid glycosides of weld than methanol-formic acid 95:5. Its use leads to a chromatogram similar to that of weld.

e.1) HPLC analysis

- Samples of students who carried out the experiment in 2011 were analysed using a traditional 25 cm-long, $5 \mu$ m-particle size RP-HPLC column. In contrast, 2012 and 2013 samples were analysed using a modern 5 cm-long, $1.8 \mu \mathrm{m}$-particle size RP-UHPLC column, but also mounted in a conventional HPLC system. Details of the chromatographic methods using both columns were described by Villela et al. [1].

- The identities of the main compounds of the extract of weld are indicated in Figure 5.2. Largely based on the works by Marques et al. and Peggie et al. [8, 9], in decreasing order of retention times, the identities of the compounds responsible for the minor peaks seen in the same chromatograms are:

○ 5,7-dihydroxy-2-(4-hydroxy-3-methoxyphenyl)-4H-1-benzopyran-4-one (lut-3'methyl ether, chrysoeriol);

○ 5,7-dihydroxy-2-(4-hydroxyphenyl)-4H-1-benzopyran-4-one (apigenin);

$\circ$ an isomer of lmg;

○ chrysoeriol glycoside (possibly);

$\circ$ apigenin-7-O-glucoside;

$\circ$ an isomer of ldg;

○ apigenin-6,8- $C$-diglucoside.

These assignments were based on chromatographic retention times, mass spectral data and UV-vis absorption spectral data, using information from the literature and reference compounds [8]. Additionally, acid hydrolysed-extracts of wool dyed with weld were spiked with reference chrysoeriol and diosmetin (lut-4'-methyl ether) for assignment of the position of the methyl group of the lut methyl ether using HPLC-photodiode array detector [9]. Finally, this information was combined with that obtained through preliminary observations carried out at the Laboratory of Organic Chemistry of Wageningen University by means of HPLC-mass spectrometry, also using information from the literature. 
- The use of $96 \%$ alcohol-water 3:1 for the extraction of the flavonoids of weld leads to deformation of the peaks of the most polar compounds. This is most obvious when the HPLC column is used. The peak corresponding to apigenin-6,8-C-diglucoside is split in two and the one corresponding to the isomer of Idg is partially split. The effect is noticeable when compared with Figure 1A of the work by Villela et al. [1], in which the flavonoids of weld were extracted with methanol-water 8:2. Deformation of the peaks is also seen when the UHPLC column is used, although possibly to a smaller extent than when the HPLC column is used. However, this does not hamper the use of the method, as the peaks of interest—i.e., ldg, lmg, and lut — do not display shoulder(s) with either column (Figures SI D.2 and SI D.3).

e.2) Determination of the concentration of $\mathbf{l d g}$, Img, and lut in the weld sample:

- The RRFs listed were determined in an earlier stage of the project and reported by Villela et al. in 2011 (see text in page 8549 and footnote $d$ of Table 4 of that article) [1]. The HPLC analytical conditions used in this laboratory experiment are the same as those reported then (see section SI D.3).

- Assumptions of $100 \%$ extraction efficiency and $100 \%$ recovery are made as they are not known. $N B$ As described above, the analytical method used here is an adapted combination of the methods reported by Gaspar et al. and Villela et al. [1,2].

\section{Questions}

4. Zhang and Laursen, and Valianou et al. described the observations and information on which the following was based:

○ Even under these mild conditions, glycosidic bonds (= chemical bonds between the sugar part and the main flavonoid structure of the sugar-containing flavonoids) are possibly partially broken [10].

○ This is much worsened by the harsh conditions (hydrochloric acid; $100{ }^{\circ} \mathrm{C}$ ) of a traditional procedure as, then, the sugar-containing flavonoids are no longer seen in the chromatograms $[10,11]$.

\section{SI D.3. Material and methods for the preparation of the experiment}

\section{Part 1: Preparation of the dyeing bath and extraction of weld for HPLC analysis}

a) Extraction of weld for wool dyeing:

- Dried and ground weld: dried aerial parts of weld (Reseda luteola L.) plants are ground and sieved using a mill, e.g., cutting mill from Retsch (type SM1; $0.25 \mathrm{~mm}$ sieve). The plant material is stored in the dark, except for what is placed in the basket in an amber glass bottle;

- $1 \times 100 \mathrm{~mL}$ Erlenmeyer with a rubber stopper;

- 96\% alcohol-water 3:1 (v/v): 375 mL of 96\% alcohol (CAS RN: 64-17-5; e.g., for general laboratory use) and $125 \mathrm{~mL}$ of deionized water, for $500 \mathrm{~mL}$;

- Adapted test-tube rack: this is a test-tube rack that had parts of its grid removed using a pair of pliers in order to accommodate two Erlenmeyers (for placement in the sonication bath).

- Alternatively to weld, the easy to obtain and widely available, outer scales of onions could be used as the source of a flavonoid dye [12-14]. There is the need for adaptation of the 
experiment though. The following is either needed or might be important: use of different authentic standards, adaptation of the chromatographic gradient, determination of new RRFs, use of $1 \%(\mathrm{w} / \mathrm{w})$ of extract (total extract relative to wool), simultaneous addition of all pre-soaked pieces of wool, and increase of the ratio volume of water-weight of wool to $\sim 50$.

- Grinding of weld: in the absence of a laboratory mill, although not tried during this work, a grinder for coffee beans could be tried.

- Alternatively to the use of one's own cultivated plants, weld can be bought. Below, two suppliers of chopped dried weld are listed:

- Kremer Pigmente [15];

○ Brush Creek Wool Works [16].

b) Extraction of weld for HPLC analysis and HPLC-sample preparation:

- $1 \times 50 \mathrm{~mL}$ Erlenmeyer with a rubber stopper;

- $0.5 \mathrm{mg} \mathrm{mL} \mathrm{m}^{-1}$ i.s. solution in methanol: $50 \mathrm{mg}$ of chrysin (480-40-0; e.g., 97\% grade, Aldrich) are weighed in a $100 \mathrm{~mL}$ volumetric flask. Methanol (67-56-1; e.g., p.a. grade) is added up to $\sim 3 / 4$ of the volume of the flask, which is then wrapped in aluminum-foil and placed in a shaker (150 rpm; room temperature) overnight. Finally, methanol is added to the mark. The solution is kept in a refrigerator. $N B$ In case the $0.5 \mathrm{mg} \mathrm{mL}^{-1}$ i.s. solution is prepared in $96 \%$ alcohol: all as described for its preparation in methanol, except for the use of $96 \%$ alcohol (as above) instead of methanol;

- Syringe filters: $0.45 \mu \mathrm{m}$, e.g., PTFE membrane, $13 \mathrm{~mm}$ (catalogue 2165, Grace Davison Discovery Science);

- Disposable polypropylene (PP) syringes of $2 \mathrm{~mL}$. $N B$ There must be a rubber seal at the tip of the plunger for the solution to be properly pushed through the syringe filter;

- Standard HPLC vials with caps. $N B$ Vials and caps may vary, depending on the HPLC system being used (see item e.1 below).

- If $k^{\prime}$ is used, $0.02 \mathrm{mg} \mathrm{mL}^{-1}$ uracil solution in water: $2 \mathrm{mg}$ of 2,4(1H,3H)-pyrimidinedione (uracil; 66-22-8; e.g., 99+\%, Acros Organics) are weighed in a $100 \mathrm{~mL}$ volumetric flask. Deionized water is added up to $\sim 3 / 4$ of the volume of the flask, which is then placed during $10 \mathrm{~min}$ in a ultrasonic bath (neither heating nor cooling applied). Finally, deionized water is added to the mark.

$N B$

○ If a 0.1 mg-least division scale is used, a large weighing error results, being the uncertainty of the weighing estimated to be $0.3 \mathrm{mg}$. This is of no relevance for the purpose of use of this solution, i.e., determination of $t_{\mathrm{m}}$. The nominal concentration of the solution remains unchanged, i.e., $0.02 \mathrm{mg} \mathrm{mL}^{-1}$;

○ No toxicity of uracil is reported in the Merck Index Online [17].

Part 2: Wool dyeing and extraction of dyed wool for HPLC analysis

c.1) Pre-treatment of the wool:

- $2 \mathrm{~L}$ of aqueous $10 \mathrm{~g} \mathrm{~L}^{-1}$ alum solution: $20 \mathrm{~g}$ of aluminum potassium sulfate dodecahydrate (alum) $\left[\mathrm{KAl}\left(\mathrm{SO}_{4}\right)_{2} \cdot 12 \mathrm{H}_{2} \mathrm{O}\right]$ (10043-67-1; e.g., puriss. p.a. grade, Sigma-Aldrich) are dissolved in $2 \mathrm{~L}$ of deionized water; 
- Wool treatment: 15 pieces of wool prepared for dyeing [e.g., Kova Wool Sateen White (part number W110); Whaleys (Bradford) Limited], of $\sim 17 \times 17 \mathrm{~cm}$ (120 g overall) are individually rolled and placed in a $3 \mathrm{~L}$ round-bottom flask. The $2 \mathrm{~L}$ of alum solution are transferred to it. The flask is heated over a $0.5-1 \mathrm{~h}$ period until $\mathrm{T}>90^{\circ} \mathrm{C}$, using the motor of a rotatory evaporator for stirring the wool $(N B$ The water bath of the rotatory evaporator is suitable for that). It is kept stirring at $\sim 95{ }^{\circ} \mathrm{C}$ for $1 \mathrm{~h}$ (NB If the wool is being stirred nonoptimally, decrease of the stirring rate can be tried). Then, the flask is removed from the heating bath and left to cool down for some time. Next, the treated wool is thoroughly rinsed with deionized water and hung to dry. Finally, the wool is cut into pieces of $\sim 5 \times 5$ $\mathrm{cm}$ and the pieces of treated wool are placed in small plastic bags (4 pieces per bag). $N B$

○ Use tweezers or gloves to handle the wool at all times (as fat, protein and dirt from one's hand may lead to uneven colour of the dyed wool);

- Safety warning: do not use any connecting part between the round-bottom flask and the rotatory evaporator, but connect the two directly (hazard of glassware breakage).

c.2) Dyeing procedure: nothing in particular.

d) Extraction of dyed wool for HPLC analysis and HPLC-sample preparation:

- Microcentrifuge tubes of $2 \mathrm{~mL}$ (e.g., Eppendorf);

- $20 \mathrm{~mL}$ of methanol-water-formic acid 80:15:5 (v/v/v): $16 \mathrm{~mL}$ of methanol (as above), 3 $\mathrm{mL}$ of deionized water, and $1 \mathrm{~mL}$ of formic acid (64-18-6; e.g., 98+\%, Acros Organics);

- Syringe filters: $0.45 \mu \mathrm{m}$, e.g., cellulose membrane, $4 \mathrm{~mm}$ (Minisart RC4, Sartorius Stedim Biotech);

- Disposable polypropylene (PP) syringes of $1 \mathrm{~mL}$. $N B$ Also here, there must be a rubber seal at the tip of the plunger;

- Standard HPLC vials with caps and inserts (due to the small volume of solution available).

Part 3: HPLC analysis: quantitation of Idg, Img, and lut in the weld extract using the internal standard method and qualitative analysis of the flavonoids extracted from the dyed wool

e.1) HPLC analysis:

Analyses can be carried out using either an HPLC column or a UHPLC column (in a conventional HPLC system) as described by Villela et al. [1]. The preparation of HPLC solvent $\mathrm{A}$ and the conditions of HPLC analysis using both columns are detailed below.

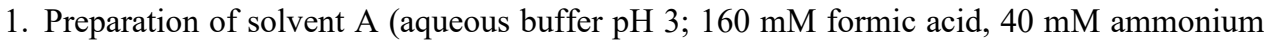
formate, and $0.04 \mathrm{mM}$ of EDTA), that is used in both HPLC systems:

- Add a magnetic stir bar to a $2.5 \mathrm{~L}$ bottle, followed by the addition of:

- 2,100 mL of "ultrapure water", that can either be prepared (e.g., with an EasyPure UV system, Barnstead/Thermolyne) or purchased (e.g., Lichrosolv water for chromatography, Merck);

○ $5.04 \mathrm{~g}$ of ammonium formate (540-69-2; e.g., puriss. p.a. grade, Fluka Analytical);

- $12.9 \mathrm{~mL}$ of formic acid (as above);

- $10 \mathrm{~mL}$ of $8 \mathrm{mM}$ aqueous $N, N^{\prime}$-1,2-ethanediylbis[ $N$-(carboxymethyl)glycine] (EDTA) solution. $N B$ Prepared by, e.g., the dissolution of $170 \mathrm{mg}$ of EDTA $4 \mathrm{Na} \cdot 2 \mathrm{H}_{2} \mathrm{O}(64-02-8$; $98 \%$, Aldrich-Chemie) in $50 \mathrm{~mL}$ of "ultrapure water". 


\section{HPLC column:}

- Solvent B: methanol (HPLC grade);

- Column: Alltima $250 \times 4.6 \mathrm{~mm} \mathrm{C18} 5 \mu \mathrm{m}$ (with a C18 guard column) (Grace Davison Discovery Sciences);

- HPLC system used here consists of Waters $1525 \mu \mathrm{m}$ binary pump, 996 photodiode array detector, 717 plus autosampler, and $5 \mathrm{CH}$ column oven;

- HPLC vials used:

○ $1 \mathrm{~mL}, 40 \times 8 \mathrm{~mm}$;

○ $40 \times 8 \mathrm{~mm}$, of maximal residual volume of $6 \mu \mathrm{L}$;

- Injection volume: $20 \mu \mathrm{L}$;

- Single injections;

- Needle wash solvent: methanol (HPLC grade; $N B$ Efficient for keeping sample carryover below 1\%);

- Flow: $1.00 \mathrm{~mL} \mathrm{~min}^{-1}$;

- Linear solvent gradient: 85-60\% A (0-35 min), 60-36\% A (35-47 min), 36-23\% A (47-60 min), 23-0\% A (60-65 min), 0\% A (65-70 min) (NB Subsequent injections are made after 10 min of re-equilibration);

- Column temperature: $40{ }^{\circ} \mathrm{C}$;

- Detector: set to scan from 245 to $500 \mathrm{~nm}$. $N B$ Single wavelength detection (345 nm) is also an option. There is the need for an adaptation of the experiment though. In item e. 3 of the protocol of the experiment (qualitative analysis of the flavonoids extracted from the dyed wool), together with retention times, UV-vis absorption spectra of peaks are used for the assignment of the peaks corresponding to Idg, Img, and lut. Then, the assignment of these peaks would be carried out as done in item e.2, i.e., solely based on the retention times of the compounds.

3. UHPLC column:

- Solvent B: methyl cyanide (acetonitrile) (75-05-8; HPLC grade);

- Column: Eclipse XDB-C18 $50 \times 3.0$ mm $1.8 \mu \mathrm{m}$ (without guard column) (Agilent Technologies);

- HPLC system used here consists of an Agilent 1200 Series binary pump, and Hewlett-Packard Series 1100 photodiode array detector, autosampler, and column oven;

- HPLC vials used:

○ $1.5 \mathrm{~mL}, 32 \times 12 \mathrm{~mm}$ (standard);

○ $1.5 \mathrm{~mL}, 32 \times 12 \mathrm{~mm}$, with an insert;

- Injection volume: $2 \mu \mathrm{L}$;

- Analysis in duplicate;

- Flow: $0.90 \mathrm{~mL} \mathrm{~min}{ }^{-1}$;

- Linear gradient: $85-45 \%$ A (0-4.00 min), 45-85\% A (4.00-4.01 min), 85\% A (4.01-5.00 $\mathrm{min}$ ) ( $N B$ Subsequent injections are made every $5 \mathrm{~min}$ );

- Actual column temperature: $35^{\circ} \mathrm{C}(N B$ In the system used here, due to minimization of tubing — see below - the column lies across the column oven; the column oven temperature is set to $50{ }^{\circ} \mathrm{C}$ ); 
- Detector: set to scan from 245 to $500 \mathrm{~nm}$. NB See note above (HPLC column) for the possibility of using single wavelength detection $(345 \mathrm{~nm})$.

- The following modifications are carried out to reduce the internal volume of the system:

○ The mixer is replaced by an Alltima $7.5 \times 3.0 \mathrm{~mm} \mathrm{C18} 5 \mu \mathrm{m}$ guard column, which acts as the mixer and connects the damper and the injector;

o Shortening of the tubing connecting the injector to the column and the column to the detector;

- Additionally, an in-line filter (e.g., $0.3 \mu \mathrm{m}$, Agilent Technologies) can be placed before the column, aiming at extending its lifetime. NB Analyses of 2012 samples were carried out using such a filter.

$N B$

- If the HPLC to be used is not equipped with an autosampler, instructors may consider storing the samples in refrigerator prior to their manual injection. This was observed to be fine for samples in methanol-water 8:2 [1]. Then, the experiment could be adapted for being carried out, for instance, in two $\sim 4 \mathrm{~h}$ periods with the students injecting the samples and starting processing the data.

- Injection of a solvent after the analysis of the last sample of a series can be considered for verifying whether there is sample carryover and, if so, to monitor its extent. A suggestion would be to consider sample carryovers below $1 \%$ (peak area) acceptable.

e.2) Determination of the concentration of $\mathbf{l d g}$, Img, and lut in the weld sample:

The chromatogram at $345 \mathrm{~nm}$ (Waters system) [Agilent system: $345 \mathrm{~nm}$ (bandwidth $4 \mathrm{~nm}$ ), with $470 \mathrm{~nm}$ (bandwidth $40 \mathrm{~nm}$ ) being the reference wavelength] of the weld sample, with the retention times and areas of $\mathbf{l d g}$, $\mathbf{l m g}$, lut, and i.s. peaks, is printed and given to the student. $N B$ If $k^{\prime}$ is used, additionally, the chromatograms at $260 \mathrm{~nm}$ (bandwidth $4 \mathrm{~nm}$ ) - with $470 \mathrm{~nm}$ (bandwidth $40 \mathrm{~nm}$ ) being the reference wavelength (Agilent system) - of the uracil solution, with the retention time of uracil, are printed and given to the student.

e.3) Qualitative analysis of the flavonoids extracted from the dyed wool:

To be printed and given to the student:

- Chromatogram (as above, excluding peak areas) with UV-vis absorption spectra of Idg, Img, and lut peaks;

- Chromatograms at $345 \mathrm{~nm}$ (Waters system) [Agilent system: $345 \mathrm{~nm}$ (bandwidth $4 \mathrm{~nm}$ ), with $470 \mathrm{~nm}$ (bandwidth $40 \mathrm{~nm}$ ) being the reference wavelength] of Idg, Img, and lut standards, along with retention times and UV-vis absorption spectra of the peaks. $N B$ Preparation of the standard solutions of the flavonoids was described by Villela et al. [1]. 


\section{SI D.4. Instructor notes}

For those assisting the students carrying out the experiment, in this section, there is a note on the title of the protocol handed out to students, solutions to its assignments, and answers to the questions.

\section{Title}

"Analysis of a Natural Dye: ..." (title of chapter 5 of this thesis) would be more accurate than "Analysis of a Natural Yellow Dye: ...", as the colour of textiles dyed with weld depends on the metal used in the textile's pre-treatment [18]. However, the latter title is thought to be fine, as weld was an important source in the past in Europe for dyeing textiles yellow [19], and it is more interesting than the former.

Item e. 2

With the chromatogram of the weld sample containing peak areas and retention times, students can assign the peaks corresponding to ldg, Img, lut, and i.s. based on retention times.* Calculation of concentration of $\mathbf{l d g}$, Img, and lut in the weld sample using the internal standard method can be explained as follows:

The relation between peak area and quantity (weight) of a compound can be expressed as:

$$
A_{x}=R_{x} \cdot w_{x}
$$

in which $\mathrm{A}_{\mathrm{x}}$ is the peak area of compound $x$; $\mathrm{R}_{\mathrm{x}}$ is the response factor of compound $x$; and $\mathrm{w}_{\mathrm{x}}$ is the weight of compound $x$. As this is true for any compound, it is also the case for the i.s.. Thus, the following can be written:

$$
A_{\text {i.s. }}=R_{\text {i.s. }} \cdot w_{\text {i.s. }}
$$

division of equation 1 by equation 2 leads to:

$$
\frac{A_{x}}{A_{\text {i.s. }}}=\frac{R_{X}}{R_{\text {i.s. }}} \cdot \frac{w_{X}}{w_{\text {i.s. }}}
$$

as $\mathrm{R}_{\mathrm{x}} / \mathrm{R}_{\text {i.s. }}=\mathrm{RRF}$, equation 3 can be rewritten as:

$$
\mathrm{w}_{\mathrm{x}}=\frac{\mathrm{A}_{\mathrm{x}}}{\mathrm{A}_{\mathrm{i} . \mathrm{s} .}} \cdot \frac{\mathrm{w}_{\text {i.s. }}}{\mathrm{RRF}}
$$

As the peak areas are obtained from the chromatogram, the quantity (weight) of added i.s. is known, and the RRFs are given, students can calculate the quantity of compound $x$ (Idg, lmg, or lut) in the sample using equation 4 . As $100 \%$ extraction efficiency and recovery are assumed, no corrections need to be made to the obtained values. Finally, the concentration of compound $x$ in the weld sample can be calculated. $N B$ 
- One of the strengths of the internal standard method can be highlighted to the students, i.e., sample volumes do not need to be known as the ratio flavonoid to i.s. remains always constant.

- Additionally, it can be emphasized to students that there is no need for determination of individual response factors of analytes and i.s. via calibration curves. Instead, the RRFs are determined. This can be done through analyses of solutions containing variable weights of standards of the analytes and fixed weights of the i.s.. Finally, the slopes of the curves $\mathrm{w}_{\mathrm{x}} /$ Wi.s. vs. $\mathrm{A}_{\mathrm{x}} / \mathrm{A}_{\text {i.s. }}$ provide the RRFs (see equation 3). This is described, e.g., by Villela et al. [1].

- Concentrations of Idg, lmg, and lut in a sample consisting of the aerial parts of weld were determined to be $3.5 \mathrm{mg} \mathrm{g}^{-1}$ (ldg), $6.5 \mathrm{mg} \mathrm{g}^{-1}$ (lmg) and $1.0 \mathrm{mg} \mathrm{g}^{-1}$ (lut).[1] These values, however, are weld sample-dependent.

- * If $k^{\prime}$ is used, students carry out similar work, except that the $k^{\prime}$ need to be calculated first. As the retention by the column of the very polar compound uracil is small, its retention time $\left(t_{\mathrm{r}}\right)$ is considered to be the void time $\left(t_{\mathrm{m}}\right)$, the time unretained compounds (as well as the eluent) take to move through the column. Thus, the time a compound spends in the stationary phase (the adjusted retention time, $t_{\mathrm{r}}{ }^{\prime}$ ), equals $t_{\mathrm{r}}-t_{\mathrm{m}}[20,21]$. Finally, the $k^{\prime}$ are calculated using the equation $k^{\prime}=t_{\mathrm{r}}{ }^{\prime} / t_{\mathrm{m}}[20,21]$.

Item e.3, and questions 3 and 4

Retention times and UV-vis absorption spectra of peaks in the chromatogram of the wool sample are compared with those in the chromatograms of authentic standards. This leads to assignment of the peaks corresponding to Idg, Img, and lut. Then, comparison of the chromatograms of the wool sample and of the weld sample leads to the observation that the peaks corresponding to ldg, Img, and lut - as well as other minor peaks - are present in both of them. Such observation of weld's "fingerprint" in the chromatogram of the wool sample indicates the suitability of the analytical method for identifying weld as the dye-source of a yellow historical woolen artifact.

Use of the harsh conditions to extract the flavonoids from the dyed wool would lead to disappearance of the peaks of the glycosides, due to hydrolysis of glycosidic bonds in Idg and lmg. As lut is formed in the process, a lut peak of increased height would be seen in the chromatogram. As the procedure that employs mild extraction conditions is informative on the composition of flavonoid glycosides, it is preferred over the procedure that employs harsh conditions of extraction for identifying weld as the dye-source of a yellow historical woolen artifact. The latter yield only one peak for the three main constituents; namely, lut.

\section{Question 1}

In reversed phase chromatography the mobile phase is polar and the stationary phase is nonpolar. Thus, polar compounds elute earlier than non-polar compounds. As polarity increases in the order lut $<$ lmg $<$ ldg, the observed order of elution is ldg-lmg-lut.

\section{Question 2}

As seen on page 1 of the protocol of the experiment, flavonoids Idg and Img consist of lut with sugar (glucose) moieties linked to $\mathrm{OH}$ groups. The sugar moieties do not absorb light at 345 $\mathrm{nm}$, the wavelength used for determining the concentration of Idg, Img, and lut in the weld 
sample. Only the lut part of $\mathbf{l d g}$ and $\mathbf{l m g}$ structures is responsible for the absorbance at $345 \mathrm{~nm}$. Thus, for equal weights of ldg, lmg, and lut, peak areas will decrease in the order lut $>\mathbf{I m g}>$ ldg.

Equation 4 above can be rewritten as:

$\mathrm{RRF}=\frac{\mathrm{A}_{\mathrm{x}}}{\mathrm{A}_{\mathrm{i} . \mathrm{s} .}} \cdot \frac{\mathrm{w}_{\mathbf{i . s}}}{\mathrm{w}_{\mathrm{x}}}$

As RRF and $A_{x}$ are directly proportional, RRFs will also decrease in the order lut $>\mathbf{l m g}>\mathbf{I d g}$. This is the inverse of the decrease of molecular weights (MWs), as MWldg $\left(611 \mathrm{~g} \mathrm{~mol}^{-1}\right)>$ $\mathrm{MW}_{\text {Img }}\left(448 \mathrm{~g} \mathrm{~mol}^{-1}\right)>\mathrm{MW}_{\text {lut }}\left(286 \mathrm{~g} \mathrm{~mol}^{-1}\right)$.

SI D.5. Additional observations on the students' learning based on 2011 and 2012 reports Observations on the students' learning regarding the didactic aims and background of the experiment based on 2011 and 2012 reports, in addition to those described in chapter 5:

- None of the students related the increase in molecular weight of the flavonoids due to non-345 nm-absorbing glucose moiety or moieties ( $\mathrm{WW}_{\text {lut }}<\mathrm{MW}_{\mathbf{l m g}}<\mathrm{MW}_{\mathbf{l d g}}$ ) to the decrease in RRFs (RRFlut-i.s. $>$ RRFImg-i.s. $>$ RRFIdg-i.s.) (question 2 of the experiment's protocol);

- In 2011, nearly all students observed the presence of peaks corresponding to Idg, Img, and lut in the chromatogram of the wool sample, but only two of them answered satisfactorily the question on the suitability of the analytical method for identifying the dye-source(s) of a historical woolen artifact (item e.3 and question 3);

- In 2012, three of the five students answered that mild extraction conditions are preferable to the harsh conditions of extraction for ascertaining weld as the dye-source of a yellow historical woolen artifact (question 4, introduced in 2012).

\section{SI D.6. Updated version of the inventory of specialized material handled by students}

Below, an updated version of the inventory of specialized material handled by students that is kept in the experiment's basket. $N B$ In AMOC, experiments have baskets containing specialized material.

\section{INVENTORY}

- Dried and ground weld;

- $1 \times 100 \mathrm{~mL}$ Erlenmeyer with a rubber stopper;

- $1 \times 50 \mathrm{~mL}$ Erlenmeyer with a rubber stopper;

- $150 \mathrm{~mL}$ beaker;

- 96\% alcohol-water 3:1 (v/v) (solvent cabinet);

- Adapted test-tube rack (Figure below);

- $0.5 \mathrm{mg} \mathrm{mL}^{-1}$ i.s. solution in methanol or in $96 \%$ alcohol (refrigerator);

- Box with syringe filters (disposable):

○ $13 \mathrm{~mm} / \varnothing 0.45 \mu \mathrm{m}$;

○ $4 \mathrm{~mm} / \varnothing 0.45 \mu \mathrm{m}$; 
- Disposable syringes (with a rubber seal at the tip of the plunger):

○ $1 \mathrm{~mL}$;

○ $2 \mathrm{~mL}$;

- Microcentrifuge tubes of $2 \mathrm{~mL}$;

- Methanol-water-formic acid 80:15:5 (v/v/v) (solvent cabinet);

- Pieces of alum-treated wool of $\sim 5 \times 5 \mathrm{~cm}$ (4 pieces per bag);

- Small plastic bags for storing the dyed wool;

- Floating tube rack (Figure below);

- Towel.
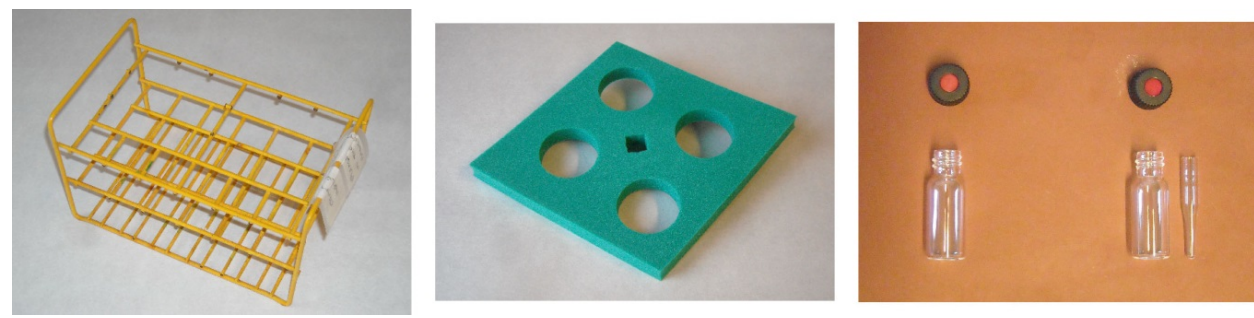

Figure SI D.1a. Adapted test-tube rack, floating tube rack, standard HPLC vial, and standard HPLC vial with insert.

The inventory ends here. Below, an alternative version of the figure is presented in case of using the HPLC column (if this is accompanied by the need to use $40 \times 8 \mathrm{~mm}$ HPLC vials and $40 \times 8$ mm HPLC vials of maximal residual volume of $6 \mu \mathrm{L}$, as it has been the case at Wageningen University):
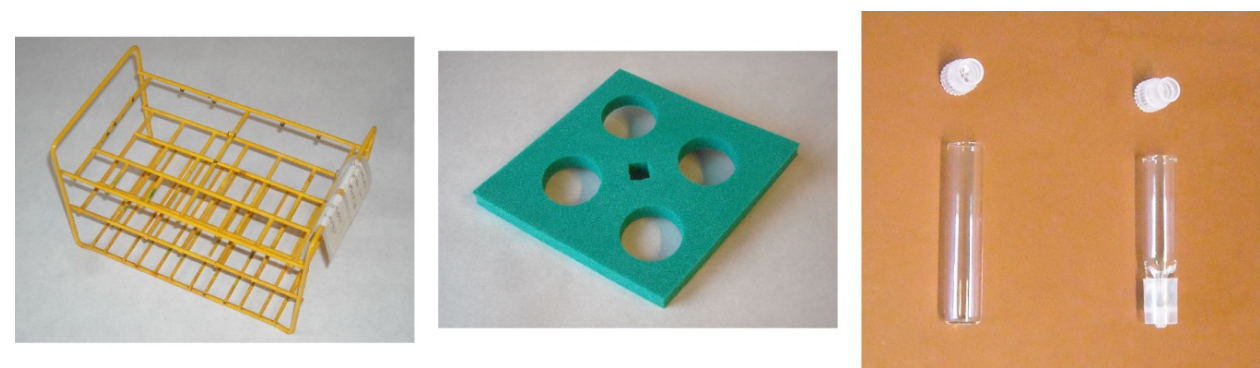

Figure SI D.1b. Adapted test-tube rack, floating tube rack, $40 \times 8 \mathrm{~mm}$ HPLC vial, and $40 \times 8 \mathrm{~mm}$ HPLC vial of maximal residual volume of $6 \mu \mathrm{L}$. 


\section{SI D.7. Example data sets of the HPLC analysis of weld sample}

Below, two example data sets of the HPLC analysis of weld sample. They might be of interest, e.g., for use as lecture examples (chromatograms and information in tables) and when HPLC systems equipped with single wavelength detectors are used (UV-vis absorption spectra of flavonoids).

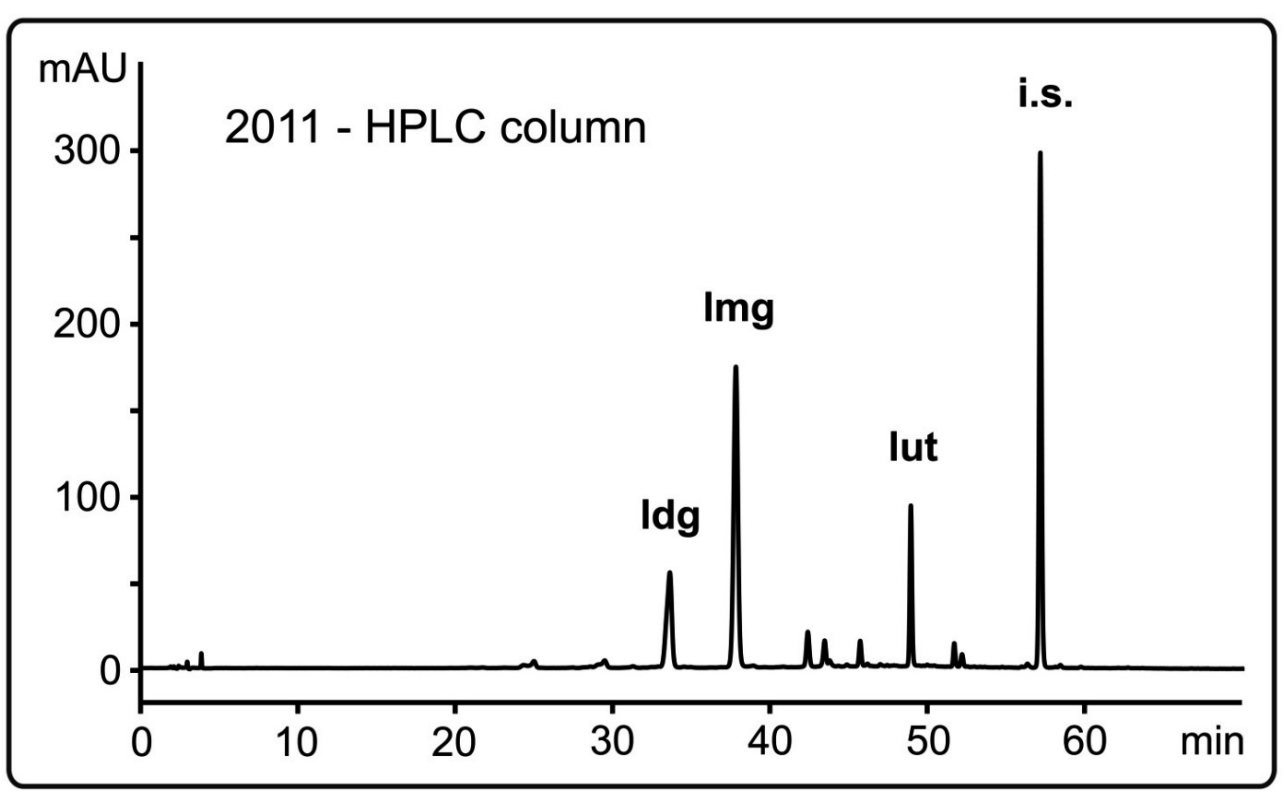

Figure SI D.2. Chromatogram of weld sample (345 nm-trace; same as top left panel of Figure 5.2).

\begin{tabular}{llll}
\hline \multicolumn{4}{l}{ Table SI D.1. HPLC data of chromatogram depicted in Figure SI D.2. } \\
\hline Flavonoids & Retention time (min) & Peak area (mAU s) & Peak height (mAU) \\
Idg & 33.6 & 1292 & 55 \\
Img & 37.8 & 3323 & 173 \\
lut & 49.0 & 912 & 93 \\
i.s. & 57.2 & 3319 & 297
\end{tabular}




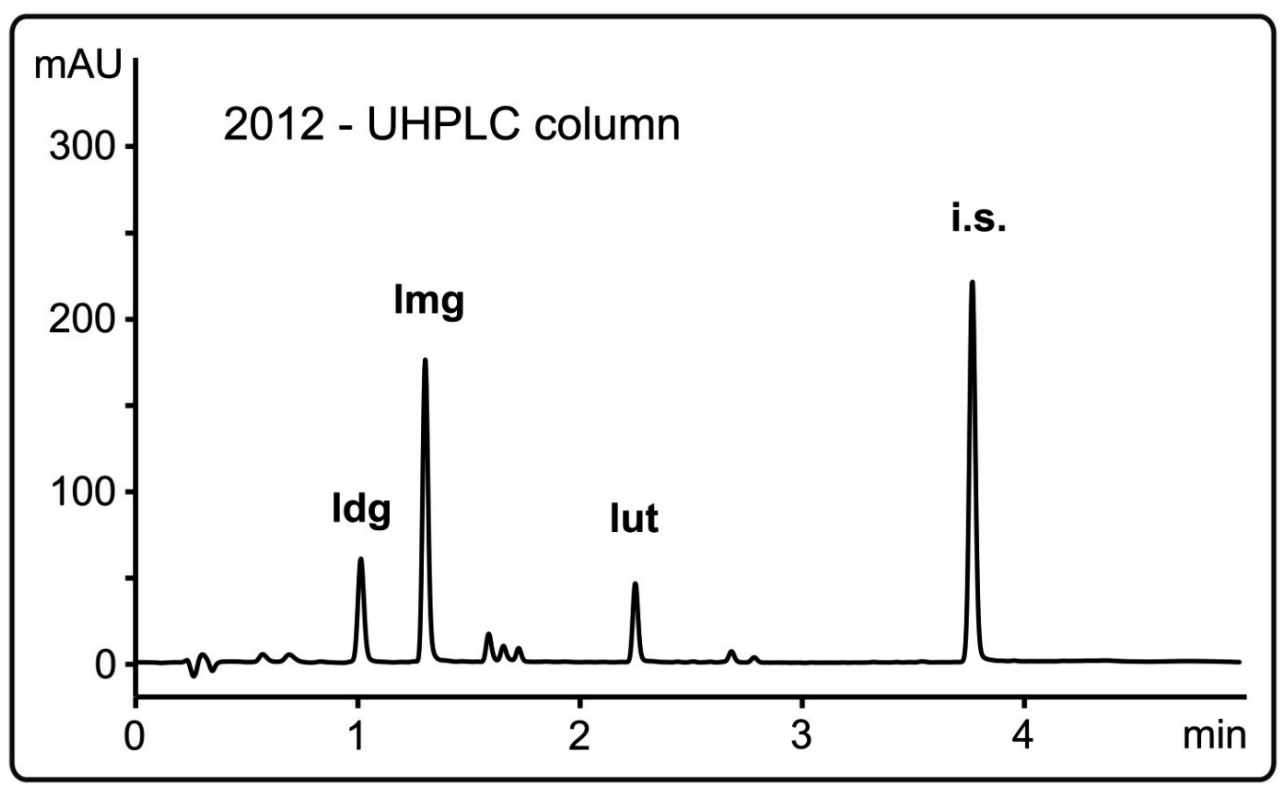

Figure SI D.3. Chromatogram of weld sample (345 nm-trace; same as top right panel of Figure 5.2).

\begin{tabular}{llll}
\hline \multicolumn{4}{l}{ Table SI D.2. HPLC data of chromatogram depicted in Figure SI D.3. } \\
\hline Flavonoids & Retention time (min) & Peak area (mAU s) & Peak height (mAU) \\
Idg & 1.02 & 124 & 60 \\
$\mathbf{I m g}$ & 1.31 & 314 & 176 \\
$\mathbf{l u t}$ & 2.26 & 82 & 46 \\
i.s. & 3.78 & 439 & 222
\end{tabular}

Finally, the following figures can be considered to be used for the calculations:

i. quantity of dried and ground weld: $199.7 \mathrm{mg}$ or $201.2 \mathrm{mg}$;

ii. concentration of the i.s. solution: $0.492 \mathrm{mg} \mathrm{mL}^{-1}$ or $0.496 \mathrm{mg} \mathrm{mL}^{-1}$. 


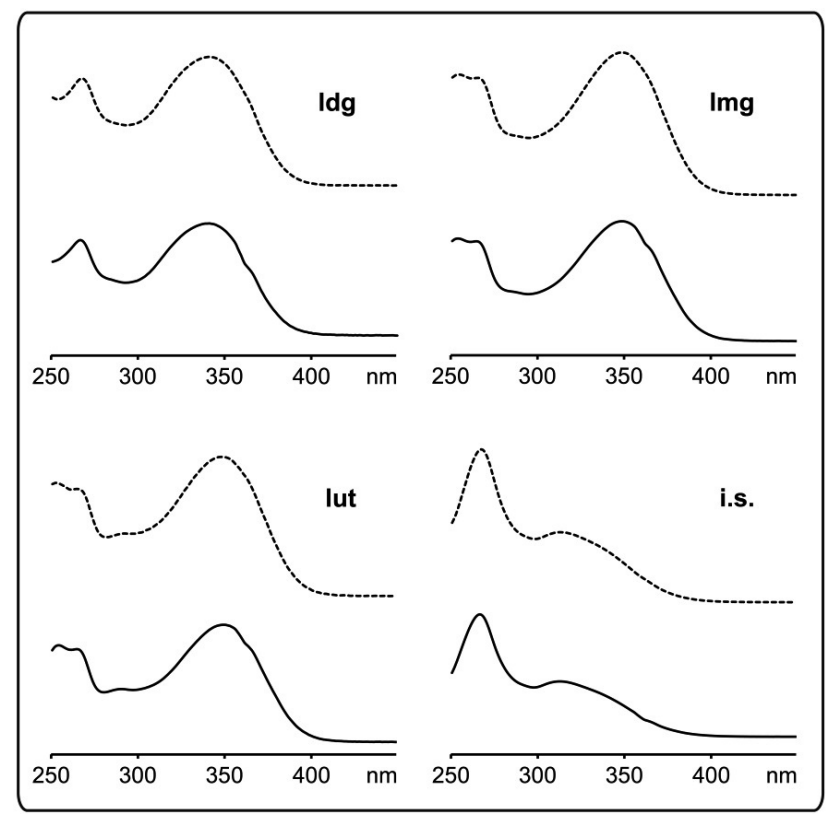

Figure SI D.4. UV-vis absorption spectra acquired during chromatographic separations depicted in Figures SI D.2 and SI D.3, at peak apices. Solvent mixtures: aqueous buffer $\mathrm{pH} 3-$ methanol (solid lines) and aqueous buffer $\mathrm{pH} 3$-acetonitrile (dashed lines).

\section{SI D.8. Supplementary references}

[1] Villela A, van der Klift EJC, Mattheussens ESGM, Derksen GCH, Zuilhof H, van Beek TA. Fast chromatographic separation for the quantitation of the main flavone dyes in Reseda luteola (weld). J Chromatogr A 2011; 1218(47): 8544-50.

[2] Gaspar H, Moiteiro C, Turkman A, Coutinho J, Carnide V. Influence of soil fertility on dye flavonoids production in weld (Reseda luteola L.) accessions from Portugal. J Sep Sci 2009; 32(23-24): 4234-40.

[3] Cardon D. Natural dyes - sources, tradition, technology and science. 1st ed. Archetype Publications: London; 2007.

[4] Cerrato A, De Santis D, Moresi M. Production of luteolin extracts from Reseda luteola and assessment of their dyeing properties. J Sci Food Agric 2002; 82(10): 1189-99.

[5] Colombini MP, Andreotti A, Baraldi C, Degano I, Lucejko JJ. Colour fading in textiles: a model study on the decomposition of natural dyes. Microchem J 2007; 85(1): 174-82. 
[6] McD. Schetky E, Woodward CH, editors. Dye plants and dyeing - a handbook, Brooklyn Botanic Garden: Brooklyn; 1975.

[7] Zhang X, Cardon D, Cabrera JL, Laursen R. The role of glycosides in the light-stabilization of 3-hydroxyflavone (flavonol) dyes as revealed by HPLC. Microchim Acta 2010; 169(3-4): 327-34.

[8] Marques R, Sousa MM, Oliveira MC, Melo MJ. Characterization of weld (Reseda luteola L.) and spurge flax (Daphne gnidium L.) by high-performance liquid chromatography-diode array detection-mass spectrometry in Arraiolos historical textiles. J Chromatogr A 2009; 1216(9): 1395-402.

[9] Peggie DA, Hulme AN, McNab H, Quye A. Towards the identification of characteristic minor components from textiles dyed with weld (Reseda luteola L.) and those dyed with Mexican cochineal (Dactylopius coccus Costa). Microchim Acta 2008; 162(3-4): 371-80.

[10] Zhang X, Laursen RA. Development of mild extraction methods for the analysis of natural dyes in textiles of historical interest using LC-diode array detector-MS. Anal Chem 2005; 77(7): 2022-5.

[11] Valianou L, Karapanagiotis I, Chryssoulakis Y. Comparison of extraction methods for the analysis of natural dyes in historical textiles by high-performance liquid chromatography. Anal Bioanal Chem 2009; 395(7): 2175-89.

[12] Harborne JB, Baxter H, editors. Chemical dictionary of economic plants, John Wiley \& Sons: Chichester; 2001.

[13] Takahama U, Hirota S. Deglucosidation of quercetin glucosides to the aglycone and formation of antifungal agents by peroxidase-dependent oxidation of quercetin on browning of onion scales. Plant Cell Physiol 2000; 41(9): 1021-9.

[14] Editorial Staff of JCE. Colors to dye for: preparation of natural dyes. J Chem Educ 1999; 76(12): 1688A-B.

[15] Kremer Pigmente. http://kremer-pigmente.com/en [accessed April 2013].

[16] Brush Creek Wool Works. http://www.brushcreekwoolworks.com [accessed April 2013].

[17] The merck index online, RSC Publishing: http://www.rsc.org/merck-index [accessed August 2013].

[18] Mihalick JE, Donnelly KM. Using metals to change the colors of natural dyes. J Chem Educ 2006; 83(10): 1550-1.

[19] Ferreira ESB, Hulme AN, McNab H, Quye A. The natural constituents of historical textile dyes. Chem Soc Rev 2004; 33(6): 329-36.

[20] Harvey D. Analytical Chemistry 2.0 . http://www.asdlib.org/onlineArticles/ecourseware/Analytical\%20Chemistry\%202.0/Text_File s.html [accessed August 2013].

[21] Robinson JW, Skelly Frame EM, Frame II GM. Undergraduate instrumental analysis. 6th ed. Marcel Dekker: New York; 2005. 
The research described in this thesis was financially supported by CAPES Brasília/Brazil (scholarship of Alexandre Villela), Wageningen University, and Rubia Natural Colours.

Cover:

Photographs by Dani Lucas-Barbosa and Gert Buurman

Design by Alexandre Villela and Loes van de Kraats-Kema (GVO printers \& designers)

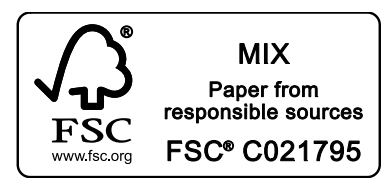

Printed by GVO printers \& designers (Ede, the Netherlands)

All 180 copies were produced on FSC-certified paper, with the interior being recycled paper 


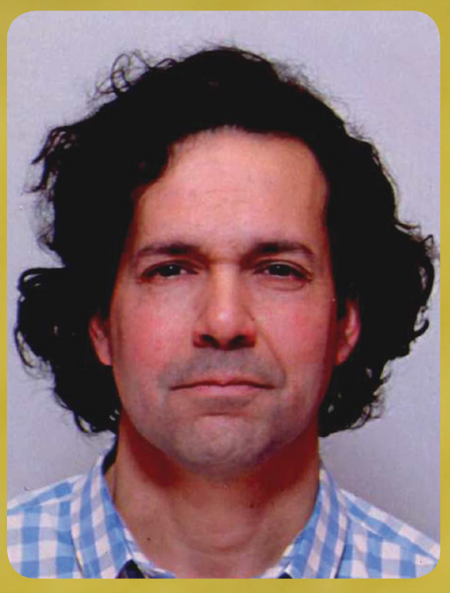

Alexandre Villela was

born in Rio de Janeiro,

Brazil in 1975.

He studied chemistry

in Brazil and the

Netherlands: BSc at the

Federal University of

Rio de Janeiro, MSc at

the Federal University of

Santa Catarina, and PhD

at Wageningen University.

Alexandre is member

of the International

Society for

Ethnopharmacology,

and can be reached

through alexandre.villela@

naturalproductschemistry.

com. 
2. 2.0 .5

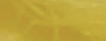

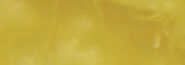

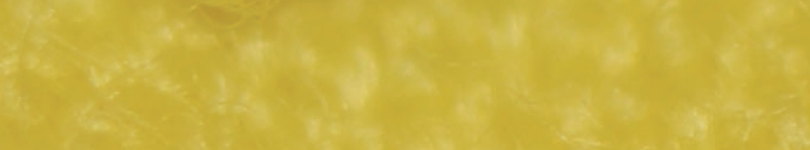

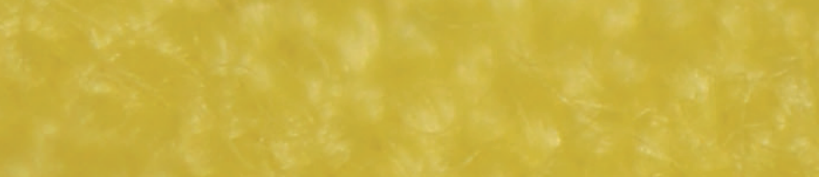

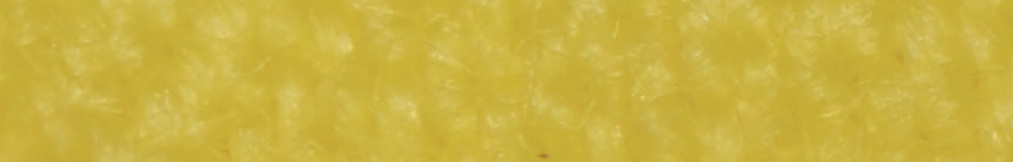

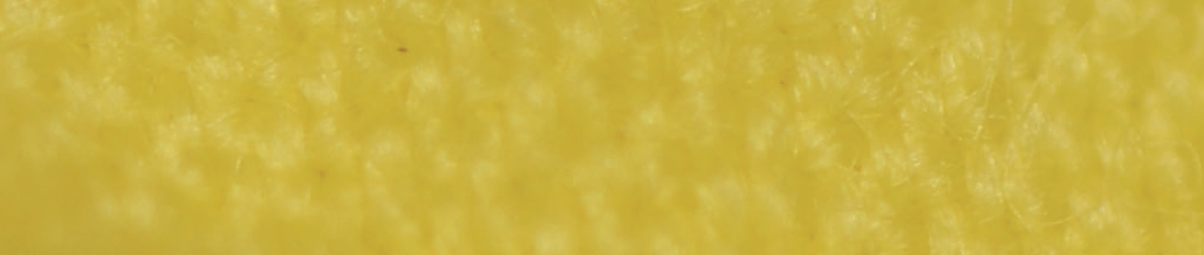

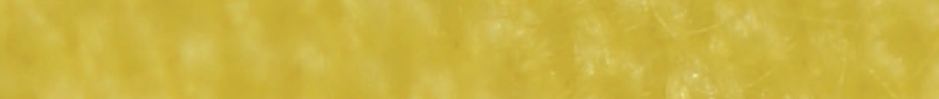

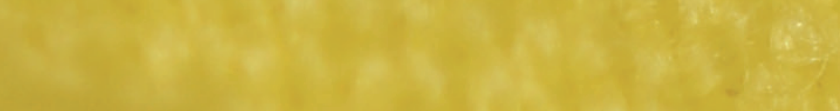

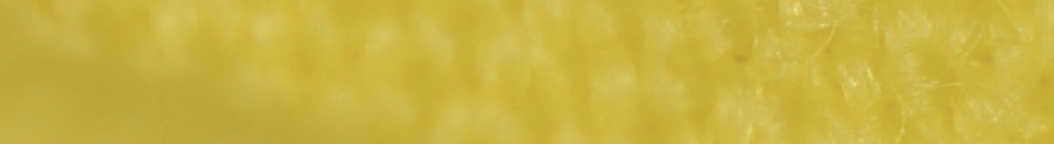

